\title{
Details of Side Load Test Data and Analysis for a Truncated Ideal Contour Nozzle and a Parabolic Contour Nozzle
}

\author{
Joseph H. Ruf ${ }^{\dagger}$, David M. McDaniels ${ }^{\ddagger}$ Andrew M. Brown" \\ NASA Marshall Space Flight Center, Huntsville, Alabama 35812
}

\begin{abstract}
Two cold flow subscale nozzles were tested for side load characteristics during simulated nozzle start transients. The two test article contours were a truncated ideal and a parabolic. The current paper is an extension of a 2009 AIAA JPC paper on the test results for the same two nozzle test articles. The side load moments were measured with the strain tube approach in MSFC's Nozzle Test Facility. The processing techniques implemented to convert the strain gage signals into side load moment data are explained. Nozzle wall pressure profiles for separated nozzle flow at many NPRs are presented and discussed in detail. The effect of the test cell diffuser inlet on the parabolic nozzle's wall pressure profiles for separated flow is shown. The maximum measured side load moments for the two contours are compared. The truncated ideal contour's peak side load moment was $45 \%$ of that of the parabolic contour. The calculated side load moments, via mean-plus-three-standard-deviations at each nozzle pressure ratio, reproduced the characteristics and absolute values of measured maximums for both contours. The effect of facility vibration on the measured side load moments is quantified and the effect on uncertainty is calculated. The nozzle contour designs are discussed and the impact of a minor fabrication flaw in the nozzle contours is explained.
\end{abstract}

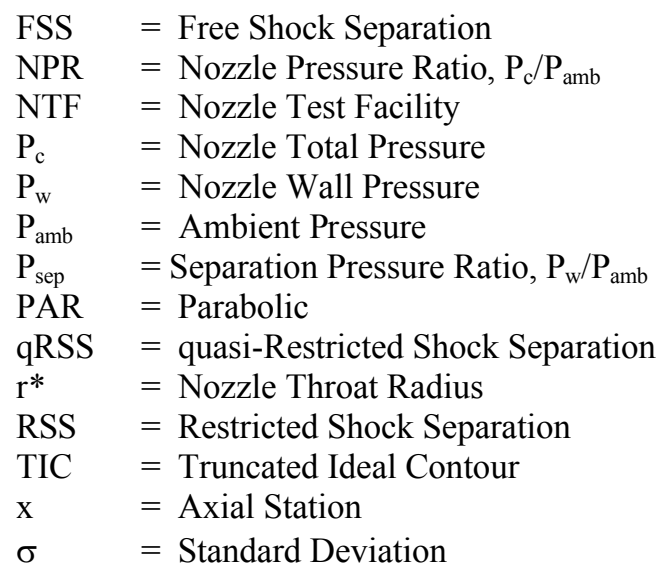

\section{Nomenclature}

\section{Introduction}

$\mathrm{N}$ OZZLE side loads are lateral forces induced by asymmetric pressure distribution in a nozzle. The most severe nozzle side loads occur during the engine start and shutdown transients as the location of the nozzle flow separation moves from the throat region to the end of the nozzle (start) and vice-versa (shutdown). Two common engine failure modes due to side loads are nozzle wall high-cycle fatigue and over loading the engine thrust vector control actuator. Most liquid rocket engines have, at one time or another, had issues due to nozzle side loads. The J-

\footnotetext{
${ }^{\dagger}$ Aerospace Engineer, ER42/Fluid Dynamics Branch, AIAA Member

* Aerospace Engineer, ER42/Fluid Dynamics Branch

"! Lead Aerospace Engineer, ER41/Propulsion Structural \& Dynamics Analysis Branch, AIAA Senior Member 
$2 \mathrm{~S}$ had excessive side loads such that an entire engine was ripped from its gimbal structure. The Space Shuttle Main Engine had side load induced nozzle coolant line (the "steer-horn") fatigue cracks. More recently, the Japanese LE7A engine had problems due to nozzle side loads during development. ${ }^{2}$

The European liquid rocket engine, the Vulcain, experiences significant side loads as well ${ }^{3}$. In the 1990's several European organizations joined together as the Flow Separation Control Devices research group to address nozzle side loads. Several experimental and analytical programs were completed that provided new and valuable insight into the nozzle fluid dynamics that are responsible for nozzle side loads ${ }^{4,5}$. However, in the U.S., there was no organized program addressing liquid rocket nozzle side loads.

The work described in this paper are results from an MSFC internally research and development (IRAD) effort begun in 2004 to develop, within the U.S., a nozzle side load test capability including the experience and knowledge base to support future liquid rocket nozzle development. The specific objective of this cold flow test campaign was to determine the relative magnitude of nozzle side loads for two test articles; a truncated ideal contour (TIC) nozzle and a thrust optimized contour, specifically a parabolic (PAR), nozzle. The side load of interest was the net throat bending moment (figure 1) during start and shutdown transients.

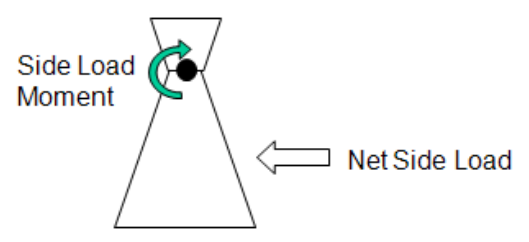

Figure 1. Throat bending moment due to side load.

Ref. 1 was the first paper on the TIC and PAR nozzle tests. This second paper significantly expands the depth of the test data presented. The current paper provides a description of the nozzle test article aerodynamic design. The nozzle wall pressure data presented in Ref. 1 is expanded on and a facility interaction is discussed. A minor fabrication flaw in the nozzle contours and its affect is discussed. The maximum measured side loads for the two nozzle start transients are compared and the magnitude of the side loads calculated via the mean-plus-three-standarddeviations is also presented. The effect of facility vibrations on the measured side load magnitude is explained and assessed.

\section{Nozzle Fluid Dynamics}

A brief and very basic explanation of the nozzle fluid dynamics that contribute to nozzle side loads follows. Several of the references provide a fuller explanation of nozzle fluid dynamics during start and shutdown. The reader is directed specifically to Refs. 5 through 9.

The key difference between the TIC and PAR nozzles is the presence of an internal shock (see figure 2) in the PAR due to the non-ideal nozzle wall curvature just downstream of the throat. At low nozzle pressure ratio (NPR), $\mathrm{P}_{\mathrm{c}} / \mathrm{P}_{\mathrm{amb}}$, this internal shock interacts with the separation induced shock (NPR 16, figure 2) and then, as NPR increases, it interacts with the Mach disk (starting at NPR 20 in figure 2). If the internal shock is strong, its interaction with the Mach disk can cause the annular jet of supersonic flow to deflect outward and reattach to the nozzle wall (NPR 21, figure 2). The reattachment results in a recirculation bubble, "restricted", between the separation location and the reattachment location. This transition to reattached flow, i.e., from free shock separation (FSS) to restricted shock separation (RSS), will invariably be asymmetric and is, therefore, a source of potentially large nozzle side loads. A second source, usually the largest, develops when the RSS reattachment location nears the end of the nozzle. The nozzle flow may flip back and forth between FSS and RSS because the nozzle end effects can change the pressure in the reciculating flow (at the wall) in time. Thus, the separation location varies in time, perhaps enough to cause the flow to switch modes.

Conversely, the TIC flow remains in FSS throughout the nozzle start transient (except at very low NPRs) as indicated in the images on the left hand side of figure 2. This continuous FSS flow in a TIC produces significantly lower side loads than the FSS-to-RSS-to-FSS transitions that are possible in a thrust optimized contoured nozzle. 


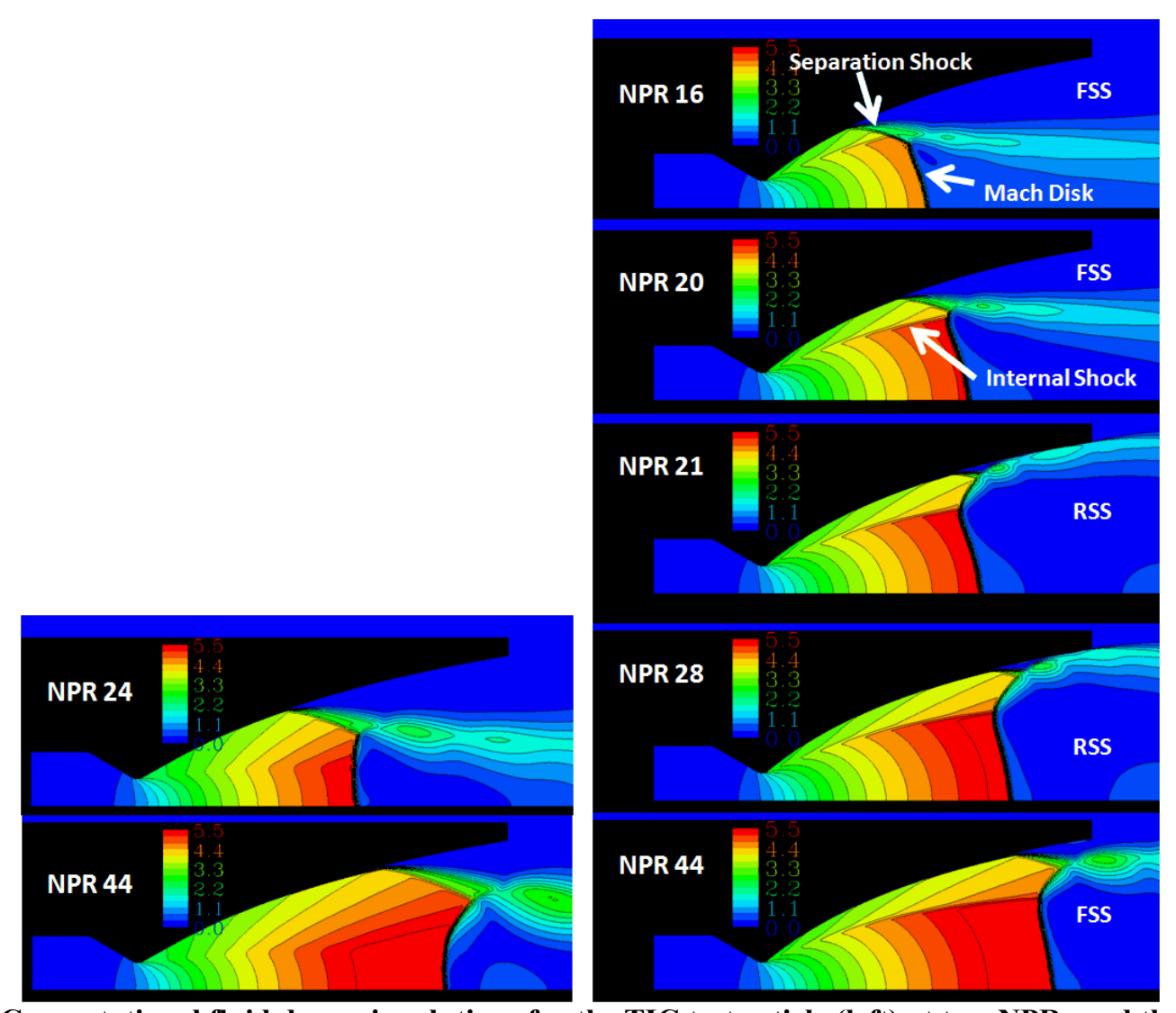

Figure 2. Computational fluid dynamic solutions for the TIC test article (left) at two NPRs and the PAR test article (right) at five NPRs.

\section{Experimental Approach}

The test approach implemented here was proposed by Dumonv ${ }^{10}$ and further developed by Frey, et $\mathrm{al}^{11}$.

The relatively thick walled nozzle test articles were mounted on a flexible, easy-to-characterize "strain tube" (figure 3 ). Moments due to off-axis forces were measured with strain gages near the rigidly mounted end of the tube. Two pairs of full-bridges were applied to measure strain in both the horizontal and vertical directions. The nozzle test articles were designed to be relatively stiff so that their throat bending and nozzle ovalization fundamental frequencies were well above the expected excitation frequency range from side loads.

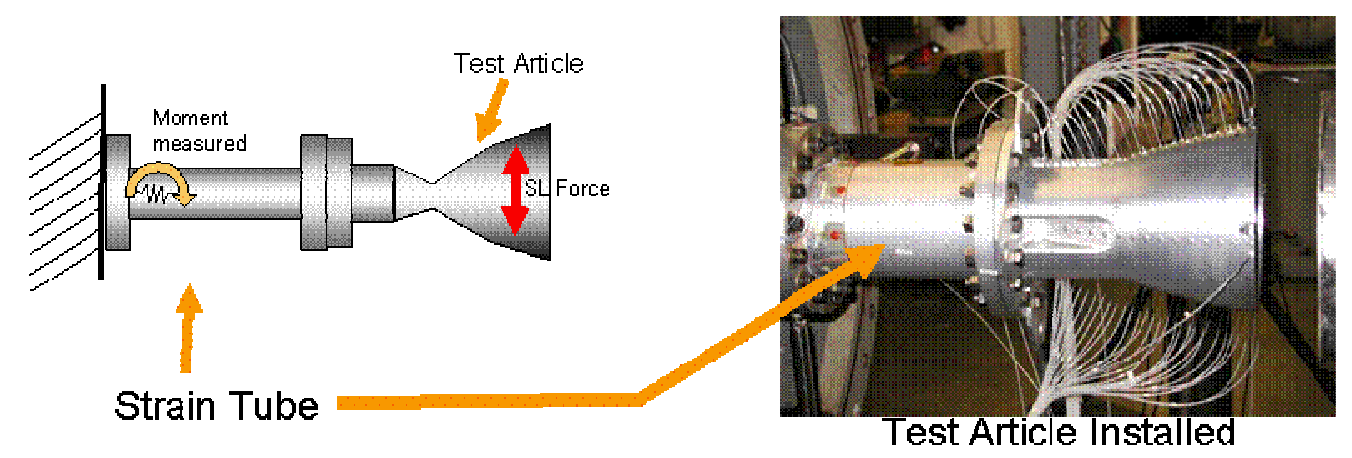

Figure 3. Schematic of the strain tube approach and a picture of the strain tube and a test article installed. 


\section{A. Running Tests}

The MSFC Nozzle Test Facility (NTF), figure 4, was designed to measure nozzle thrust performance of a range of simulated altitudes. The nozzle working gas is heated dry air at pressures up to $20 \mathrm{~atm}$. Typical run conditions are nozzle total pressure of $10.2 \mathrm{~atm}(150 \mathrm{psia})$ at $66^{\circ} \mathrm{C}\left(150^{\circ} \mathrm{F}\right)$. The NTF's two stage ejector system can pull the test cell pressure down to simulated altitudes greater than $30 \mathrm{~km}(100,000 \mathrm{ft})$.

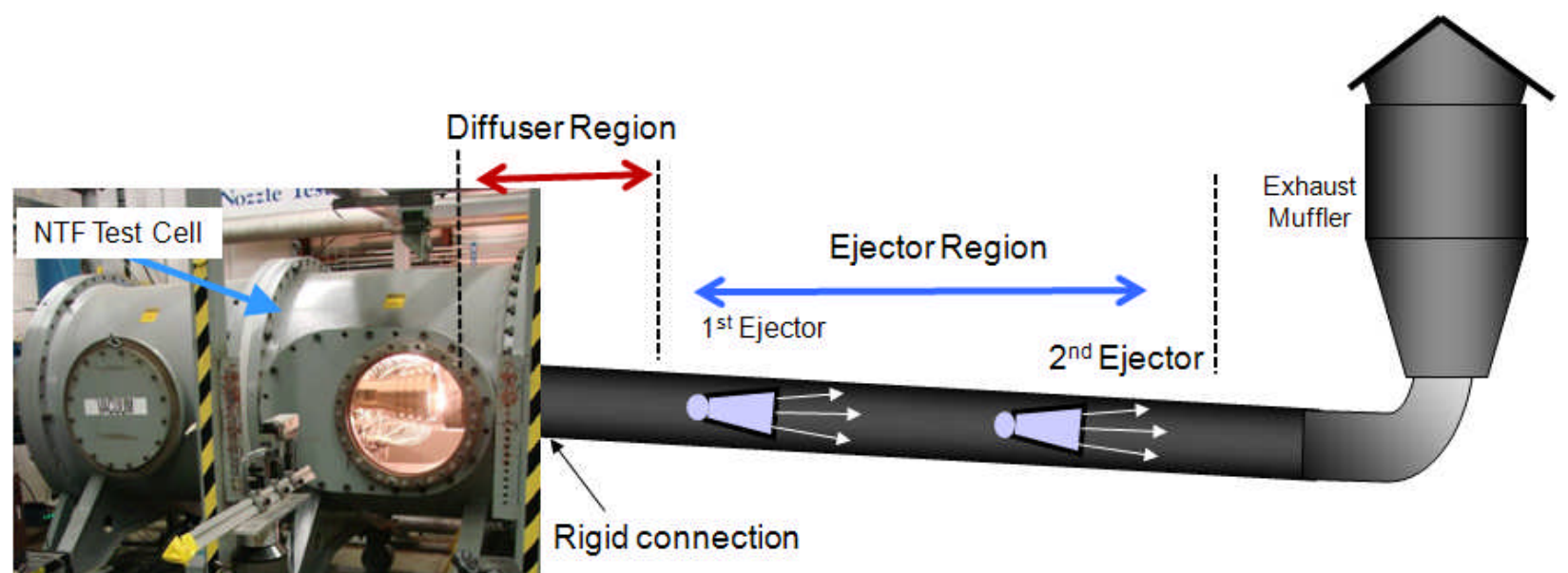

Figure 4. The NTF test cell with a nozzle test article installed and a schematic of the diffuser and ejector system.

For side load testing the axial thrust measurement system was replaced with a $51 \mathrm{~mm}(2 \mathrm{in})$ thick steel plate (figure 5) to provide a rigid, "fixed-end" mount for the strain tube.

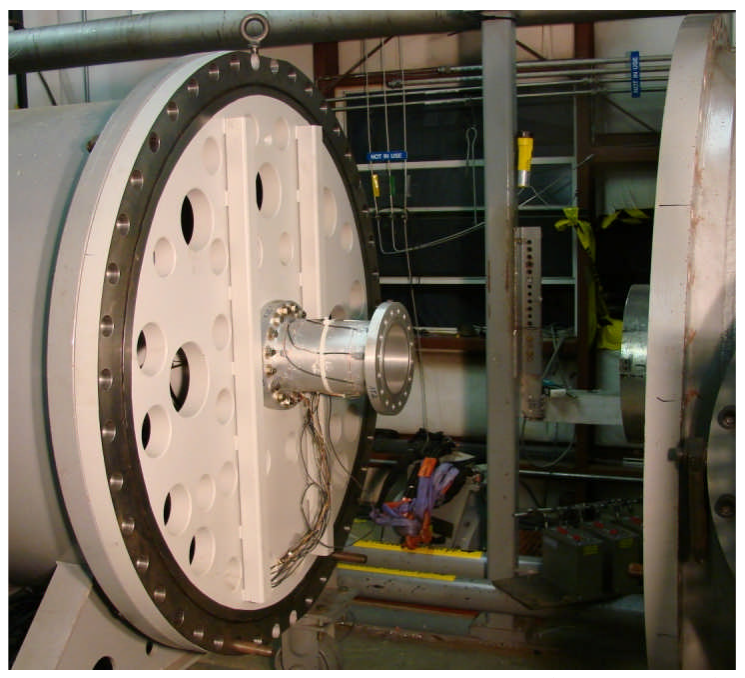

Figure 5. Stiffener plate added to the NTF shown with the strain tube attached.

Typical operating procedure in this test series was to bring the nozzle test article total conditions to set point, $10.2 \mathrm{~atm}(150 \mathrm{psia}), 66^{\circ} \mathrm{C}\left(150^{\circ} \mathrm{F}\right)$, without the ejectors running. This set point was maintained throughout the test. The NPR, prior to the ejectors being turned on, was about 10 which resulted in the nozzle flow separating just downstream of the throat. The red line in figure 6 illustrates a typical NPR time history from one test in which 35 nozzle start transients were simulated. The low-speed data system recorded continuously through the test. High frequency data was recorded during the simulate nozzle start transients and for about 15 seconds at the constant NPR set points. 


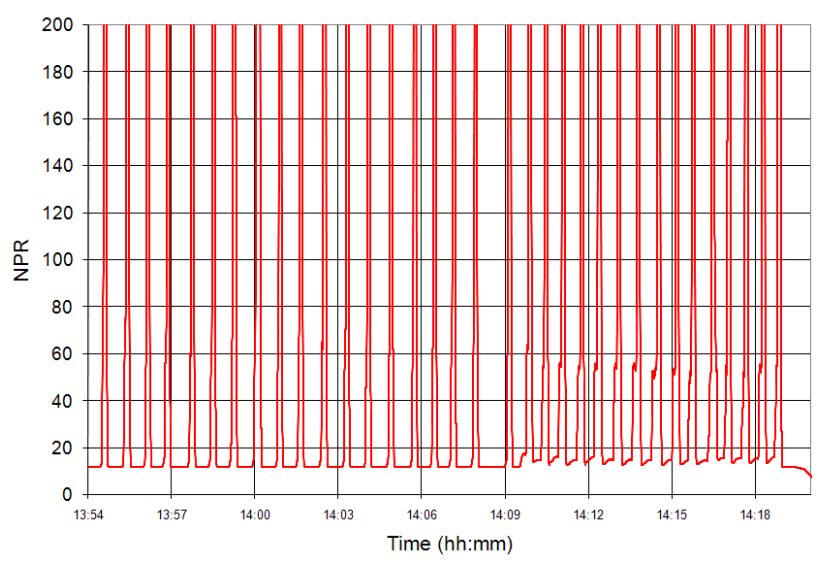

Figure 6. Example of NPR ramps from a PAR test.

To produce the simulated nozzle start transients the ejector drive gas was turned on to lower $\mathrm{P}_{\text {amb }}$ enough to induce the nozzle test article to flow full. The ejector drive gas flow was then reduced, the test cell returned to near atmospheric pressure and the nozzle flow was again separated just downstream of the throat. This cycle could be repeated, as many as 35 times in one "test", until the ejector drive gas supply ran low. A test could run as long as 40 minutes.

This constant $\mathrm{P}_{\mathrm{c}}$ with decreasing $\mathrm{P}_{\mathrm{amb}}$ approach to simulating a nozzle start transient is the inverse to a typical engine start transient where $\mathrm{P}_{\mathrm{c}}$ increases and, if not in a closed test cell, $\mathrm{P}_{\mathrm{amb}}$ is constant. This approach was used in the NTF because reaching a set point for the test article total conditions has a longer time constant than the ejector system. By using the ejector system to create the dNPR/dt, the NPR ramp rates were better controlled and realistic (absolute, but not scaled) time scales for filling the nozzle were obtained.

The NPR time histories of simulated start transients are shown in figure 7 on a finer time scale. A variety of simulated start NPR ramp rates was achieved by varying the timing of the start commands for the two ejectors and rate at which their drive gas was increased. Both figures 6 and 7 are plotted from the low-speed ( $1 / 4 \mathrm{~S} \mathrm{time-averaged)}$ data system. The time histories in figure 7 provide insight to the general trends for NPR for each nozzle transient. The NPR time history for each start transient had to be evaluated with the high frequency data as well to ensure that an interaction with the diffuser inlet did not influence the side load data.
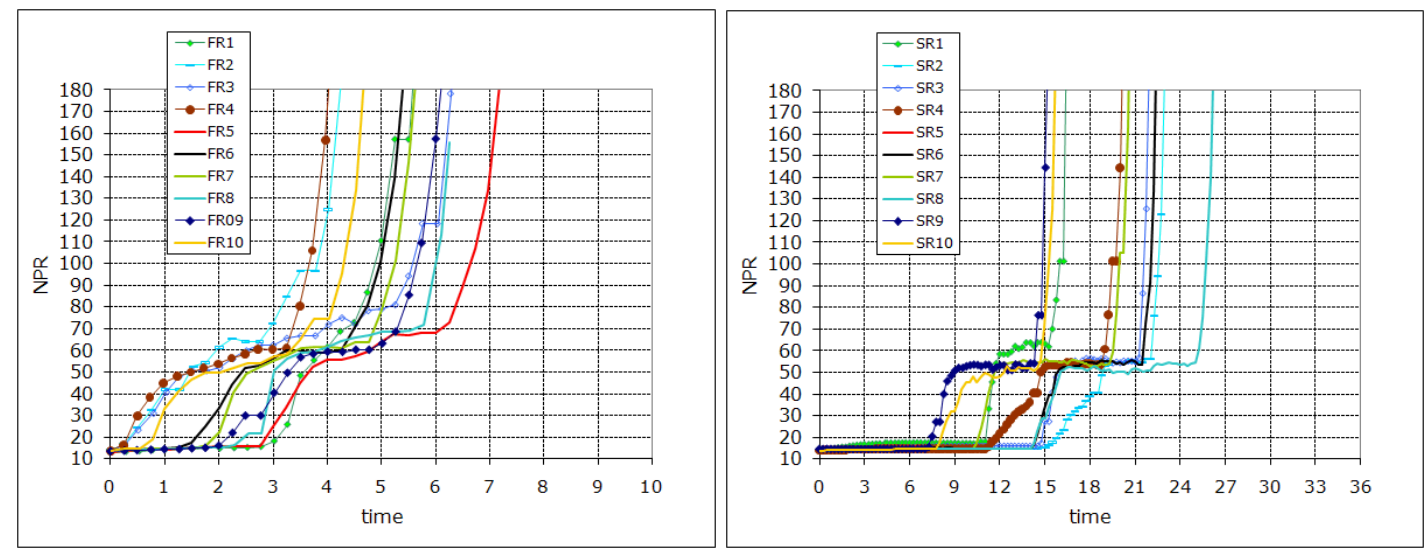

Figure 7. Example NPR ramps rates achieved for the same PAR test.

Figures 6 and 7 were generated from data recorded on the low-speed data system. The low-speed system recorded all facility conditions and test article data continuously over the length of a test run at $4 \mathrm{~Hz}$. The static pressures were sampled at $600 \mathrm{~Hz}$, averaged over approximately $1 / 4$ second intervals and recorded at $4 \mathrm{~Hz}$. The highspeed data system, recorded at 20,480 Hz, was turned on to capture each simulated nozzle start transient and constant NPR set point. The high-speed system recorded the test article total pressure, test cell pressure, nozzle wall dynamic pressure and the strain gage signals. 
The test article exits were relatively close to the diffuser inlet sleeve. The diffuser inlet sleeve can just be seen in the right hand side of the test cell window in figure 4 and in the right and image in figure 3 . During the start transients, there were times when the $\mathrm{P}_{\text {amb }}$ was increasing, instead of decreasing as desired, due to interactions between the nozzle flow, the diffuser inlet and the two ejectors downstream. Increasing $\mathrm{P}_{\text {amb }}$ (or decreasing NPR in this test approach) meant that a net mass flow was coming into the test cell through the diffuser pipe, instead of going out. This mass flow, referred to as diffuser "backwash" here, buffeted the test article producing a load source other than those from nozzle flow separation. The approach taken to filter out potential backwash-corrupted side load data is addressed, briefly, in section IV F.

Nozzle shutdown transients require decreasing NPR. For this test approach, with constant nozzle $P_{c}$, the $P_{a m b}$ would have had to increase. Due to the phenomena just discussed, testing in the NTF could not properly simulate the nozzle shutdown transients.

The testing was conducted over a period of 15 months. The nozzle wall pressure data was recorded in the earlier tests. The side load moment measurement technique took longer to refine, therefore, that data was obtained in the later test series. The side load moment data discussed in this paper was obtained in two tests of 35 simulated nozzle starts for both the TIC and PAR nozzle test articles, resulting in a total of 70 simulated starts for each nozzle

\section{B. Nozzle Test Article Design}

The TIC and PAR contours and as-designed nozzle wall pressures are shown in figure 8. The TIC test article contour was developed by first calculating a full length ideal contour with an ideal bell nozzle code ${ }^{12}$. That contour was then evaluated with TDK $02^{13}$ to verify the nozzle's design objectives had been met and to obtain higher resolution of the contour geometry. It was then truncated at $79 \%$ length of an equivalent $15^{\circ}$ conical nozzle of the same area ratio (AR). The truncation length was chosen so the desired nozzle wall pressure ratio, $\mathrm{P}_{\mathrm{w}} / \mathrm{P}_{\mathrm{c}}=0.0025$, existed at the exit. This nozzle wall exit pressure ratio was desired because it would result in nozzle flow separations over a range for which the NTF test cell pressure was easy to control.

The PAR nozzle contour was developed using the skewed parabola option in the TDK02 ${ }^{13}$. The throat expansion angle, $40^{\circ}$, was chosen higher than might otherwise be typical for a thrust optimized nozzle. Being the first, and possibly only, thrust optimized contour test article to be fabricated it was desired that the PAR test article definitely have the transition to RSS. The high initial throat angle would ensure this IRAD task was able to measure and compare side loads of a TIC nozzle contour without the FSS-to-RSS transition to side loads of a thrust optimized nozzle contour with FSS-to-RSS transition.

The PAR length and contour exit angle were adjusted so that the transition to RSS would occur at an NPR that was neither too low nor too high. This last judgment was subjective. Computational fluid dynamic simulations performed during the test article design phase indicated the transition to RSS would occur at about NPR 24.
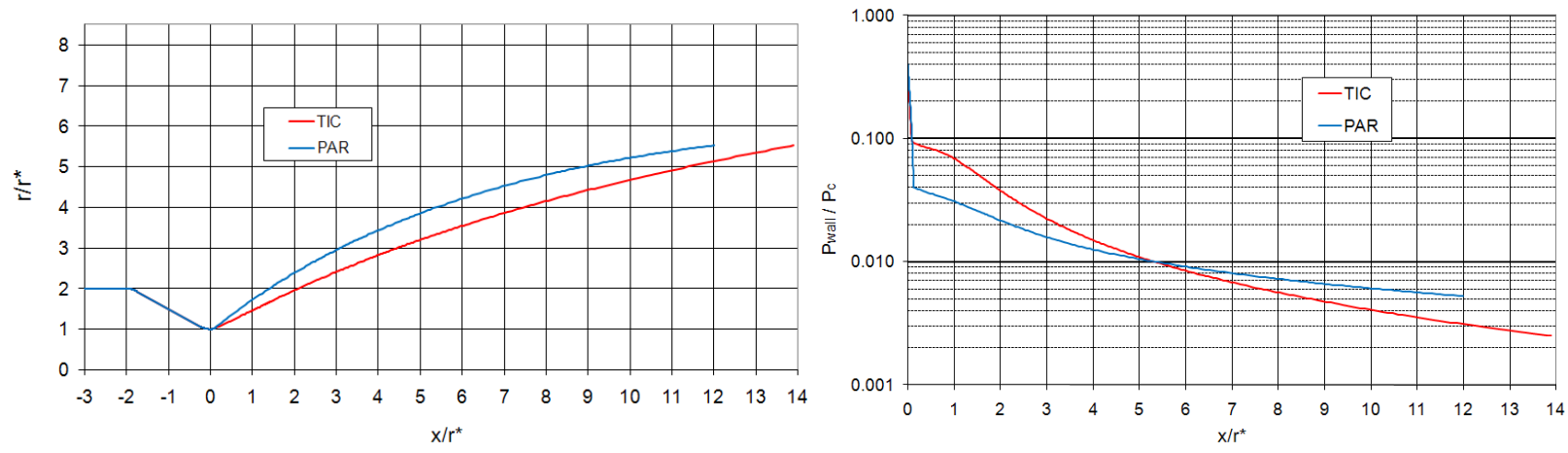

Figure 8. Nozzle test article contours (left) and as-designed wall pressures (right).

The schematics of the test article contours (figure 9) show that the convergent portions and throat diameters were the same. The radius of the initial divergence downstream of the throat was the same as well. However, the total angle of that initial divergence was different. The perfect nozzle code designed the TIC initial expansion of $22.68^{\circ}$ and, as discussed above, the PAR initial expansion of $40^{\circ}$ was iterated to. 

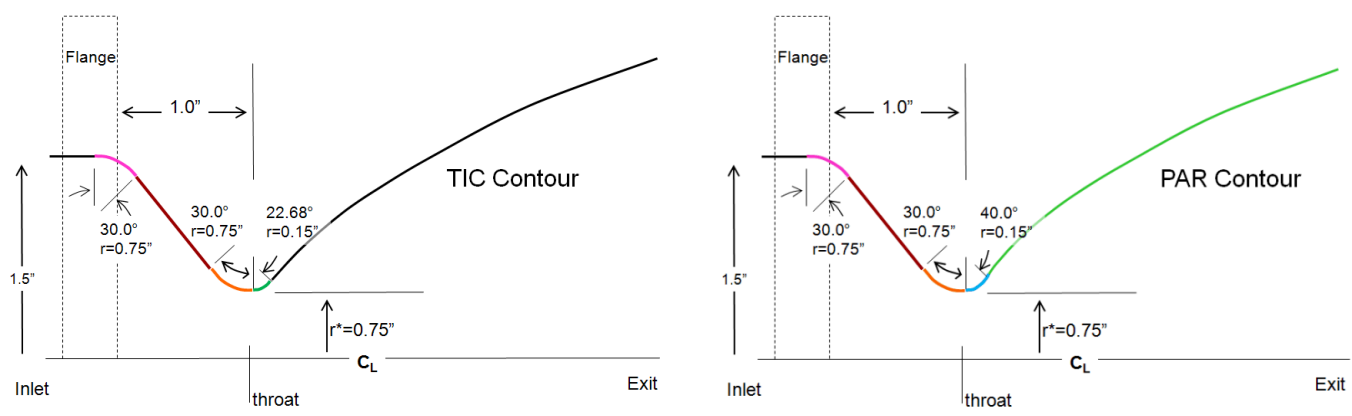

Figure 9. Schematics of the TIC and PAR test article nozzle contours.

The radius of this initial expansion was chosen as $20 \%$ of the throat radius or $3.8 \mathrm{~mm}(0.15 \mathrm{in})$. The result was that this critical portion of the nozzle contour had high wall slope gradients. Only after completion of fabrication was it realized that the machining tolerances specified for this region were insufficient to replicate the desired contours. The result of this design oversight is that the test articles both have a small contour discontinuity in the region of the throat. The discontinuities are raised bumps just perceptible to a finger running along the nozzle contour. They are estimated to be between 0.025 and $0.08 \mathrm{~mm}\left(1 / 1000^{\text {th }}\right.$ and $3 / 1000^{\text {th }}$ in). These bumps feel like they are just downstream of the throat and that they are consistent in shape and size in azimuth. The bump in the TIC nozzle feels slightly more prominent than the one in the PAR nozzle. After some additional testing effort, it was concluded that these contour flaws did not alter the separation characteristics of the nozzle flows. This conclusion was later borne out by a similar set of test articles that did not have this contour flaw.

The test articles (figure 10) were fabricated from aluminum. They both have an AR of 30.5, with a throat diameter of $38.1 \mathrm{~mm}(1.5 \mathrm{in})$. The test articles have the same mass and center of gravity so that the strain tube and nozzle system has the same response with either nozzle. Two rows of static pressure ports were machined into the nozzles staggered slightly about the $0^{\circ}$ and $180^{\circ}$ azimuths. The axial spacing of the static pressure ports was $8.6 \mathrm{~mm}$ (0.34 in). The high frequency pressure ports were in line at the $90^{\circ}$ and $270^{\circ}$ azimuths with an axial pitch of 17.3 $\mathrm{mm}(0.62$ in).

The PAR nozzle is physically shorter than the TIC nozzle. The axial pitch between that static and dynamic pressure ports was kept the same for both nozzles; therefore, the PAR has slightly fewer measurements. In the test articles there were approximately 30 static pressures in each azimuthal row and approximately 14 high frequency pressure ports in each azimuthal row.

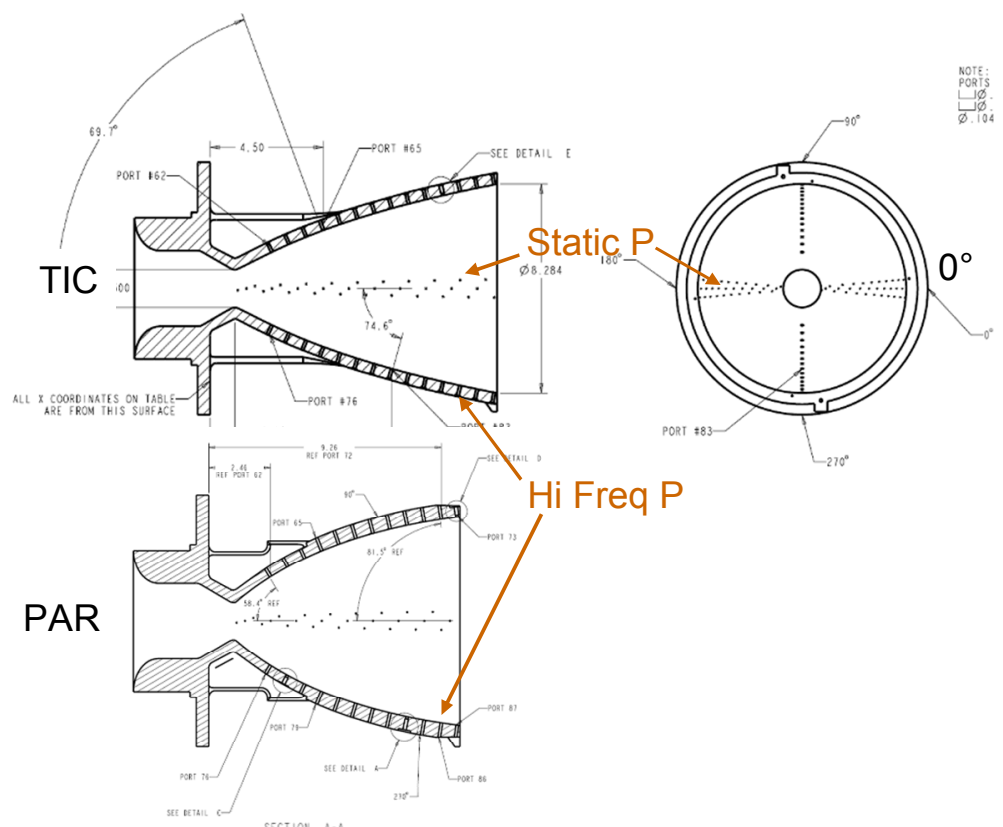

Figure 10. Cross-sections of the TIC and PAR nozzle test articles. 


\section{Calibration of the Strain Gages and Filtering}

Calibration of the strain gages was achieved by hanging weights from a system of knife edges and pulleys designed such that pure horizontal and vertical static loads were applied. These loads produced a moment and a measureable strain at the strain gage location. A full factorial experimental design was used, providing every combination of loads in a 2-factor, 5-level matrix. Strain tube temperature was carefully maintained with a small flow of temperature controlled air through the strain tube during the calibration process. This calibration data (a response surface using multiple linear regressions) was then used to calculate the moment in both directions as a function of the strain gage measurements.

The TIC and PAR test articles were designed to have the same masses and centers of gravity so that when mounted on the strain tube the strain tube/nozzle system would have the same fundamental frequencies. The fundamental frequency for the strain tube/TIC nozzle system was $207.5 \mathrm{~Hz}$ and for the strain tube/PAR nozzle system it was $215 \mathrm{~Hz}$. Note that these frequencies were within the range of expected side load excitation frequencies. This was a design compromise made early on to ensure the strain induced in the tube was sufficiently large to be measured accurately. The effect on the strain gage frequency domain is shown in figure 11. The black lines show peaks due to resonance at their respective fundamental frequencies.
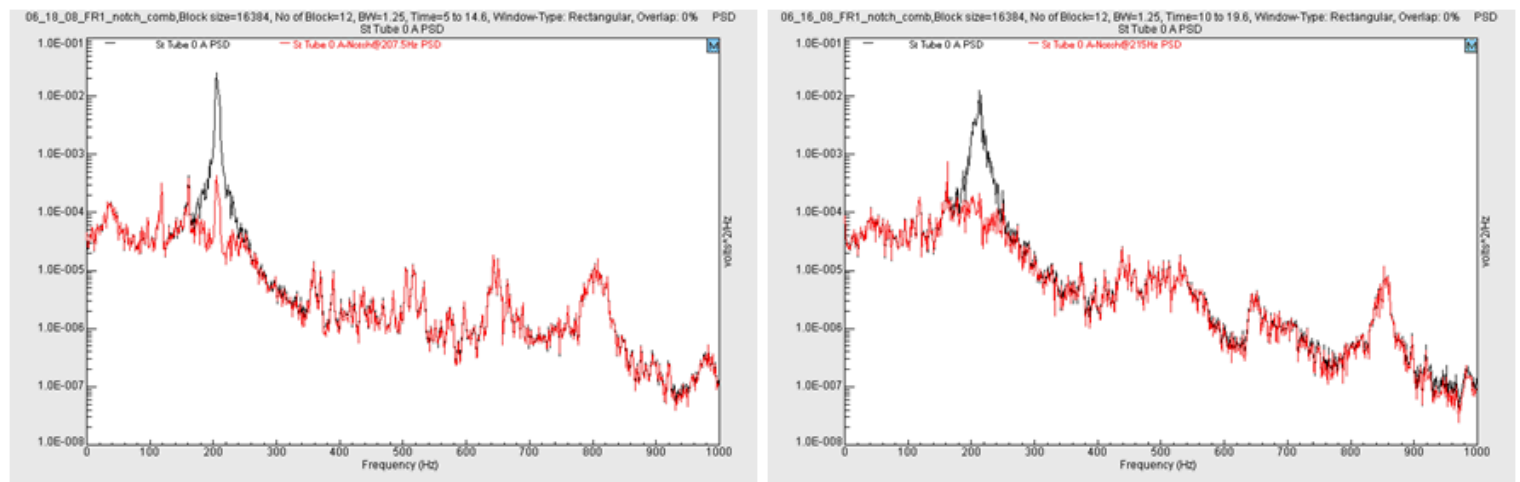

Figure 11. Frequency content of the strain gage signal of TIC (left) and PAR (right) before (black) and after (red) filtering.

The strain gage measurements reflect the equivalent, instantaneous static load on the tube. Since the actual load is extremely dynamic and excites the resonant frequency of the strain tube/nozzle system, the strain gage measurement, without a correction, would have been a largely inaccurate measurement of the applied load. It was determined that if the system resonance effect was filtered out, the remaining part of the strain gage signal was essentially equal to the static loading due to the aerodynamic side load forces ${ }^{14}$. To further reduce the impact of system dynamics on the conclusions drawn from the test data the filtered side load moments were normalized by the maximum measured moment (from the filtered data). This normalizing of the data determines the relative magnitude of side load moments for the two nozzle contours over their start transients.

The filter applied to remove the effect of the resonance from the strain gage signal was a "notch" filter, $45 \mathrm{~Hz}$ wide, with 1023 . The width of the filter was selected by examining the response power spectral densities. The value of $\pm 22.5 \mathrm{~Hz}$ around the resonant peak spanned the region in which the response appeared to be magnified by the resonance. The red lines in figure 9 show the effect of the $45 \mathrm{~Hz}$-wide notch filter on the strain gage signal. Further details of the effort to determine the true value of the aerodynamic force (the side load) from the test data can be found in Ref. 14.

The strain gage signals, $P_{c}$ and $P_{a m b}$ were recorded at 20,480 Hz. After filtering of the strain gage signal these three measurements were imported into MATLAB. The calibration equations were applied to the strain gage signals to convert them to engineering units of side load moment. The NPR was calculated for each data point from a running average over 128 of the $P_{c}$ and $P_{a m b}$. The $P_{c}$ signal was very steady and the averaging of it was not really necessary, however, the $\mathrm{P}_{\mathrm{amb}}$ value varied about a small but non-trivial amount continuously.

To make the volume of data more manageable the data was grouped into different "bins" of NPR (Table 1). Depending on the rate of change of NPR the bins for a single simulated nozzle start could have between a few hundred and several hundred thousand data points. For each of these bins of data the maximum, minimum, mean and standard deviation $(\sigma)$ of nozzle side load moment were calculated. 
Table 1. Bins of NPR

\begin{tabular}{|c|c|c|c|c|c|}
\hline $\begin{array}{c}\text { bin } \\
\text { minimum }\end{array}$ & bin center & $\begin{array}{c}\text { bin } \\
\text { maximum }\end{array}$ & $\begin{array}{c}\text { bin } \\
\text { minimum }\end{array}$ & bin center & $\begin{array}{c}\text { bin } \\
\text { maximum }\end{array}$ \\
\hline 12.0 & 13.0 & 14.0 & 61.0 & 62.5 & 64.0 \\
\hline 14.0 & 15.0 & 16.0 & 64.0 & 66.0 & 68.0 \\
\hline 16.0 & 17.0 & 18.0 & 68.0 & 70.0 & 72.0 \\
\hline 18.0 & 19.0 & 20.0 & 72.0 & 74.0 & 76.0 \\
\hline 20.0 & 21.0 & 22.0 & 76.0 & 78.0 & 80.0 \\
\hline 22.0 & 23.0 & 24.0 & 80.0 & 82.0 & 84.0 \\
\hline 24.0 & 25.0 & 26.0 & 84.0 & 86.0 & 88.0 \\
\hline 26.0 & 27.0 & 28.0 & 88.0 & 90.0 & 92.0 \\
\hline 28.0 & 29.0 & 30.0 & 92.0 & 94.0 & 96.0 \\
\hline 30.0 & 31.0 & 32.0 & 96.0 & 98.0 & 100.0 \\
\hline 32.0 & 33.0 & 34.0 & 100.0 & 102.5 & 105.0 \\
\hline 34.0 & 35.0 & 36.0 & 105.0 & 107.5 & 110.0 \\
\hline 36.0 & 37.0 & 38.0 & 110.0 & 112.5 & 115.0 \\
\hline 38.0 & 39.0 & 40.0 & 115.0 & 117.5 & 120.0 \\
\hline 40.0 & 41.5 & 43.0 & 120.0 & 122.5 & 125.0 \\
\hline 43.0 & 44.5 & 46.0 & 125.0 & 127.5 & 130.0 \\
\hline 46.0 & 47.5 & 49.0 & 130.0 & 132.5 & 135.0 \\
\hline 49.0 & 50.5 & 52.0 & 135.0 & 137.5 & 140.0 \\
\hline 52.0 & 53.5 & 55.0 & 140.0 & 142.5 & 145.0 \\
\hline 55.0 & 56.5 & 58.0 & 145.0 & 147.5 & 150.0 \\
\hline 58.0 & 59.5 & 61.0 & 150.0 & 152.5 & 155.0 \\
\hline
\end{tabular}




\section{Results}

\section{A. Nozzle Wall Pressure}

Nozzle wall pressures $\left(\mathrm{P}_{\mathrm{w}}\right)$ were recorded at $4 \mathrm{~Hz}$ in the low-speed data system. To obtain the $\mathrm{P}_{\mathrm{w}}$ profiles the NPR was held constant or the ramp rate was sufficiently slow that valid static pressure data was recorded. The pressure measurements presented previously ${ }^{1}$ were recorded in tests with the diffuser inlet approximately $76 \mathrm{~mm}(3$ in) downstream of the TIC nozzle exit plane and $127 \mathrm{~mm}(5 \mathrm{in})$ downstream of the PAR nozzle exit plane (figure 12.) At this distance downstream it appears the diffuser inlet had no or minimal effect on $P_{w}$. This data is presented in further detail the current paper.
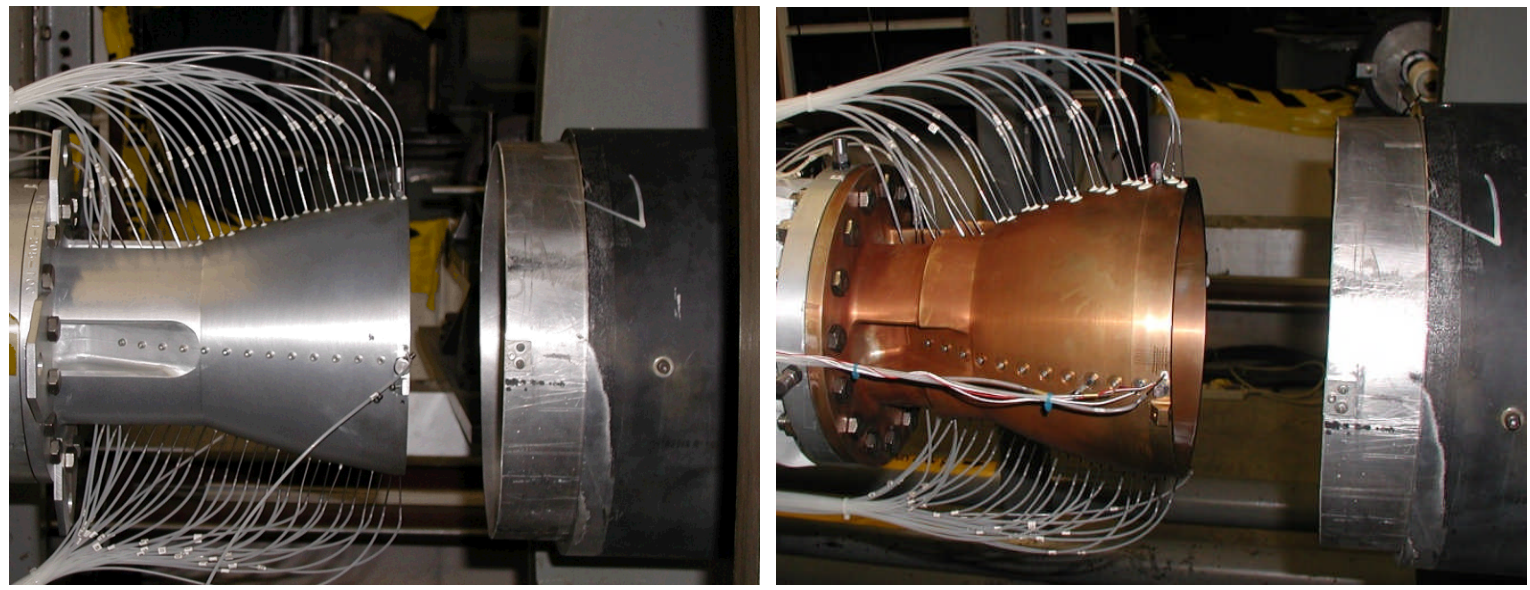

Figure 12. Diffuser inlet position with test articles installed; TIC (left) and PAR (right).

At the time those $\mathrm{P}_{\mathrm{w}}$ datasets were recorded the side load measurements technique was still being refined. Subsequent facility modifications and changes to the test approach improved the side load measurements. One of the changes made was to move the diffuser inlet closer to the nozzle exit plane in an attempt to reduce plume spillage and enable better control of the test cell pressure (i.e., $\mathrm{P}_{\mathrm{amb}}$ for the test articles). The side load data reported in Ref. 1 and in further detail in this paper was recorded with the diffuser inlet approximately $32 \mathrm{~mm}$ (1.25 in) downstream of the nozzle exit plane. Unfortunately, the time available to perform these tests was limited and the pressure instrumentation was not hooked up. Therefore, $\mathrm{P}_{\mathrm{w}}$ datasets do not exist for the tests in which side load moment data was recorded.

However, in between those two test series, PAR $\mathrm{P}_{\mathrm{w}}$ was recorded with the diffuser approximately $51 \mathrm{~mm}(2 \mathrm{in})$ downstream of the nozzle exit plane. In this test series, the close proximity of the diffuser inlet induced a different behavior of nozzle flow separation vs. NPR. This "with diffuser effect" PAR $\mathrm{P}_{\mathrm{w}}$ dataset is presented after the PAR data with the diffuser inlet at $127 \mathrm{~mm}$ downstream (i.e., no or minimal diffuser inlet effect on the data). The diffuser inlet effect did not change the shape of $\mathrm{P}_{\mathrm{w}}$ profiles. It did, however, move the separation location downstream for a given NPR.

The TIC nozzle was not tested with the diffuser inlet close to the nozzle exit other than in the tests in which side loads were recorded. Hence, no TIC $\mathrm{P}_{\mathrm{w}}$ data with diffuser inlet effect is available. Table 2 lists the tests, diffuser inlet positions and data just discussed.

Table 2. Nozzle tests and data presented the current paper.

\begin{tabular}{c|c|c|c|c|c|l|} 
Nozzle & Test Date & $\begin{array}{c}\text { Wall } \\
\text { Pressure } \\
\text { Data }\end{array}$ & $\begin{array}{c}\text { Diffuser Dist. } \\
\text { Downstream } \\
(\mathbf{m m})\end{array}$ & $\begin{array}{c}\text { Diffuser Effect } \\
\text { on Nozzle Flow }\end{array}$ & $\begin{array}{l}\text { Good Side } \\
\text { Load Data }\end{array}$ & Notes \\
\hline TIC & Early Spring '07 & Yes & 76 & minimal to none & No & Subset of $\mathrm{P}_{\mathrm{w}} 1^{\text {st }}$ presented in "Ruf, AIAA JPC 2009". Presented in finer detail here. \\
\hline PAR & Spring '07 & Yes & 127 & minimal to none & No & Subset of $\mathrm{P}_{\mathrm{w}} 1^{\text {st }}$ presented in "Ruf, AIAA JPC 2009". Presented in finer detail here. \\
\hline PAR & Fall '07 & Yes & 51 & yes & No & New data, $\mathrm{P}_{\mathrm{w}}$ presented here. \\
\hline TIC & Summer '08 & No & 32 & likely & Yes & Side Load Moments $1^{\text {st }}$ presented "Ruf, AIAA JPC 2009". Presented in finer detail here. \\
\hline PAR & Summer '08 & No & 32 & likely & Yes & Side Load Moments $1^{\text {st }}$ presented "Ruf, AIAA JPC 2009". Presented in finer detail here. \\
\hline
\end{tabular}


The remainder of this subsection on $\mathrm{P}_{\mathrm{w}}$ presents the TIC and then the PAR $\mathrm{P}_{\mathrm{w}}$ recorded in the spring of 2007. As mentioned above, these $\mathrm{P}_{\mathrm{w}}$ appear to have been unaffected by the diffuser inlet effect. The PAR $\mathrm{P}_{\mathrm{w}}$ recorded in fall of 2007 follow. The two sets of PAR $P_{w}$ are then compared to illustrate the diffuser inlet effect.

\section{1. $\quad$ TIC Nozzle Wall Pressures}

The TIC $P_{w}$ data presented here is from the same dataset presented in $2009^{1}$. The diffuser inlet was located 76 $\mathrm{mm}$ downstream of the nozzle exit plane. As discussed above it is believed the diffuser inlet did not significantly alter the nozzle flow separation characteristics.

Figure 13a compares the measured full flowing $\mathrm{P}_{\mathrm{w}}$ to the as-designed $\mathrm{P}_{\mathrm{w}}$. Figure $13 \mathrm{~b}$ presents the difference between the measured and the as-designed $\mathrm{P}_{\mathrm{w}}$. The differences are non-trivial for the first half of the nozzles and likely result from the aberrations of the as-built throat contour.

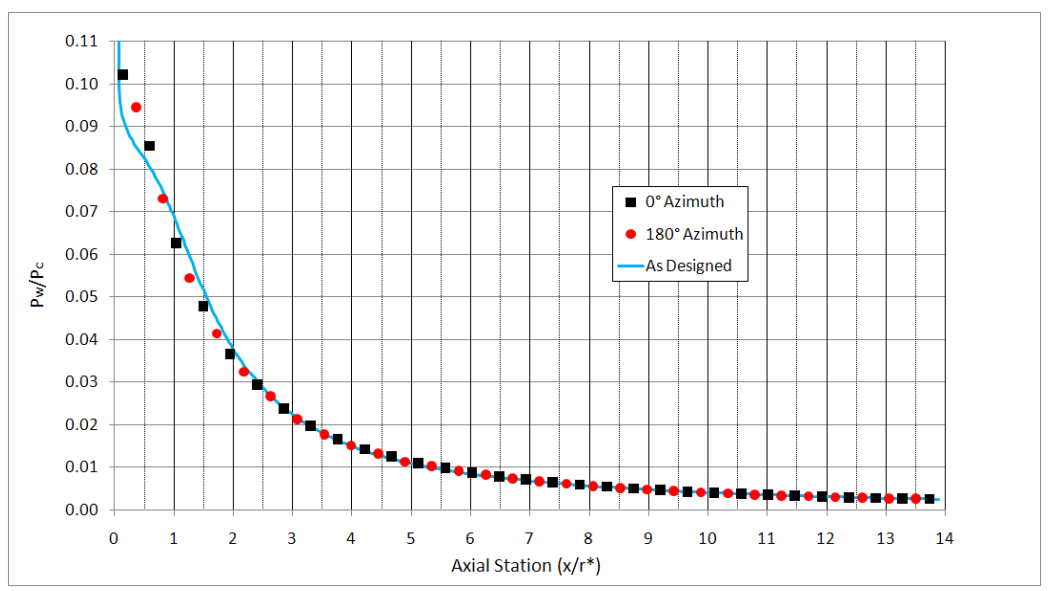

(a)

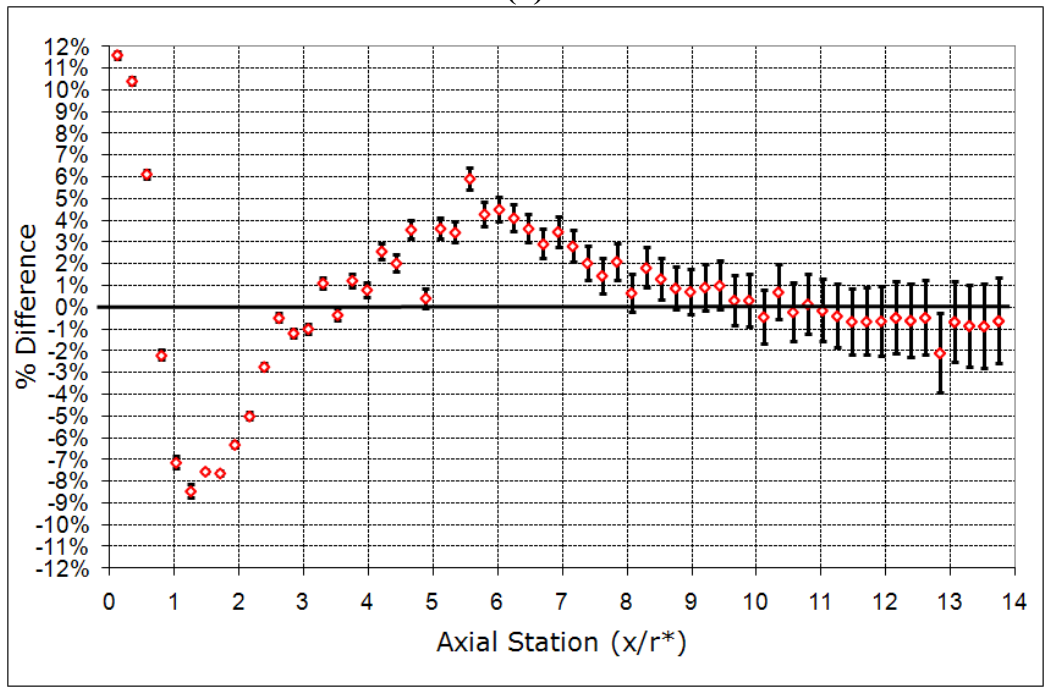

(b)

Figure 13. TIC normalized $P_{w}$ compared to the as-designed.

Figures 14 and 15 present the TIC test article's $\mathrm{P}_{\mathrm{w}}$ data for the $0^{\circ}$ and $180^{\circ}$ azimuth measurements, respectively, in two nondimensional forms. The profiles show the typical FSS characteristics of a TIC nozzle; a sharp rise in the wall pressure at the separation point, a plateau pressure close to $\mathrm{P}_{\mathrm{amb}}$ and then disappearance of the plateau as the separation location approaches the nozzle exit plane.

The NPRs plotted were chosen to document the $\mathrm{P}_{\mathrm{w}}$ profile that existed when the separation location was at each pressure measurement location. The NPRs plotted in figure 14 are different than those in figure 15 because the measurements were at different axial stations on the two azimuths. The NPRs above 11 were recorded during the main part of a test when the nozzle's $P_{c}$ was constant at the set point. Those data are from times when the nozzle test 
conditions were stationary (no significant changes in the NPR in time). The NPRs below 11 were recorded at the end of a test, after the ejectors were turned off, while the nozzle $P_{c}$ was decreasing. The change in the NPR and the $\mathrm{P}_{\mathrm{w}}$ was slow enough to obtain reasonably accurate static pressure measurements. Therefore, although the test conditions were not stationary, the five $\mathrm{P}_{\mathrm{w}}$ profiles below NPR 11 (three on the $0^{\circ}$ azimuth and two on the $180^{\circ}$ azimuth) are effectively stationary data.

The maximum NPR in the $\mathrm{P}_{\mathrm{w}} / \mathrm{P}_{\mathrm{c}}$ plots of figures 14 and 15 are 380.4 and 164.2 , for the $0^{\circ}$ and $180^{\circ}$ azimuths, respectively. At those NPRs the last measurement location, $\mathrm{x} / \mathrm{r}^{*}=13.733$ and 13.507 , on the respective azimuths, became insensitive to $P_{a m b}$. The $x / r^{*}=13.507$ behaved similar to the rest of the pressure measurements in that its value was affected by the separated flow until the flow separation location moved downstream of it, at which time it then became a constant value. The $\mathrm{x} / \mathrm{r}^{*}=13.733$ measurement, however, behaved different from the other $\mathrm{P}_{\mathrm{w}}$ measurements because it was essentially at the nozzle exit plane. The nozzle exit was at $\mathrm{x} / \mathrm{r}^{*}=13.812$, only 0.079 $\mathrm{x} / \mathrm{r}^{*}$ units $(1.5 \mathrm{~mm}$ or $0.059 \mathrm{in})$ downstream of the $\mathrm{x} / \mathrm{r}^{*}=13.733$ measurement. Close inspection of the $\mathrm{x} / \mathrm{r}^{*}=13.733$ data indicates that up to an NPR of about 175 that measurement location was affected by flow separation. Above approximately 175 and up to 380.4 the pressure did not become a constant value (as the other $\mathrm{P}_{\mathrm{w}}$ measurements had) but tracked $\mathrm{P}_{\mathrm{amb}}$ closely. This measurement was close enough to the nozzle exit plane for the $\mathrm{P}_{\mathrm{amb}}$ to communicate upstream through the subsonic part of the nozzle's boundary layer. 


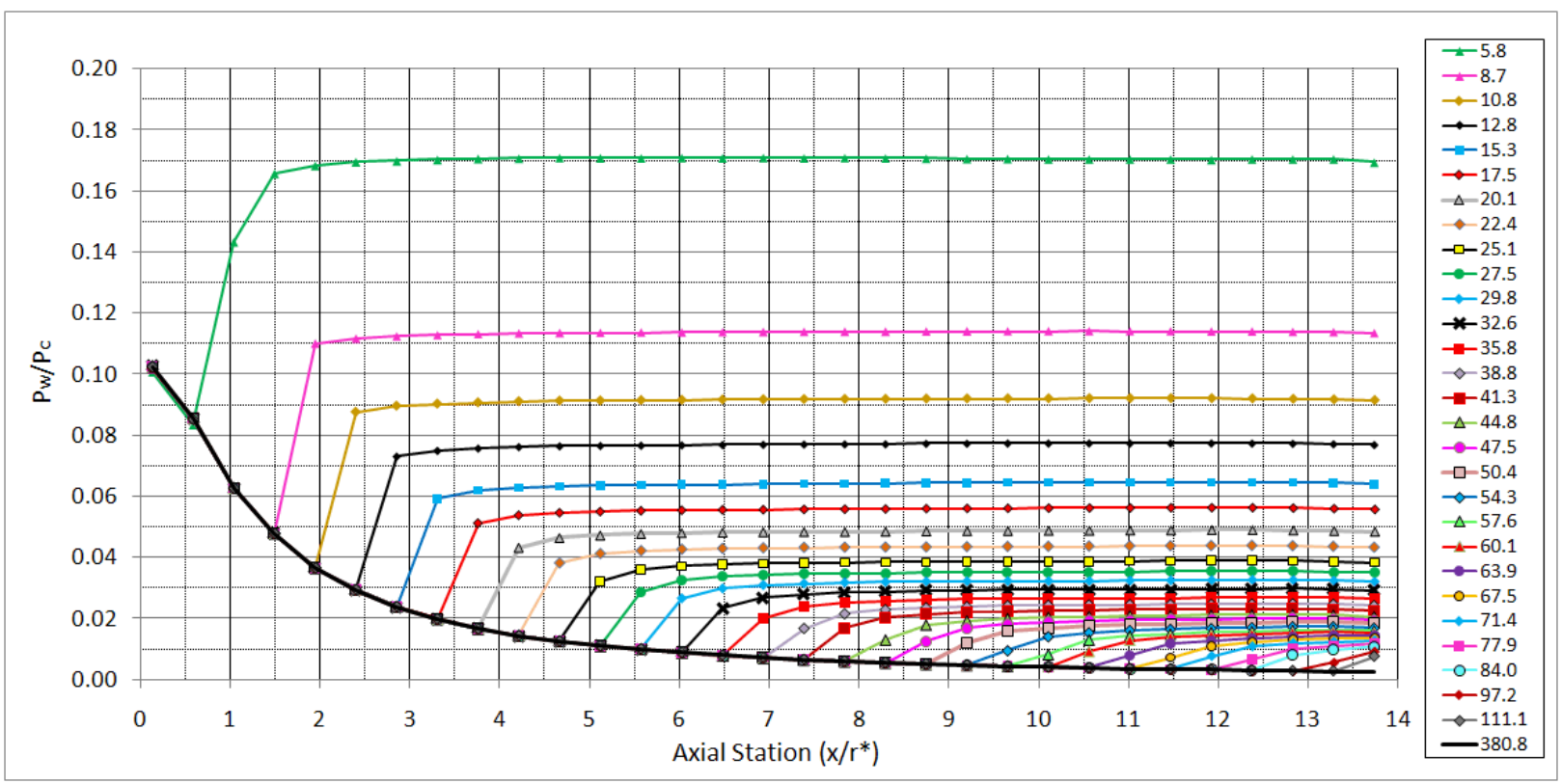

(a)

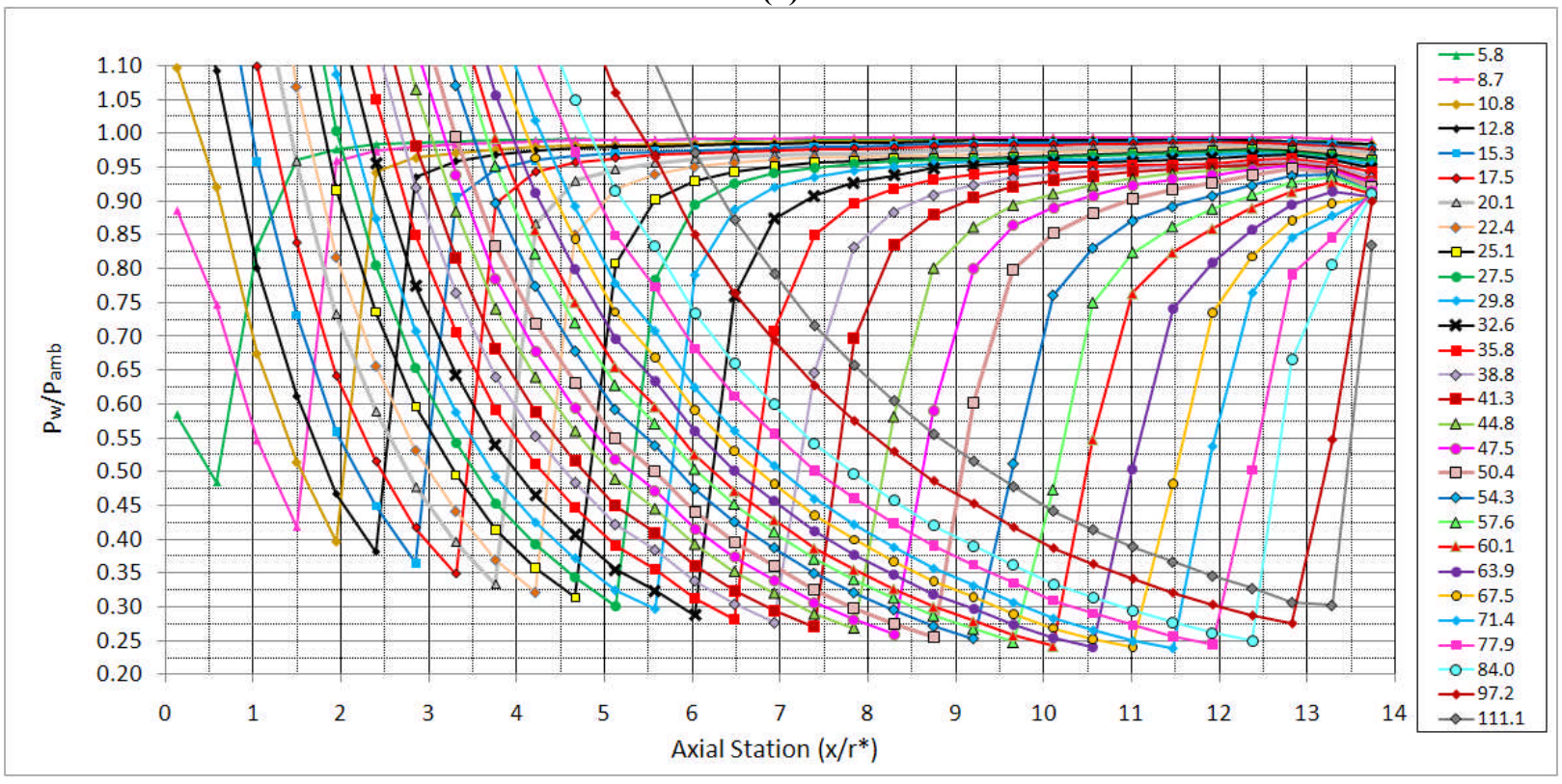

(b)

Figure 14. TIC test article $0^{\circ}$ azimuth normalized $P_{w}$.

The decrease seen in the $\mathrm{P}_{\mathrm{w}} / \mathrm{P}_{\mathrm{amb}}$ profiles at the last three measurements was due to local flow acceleration as ambient air was pulled into the recirculation region downstream of the nozzle flow separation. The normalized profiles for full flowing nozzles are included in the $\mathrm{P}_{\mathrm{w}} / \mathrm{P}_{\mathrm{c}}$ plots, however, they are omitted from the $\mathrm{P}_{\mathrm{w}} / \mathrm{P}_{\text {amb }}$ plots because the full flowing nozzle $P_{w}$ profiles, when normalized by $P_{a m b}$, provide no insight to the nozzle flow separation location. The values plotted in figures 14 and 15 are presented in tabular form in Appendix A of this paper (tables A1a through A2b). 


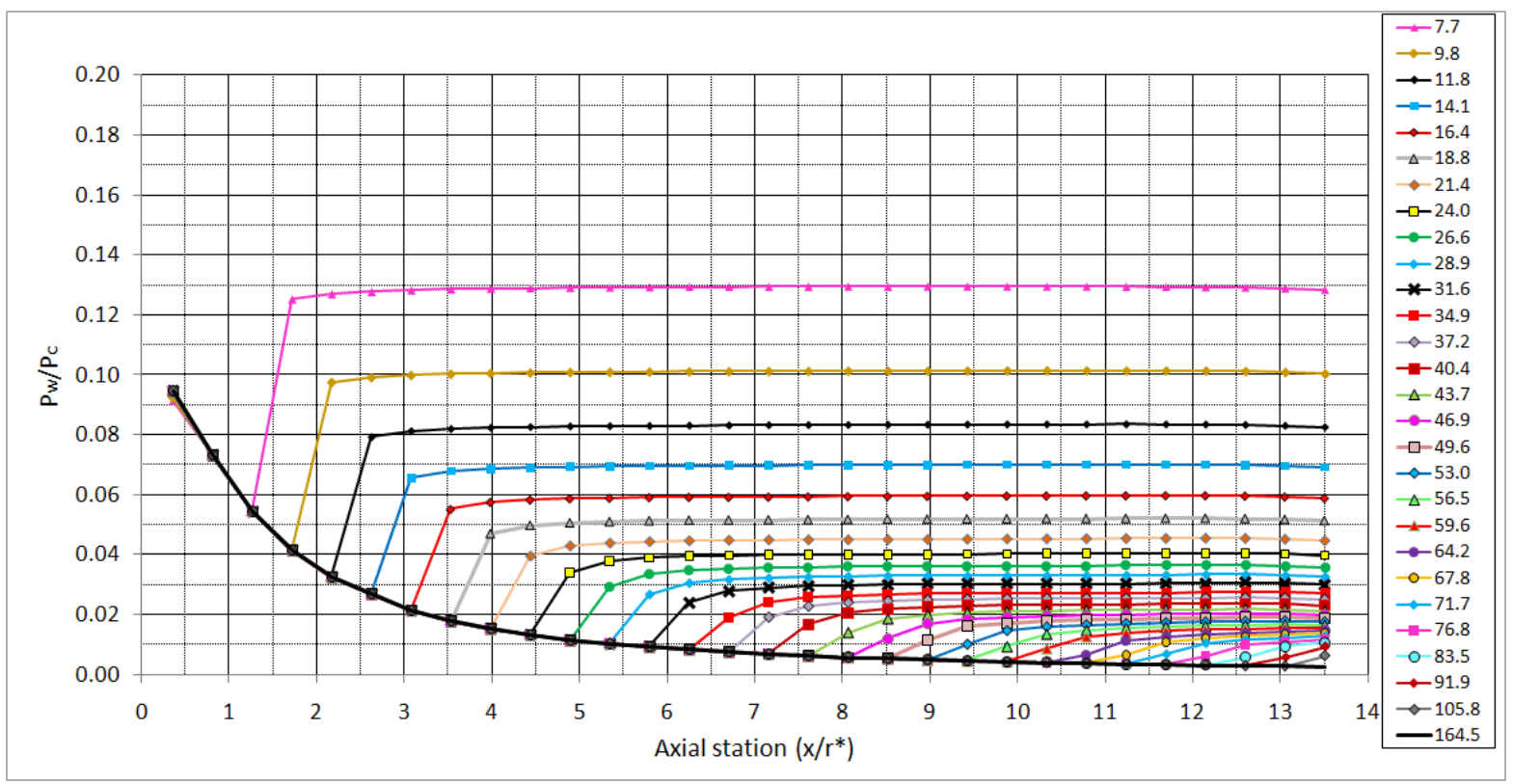

(a)

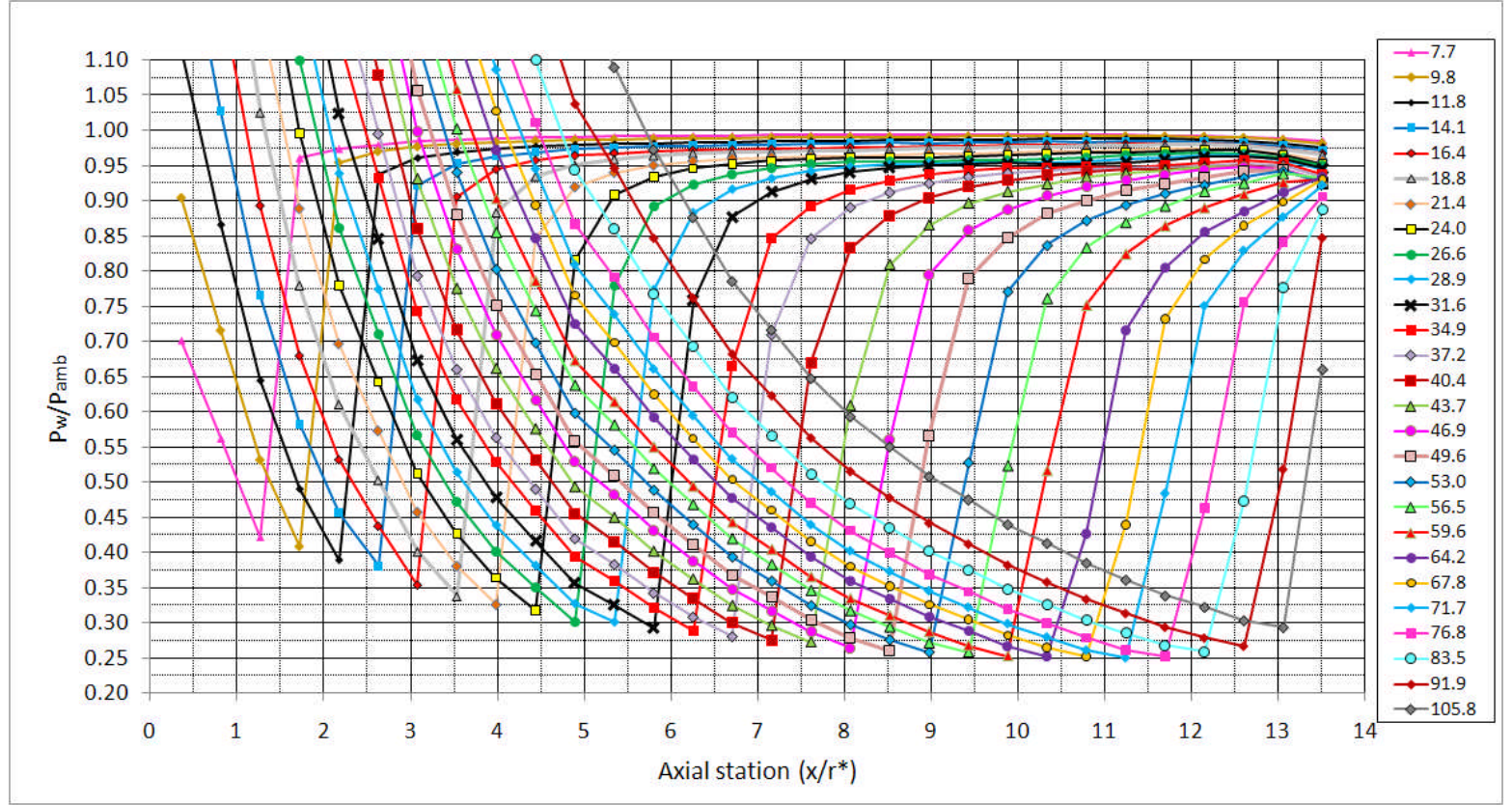

(b)

Figure 15. TIC test article $180^{\circ}$ azimuth normalized $P_{w}$.

14

American Institute of Aeronautics and Astronautics 
The separation pressure ratio $\left(\mathrm{P}_{\text {sep }}\right)$ is the ratio of $\mathrm{P}_{\mathrm{w}} / \mathrm{P}_{\mathrm{amb}}$ at which, for a given location, the flow will just remain attached. At a slightly lower ratio (either due to lower $\mathrm{P}_{\mathrm{w}}$ or higher $\mathrm{P}_{\mathrm{amb}}$ ) the flow would separate from the nozzle wall at that location. The NPRs plotted in figures 14 and 15 were chosen such that when $\mathrm{P}_{\mathrm{w}}$ was normalized by $\mathrm{P}_{\mathrm{amb}}$ as in 14(b) and 15(b) the $\mathrm{P}_{\text {sep }}$ is evident for each $\mathrm{P}_{\mathrm{w}}$ measurement location. These $\mathrm{P}_{\text {sep }}$, as a function of axial station, for both azimuths are presented in figure 16. The two curves agree down to $\mathrm{x} / \mathrm{r}^{*}$ of about 8 at which point they diverge up to a maximum difference of about $1 \%$ of $\mathrm{P}_{\mathrm{amb}}$. This difference may have resulted from asymmetries in the nozzle hardware. However, it also could have been the result of instrumentation effects. The pressures on the two azimuths were measured via separate, independent modules. The values plotted in figure 16 are the red colored, bold text in Tables A1band A2b in Appendix A.

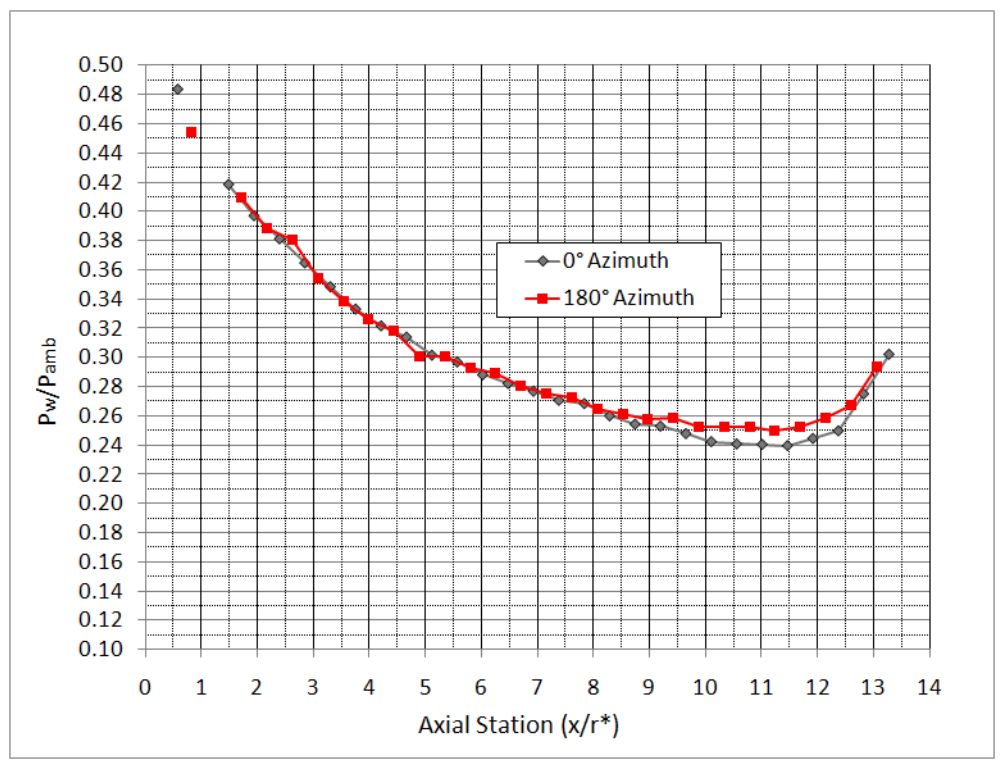

Figure 16. TIC $P_{\text {sep }}$ as a function of axial station.

Pressure was measured at four circumferential locations on the nozzle base (the downstream facing surface at the nozzle exit plane) as indicated in figure 17. Those four pressures were averaged (called " $\mathrm{P}_{\text {base }}$ ") and normalized by $\mathrm{P}_{\mathrm{amb}}$ (figure 18).
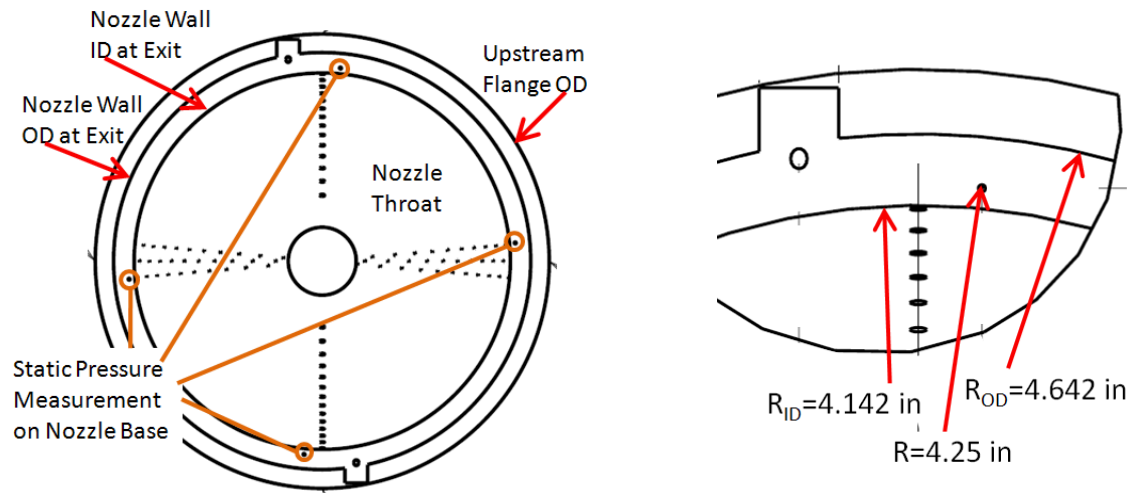

Figure 17. View of nozzle looking upstream (left) and an enlargement (right). 


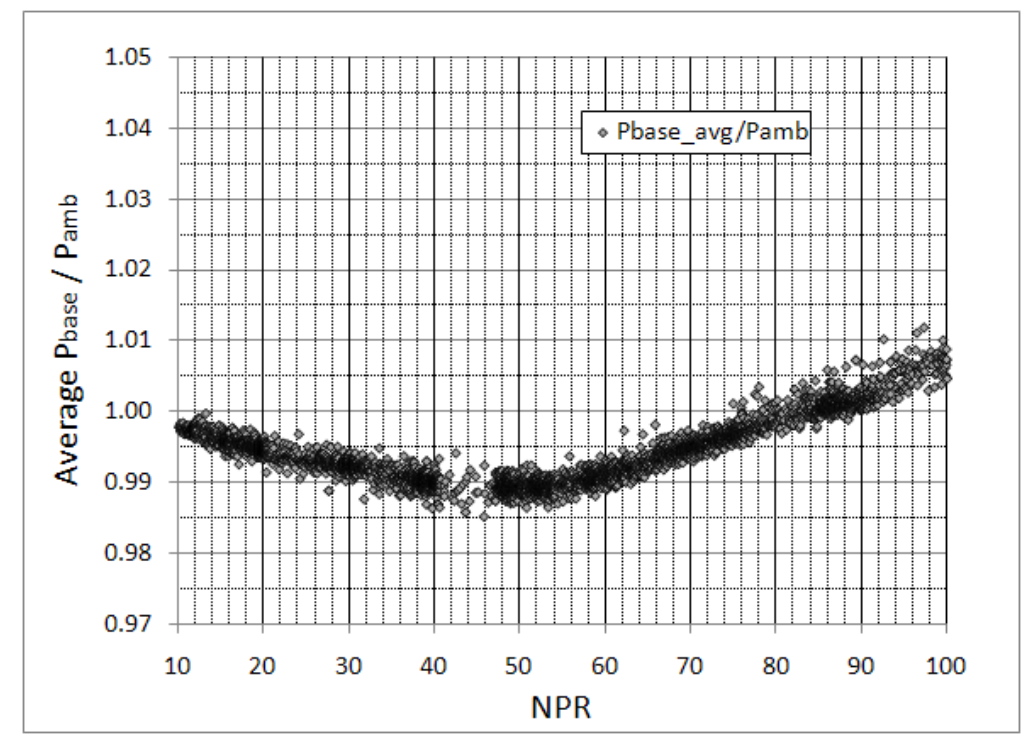

Figure 18. TIC average $P_{\text {base }}$. Diffuser inlet 76 mm downstream.

The variation of the $\mathrm{P}_{\text {base }} / \mathrm{P}_{\text {amb }}$ curve with NPR was caused by the decrease in $\mathrm{P}_{\text {base }}$ due to the acceleration of the test cell air over the nozzle aft lip. The acceleration was induced by the less-than- $\mathrm{P}_{\mathrm{amb}}$ pressure that developed in the recirculation zone downstream of the separation location. 


\section{PAR Nozzle Wall Pressures}

Figures 19 through 24 present the PAR test article $\mathrm{P}_{\mathrm{w}}$ recorded in the first test series when the diffuser inlet was approximately $127 \mathrm{~mm}$ (5 in) downstream of the nozzle exit plane. This $\mathrm{P}_{\mathrm{w}}$ data is from the same set of test data presented in the 2009 paper $^{1}$. In this test series the diffuser inlet effect did not appear to have a significant effect on the separation characteristics of the nozzle flow. As discussed previously, the side load moment measurement technique was not yet refined when this $\mathrm{P}_{\mathrm{w}}$ data was obtained. Therefore, good side load moment data does not exist for the PAR nozzle when unaffected by the diffuser inlet.

Figure 19a compares the PAR nozzle normalized $\mathrm{P}_{\mathrm{w}}$ at full flowing condition to the as-designed curve and figure $19 \mathrm{~b}$ presents the differences between them. The measured values were slightly higher than the as-designed curve over most of the length of the nozzle.

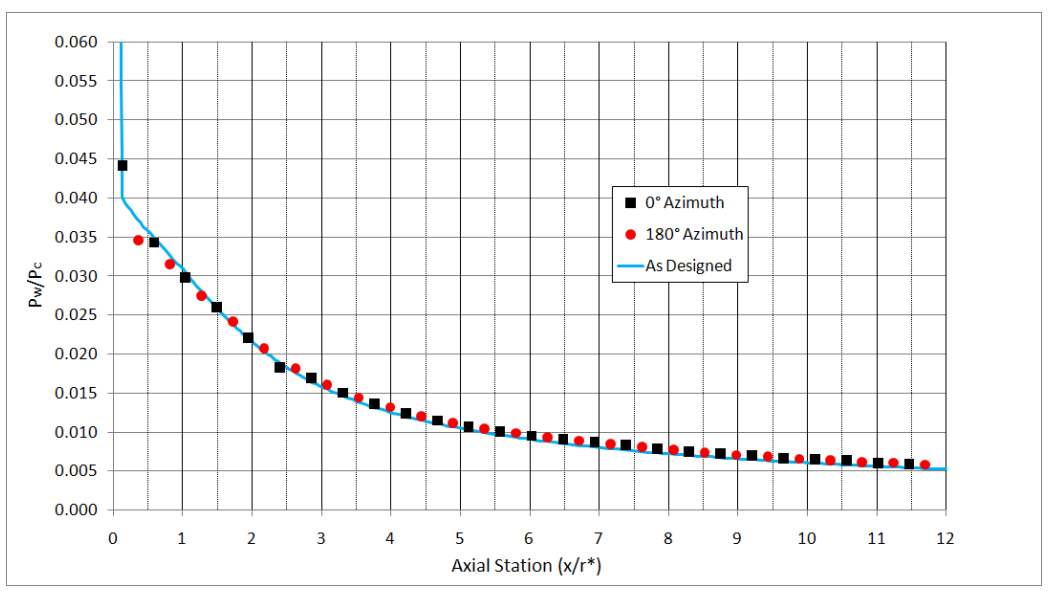

(a)

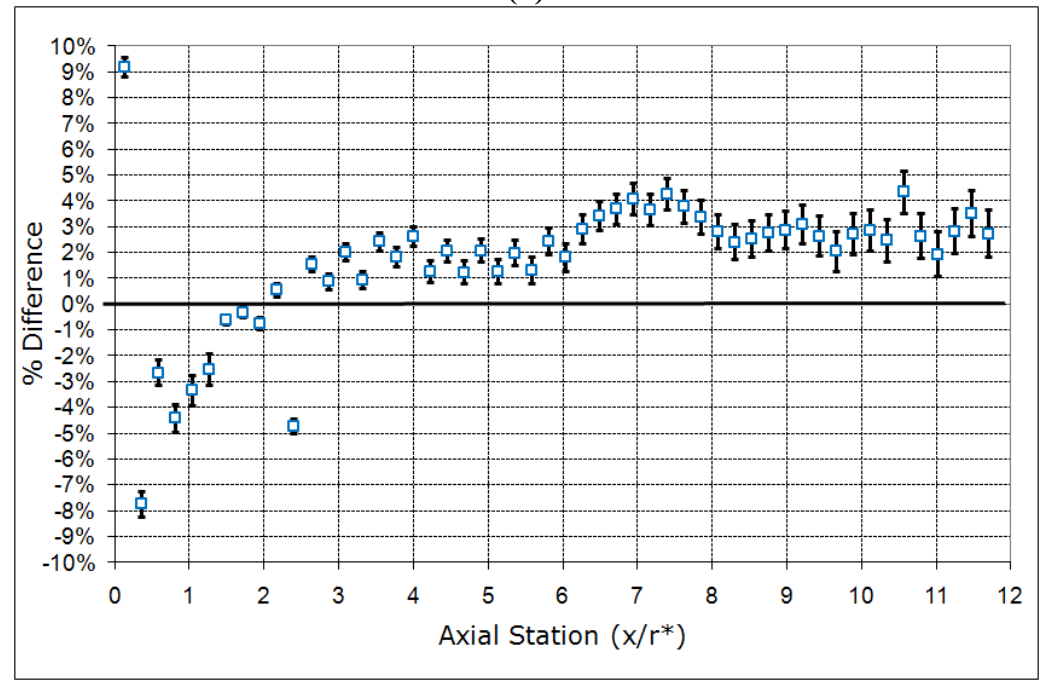

(b)

Figure 19. PAR normalized $P_{w}$ compared to the as-designed from the Spring ' 07 test series

Figures 20 and 21 present the normalized wall pressures for the $0^{\circ}$ and $180^{\circ}$ azimuths. The NPRs plotted were chosen based on the $\mathrm{P}_{\text {sep }}$ for each pressure measurement location. The NPRs are slightly different for the two azimuths in figures 20 and 21 because the pressure measurements were at different axial locations. 


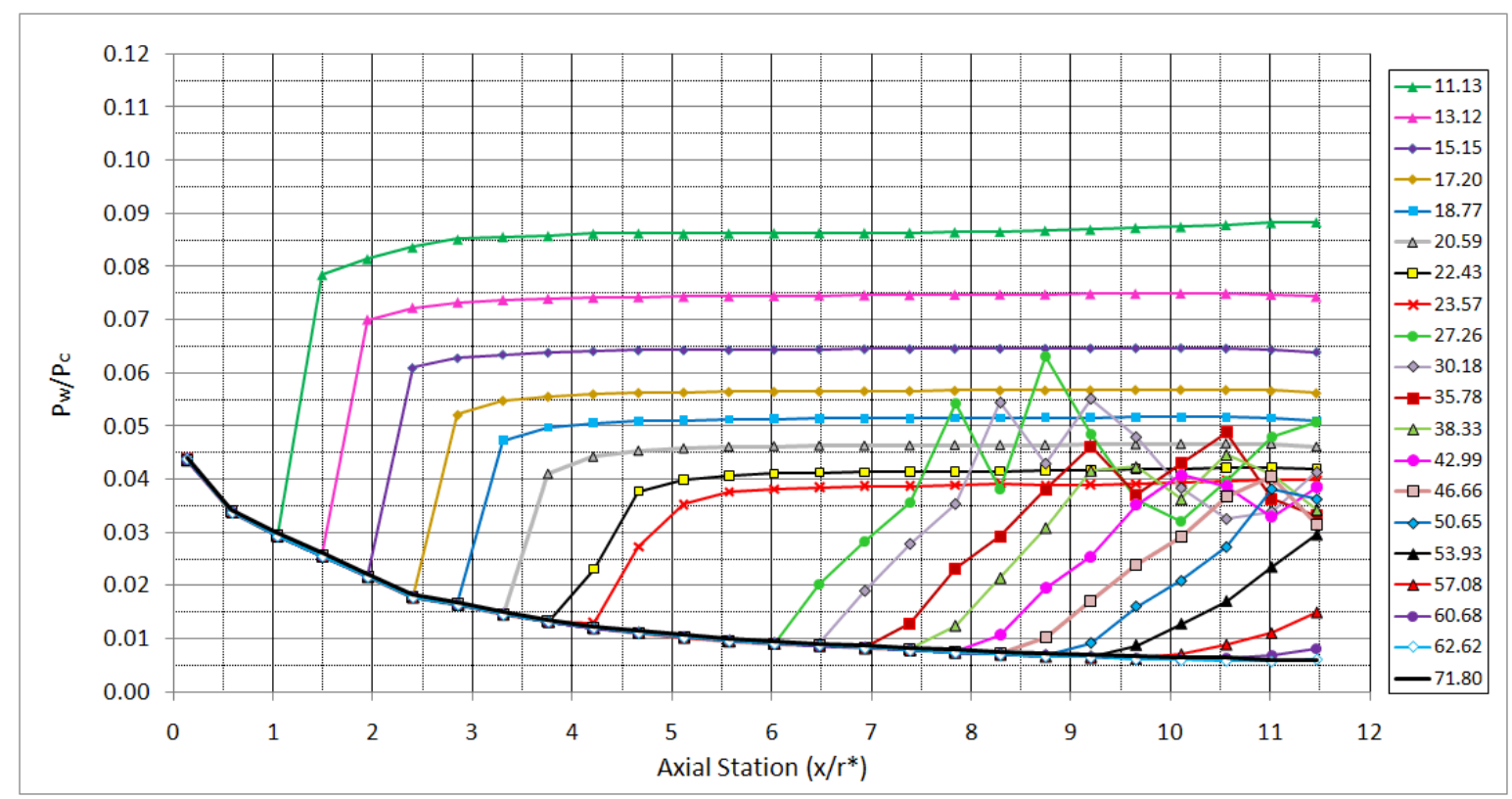

(a)

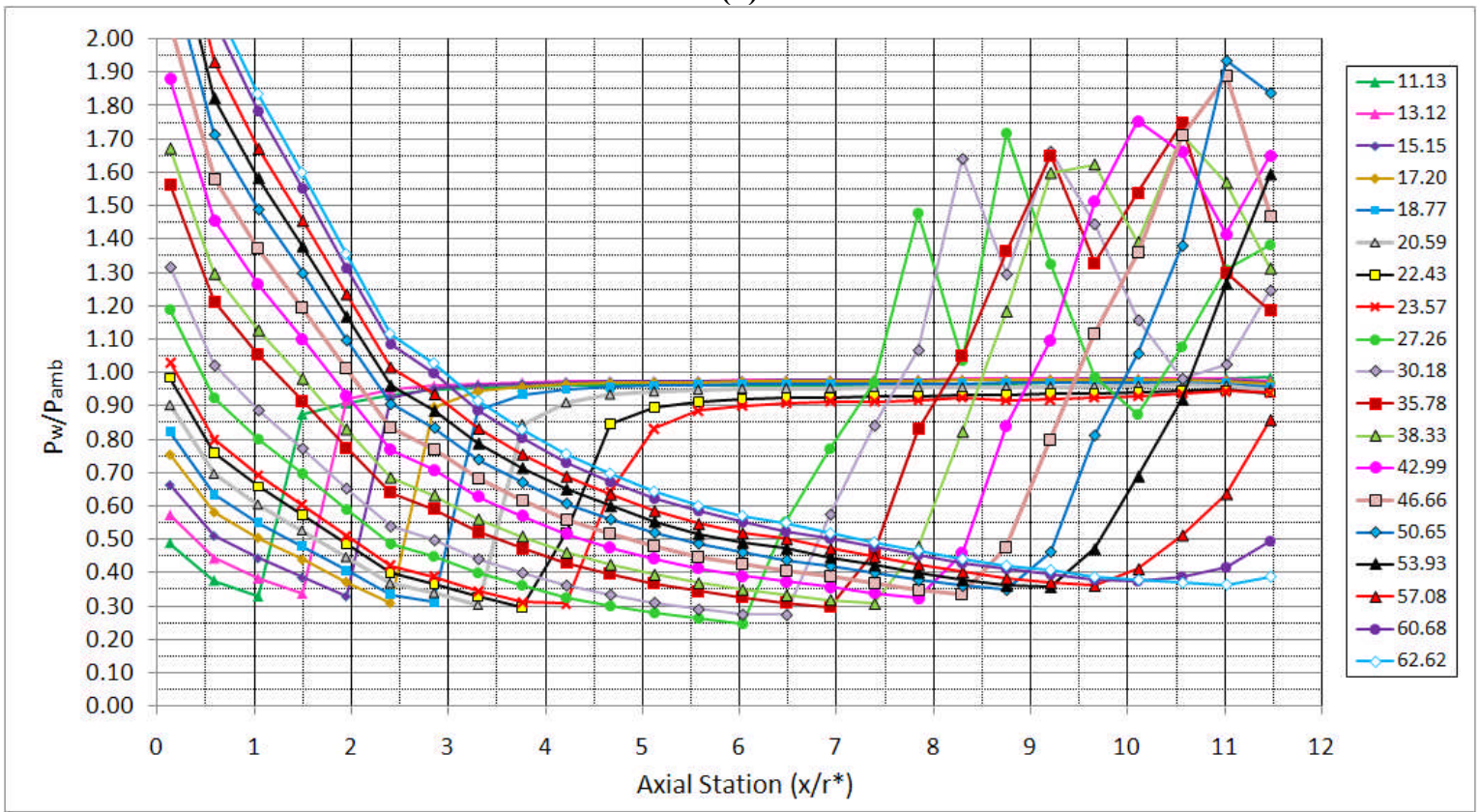

(b)

Figure 20. PAR test article $0^{\circ}$ azimuth normalized $P_{w}$ for increasing NPR.

18

American Institute of Aeronautics and Astronautics 


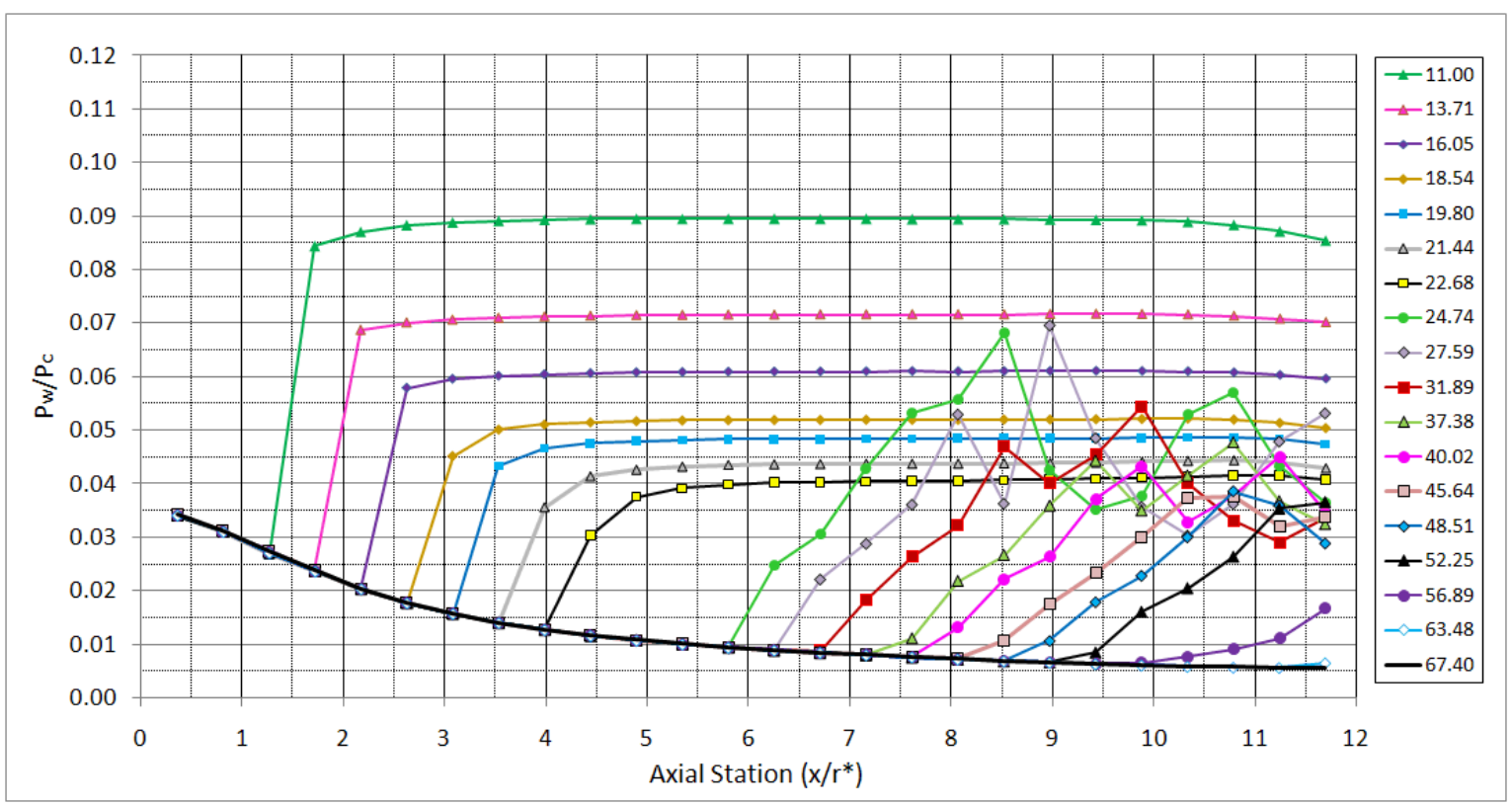

(a)

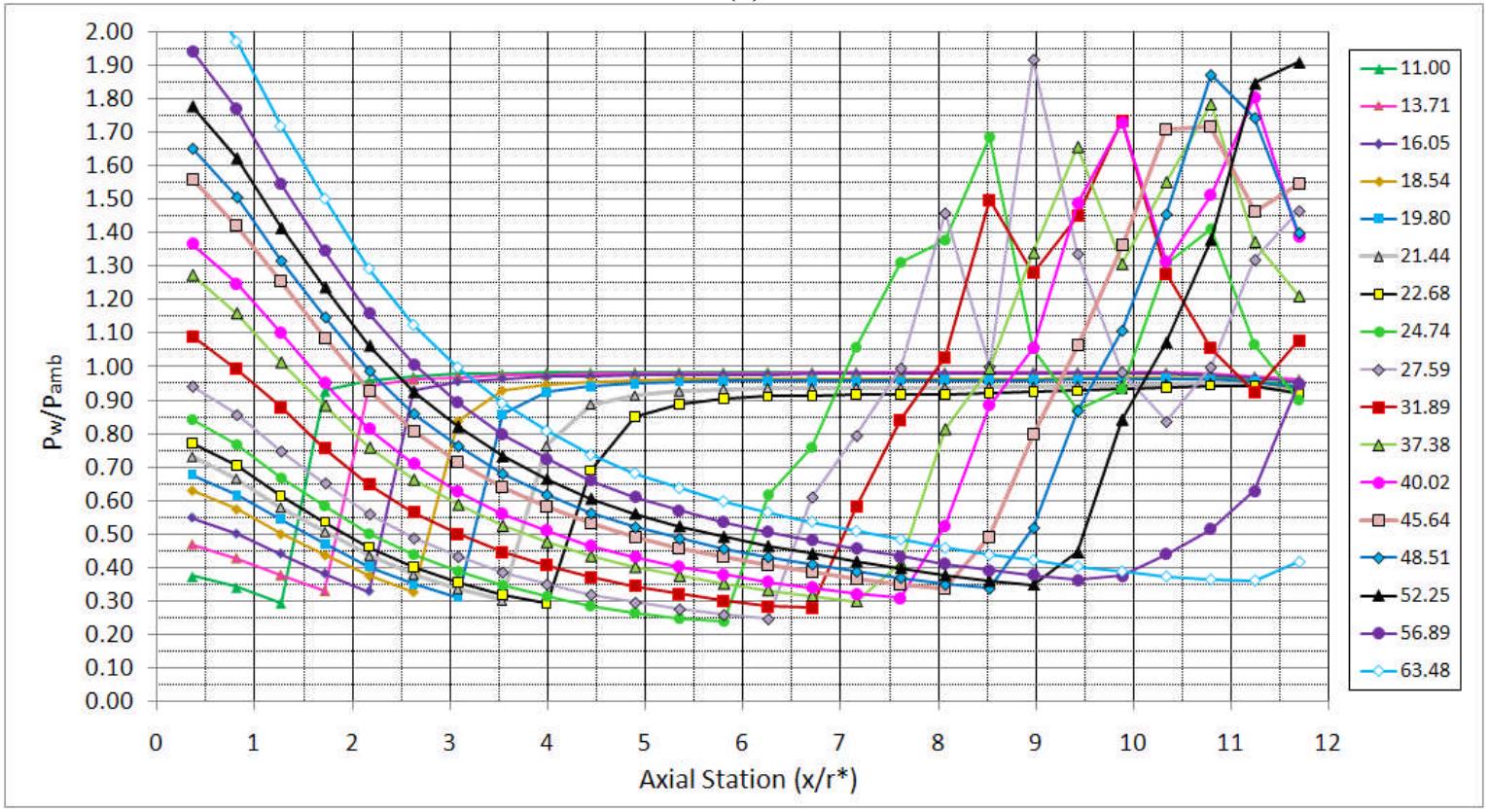

(b)

Figure 21. PAR test article $180^{\circ}$ azimuth normalized $P_{w}$ for increasing NPR.

The first eight NPRs in figure 20 (and first seven in figure 21) indicate that nozzle flow was in FSS. When NPR was slowly increased the flow became noticeably more unsteady starting at NPR 23.1 and increasing until complete transition to full RSS occurred at 23.6. In the transition the separation location jumped downstream from $\mathrm{x} / \mathrm{r}^{*}=4.21$ (NPR 23.57 in figure 20) between $\mathrm{x} / \mathrm{r}^{*}=5.57$ and 5.80 .

In RSS the annular jet of supersonic flow reattaches to the nozzle wall inducing a local high pressure region. From this high pressure region most of the flow expands downstream and, depending on the downstream flow, it may separate again. Because the reattached flow creates higher pressure than that immediately upstream of it, some of the flow reciculates, forward, along the nozzle wall. This reattaching and separating of the nozzle flow can occur multiple times. For example, in figure 20(b), the NPR $27.26 \mathrm{P}_{\mathrm{w}}$ profile had three reattached regions at approximately $\mathrm{x} / \mathrm{r}^{*}=7.8,8.7$ and 11.5. Upstream of each of these was a separated, reciculating region trapped between the nozzle wall and the annular jet of supersonic flow. 
The RSS flow was highly dynamic even though the NPR was relatively constant. The static measurement instrumentation averages the highly variable instantaneous pressures. Care was taken to present the best representative $\mathrm{P}_{\mathrm{w}}$ profiles.

The flow remained in RSS with reattached flow around the full circumference up to an NPR of about 55. Above NPR 55 the flow was no longer fully attached around the nozzles circumference but had changed to an oscillatory partial reattachment. This change in flow structure is visible in the difference between the $\mathrm{P}_{\mathrm{w}}$ profiles for NPR 53.93 and 57.08 in figure 20(b) (and between NPR 52.25 and 56.89 in 21(b)). The flow was visibly oscillatory at a high frequency at these NPRs. This transition from fully attached RSS to the partial and intermittently attached RSS was the source of the highest side loads moment for the PAR nozzle. As the NPR increased the intermittent flow reattachment occurred less and this is reflected in the decreasing pressure at NPR 60.68 and 62.62. Between NPR 62 and 70 the nozzle flowed full and the nozzle flow became steady.

The flow did not transition from RSS to FSS before flowing full, as is often seen in TOC nozzles. Instead, as just described, it transitioned from RSS to a partial-RSS then snapped to a full flowing condition.

The values plotted in figures 20 and 21 are provided in tabular form in Appendix A (tables A3a through A4b). 
With decreasing NPR the nozzle flow exhibited a hysteresis in the transition between FSS and RSS. As mentioned above, the transition from FSS to RSS with increasing NPR occurred between 23.1 and 23.6, but when NPR was decreasing, the transition from RSS back to FSS did not occur until an NPR of about 12.7. Figures 22 and 23 present the $\mathrm{P}_{\mathrm{w}}$ profiles on the two azimuths for NPRs within this hysteresis regime: that is, profiles that existed while the NPR decreased from 23.3 to 12.8. The values plotted in figures 22 and 23 are provided in tabular form in Appendix A (tables A5a through A6b).

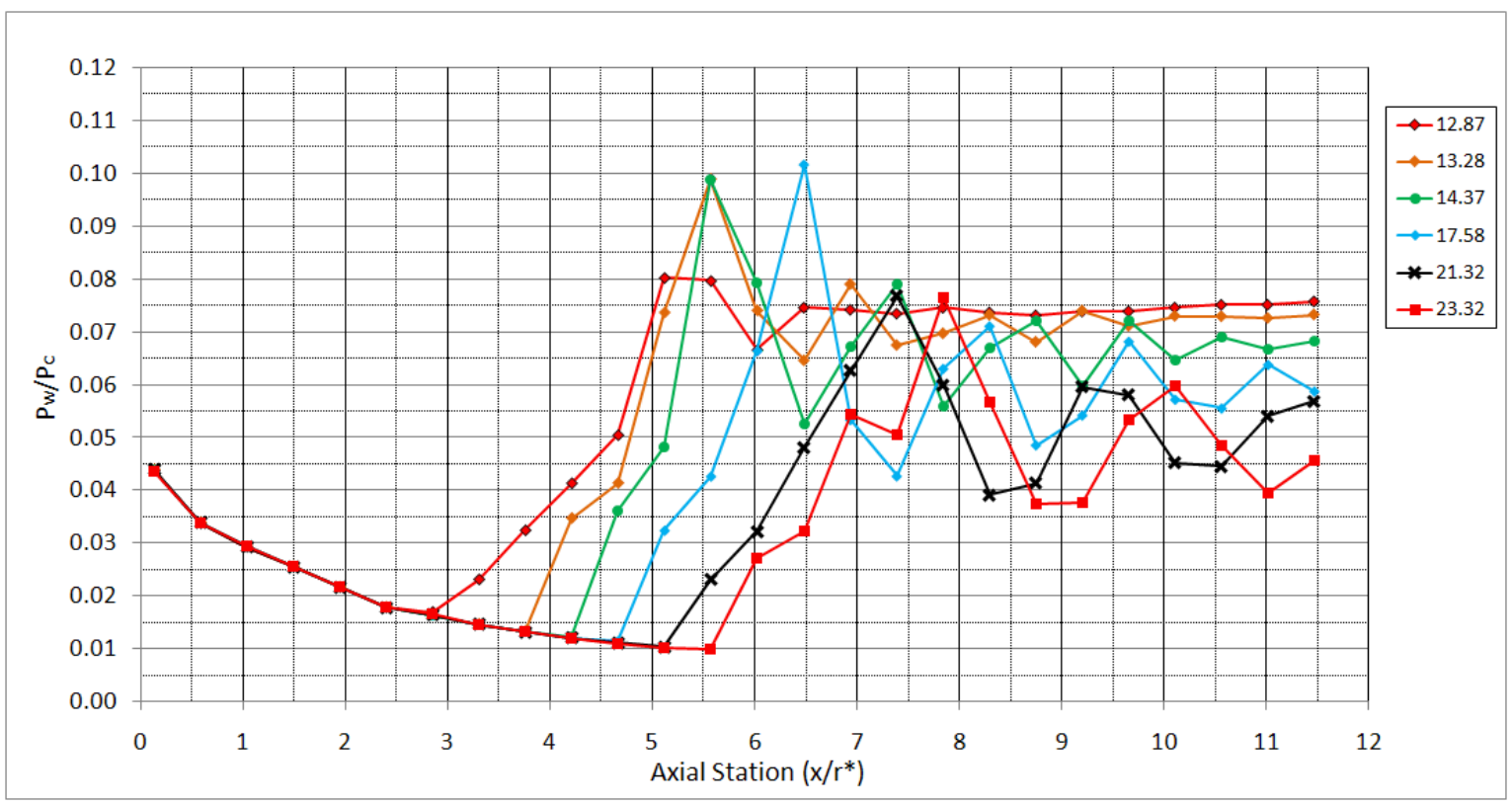

(a)

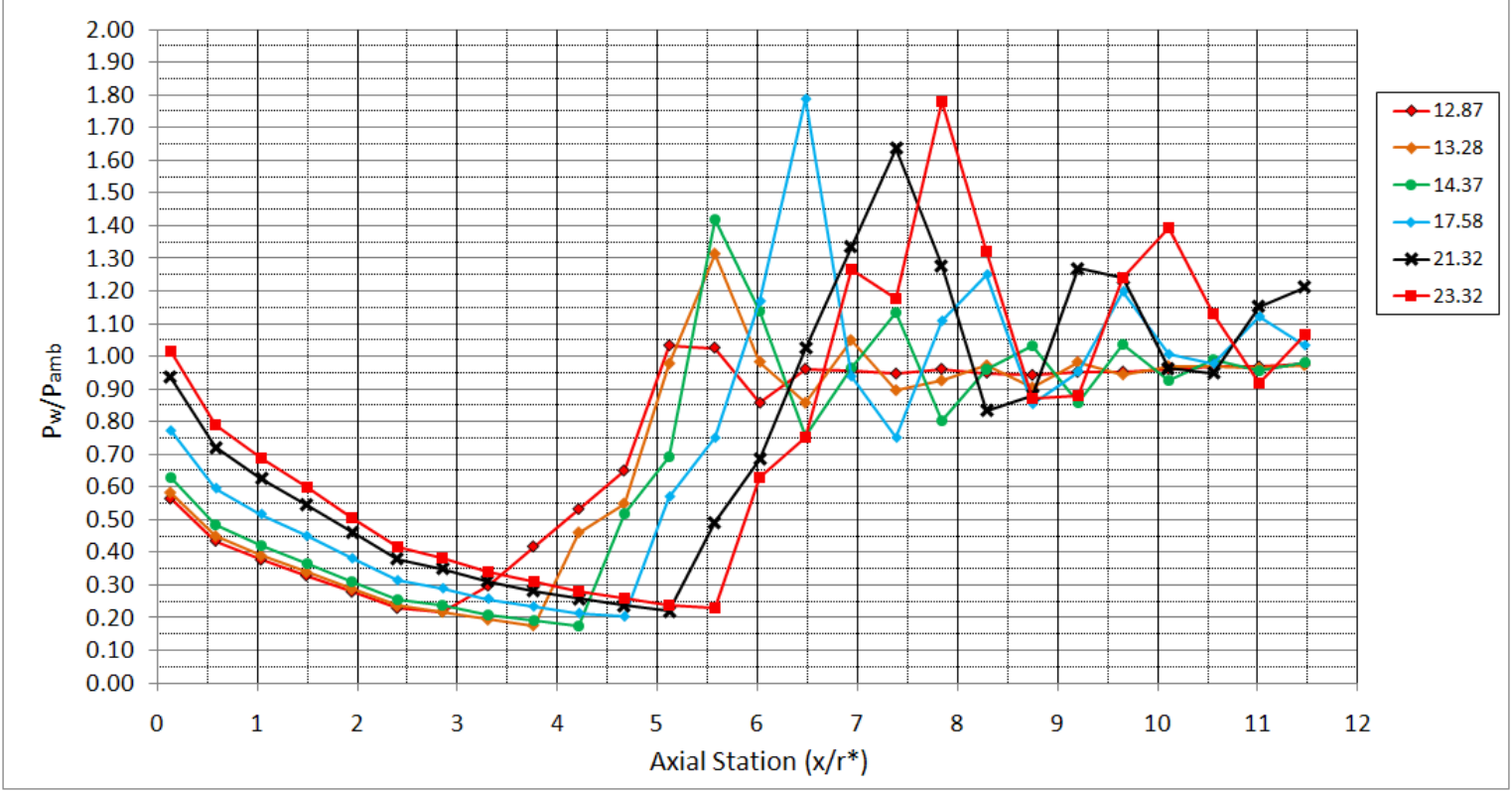

(b)

Figure 22. PAR test article $0^{\circ}$ azimuth normalized $P_{w}$ within the RSS-to-FSS hysteresis regime. 


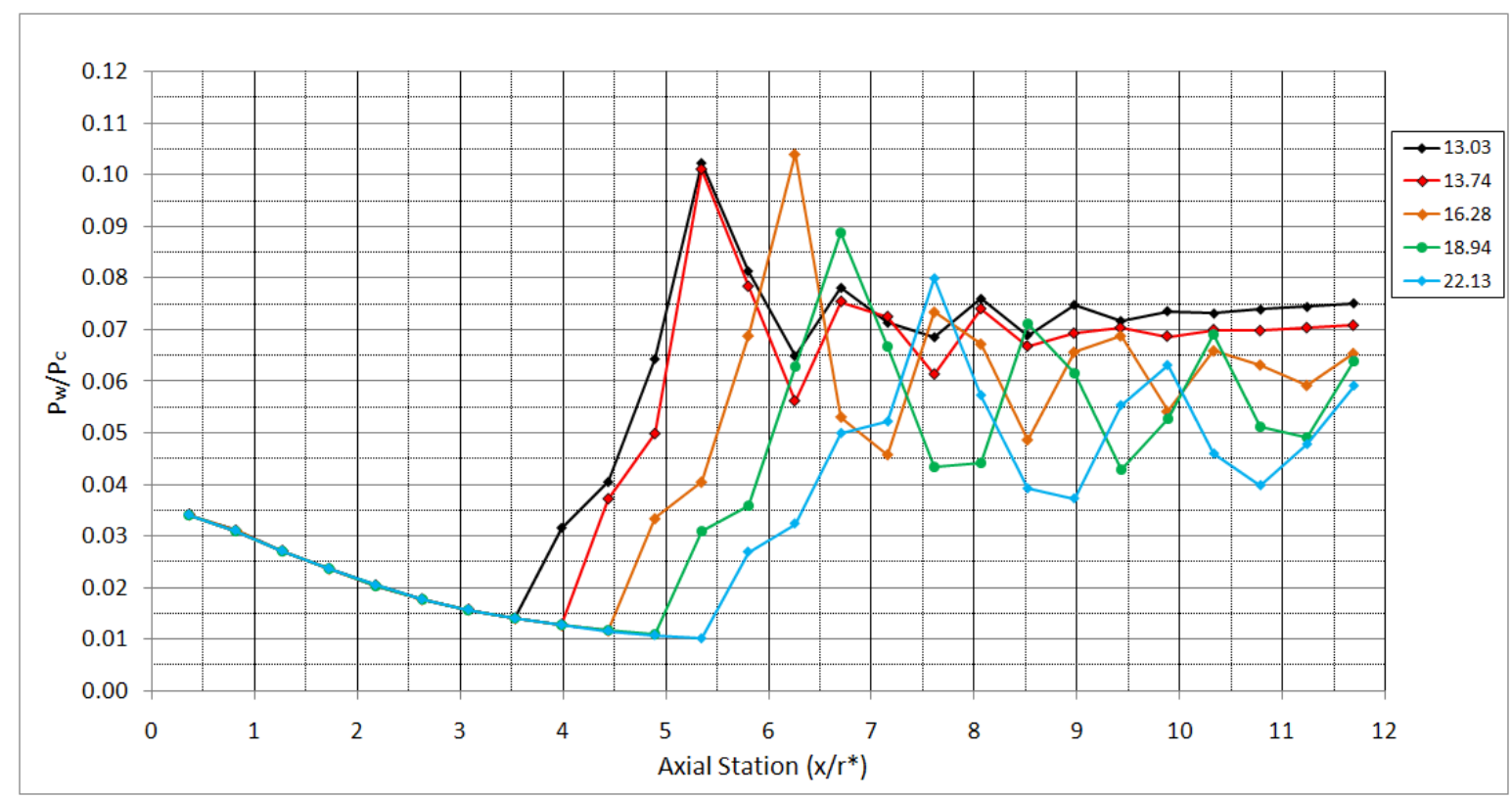

(a)

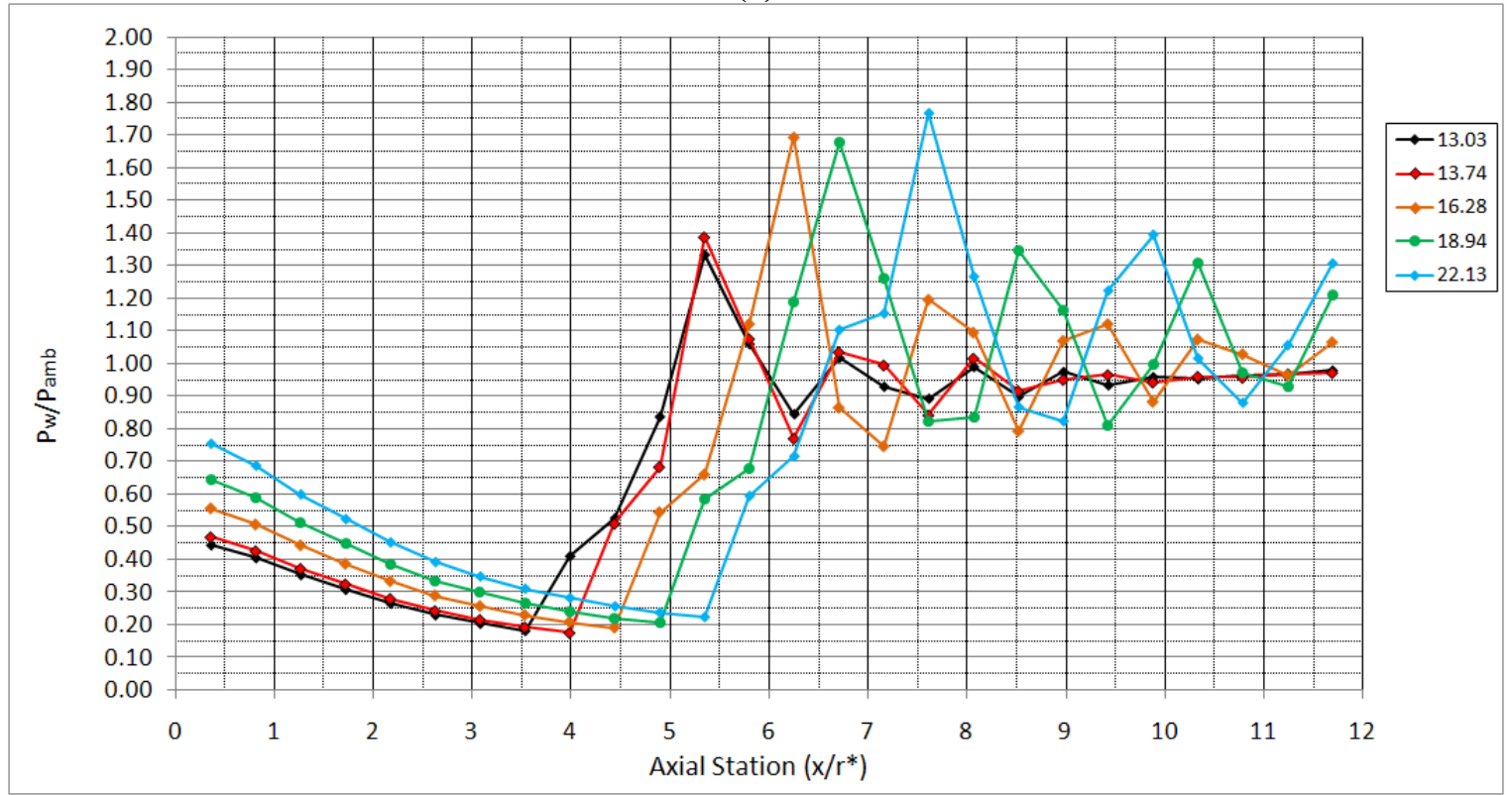

(b)

Figure 23. PAR test article $180^{\circ}$ azimuth normalized $P_{w}$ within the RSS-to-FSS hysteresis regime. 
Figure 24 plots the $\mathrm{P}_{\text {sep }}$ for the PAR test article. The solid symbols are $\mathrm{P}_{\text {sep }}$ for increasing NPR and the open symbols are the $\mathrm{P}_{\text {sep }}$ from the hysteresis regime during decreasing NPR. The two azimuths have similar values with the only significant difference being between $\mathrm{x} / \mathrm{r}^{*}=1.0$ and 4.5 . Some of those differences are attributed to instrumentation effects as the next test series had better agreement in this region.

The values plotted in figure 24 are the red, bold values in Tables A3b, A4b, A5b and A6b.

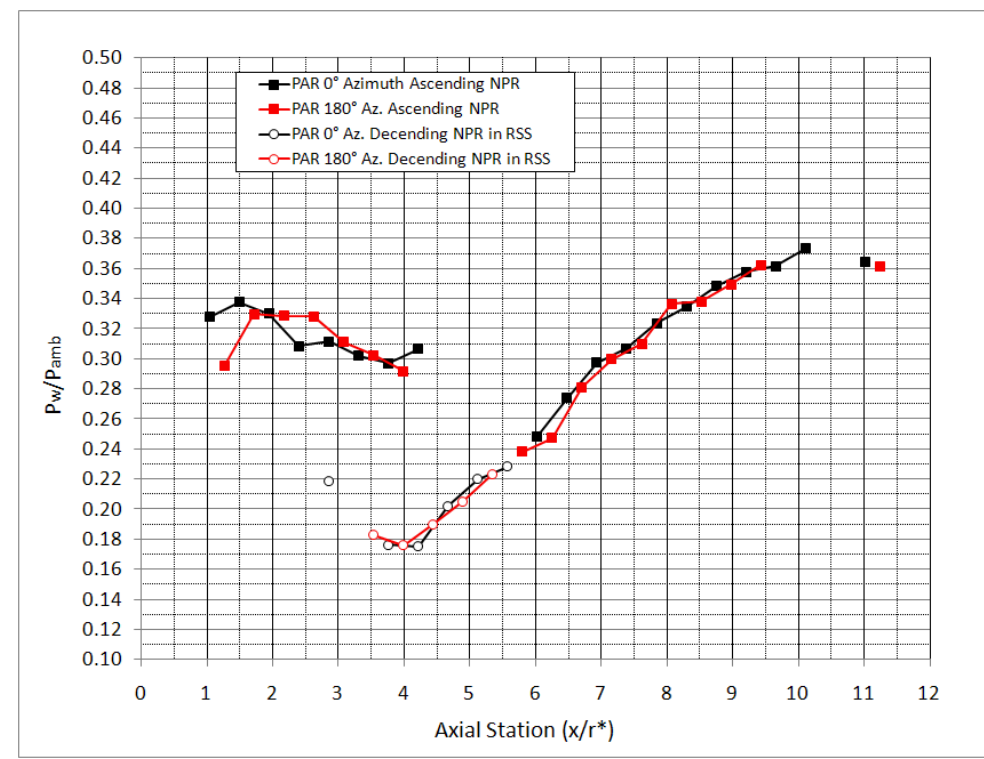

Figure 24. PAR test article $P_{\text {sep }}$.

Figure 25 compares the $\mathrm{P}_{\text {sep }}$ for the two test articles.

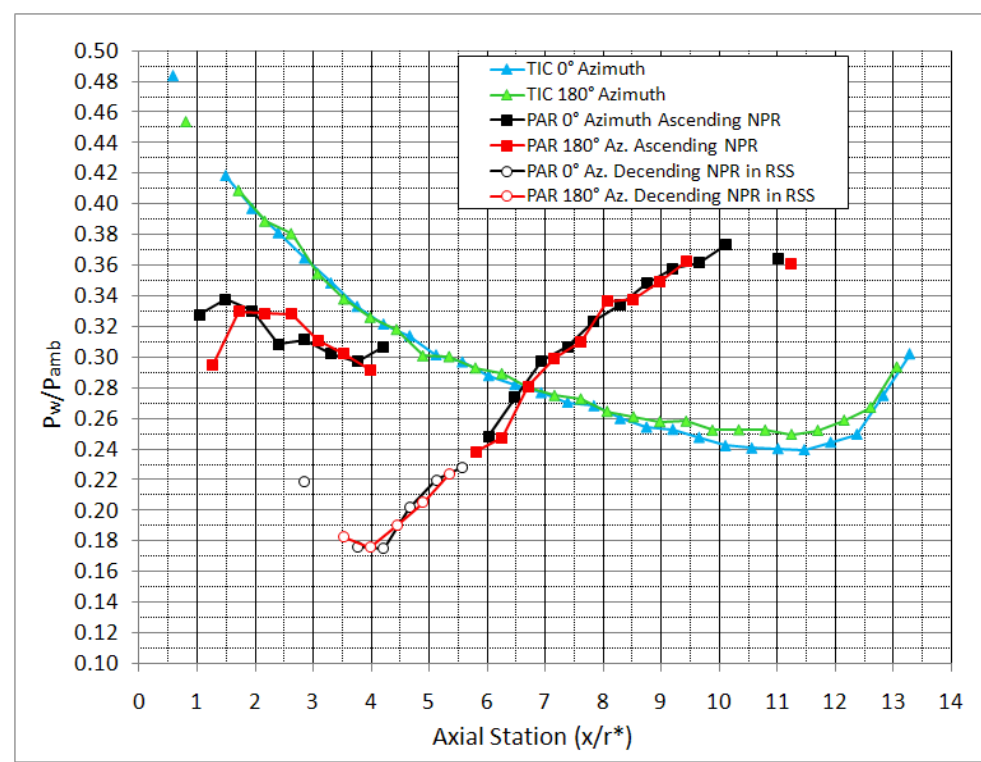

Figure 25. Comparison of TIC and PAR test article $\mathbf{P}_{\text {sep. }}$. 
Figure 26 presents the PAR test article's normalized average $\mathrm{P}_{\text {base }}$ variation with NPR. The $\mathrm{P}_{\text {base }}$ was responding to the nozzle wall static pressure just upstream of the nozzle exit plane. Between NPR 10 and 20 the Pbase $_{\text {becreased, }}$ dectir similarly to that of the TIC's $\mathrm{P}_{\text {base }}$, as flow was pulled over the nozzle base into the less-than- $\mathrm{P}_{\text {amb }}$ in the recirculation downstream of the (FSS) separation location. After transition to RSS the $P_{\text {base }}$ varied as the $P_{w}$ near the nozzle exit varied with the pressure recovered via the recompressions. The hysteresis incurred in decreasing NPR is evident in $\mathrm{P}_{\text {base }}$ as well.

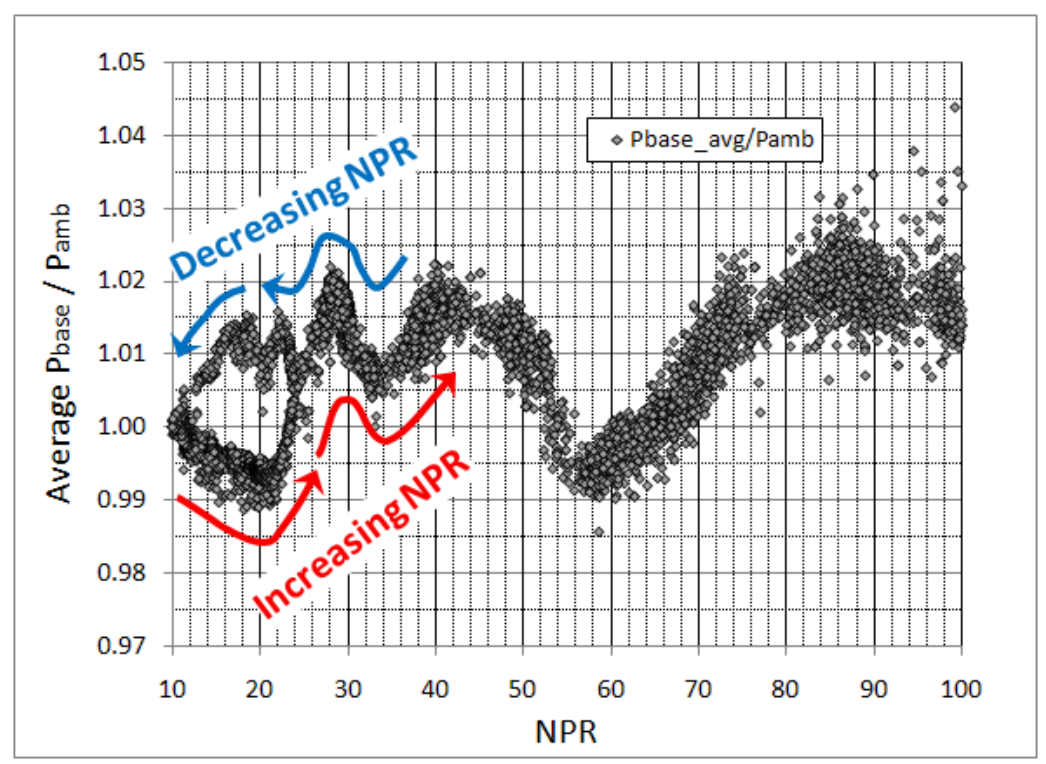

Figure 26. PAR test article $P_{\text {base }}$ without diffuser inlet effect. Diffuser inlet at $51 \mathrm{~mm}$ in downstream. 


\section{PAR Nozzle Wall Pressures when in "Diffuser Inlet Effect"}

Figure 27 compares the PAR nozzle normalized $\mathrm{P}_{\mathrm{w}}$ for a full flowing nozzle to the as-designed curve. Note that these full flowing $P_{w}$ values were unaffected by the diffuser inlet effect. The comparison between the measured and as-designed values for the initial expansion of the flow, between $\mathrm{x} / \mathrm{r}^{*}=0$ and about 3 , is similar to that in figure 19a. However, downstream of $\mathrm{x} / \mathrm{r}^{*}=3.0$ the data agrees well with the as-designed curve. This second set of $\mathrm{P}_{\mathrm{w}}$ data is shifted slightly downward relative to the first set of PAR test data, (figure 19a) resulting in an improved $\mathrm{P}_{\mathrm{w}}$ agreement with the as-designed values (comparing figures $27 \mathrm{~b}$ and $19 \mathrm{~b}$ ).

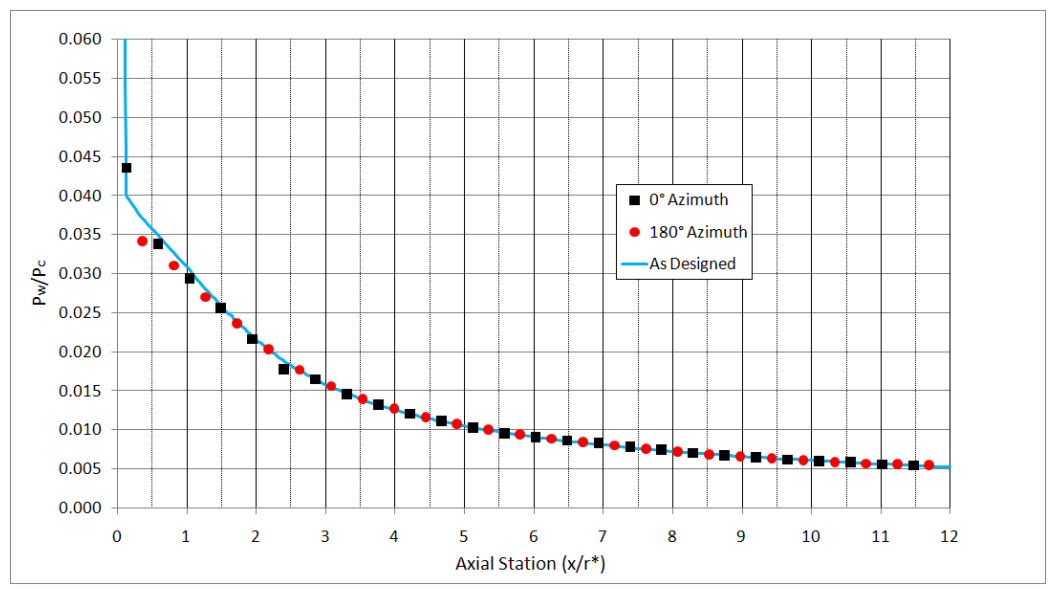

(a)

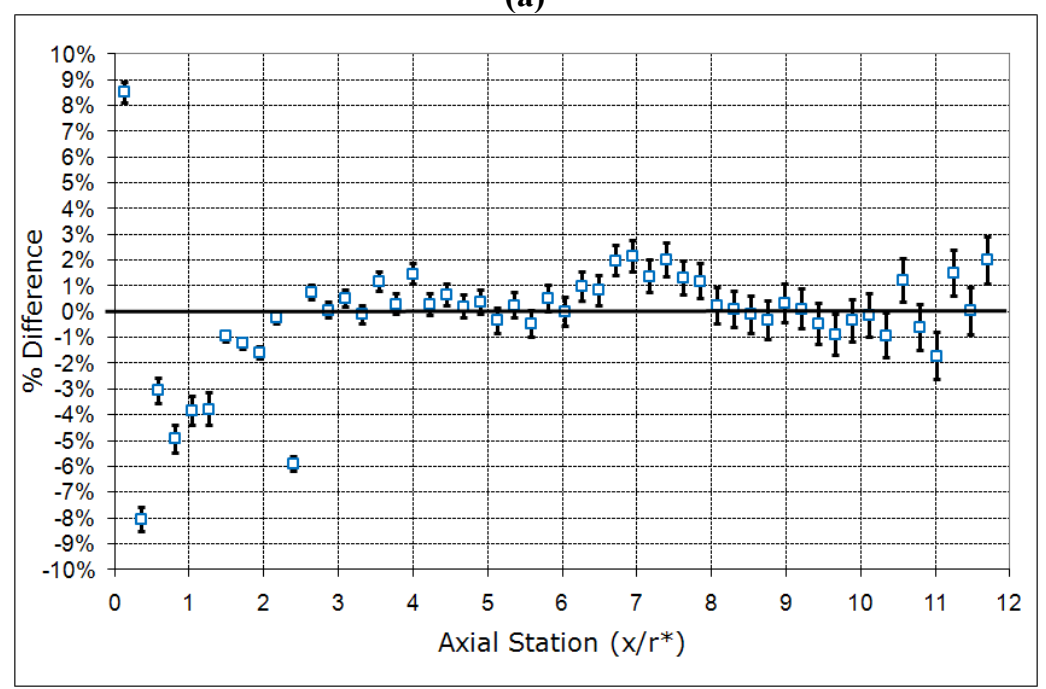

(b)

Figure 27. PAR test article normalized $P_{w}$ compared to the as-designed for the Fall ' 07 test series.

Figures 28 to 32 present the PAR test article normalized $\mathrm{P}_{\mathrm{w}}$ recorded in Fall ' 07 test series where the diffuser inlet was approximately $51 \mathrm{~mm}(2 \mathrm{in})$ downstream of the nozzle exit plane. This test data shows that the proximity of the diffuser inlet to the nozzle exit plane changed the NPR at which the nozzle flow would separate at a given location. This PAR $\mathrm{P}_{\mathrm{w}}$ data with "diffuser inlet effect" is presented because the test series in which nozzle side load moments were measured, in all likelihood, experienced a similar affect on the separation locations due to the diffuser inlet. The side load moments were measured in tests with the diffuser at $32 \mathrm{~mm}$ (1.25 in) downstream. 
Figures 28 and 29 present the normalized wall pressures for the $0^{\circ}$ and $180^{\circ}$ azimuths, respectively. The NPRs plotted were, again, chosen based on the $\mathrm{P}_{\text {sep }}$ for each pressure measurement location. The FSS $\mathrm{P}_{\mathrm{w}}$ profiles for FSS up to transition to RSS were unaffected by the diffuser inlet. The transition to RSS was NPR 23.8, essentially unaltered from that of the tests with the diffuser further downstream.

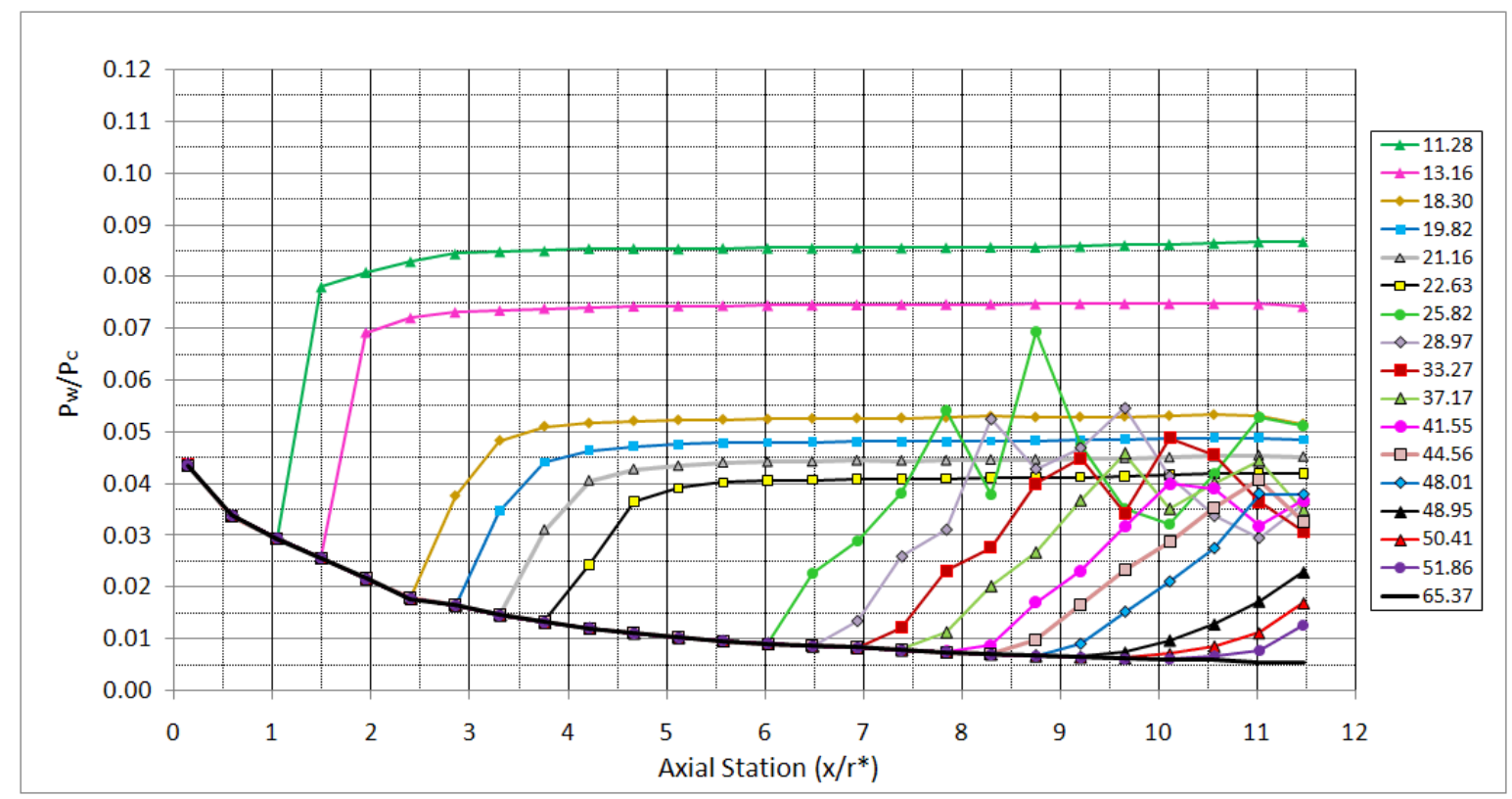

(a)

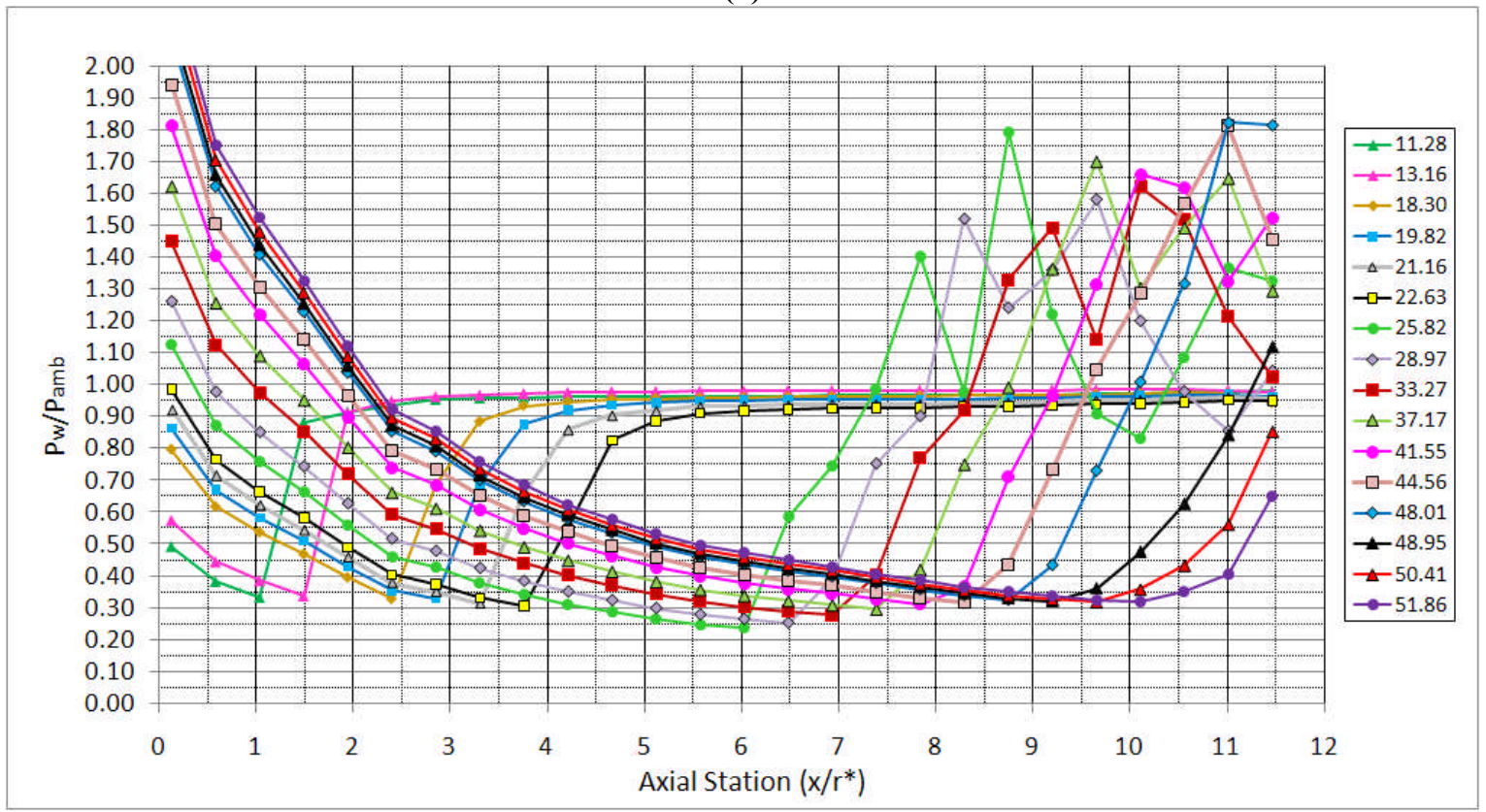

(b)

Figure 28. PAR test article $0^{\circ}$ azimuth normalized $P_{w}$, for increasing NPR, when in diffuser inlet effect.

With the diffuser closer to the nozzle exit the flow remained in RSS with complete axisymmetric reattachment up to NPR 48 (w/the diffuser further downstream, it was NPR 52). Above NPR 48 the RSS reattachment was not fully attached around the nozzles circumference but had become intermittently and/or partially attached. The pressure profile for NPR 48.95 (figure 28(b)) indicates a large change in the (average) $P_{w}$ from those of NPR 48. The flow was visibly oscillatory at a high frequency at these NPRs. As the NPR increased the flow reattachment occurred less and this is reflected in the decreasing $P_{w}$ at NPR 50.41 and 51.86. Between NPR 52 and 53 the nozzle 
flowed full and the flow became steady. It is this transition from full flowing RSS at NPR 48 to partial and intermittent RSS up through about NPR 53 that was the source of the highest side loads measured for the PAR nozzle.

The flow did not appear to transition from RSS to FSS before flowing full. Instead, as just described, it transitioned from RSS to a partial-RSS then snapped to a full flowing condition.

The values plotted in figures 28 and 29 are provided in tabular form in Appendix A (tables A7a through A8b).

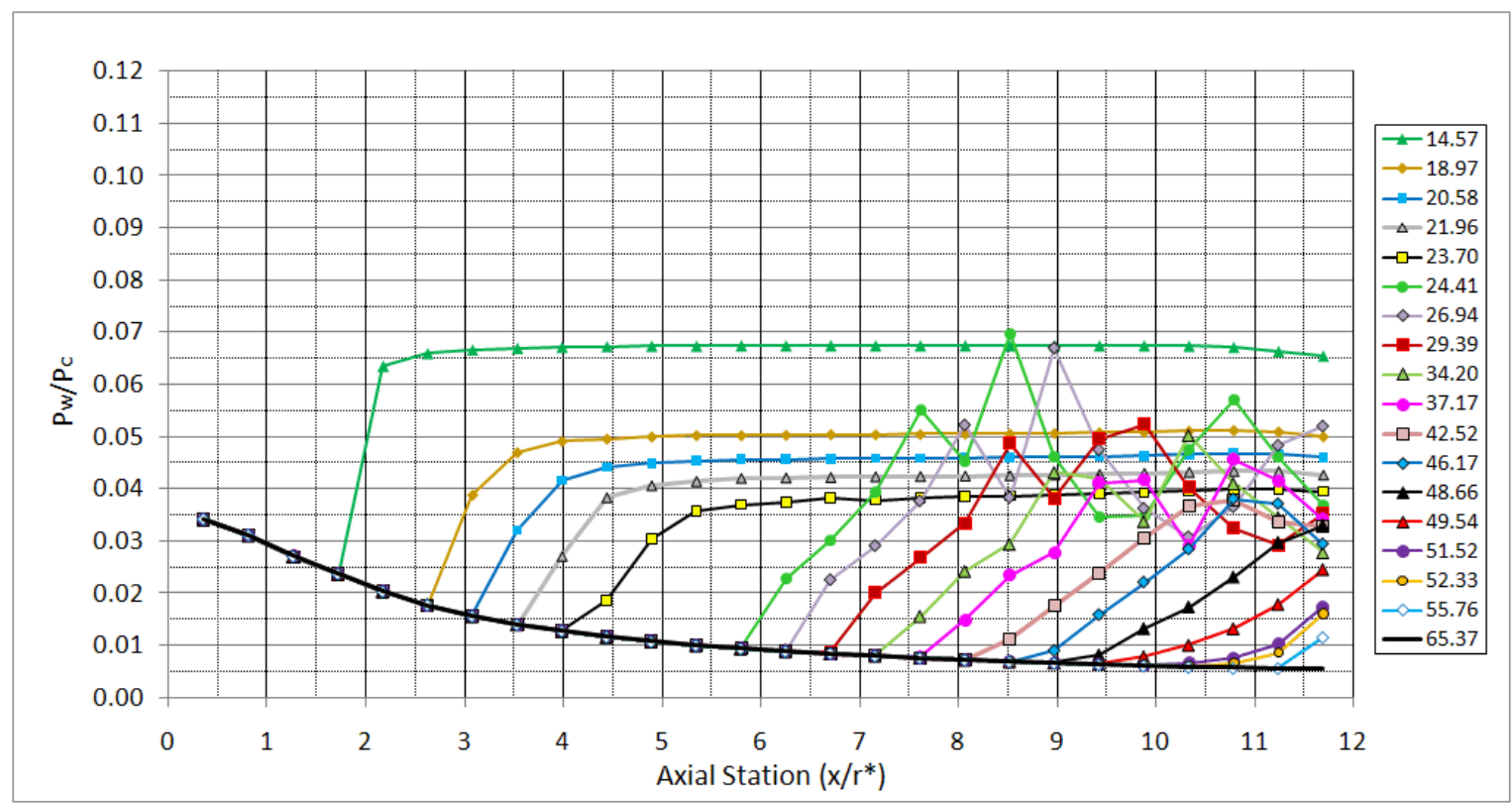

(a)

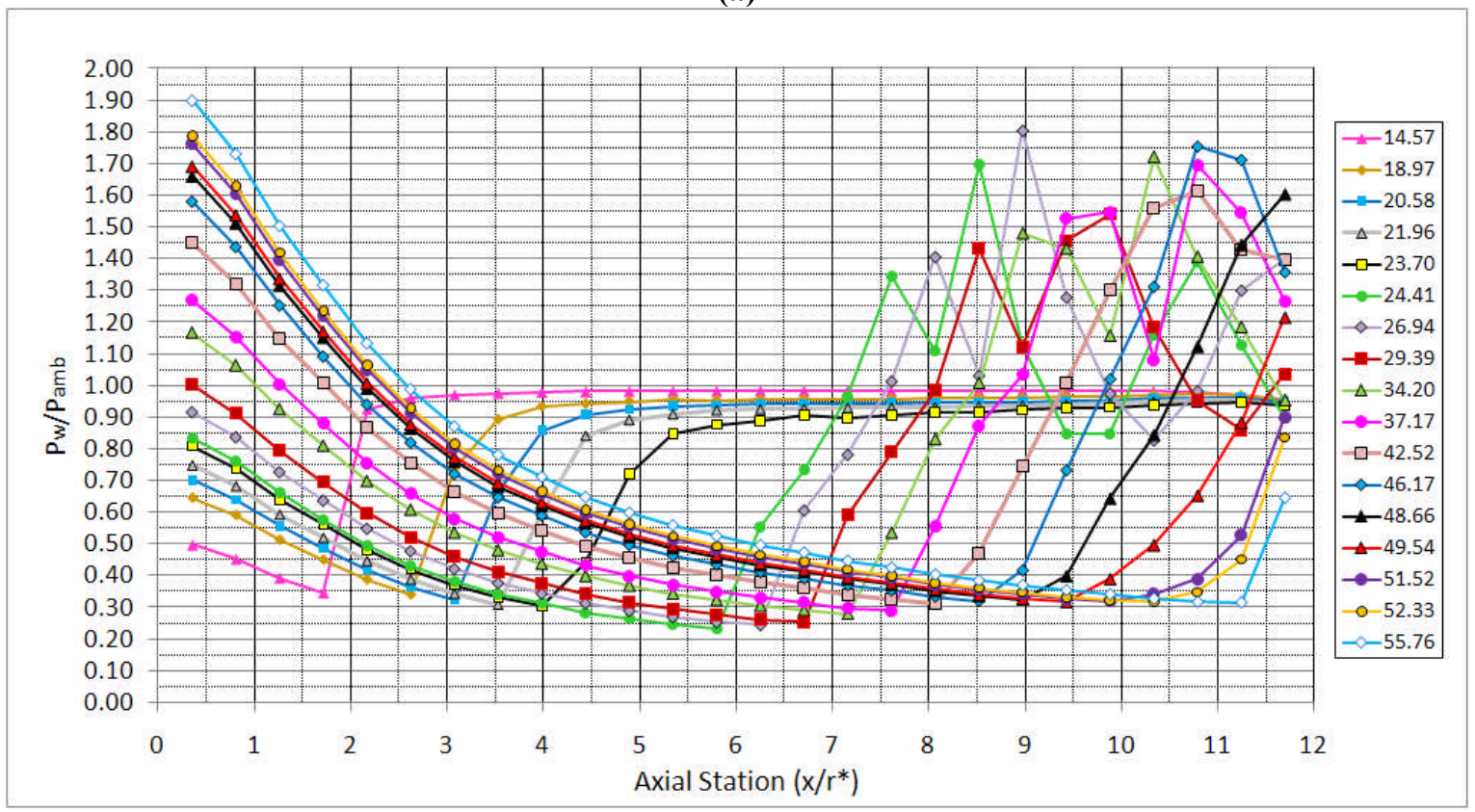

(b)

Figure 29. PAR test article $180^{\circ}$ azimuth normalized $P_{w}$, for increasing NPR, when in diffuser inlet effect. 
The hysteresis of the transition between RSS and FSS at low NPR when NPR was decreasing appeared to be unaffected by the diffuser inlet being closer to the nozzle exit. Figures 30 and 31 present the $\mathrm{P}_{\mathrm{w}}$ profiles on the two azimuths for NPRs within the hysteresis regime for the tests with the diffuser inlet near the nozzle exit. They do not appear different than with the diffuser inlet further downstream (figures 22 and 23). The values plotted in figures 30 and 31 are provided in tabular form in Appendix A (tables A9a through A10b).

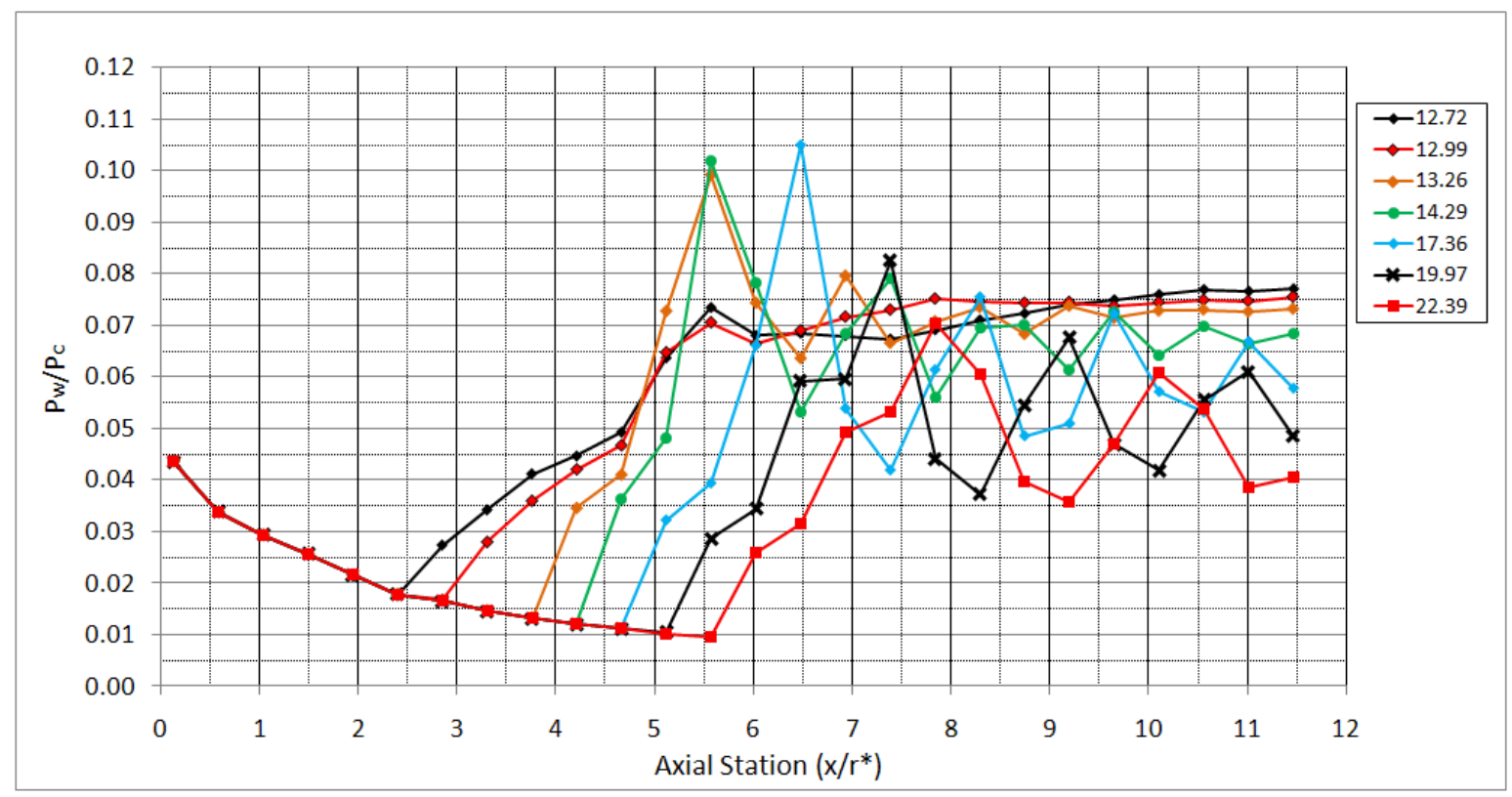

(a)

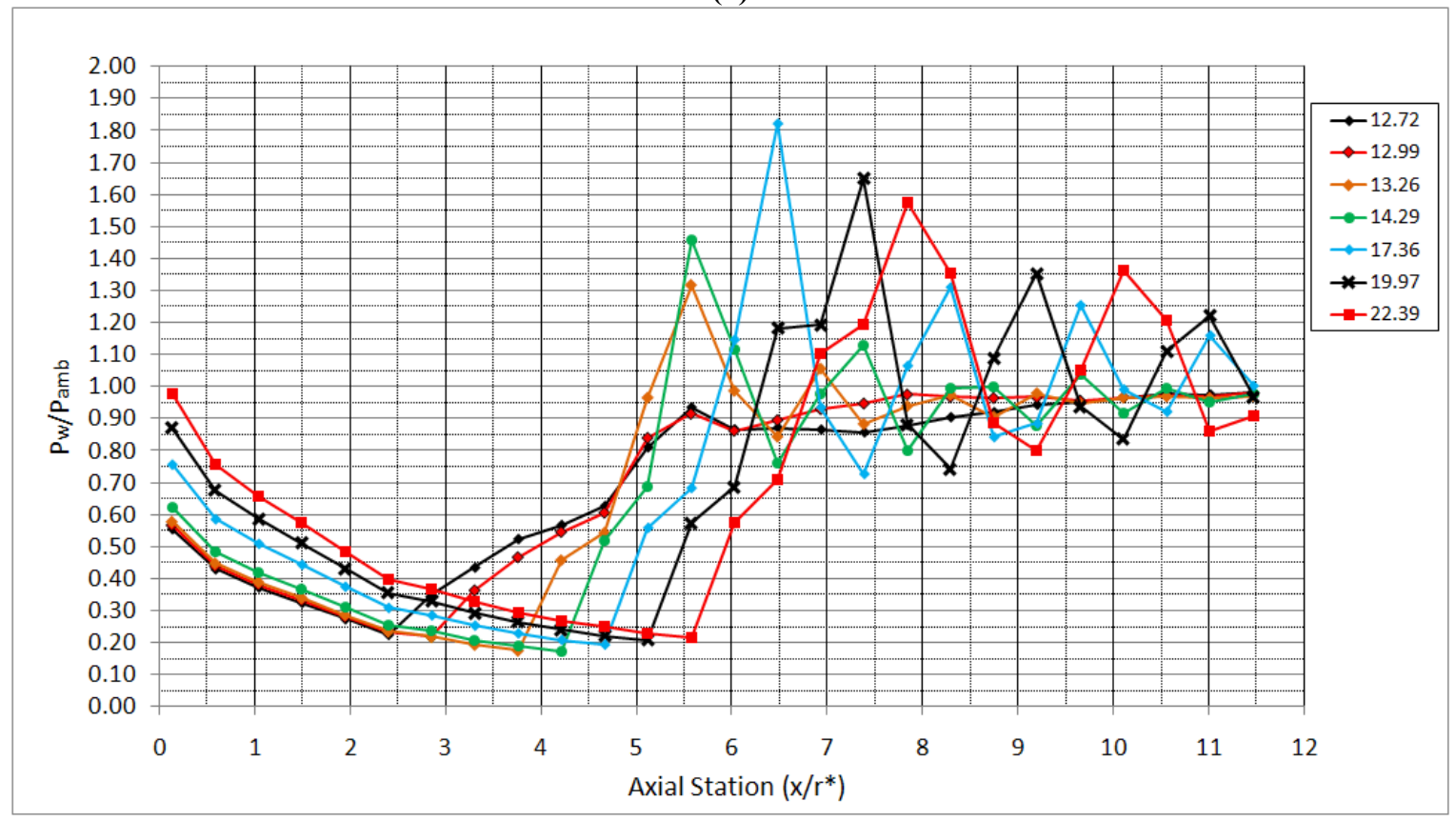

(b)

Figure 30. PAR test article $0^{\circ}$ azimuth normalized $P_{w}$ that existed during the RSS-to-FSS hysteresis during decreasing NPR with the diffuser inlet near the nozzle exit. 


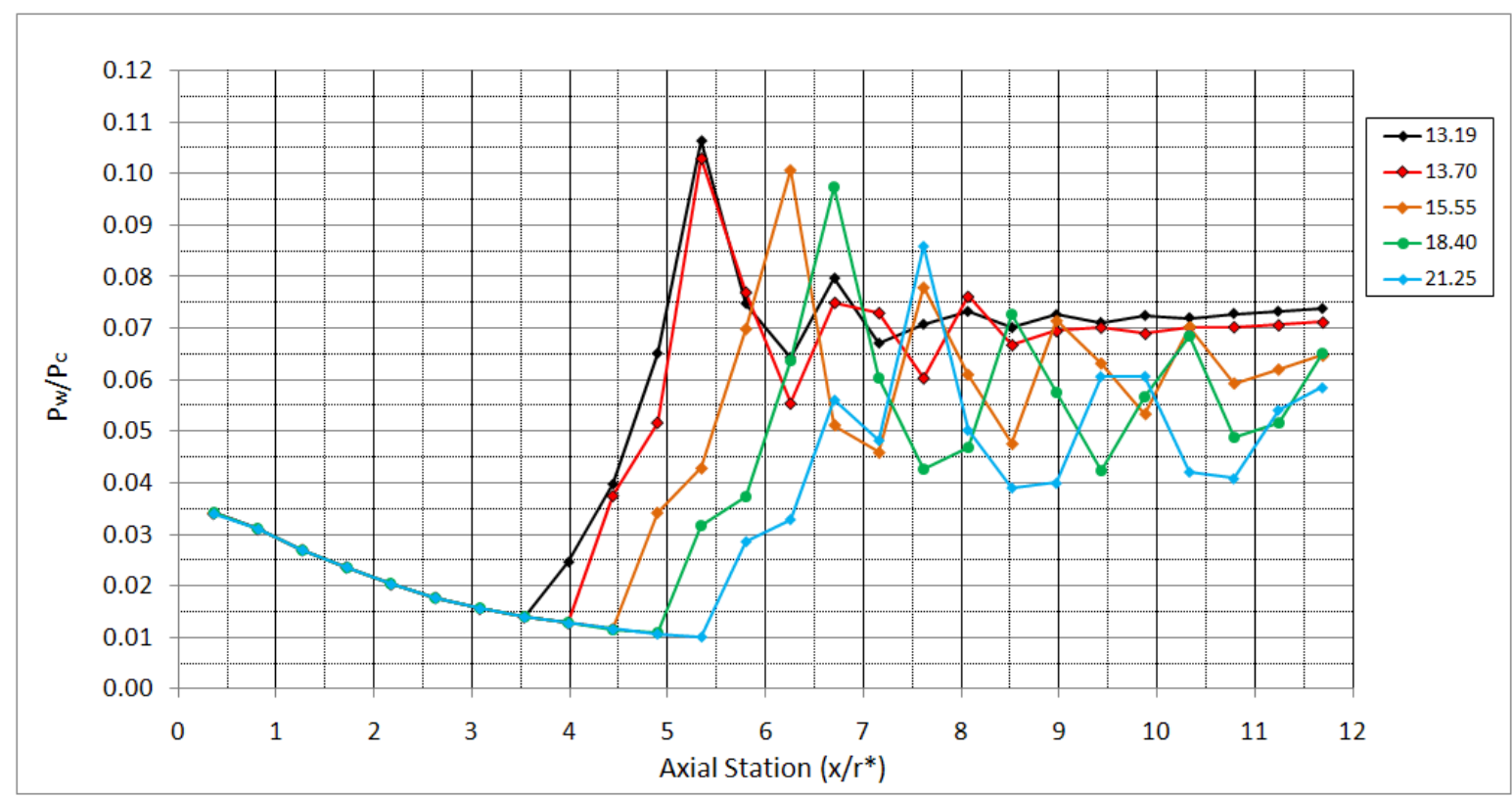

(a)

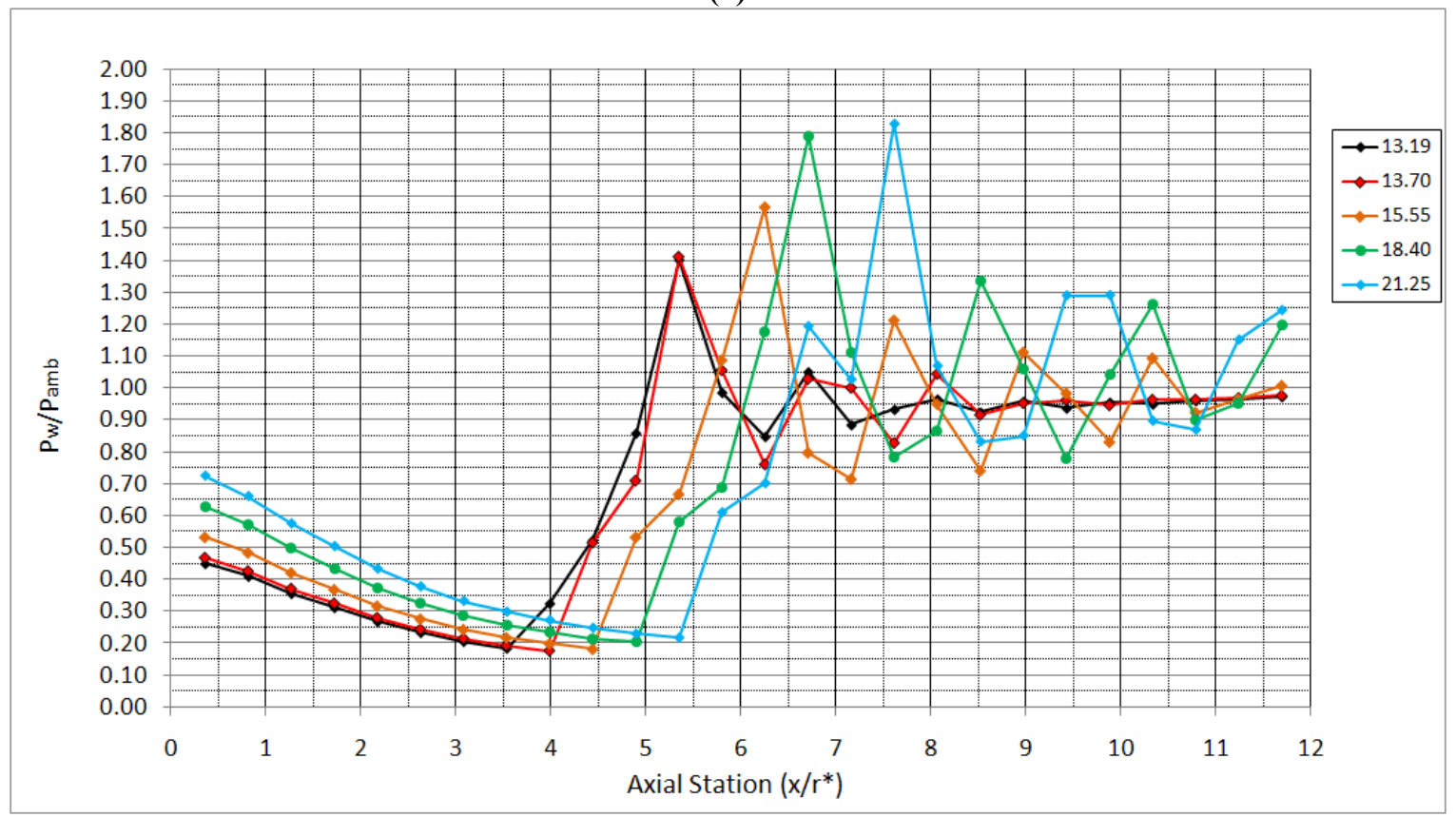

(b)

Figure 31. PAR test article $180^{\circ}$ azimuth normalized $P_{w}$ that existed during the RSS-to-FSS hysteresis during decreasing NPR with the diffuser inlet near the nozzle exit. 
Figure 32 plots the $\mathrm{P}_{\text {sep }}$ of the PAR nozzle for both test series. The solid symbols are for increasing NPR and the open symbols are from the hysteresis regime during decreasing NPR. The agreement between the azimuths for $\mathrm{x} / \mathrm{r}^{*}=1.0$ to 4.0 in the second set of data is improved relative to that in the first set of test data. This indicates that that some of the disagreement for these measurements in the first data set was due to measurement error. Over the remainder of the nozzle the agreement in the azimuths was similar.

The two sets of data appear the same in the hysteresis regime ( $\mathrm{x} / \mathrm{r}^{*}=3.5$ to 5.6$)$. From $\mathrm{x} / \mathrm{r}^{*}=6.0$ to about 8.0 the slopes of the curves for the without and with diffuser inlet effect are similar but the diffuser inlet affected $\mathrm{P}_{\text {sep }}$ was consistently lower. From $\mathrm{x} / \mathrm{r}^{*}=8.0$ to the end of the nozzle the differences in the two datasets increase with axial station indicating an increasing effect of the diffuser inlet. The values plotted in figure 34 are the red, bold values in Tables A7b, A8b, A9b and A10b.

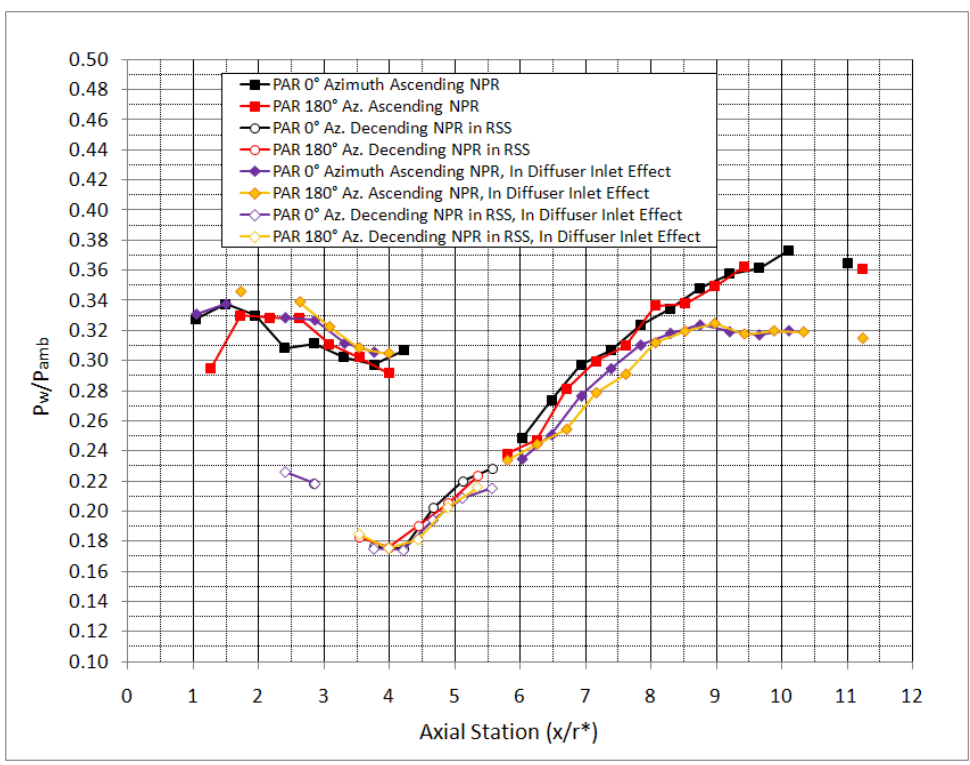

Figure 32. PAR $P_{\text {sep }}$ as a function of axial station for without and with diffuser inlet effect. 
Figure 33 plots a subset of the normalized $P_{w}$ from the datasets shown in figures 20 and 32 . The $P_{w}$ profiles shown were chosen based on the location of the nozzle flow separation. The open symbols are from the first test series when the nozzle flow was not affected by the diffuser inlet. The filled symbols are from the second test series when the diffuser inlet did have an effect on the nozzle flow. These profiles show that the $\mathrm{P}_{\mathrm{w}}$ profile shapes were, in fact, similar for the two tests when compared based on $\mathrm{P}_{\text {sep }}$ location. These plots show that the diffuser effect did not change the nozzle fluid dynamics but did alter the NPR at which specific flow structures occurred. Note that the NPRs differed between the pairs of Pw profiles as the separation location moved toward the nozzle exit. This is consistent with the trends in figure 32 .

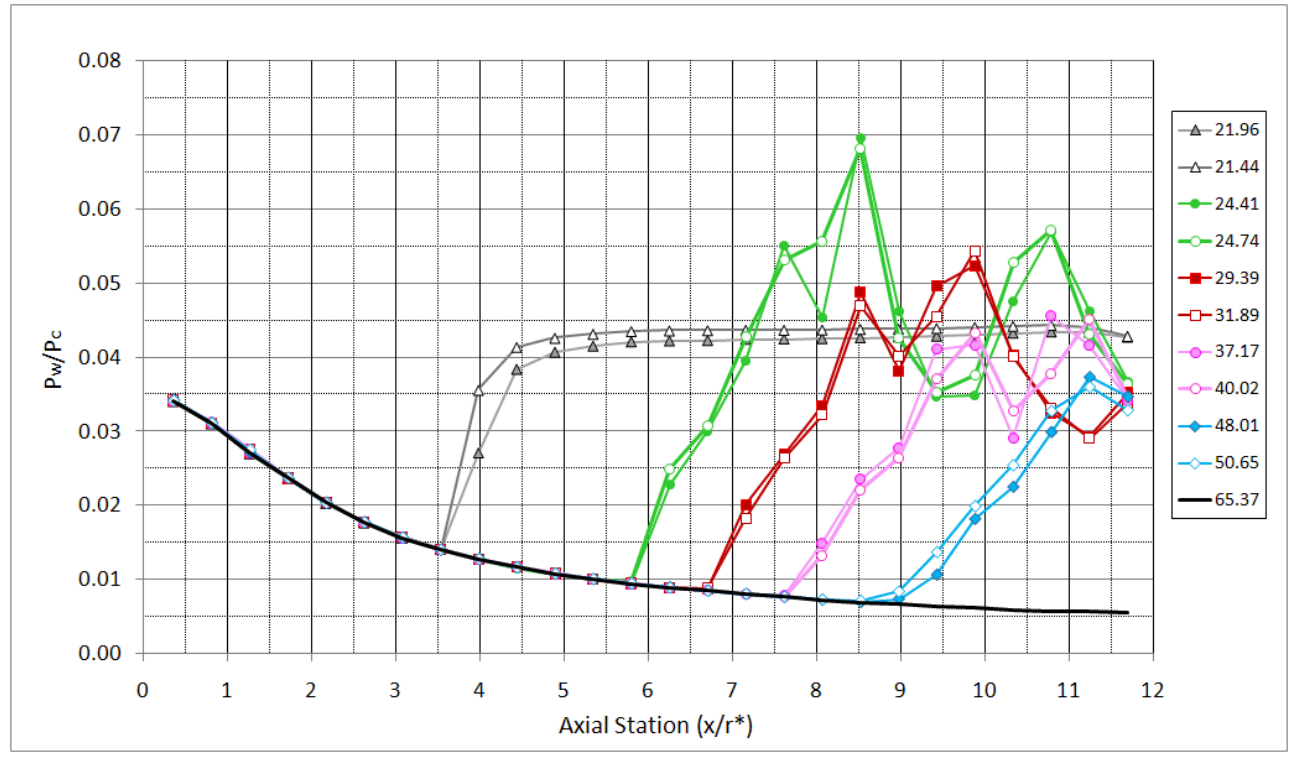

(a)

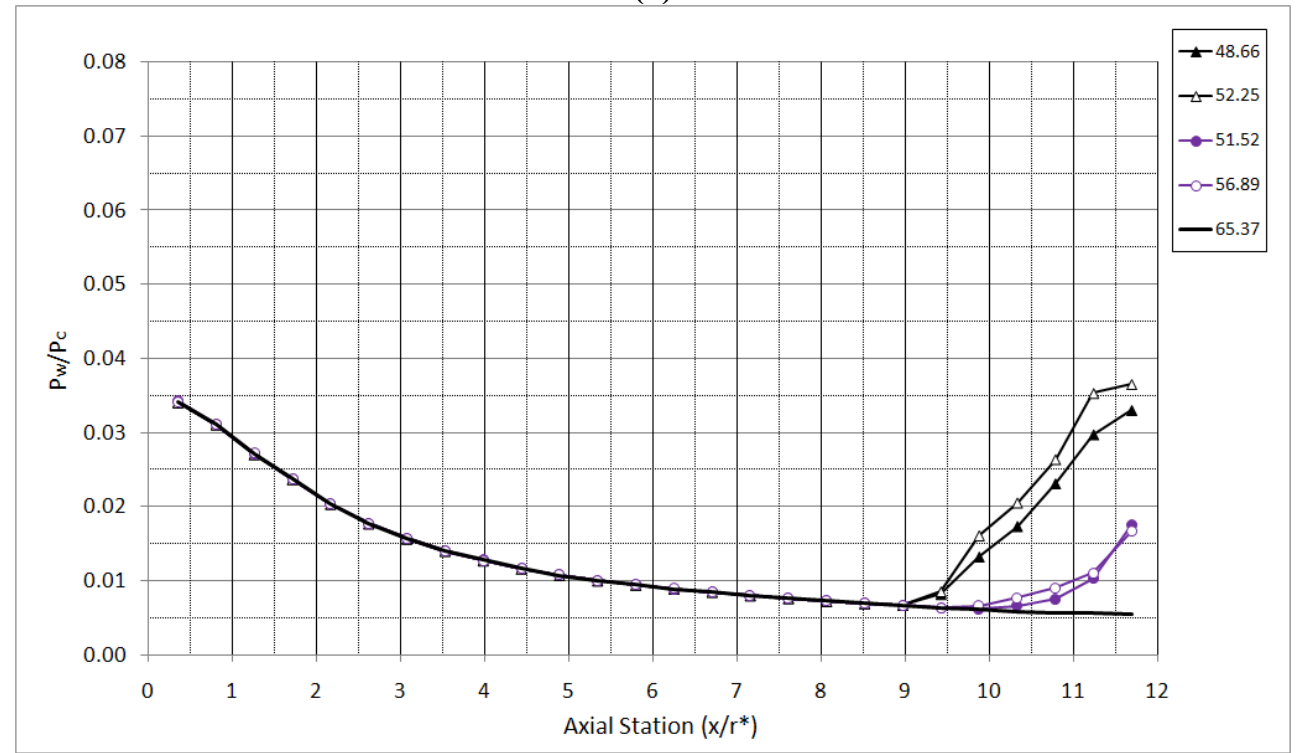

(b)

Figure 33. Comparison of $P_{w}$ profiles for the two PAR test series. Open symbols are first test series, when not in diffuser inlet effect. Filled symbols are the second test series, when in diffuser inlet effect. 
The NPR quoted throughout this paper is a global NPR. That is, the $\mathrm{P}_{\mathrm{amb}}$ is the test cell pressure which was measured well away from the nozzle exit plane. The supersonic annular nozzle flow exiting the nozzle and flowing into the diffuser induced a local pressure (near the nozzle exit) that was lower than the farfield $\mathrm{P}_{\mathrm{amb}}$ used in the NPR.

Figure 34(b) plots the average base pressure for the diffuser inlet affected set of test data which shows that the base pressure, once it transitioned to RSS, no longer varied significantly with NPR. That is the base pressure was no longer showed a strong dependence on $\mathrm{P}_{\mathrm{w}}$ at the nozzle exit, as in figure 34(a) but, was dominated by the diffuser inlet effect.

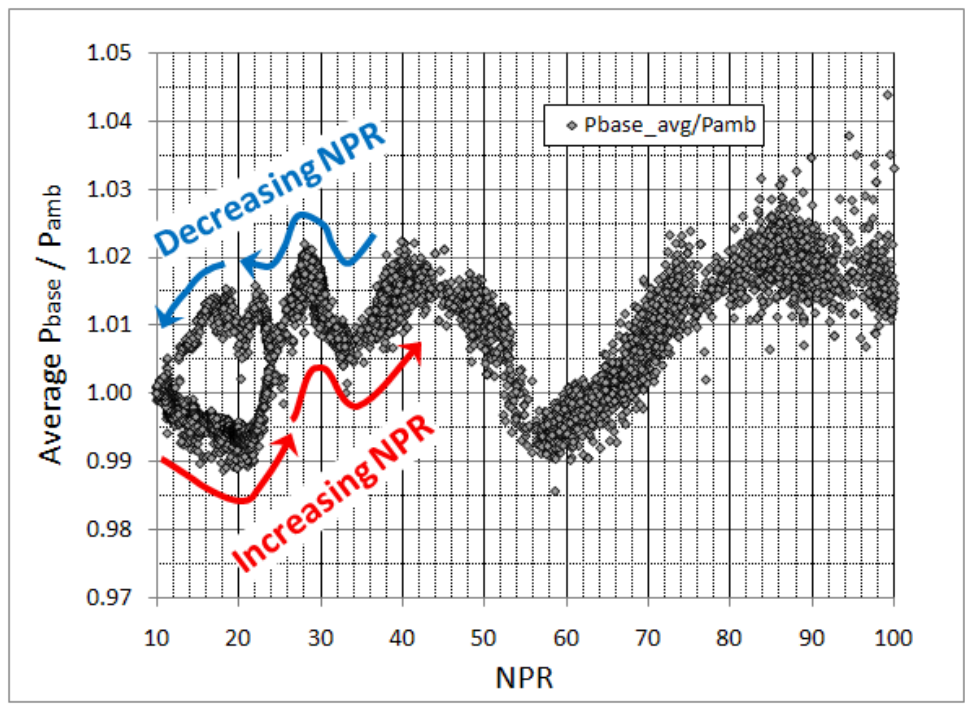

(a)

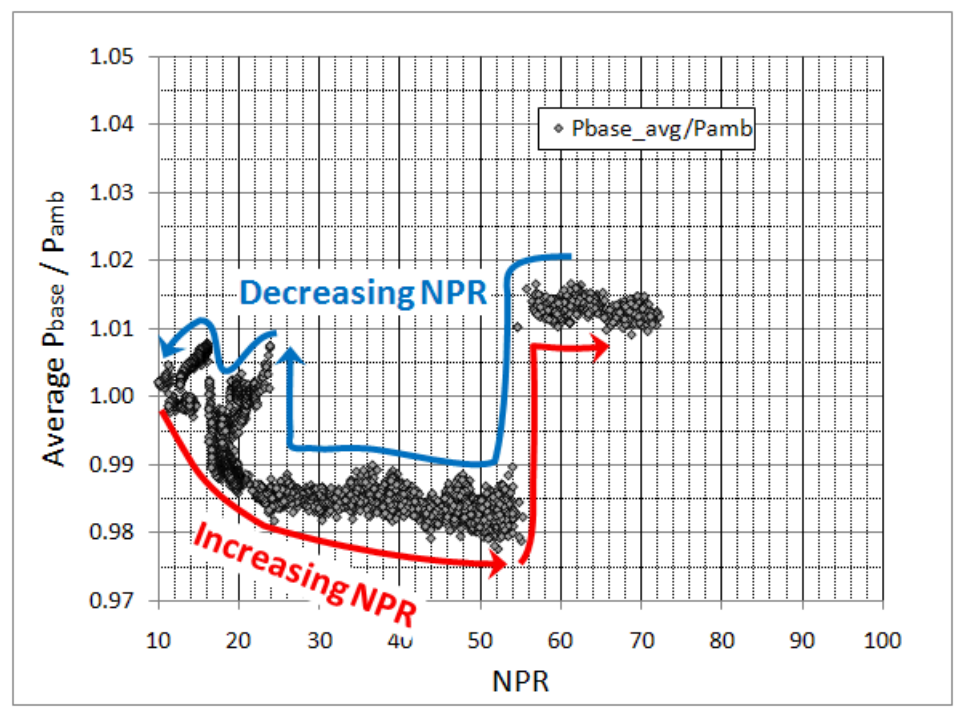

(b)

Figure 34. PAR average nozzle base pressure, normalized, from the two test series. Without diffuser inlet effect (a) and in diffuser inlet effect $(b)$. 


\section{B. Side Load Moments Unscaled}

The side load data presented here was recorded near the end of the test campaign after the best testing approach, for obtaining good side load data, had been determined. As discussed previously, the $20,480 \mathrm{~Hz}$ strain gage data was filtered and converted to a moment and collected in bins of NPR (Table 1) for each simulated nozzle start transient. The maximum side load moment in each NPR bin over the approximate 70 starts for the two nozzles is plotted in figure 35. This data was normalized by the peak magnitude of side load moment measured for the PAR nozzle.

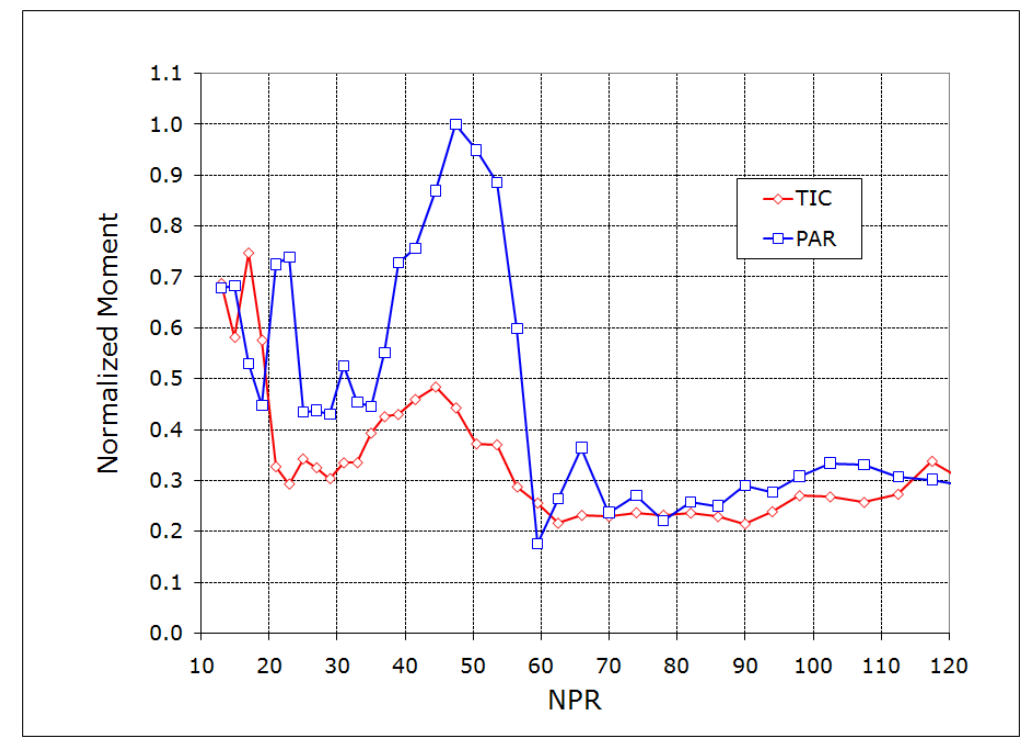

Figure 35. Relative side load of TIC and PAR nozzles.

Both nozzles had two peaks in side load moment: one at low NPR and one at a mid-range NPR. The maximum side load moment of the PAR nozzle, at NPR 47.5, was significantly higher than either of the peak moments from the TIC nozzle. The maximum moment of the PAR nozzle occurred as the last RSS separation bubble reached the end of the contour. Highly oscillatory flow existed as the nozzle flow transitioned back and forth rapidly between RSS and FSS. Conversely, the maximum side load moments of the TIC nozzle at NPRs in the mid-40s were due only to FSS separation line oscillation. This conclusion was drawn from observations of the Schlieren video and high frequency pressure measurements made in another test series on these same test articles. After the nozzles flowed full, above NPRs of about 60 , the side load moments of both decreased significantly. The moments present at the higher NPRs on figure 13 were similar to those obtained from a reference, sonic nozzle. The sonic nozzle produced no aerodynamic side loads; therefore, the moments measured during the sonic nozzle tests were a measure of the facility effects (i.e., random noise) in the test data.

The peaks in side load moment at low NPRs for the two nozzles were very similar in magnitude. However, the low NPR peaks were, in part, due to different fluid dynamics. The PAR nozzle had two peaks at low NPR. The first, at NPR 13, was probably due to transition from FSS to a flow state called "quasi-RSS" (qRSS). qRSS is a shortlived asymmetric flow reattachment that can occur as the plume expands just past the throat. The second low NPR peak for the PAR nozzle, at NPRs 21 and 23, was a result of the nozzle flow's transition from FSS-to-RSS transition. The peak in the TIC's side load moments at NPR 17 was most likely due to FSS-to-qRSS-FSS flow transitions. 


\section{Facility Vibration Effects On Measured Nozzle Side Loads}

When running, the NTF vibrates due to the ejector system. These facility vibrations caused the cantilevered test article to move with respect to the facility, producing a fluctuating strain in the strain tube. This vibration is a facility induced random noise embedded in the side load test data. There is no explicit method to distinguish the vibration induced strains from nozzle side load induced strains. To quantify this facility noise the Sonic nozzle was run in the same manner as the TIC and PAR. The Sonic nozzle has the same mass and center of gravity as the TIC and PAR test articles. The significant difference between the Sonic nozzle and the TIC and PAR is that it did not have nozzle flow separation within a diverging nozzle, as sketched in figure 36 . Therefore, any apparent side loads were due only to the facility vibrations.
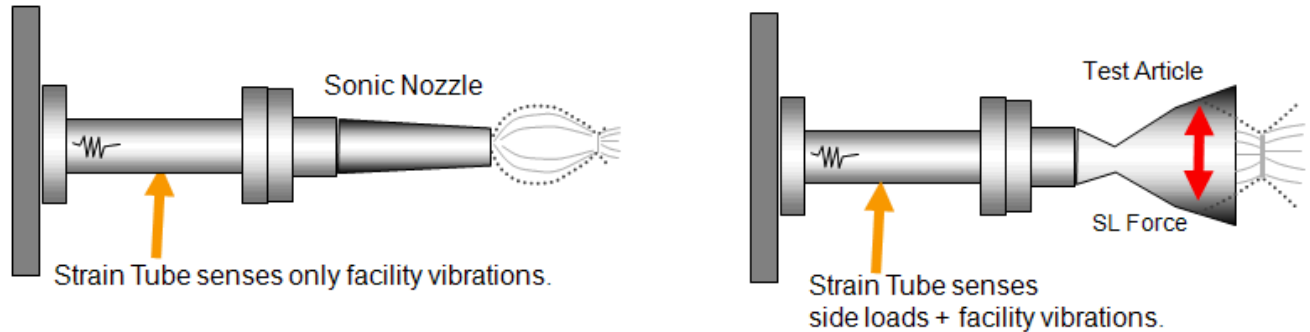

Figure 36. Comparison of the Sonic nozzle to a converging-diverging nozzle.

Figure 37 plots the $\sigma$ and the mean $+3 \sigma$ of the measured moment in each NPR bin for the nine NPR transients performed with the Sonic nozzle. This $\sigma$ is a statistical measure of the magnitude, but not the direction of the vibration induced moments. As indicated in figure 38, this vibration induced moment could occur in any direction. The mean $+3 \sigma$ is the level of vibration induced moment that one can, statistically, be fairly sure will not be exceeded during nozzle tests.
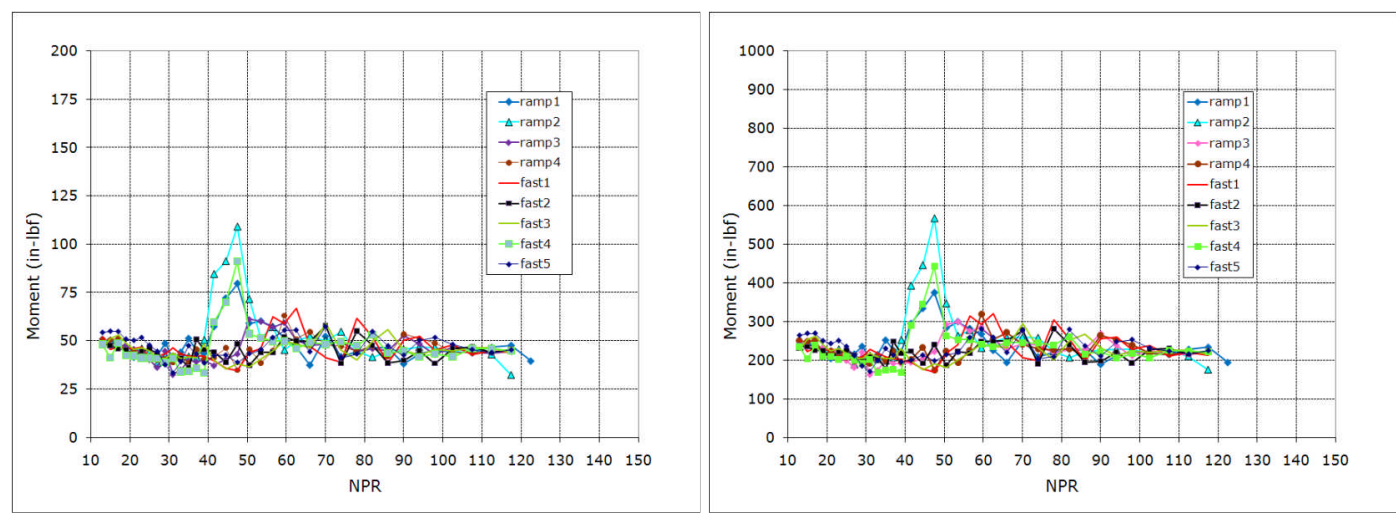

Figure 37. Sonic nozzle's $\sigma$ (left) and mean $+3 \sigma$ (right) of vibration induced moments.

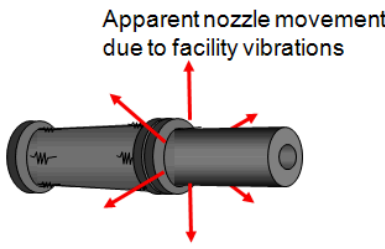

Noise, statistically, could be in any direction.

Figure 38. The vibration induce moment could be in any direction.

Now, if one considers a specific side load event, unaffected by facility vibrations, such as sketched on the left in figure 39, it is a unique data point with a specific direction and magnitude. However, in the MSFC NTF the strain measured at any time was the combination of the side load and facility noise strains. That is, as indicated in figure 
39 , the strain measured was the vector summation of the two such that the vibration strain could have increased or decreased the measured side load magnitude. This means that the facility induced vibrations can be quantified as an uncertainty on the magnitude of the measured maximum side loads.

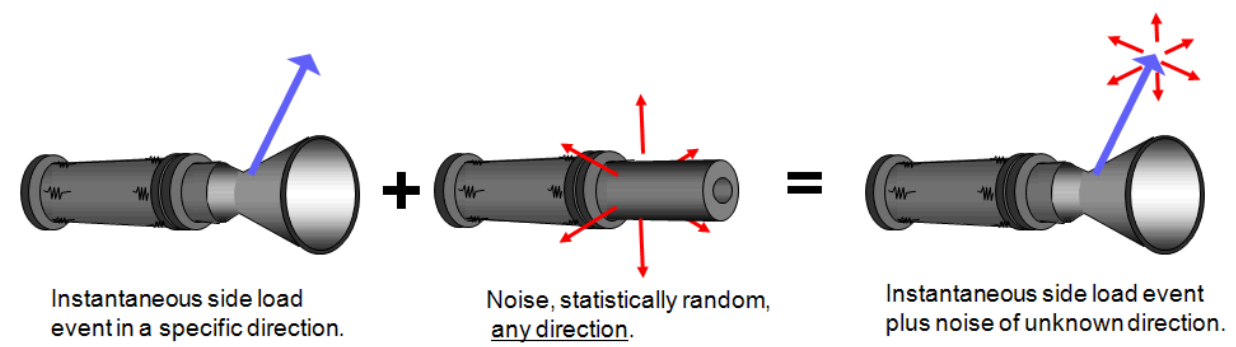

Figure 39. Sketch of vector addition of a unique side load event and random noise.

Figure 40 plots the TIC and PAR maximum side loads with bands of $2 \sigma$ of the facility vibrations on either side of the curves. The $\sigma$ magnitude applied is the average of the Sonic nozzle's $\sigma$ in each NPR bin for the nine transients run (figure 38). Above NPR 120 the magnitude of the $\sigma$ at NPR 120 was applied.

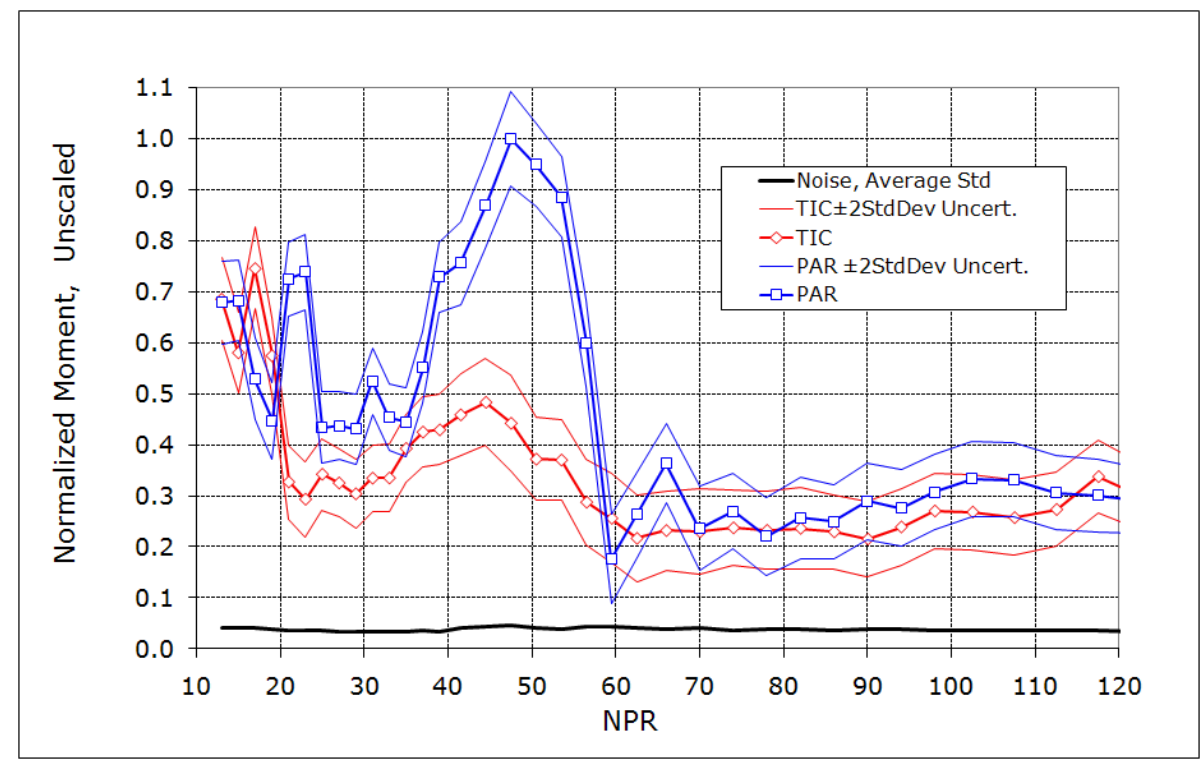

Figure 40. Maximum nozzle side load moment and uncertainty, unscaled.

\section{Scaling for Ambient Pressure}

In this test the $P_{c}$ was held constant and the test cell was evacuated to increase the NPR, thereby, inducing the nozzles to flow full. In doing so, test cell pressure, $\mathrm{P}_{\mathrm{amb}}$ for the nozzles, dropped from near atmospheric to below 0.5 psia. As a result the magnitude of the aerodynamic force produced by any asymmetric flow separation decreased with increasing NPR. Therefore, a relationship was required to scale the measured side load moments to the more normal operating procedure for nozzle transients, where $\mathrm{P}_{c}$ is increased against a constant $\mathrm{P}_{\mathrm{amb}}$. As it turns out that relationship is rather simple as shown in equation 1.

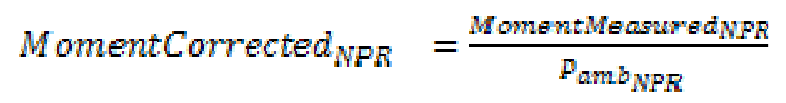

where the NPR subscript indicates those values at a given NPR and $\mathrm{P}_{\mathrm{amb}}$ is expressed as a fraction of an atmosphere. Ref. 2 contains the full derivation of equation 1. With equation 1, the moments measured in the MSFC NTF were scaled back to $\mathrm{P}_{\mathrm{amb}}$ of $1 \mathrm{~atm}$. Since side load moments were grouped by NPR bins, the moments in each NPR bin were scaled by the $\mathrm{P}_{\mathrm{amb}}$ that corresponds to the bin center NPR (table 1). 


\section{E. Side Load Moments After Scaling}

Figure 41 presents the normalized side load moments after they were scaled for the effect of $\mathrm{P}_{\text {amb }}$ per relationship derived in Ref. 1. The PAR's peak maximum side load moment, after scaling, was at NPR 50.5 and the TIC's was at NPR 44.5. The $\pm 2 \sigma$ uncertainty for the PAR's side load at NPR 50.5 was $8.6 \%$ and for the TIC's side load at NPR 44.5 it was $17.7 \%$. The magnitude of the TIC's peak maximum side load moment was $45 \%$ of the PAR nozzle's peak maximum moment. The low NPR side load moments, when scaled, were significantly lower than their respective maximum side loads at the mid-range NPRs. Note that the side load moments induced by the PAR nozzle's FSS-toRSS transition and the TIC nozzle's FSS-to-qRSS-to-FSS are still apparent.

The scaling factor was not applied to the measured side load moments for the PAR and TIC nozzles above NPRs 66 and 86, respectively. In another test series, high frequency pressure measurements were obtained near the nozzle exit planes. NPRs 66 and 86 were the highest NPRs in which the high frequency wall pressure indicated any rise in the wall pressure (due to flow separation). Above these NPRs the nozzles were flowing completely full and any measured moment was not due to separated flow, and therefore, scaling should not be applied.

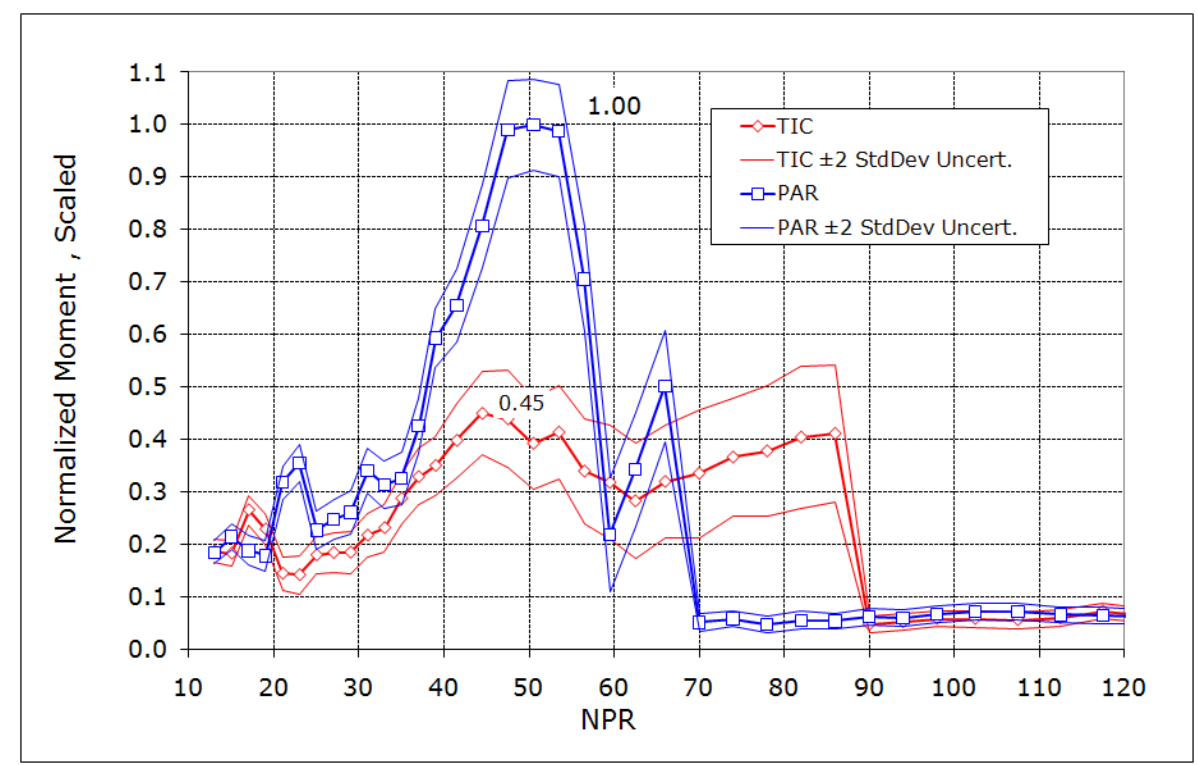

Figure 41. Maximum nozzle side load moment and uncertainty after scaling.

\section{F. Population of Maximum Side Load Moment Data Points}

Figures 42 and 43 present the population of the maximum side load data points, after scaling, for the TIC and PAR, respectively. Each data point is the maximum side load within an NPR bin during a specific nozzle start transient. The maximum values in each bin are on the red and blue lines for the TIC and PAR, respectively. These maximum data points are the same as those shown in figures 35 and 41 . Figures 42 and 43 contain a solid black line which is the maximum of the Sonic nozzle's mean $+3 \sigma$ values for each bin. This curve was included to provide a reference for the extent of the facility vibrations effect on the TIC and PAR side load data. The Sonic nozzle mean + $3 \sigma$ line represents the near maximal levels one would expect, from a statistical standpoint, for facility vibration induced moments. Figures 42 and 43 show that the facility vibrations fall in the lower range of the side load data and, therefore, did not significantly affect the TIC and PAR peak side load magnitudes.

Note in figure 43 that the number of valid measurements at NPR bins 53.5 and 56.5 were three and two, respectively. This sparseness results from filtering the test data to remove those bins of data potentially corrupted by adverse dNPR/dt (increasing NPR). (During periods of increasing NPR there would have been diffuser backwash.) Most of the data in these bins had to be discarded because the direction of the NPR ramp changed from increasing to decreasing, if only for a moment. This filtering is discussed further in Ref. 16.

Note that in the NPR bins at which the peak maximum side load occurred for the nozzles (44.5 and 50.5) there were a reasonable number of valid data points. None-the-less, the sparseness of valid measurements for PAR maximum side load in NPR bins 53.5 and 56.5, potentially high side load NPRs, was a concern because the absolute peak PAR nozzle side loads may have been filtered out. 


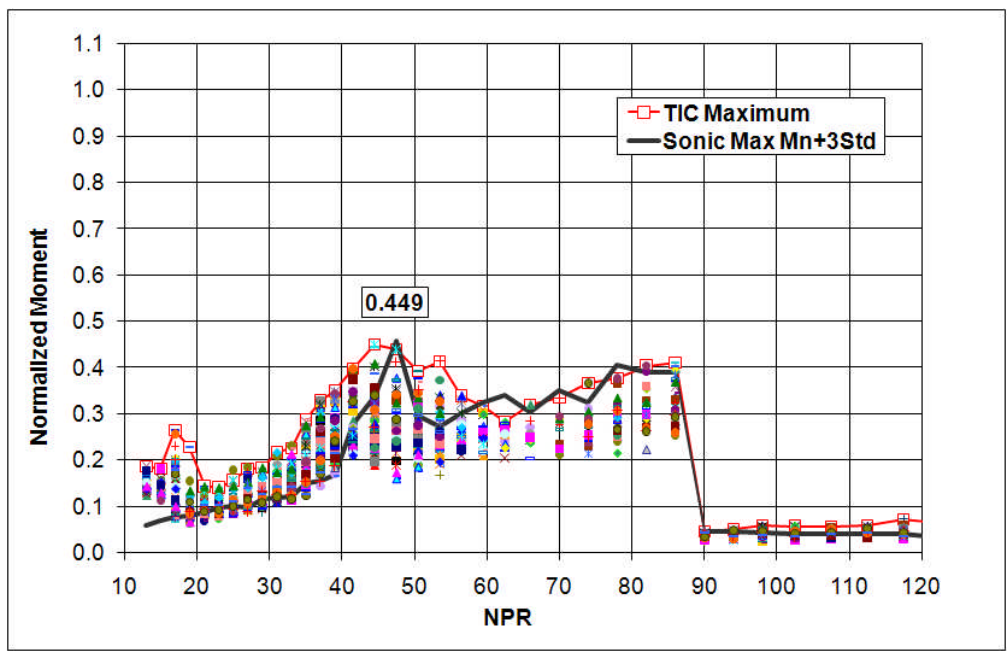

Figure 42. TIC nozzle's population of maximum nozzle side load data after removal of those potentially affected by diffuser backwash.

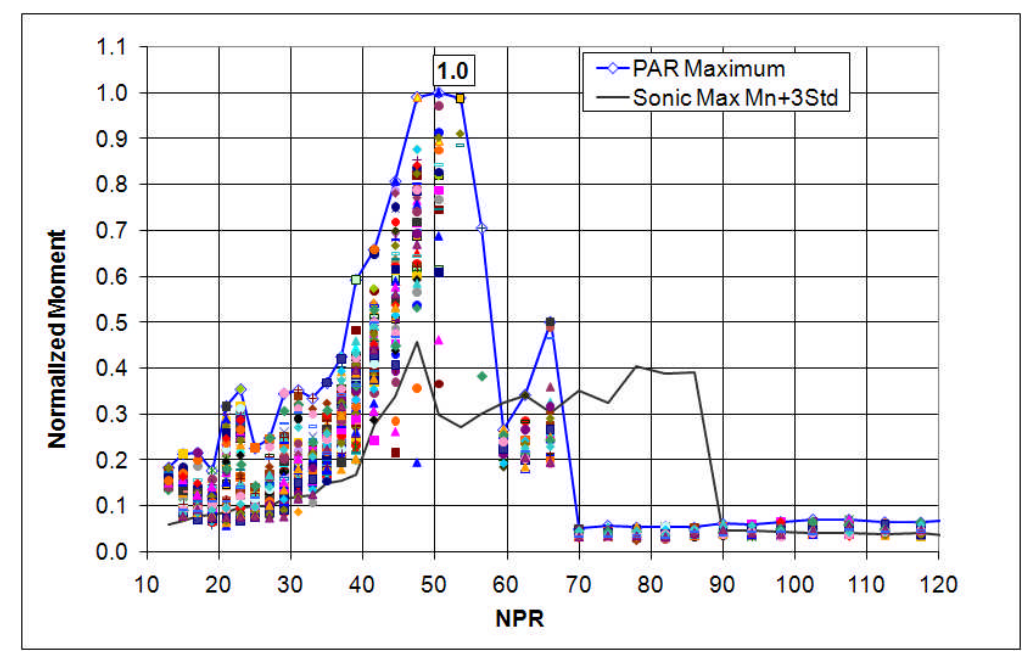

Figure 43. PAR nozzle's population of maximum nozzle side load data after removal of those potentially affected by diffuser backwash.

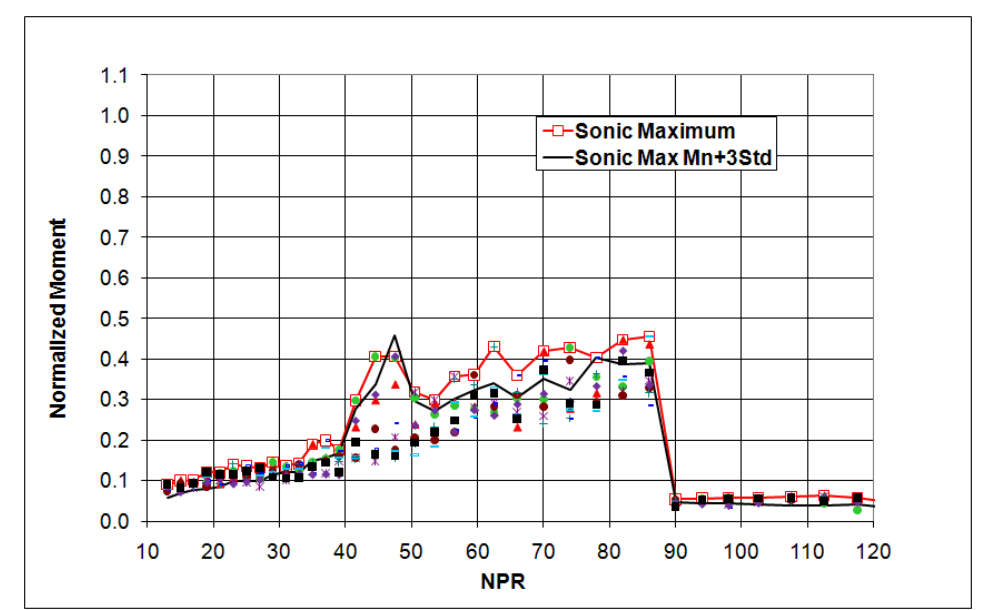

Figure 44. Sonic nozzle's population of maximum nozzle side load data after removal of those potentially affected by diffuser backwash.

38

American Institute of Aeronautics and Astronautics 


\section{G. Mean $+3 \sigma$ for Maximum Side Load Moments}

Figures 44 and 45 present the side load mean $+3 \sigma$ for all NPR bins for the TIC and PAR nozzles. No filtering for the diffuser backwash was applied here; that is, all data points in all of the NPR bins are shown. The magnitude of these mean $+3 \sigma$ side loads was normalized by the peak maximum from the PAR data (just as done for figures 42 and 43). The general shape and distributions in figures 45 and 46 appear similar to those in figures 42 and 43 ,

respectively. Also, the ratio of the TIC to PAR peak side loads from the mean $+3 \sigma$ of the dataset was surprisingly similar to that from the valid maximum side loads curves; $0.443(0.423 / 0.956)$ for the mean $+3 \sigma$ compared to 0.449 (see figure 42).

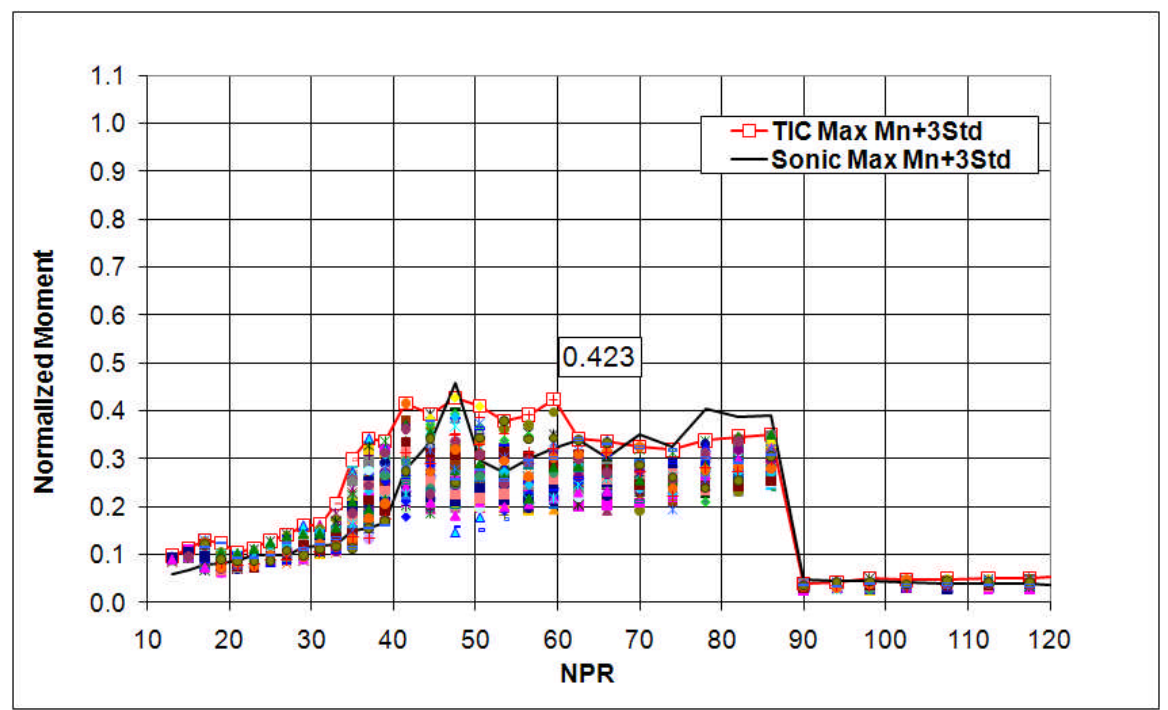

Figure 45. TIC nozzle's mean $+3 \sigma$ nozzle side loads.

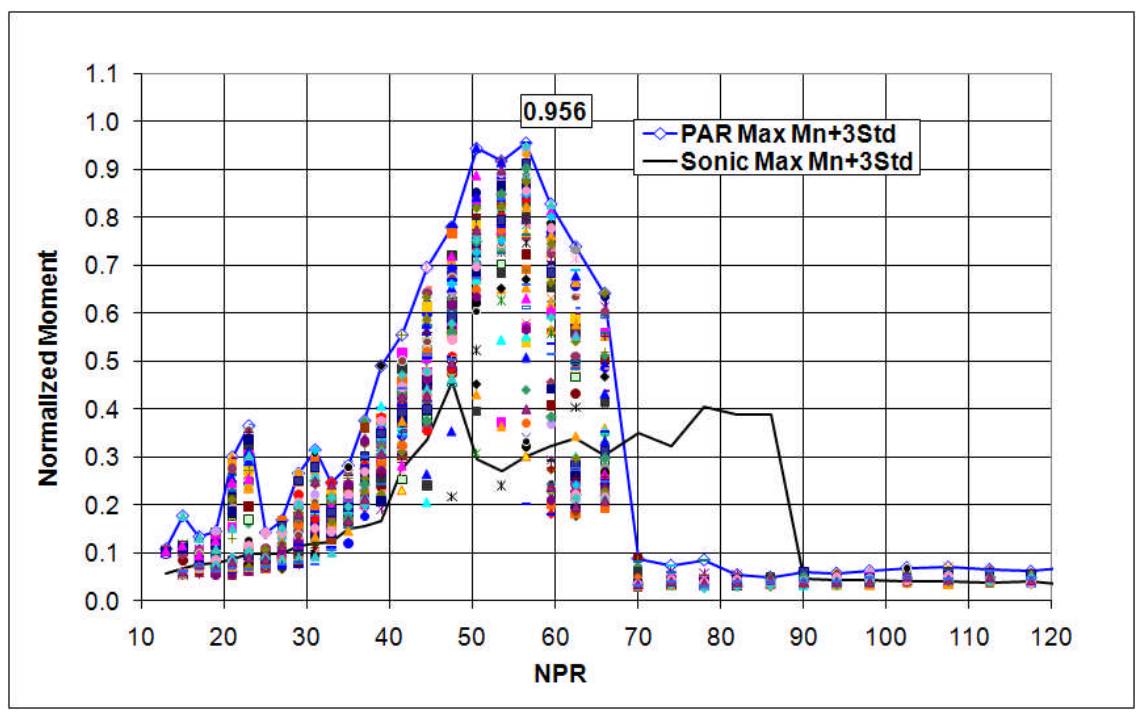

Figure 46. PAR nozzle's mean $+3 \sigma$ nozzle side loads.

The mean $+3 \sigma$ distributions do have a broader range, in NPR, of high side loads than those of figures 43 and 44 . Also, the peak magnitude for both the TIC and PAR nozzles shifted to slightly higher NPRs. For the TIC nozzle the range of high side loads in figure 45 is approximately from NPR 40 to 60 with the peak magnitude at NPR 60 , compared to a range of 40 to 54 and peak magnitude in figure 42. For the PAR nozzle the range of high side load NPRs in figures 43 and 46 were both three NPR bins wide but the mean $+3 \sigma$ distribution shifted up to NPR bins 50.5 to 56.5. It is also much fuller on the right hand side of the peak magnitude NPRs. 
The fact that these maximums of the mean $+3 \sigma$ are so similar to the (backwash effect filtered) valid maximal curves (figures 42 and 43) indicates that the diffuser backwash did not have a statically significant impact on the side loads. Therefore, the mean $+3 \sigma$ side load datasets provide a correct representation of the nozzle side load distributions and relative magnitudes. The reader is reminded that each data point shown represents $100 \mathrm{~s}$ up to 10,000 strain measurements because the data was sampled at 20,480 $\mathrm{Hz}$.

\section{Conclusions}

The strain tube side load measurement approach was successfully implemented in MSFC's Nozzle Test Facility for nozzle start transients. Two cold flow nozzle test articles were developed, a truncated ideal and a parabolic contour, which produced the desired types of nozzle flows. The truncated ideal contour test article's wall pressures and side load moments exhibited FSS behavior expected for truncated ideal nozzles. The parabolic contoured nozzle test article's wall pressures and side load moments indicated transitional nozzle flow behavior, FSS-to-RSS-to-FSS, typical of thrust optimized contours. The $\mathrm{P}_{\mathrm{w}}$ distributions first presented in $2009^{1}$ were further post processed to provide an extensive $\mathrm{P}_{\mathrm{w}}$ dataset for separated nozzle flows. The $\mathrm{P}_{\mathrm{w}}$ distributions presented in 2009 and here (in finer detail) were unaffected by the diffuser inlet's proximity to the nozzle exit plane.

A second set of $\mathrm{P}_{\mathrm{w}}$ data for the PAR nozzle that was affected by the presence of the diffuser inlet was presented and compared to the $\mathrm{P}_{\mathrm{w}}$ dataset unaffected by the diffuser inlet. The $\mathrm{P}_{\mathrm{w}}$ profiles for the nozzle flow separated at a given location were similar for both datasets, i.e., without and with the diffuser inlet effect. However, the diffuser inlet effect did lower the NPR at which the nozzle flow, at given axial station, would separate. That is, the diffuser inlet caused the nozzle to flow full at a lower NPR. The diffuser inlet effect appeared to be limited to the last third of the nozzle length.

During simulated nozzle start transients, the maximum side load magnitude of the TIC test article was $45 \%$ of that of the PAR test article. The effect of facility vibrations on the measured side loads was explained and quantified. The effect of the backwash from the diffuser was described and affected data was filtered out to create a dataset for the maximum side loads. The population of this maximum side load data points was presented. The magnitude of side loads was presented using the mean $+3 \sigma$ for the full population of test points. The mean $+3 \sigma$ data were similar to that of the maximum side loads. Therefore, the mean $+3 \sigma$ side load datasets provide a correct representation of the nozzle side load distributions and relative magnitudes.

The nozzle side load data was obtained with the diffuser inlet in close proximity to the nozzle exit plane. It is likely that the side load data presented here was affected by the diffuser inlet effect.

\section{Acknowledgments}

The authors would like to thank the cold flow nozzle test team (figure 47) for their contribution to this task. The authors would also like to thank Roberto Garcia and Bruce Tiller, both of MSFC, for their continual support of this task during its formative stages.

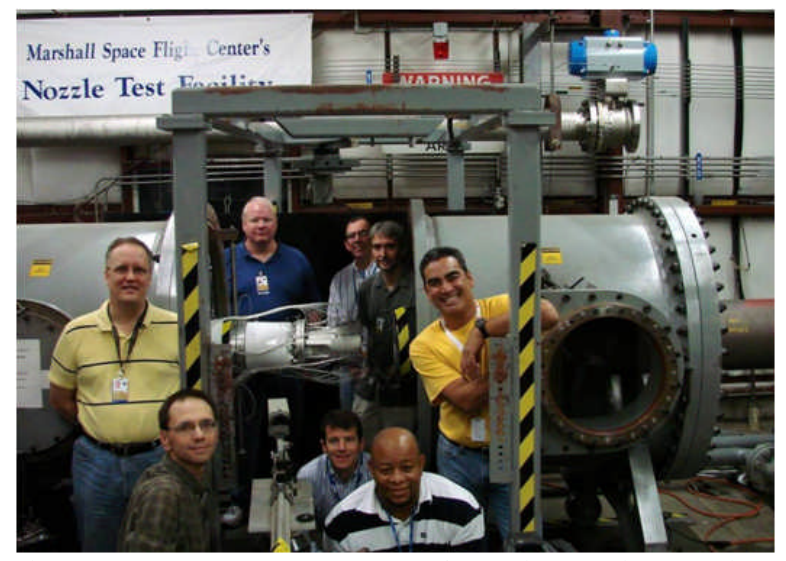

Figure 47. The NTF nozzle side load team. Front row, left to right, Tim Karigan, Joe Ruf, Andy Brown, Al Mayer, Martin Cousins, Back Row, Jim Sieja, Doug Counter and Dave McDaniels. Not pictured: Kris McDougal and Dick Branick. 


\section{References}

1. Ruf, J., H., McDaniels, D., M., and Brown, A., M, "Nozzle Side Load Testing and Analysis at Marshall Space Flight Center", AIAA Paper No 2009-4856, August 2009.

2. Wantabe, Y.; Sakazume, N.; and Tsuboi, M.: "LE-7A Engine Nozzle Problems During the Transient Operations," AIAA Paper No. 2002-3841, July 2002.

3. Hagemann, G.; et al.: "Flow Separation and Side-Loads in Rocket Nozzles," Paper at the $4^{\text {th }}$ International Symposium Rocket Space Propulsion, March, 2000. Lampoldshausen, Germany.

4. Ostlund, J.; et al.: "Side Load Phenomena in Highly Over-Expanded Rocket Nozzles," AIAA Paper No. 2001 3684 , July 2001.

5. Terhardt, J.; and Hagemann, G.: "Flow Separation and Side-Load Behavior of Truncated Ideal Rocket Nozzles." AIAA Paper No. 2001-3686, July 2001.

6. Frey, M.; Hagemann, G.: "Status of Flow Separation Prediction in Rocket Nozzles," AIAA Paper No. 19983619, July 1998.

7. Hagemann, G., Shock Waves, Proceedings of $26^{\text {th }}$ International Symposium on Shock Waves, $1^{\text {st }}$ ed., Springer Berlin Heidelberg, Germany, 2009, Part 1, pgs 59-66.

8. Hagemann, G., Frey, M., "Shock pattern in the plume of rocket nozzles: needs for design consideration," $26^{\text {th }}$ International Symposium on Shock Waves, Gottingen, Germany, July 2007.

9. Reijasse, Ph., et al.: "Flow Separation Experimental Analysis in Overexpanded Subscale Rocket-Nozzles," AIAA Paper No. 2001-3556, July 2001.

10. Dumnov, G., E.: "Unsteady Side-Loads Acting on the Nozzle With Developed Separation Zone," AIAA Paper No. 1996-3220, July 1996.

11. Frey, M.; et al.: "Subscale Nozzle Testing at the P6.2 Test Stand," AIAA Paper No. 2000-3777, July 2000.

12. Smith, S., D., "Final Report, Aerospike Design and Performance Tool", Contract ESI-SUB-002 \& NAS8-0002, 6 August, 2001. Plumetech, Huntsville, AL., 35805.

13. Dunn, S., S., \& Coats, D., E., "TDK02 Two-Dimensional Kinetics Nozzle Performance Program, User Manual", December, 2002, SEA, Inc. Carson City, NV, 89701.

14. Brown, A., M., Ruf, J., H., McDaniels, D., M.,; "Recovering Aerodynamic Side Loads on Rocket Nozzles using Quasi-Static Strain-Gage Measurements," $50^{\text {th }}$ Structures, Structural Dynamics, and Materials Conference, Palm Springs, California, AIAA Paper No. 2009-2681 May 2009.

15. Kwan, W., Stark, R., "Flow Separation Phenomena in Subscale Rocket Nozzles", AIAA Paper No. 2002-4229, July 2002.

16. Ruf, J., H., McDaniels, D., M., and Brown, A., M, "Cold Flow Test Results for Nozzle Side Loads for J-2X and SSME Test Articles", a JANNAF Paper, Presented at the 57th JANNAF Propulsion Meeting/5th Liquid Propulsion Subcommittee, May, 2010. 


\section{Appendix A}

Table A1a. TIC 0 ${ }^{\circ}$ Azimuth normalized (by $P_{c}$ ) wall pressures as presented in figure 14a. Diffuser inlet 76 mm downstream.

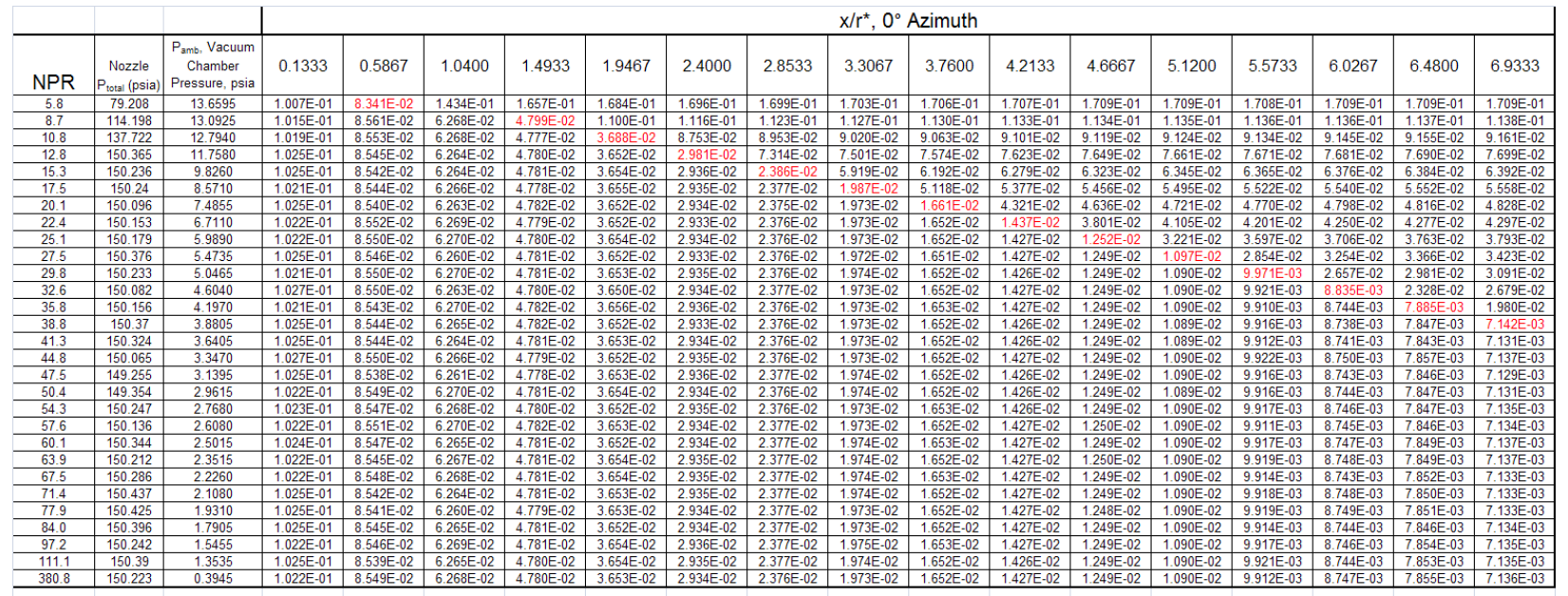

\begin{tabular}{|c|c|c|c|c|c|c|c|c|c|c|c|c|c|c|c|c|c|}
\hline & & & \multicolumn{15}{|c|}{$\mathrm{x} / \mathrm{r}^{*}, 0^{\circ}$ Azimuth } \\
\hline NPR & \begin{tabular}{|c} 
Nozzlat \\
Protal (psia
\end{tabular} & $\begin{array}{l}\text { Pant, Vacuum } \\
\text { Phamber } \\
\text { Pressure, psia }\end{array}$ & 7.3867 & 7.8400 & 8.2933 & 8.7467 & 9.2000 & 9.6533 & 10.1067 & 10.5600 & 11.0133 & 11.4667 & 111.9200 & 12.3733 & 12.8267 & 13.2800 & 13.7333 \\
\hline $\begin{array}{l}5.8 \\
8.7 \\
\end{array}$ & \begin{tabular}{|l|l|}
79.208 \\
114.198 \\
\end{tabular} & $\begin{array}{l}13.6595 \\
13.0925 \\
\end{array}$ & $1.709 E-0$ & 1.709E & $\begin{array}{l}1.7086-1 \\
1.139-2\end{array}$ & 1.707E & $\begin{array}{l}1.706 E_{-} \\
1.140 E \\
\text {. }\end{array}$ & $\begin{array}{l}1.706 \mathrm{E} \\
1.140 \mathrm{E} \\
\mathrm{s}\end{array}$ & & $1705 \mathrm{E}$ & 704E & 1.704E & & & 38E & & 134E \\
\hline & \begin{tabular}{|l|l|l|l}
137.722 \\
150.365 \\
\end{tabular} & $\begin{array}{l}12.72940 \\
11.7580\end{array}$ & $169 \mathrm{E}-02$ & $\begin{array}{l}.1744-02 \\
.712 E-02\end{array}$ & 1716E-0 - & & (1900 & 193E- & $\frac{5 E-0.0}{10 E-0.0}$ & 1986-- & 000 & 14te- & BE & & OOE. & $9 \mathrm{gE}-$ & 137 \\
\hline$\overline{15.3}$ & \begin{tabular}{|l|l|}
150.236 \\
15234 \\
\end{tabular} & & $\begin{array}{ll}705 E-0.02 \\
405-0\end{array}$ & 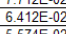 & 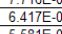 & & (1) & 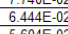 & $\frac{1.40602}{6.466-02}$ & 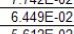 & & & & & wer & 30E & 391E \\
\hline 20.5 & \begin{tabular}{|l|}
150.24 \\
150.096 \\
\end{tabular} & $\frac{8.5710}{7.4855}$ & 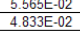 & & . & & & 4.870E & $5 E-0$ & B1E. & & & & & & & 841E \\
\hline & & $\frac{6.7}{50}$ & & & & & & & & & & & & & & & $316 \mathrm{E}$ \\
\hline$\frac{2.17}{27.5}$ & \begin{tabular}{|l|l|}
$150.7 / 9$ \\
150.376 \\
\end{tabular} & $\begin{array}{l}5.9990 \\
5.4735 \\
\end{array}$ & $52 \mathrm{E}-\mathrm{-}$ & 3E- & .8567e & 3.497E-C & .5000 & $3056-$ & $5096-202$ & 5165e- & $.824 \mathrm{E}-\mathrm{E}-\mathrm{s}$ & $35325 \mathrm{~s}$ & 3.540E & 3.545E & & ge & 925 \\
\hline $\begin{array}{l}29.8 \\
326\end{array}$ & \begin{tabular}{|l|}
155.233 \\
150.082 \\
\end{tabular} & $\begin{array}{l}5.0465 \\
4.6040 \\
\end{array}$ & 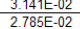 & $\begin{array}{l}E-02 \\
E-02\end{array}$ & 287 & 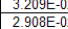 & $2021 \mathrm{E}$ & & 要E-02 & $36 \mathrm{E}$ & . & $476-6$ & $2955 \mathrm{E}$ - & $968 \mathrm{E}-$ & Ge. & g48E- & 100 \\
\hline 0.0 & \begin{tabular}{|l|}
155.156 \\
150.37 \\
\end{tabular} & $\begin{array}{l}4.1970 \\
38805 \\
\end{array}$ & 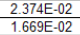 & 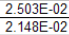 & 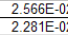 & $\begin{array}{l}2.602 E-0.0 \\
2.3477-0.0\end{array}$ & 2..365e & $\frac{2.6431 E-02}{2.211 E-02}$ & $\begin{array}{l}\frac{2.655 \mathrm{E}-02}{2.246-02} \\
2\end{array}$ & $\frac{2.043}{2.48}$ & \begin{tabular}{|l|l|}
$2.633 \mathrm{E}-$ \\
$2.448 \mathrm{E}-$
\end{tabular} & $\frac{2.6}{2.4}$ & $2456 \mathrm{E}$ & 67" & t & 670E & 2.414te \\
\hline$\frac{41.3}{44.8}$ & \begin{tabular}{|l|l|}
150.324 \\
150.065 \\
\end{tabular} & $\begin{array}{l}3.6405 \\
3.370 \\
\end{array}$ & (5531 & $\begin{array}{l}1.687 \mathrm{E}-02 \\
5.948 \mathrm{E}-03\end{array}$ & 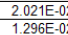 & $\begin{array}{l}2.130 \mathrm{E}-0.0 \\
1.7778-0\end{array}$ & $\begin{array}{l}2.191 E-0 \\
1.922 E-0\end{array}$ & $\begin{array}{l}2.2314-02 \\
1.9944-02\end{array}$ & $\begin{array}{l}2.252 E-02 \\
0235-02\end{array}$ & 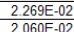 & $2.286 E$ & $\begin{array}{l}2.296 E-0 \\
2097 F-0\end{array}$ & 20 & $\begin{array}{l}2.308 \mathrm{E} \\
2118 \mathrm{E}\end{array}$ & $\frac{2.325}{2124 E}$ & $96 \mathrm{E}$ & $2.2496-2$ \\
\hline 47 & 149.255 & 3.1395 & 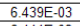 & & & & 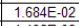 & & & & 971 & & & & & & \\
\hline 0.4 & $\frac{149.354}{150.247}$ & 29615 & $\begin{array}{l}444 E-0 \\
436 E-0\end{array}$ & $910-1$ & 1434 & $\begin{array}{l}0.04 E-1 \\
.992 E-0\end{array}$ & $\frac{1.192 E-0}{4625-0}$ & $\frac{1.5844}{9.4245}$ & 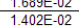 & $1.530 \mathrm{E}$ & 1.7.725e- & $\frac{1.8}{1.6}$ & $\frac{1.8}{16}$ & $\frac{1 .}{1}$ & $10.010 \mathrm{E}$ & $\frac{9 \mathrm{E}-\mathrm{E}}{11 \mathrm{E}}$ & 864E \\
\hline 57.6 & & 2.6080 & 141E & & $5442 E_{-}$ & $\begin{array}{l}.9892-0.0 \\
.00250\end{array}$ & $\begin{array}{ll}649 E-0 \\
653 E-0\end{array}$ & & $\begin{array}{l}219 E-03 \\
2015-03\end{array}$ & & A30E & . $496 \mathrm{E}-\mathrm{0}$ & & & & & \\
\hline$\frac{60.1}{63.9}$ & \begin{tabular}{|l|}
150.344 \\
150.212 \\
\end{tabular} & 2.3515 & 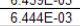 & $12 E-0$ & $\frac{5.441 E-0.0}{5.446 E-0.0}$ & 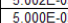 & \begin{tabular}{|l|}
$4.46452-03$ \\
$4.647 E-03$ \\
\end{tabular} & $\frac{4.29}{4.29}$ & $3.974 \mathrm{E}-03$ & $\begin{array}{ll}3.1756-0-0 \\
3.76 E-0\end{array}$ & $\frac{1.2100-2}{7.825-6}$ & 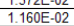 & \begin{tabular}{|l|l}
1.2 \\
1.2
\end{tabular} & & & & \\
\hline & $\frac{150.28}{150.43}$ & $\frac{2.226}{2108}$ & $1 \mathrm{E}-0$. & $\begin{array}{l}5.915 \mathrm{E}-0.02 \\
5916-0.0\end{array}$ & 5.4436 & 997 & 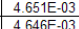 & & $\begin{array}{l}979 E-03 \\
995-03\end{array}$ & $\begin{array}{l}3.733 \mathrm{E}-0 \\
3729 \mathrm{E}-\mathrm{e}\end{array}$ & $3500 \mathrm{E}$ & 714 & $\frac{1.089 \mathrm{E}}{7531 \mathrm{E}}$ & & & $\begin{array}{l}1.327 \mathrm{E} \\
1.20 \mathrm{C}\end{array}$ & \\
\hline$\frac{71.4}{77.9}$ & 150.437 & $\begin{array}{l}2.1060 \\
1.9310 \\
\end{array}$ & $\begin{array}{l}6.441 E-03 \\
6.442 E-03 \\
\end{array}$ & $.917 E-03$ & $5.4445 E-0.0 .0$ & $\begin{array}{l}5.0056-0 \\
5.006 E-0.0\end{array}$ & $\begin{array}{l}4.644 E-035 \\
4.647 E-03 \\
\end{array}$ & $\begin{array}{l}4.30115-5,5 \\
4.301 E-03 \\
\end{array}$ & $\begin{array}{l}3.956-03 \\
3.975-03 \\
\end{array}$ & 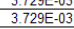 & 3.503E- & . $3.291 E-03$ & \begin{tabular}{|l|l|l|l|l|}
$3.138 E$ \\
\end{tabular} & $\frac{1.070 E-0.0}{6.448 E-0}$ & $1.016 \mathrm{E}-02$ & 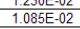 & $1.173 \mathrm{E}-\mathrm{C}$ \\
\hline 97. & $\frac{150.396}{150.242}$ & $\begin{array}{l}1.7905 \\
1.545 \\
\end{array}$ & 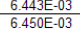 & 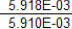 & $\begin{array}{ll}5.439 E-0.0 \\
5.445-0.0\end{array}$ & $\begin{array}{l}0.07 E-0.0 \\
999 E-0\end{array}$ & $\begin{array}{l}648 \mathrm{E}-0 \\
652 \mathrm{E}-0\end{array}$ & 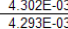 & $\begin{array}{l}3.996 E-03 \\
3.974-03\end{array}$ & 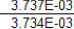 & 3.554E- & $\begin{array}{ll}3.2985-\mathrm{C} \\
32295 \mathrm{E}-\mathrm{C}\end{array}$ & $\frac{3.11125}{31115 \mathrm{E}}$ & & & & \\
\hline$\frac{312}{11.2}$ & $\begin{array}{l}150.239 \\
1592\end{array}$ & 1.35 & . & 2. & 5.446E & & & & $6 E-0$ & BOE- & 3.504E- & & & 2.0465 & & & \\
\hline & & 0.3945 & & & & & & & & & & & & & & & \\
\hline
\end{tabular}


Table A1b. TIC $0^{\circ}$ Azimuth normalized (by $P_{a m b}$ ) wall pressures as presented in figure 14b. Diffuser inlet 76 mm downstream.

\begin{tabular}{|c|c|c|c|c|c|c|c|c|c|c|c|c|c|c|c|c|c|c|}
\hline \\
\hline & & & \multicolumn{16}{|c|}{$\mathrm{x} / \mathrm{r}^{*}, 0^{\circ}$ Azimuth } \\
\hline NPR & $\mid \begin{array}{c}\text { Nozzle } \\
P_{\text {total }} \text { (psia) }\end{array}$ & $\begin{array}{c}\text { Pamb, Vacuum } \\
\text { Chamber } \\
\text { Pressure, psia }\end{array}$ & 0.1333 & 0.5867 & 1.0400 & 1.4933 & 1.9467 & 2.4000 & 2.8533 & 3.3067 & 3.7600 & 4.2133 & 4.6667 & 5.1200 & 5.5733 & 6.0267 & 6.4800 & 6.9333 \\
\hline 5.8 & 79.208 & 13.6595 & 0.5840 & 0.4837 & 0.8314 & 0.9611 & 0.9762 & 0.9832 & 0.9850 & 0.9876 & 0.9893 & 0.9899 & 0.9910 & 0.9907 & 0.9905 & 0.9908 & 0.9907 & 0.9910 \\
\hline 8.7 & \begin{tabular}{|l|l|}
114.198 \\
\end{tabular} & 13.0925 & 0.8857 & 0.7467 & 0.5467 & 0.4186 & 0.9594 & 0.9733 & 0.9796 & 0.9834 & 0.9860 & 0.9883 & 0.9895 & 0.9899 & 0.9906 & 0.9913 & 0.9919 & 0.9923 \\
\hline 10.8 & 137.722 & 12.7940 & 1.0972 & 0.9207 & 0.6747 & 0.5142 & 0.3970 & 0.9422 & 0.9637 & 0.9710 & 0.9756 & 0.9797 & 0.9816 & 0.9822 & 0.9833 & 0.9844 & 0.9855 & 0.9862 \\
\hline 12.8 & 150.365 & 11.7580 & 1.3113 & 1.0928 & 0.8011 & 0.6113 & 0.4671 & 0.3812 & 0.9353 & 0.9593 & 0.9686 & 0.9748 & 0.9782 & 0.9798 & 0.9810 & 0.9822 & 0.9834 & 0.9845 \\
\hline 15.3 & 150.236 & 9.8260 & 1.5671 & 1.3060 & 0.9578 & 0.7310 & 0.5586 & 0.4489 & 0.3647 & 0.9049 & 0.9468 & 0.9601 & 0.9668 & 0.9702 & 0.9731 & 0.9749 & 0.9761 & 0.9773 \\
\hline 17.5 & 150.24 & 8.5710 & 1.7905 & 1.4976 & 1.0984 & 0.8376 & 0.6406 & 0.5144 & 0.4166 & 0.3484 & 0.8971 & 0.9425 & 0.9564 & 0.9631 & 0.9679 & 0.9711 & 0.9732 & 0.9742 \\
\hline 20.1 & 150.096 & 7.4855 & 2.0561 & 1.7124 & 1.2559 & 0.9588 & 0.7323 & 0.5883 & 0.4763 & 0.3957 & 0.3330 & 0.8663 & 0.9297 & 0.9466 & 0.9564 & 0.9621 & 0.9657 & 0.9680 \\
\hline 22.4 & 150.153 & 6.7110 & 2.2859 & 1.9134 & 1.4026 & 1.0693 & 0.8172 & 0.6562 & 0.5315 & 0.4414 & 0.3697 & 0.3216 & 0.8504 & 0.9185 & 0.9399 & 0.9508 & 0.9569 & 0.9614 \\
\hline 25.1 & 150.179 & 5.9890 & 2.5622 & 2.1439 & 1.5722 & 1.1987 & 0.9163 & 0.7358 & 0.5958 & 0.4947 & 0.4143 & 0.3578 & 0.3139 & 0.8076 & 0.9020 & 0.9292 & 0.9436 & 0.9512 \\
\hline 27.5 & 150.376 & 5.4735 & 2.8159 & 2.3479 & 1.7197 & 1.3136 & 1.0032 & 0.8057 & 0.6528 & 0.5419 & 0.4535 & 0.3921 & 0.3431 & 0.3015 & 0.7840 & 0.8939 & 0.9246 & 0.9405 \\
\hline 29.8 & 150.233 & 5.0465 & 3.0409 & 2.5453 & 1.8666 & 1.4232 & 1.0875 & 0.8737 & 0.7074 & 0.5875 & 0.4918 & 0.4247 & 0.3719 & 0.3244 & 0.2968 & 0.7908 & 0.8875 & 0.9202 \\
\hline 32.6 & 150.082 & 4.6040 & 3.3464 & 2.7871 & 2.0417 & 1.5582 & 1.1898 & 0.9563 & 0.7748 & 0.6431 & 0.5384 & 0.4650 & 0.4070 & 0.3553 & 0.3234 & 0.2880 & 0.7589 & 0.8732 \\
\hline 35.8 & \begin{tabular}{|l|l|}
150.156 \\
\end{tabular} & 4.1970 & 3.6536 & 3.0565 & \begin{tabular}{|l|}
2.2433 \\
\end{tabular} & 1.7107 & 1.3078 & 1.0503 & 0.8501 & 0.7060 & 0.5914 & 0.5104 & 0.4470 & 0.3898 & 0.3545 & 0.3128 & 0.2821 & 0.7084 \\
\hline 38.8 & 150.37 & 3.8805 & 3.9717 & 3.3107 & \begin{tabular}{|l}
2.4275 \\
\end{tabular} & 1.8531 & 1.4150 & 1.1365 & 0.9208 & 0.7646 & 0.6401 & 0.5528 & 0.4840 & 0.4221 & 0.3842 & 0.3386 & 0.3041 & 0.2768 \\
\hline 41.3 & 150.324 & 3.6405 & 4.2307 & 3.5278 & \begin{tabular}{|l|l}
2.5867 \\
\end{tabular} & 1.9742 & 1.5086 & 1.2116 & 0.9812 & 0.8147 & 0.6820 & 0.5889 & 0.5156 & 0.4497 & 0.4093 & 0.3609 & 0.3239 & 0.2945 \\
\hline 44.8 & 150.065 & 3.3470 & 4.6050 & 3.8336 & 2.8094 & 2.1428 & 1.6376 & 1.3158 & 1.0651 & 0.8847 & 0.7407 & 0.6397 & 0.5599 & 0.4888 & 0.4449 & 0.3923 & 0.3523 & 0.3200 \\
\hline 47.5 & 149.255 & 3.1395 & 4.8743 & 4.0592 & 2.9766 & 2.2714 & 1.7366 & 1.3958 & 1.1301 & 0.9384 & 0.7855 & 0.6781 & 0.5937 & 0.5182 & 0.4714 & 0.4157 & 0.3730 & 0.3389 \\
\hline 50.4 & 149.354 & 2.9615 & 5.1518 & 4.3113 & \begin{tabular}{|l}
3.1622 \\
\end{tabular} & 2.4109 & 1.8430 & 1.4797 & 1.1984 & 0.9954 & 0.8334 & 0.7192 & 0.6301 & 0.5494 & 0.5001 & 0.4410 & 0.3957 & 0.3596 \\
\hline 54.3 & 150.247 & 2.7680 & 5.5506 & 4.6391 & 3.4021 & 2.5947 & 1.9823 & 1.5928 & 1.2897 & 1.0712 & 0.8970 & 0.7742 & 0.6781 & 0.5918 & 0.5383 & 0.4747 & 0.4259 & 0.3873 \\
\hline 57.6 & 150.136 & 2.6080 & 5.8808 & 4.9225 & 3.6097 & 2.7527 & 2.1028 & 1.6890 & 1.3681 & 1.1357 & 0.9509 & 0.8213 & 0.7193 & 0.6273 & 0.5706 & 0.5035 & 0.4517 & 0.4107 \\
\hline 60.1 & 150.344 & 2.5015 & 6.1563 & 5.1369 & 3.7653 & 2.8735 & 2.1947 & 1.7633 & 1.4287 & 1.1865 & 0.9934 & 0.8575 & 0.7507 & 0.6552 & 0.5960 & 0.5257 & 0.4717 & 0.4289 \\
\hline 63.9 & 150.212 & 2.3515 & 6.5282 & 5.4582 & 4.0034 & 3.0538 & 2.3338 & 1.8750 & 1.5186 & 1.2609 & 1.0555 & 0.9118 & 0.7982 & 0.6962 & 0.6336 & 0.5588 & 0.5014 & 0.4559 \\
\hline 67.5 & 150.286 & 2.2260 & 6.8976 & 5.7709 & 4.2318 & 3.2278 & 2.4668 & 1.9816 & 1.6047 & 1.3324 & 1.1159 & 0.9636 & 0.8432 & 0.7358 & 0.6694 & 0.5903 & 0.5301 & 0.4816 \\
\hline 71.4 & 150.437 & 2.1080 & 7.3150 & 6.0958 & \begin{tabular}{|l|l|l}
4.401 \\
\end{tabular} & 3.4118 & 2.6072 & 2.0949 & 1.6964 & 1.4089 & 1.1788 & 1.0180 & 0.8914 & 0.7780 & 0.7078 & 0.6243 & 0.5602 & 0.5090 \\
\hline 77.9 & 150.425 & 1.9310 & 7.9814 & 6.6535 & 4.8762 & 3.7229 & 2.8457 & 2.2859 & 1.8519 & 1.5370 & 1.2869 & 1.1113 & 0.9726 & 0.8488 & 0.7727 & 0.6815 & 0.6116 & 0.5557 \\
\hline 84.0 & \begin{tabular}{|l|l|}
150.396 \\
\end{tabular} & 1.7 & 8.61 & 7.1773 & 5.2628 & 4.0162 & 3.0673 & 2.4647 & 1.9966 & 1.6576 & 1.3873 & & & 0.9154 & 0.8327 & 0.7344 & 0.6590 & 0.5993 \\
\hline 97.2 & 1050.242 & 1.5455 & 9.9340 & 8.3073 & 6.0945 & 4.6477 & 3.5522 & 2.8541 & 2.3112 & 1.9198 & 1.6066 & 1.3873 & 1.2145 & 1.0599 & 0.9641 & 0.8502 & 0.7635 & 0.6936 \\
\hline 111.1 & 150.39 & 1.3535 & \begin{tabular}{|l|l}
11.3905 \\
\end{tabular} & 9.4880 & 6.9612 & 5.3107 & 4.0606 & 3.2612 & 2.6413 & 2.1936 & 1.8352 & 1.5848 & 1.3875 & 1.2117 & 1.1023 & 0.9716 & 0.8726 & 0.7928 \\
\hline \multirow[t]{2}{*}{380.8} & 150.223 & 0.3945 & 38.9125 & \begin{tabular}{|l}
32.5551 \\
\end{tabular} & \begin{tabular}{|l|l}
23.8682 \\
\end{tabular} & 18.2028 & 13.9113 & \begin{tabular}{|l|l}
11.1736 \\
\end{tabular} & 9.0494 & 7.5133 & 6.2915 & 5.4322 & 4.7554 & 4.1521 & 3.7744 & 3.3308 & 2.9911 & 2.7174 \\
\hline & & & & \multicolumn{15}{|c|}{$\mathrm{x} / \mathrm{r}^{\star}, 0^{\circ}$ Azimuth } \\
\hline NPR & $\mid \begin{array}{c}\text { Nozzle } \\
\mathrm{P}_{\text {total }}(\mathrm{psia})\end{array}$ & $\begin{array}{l}\text { Pamb, Vacuum } \\
\text { Chamber } \\
\text { Pressure, psia }\end{array}$ & & 7.3867 & 7.8400 & 8.2933 & 8.7467 & 2000 & 9.6533 & 10.1067 & 10.5600 & 11.0133 & 11.4667 & 11.9200 & 12.3733 & 12.8267 & 13.2800 & \#\#\#\# \\
\hline 5.8 & $\begin{array}{l}79.208 \\
\end{array}$ & 13.6595 & & 0.9907 & 0.9909 & 902 & 0.9899 & 0.989 & 9892 & 0.9885 & 0.9887 & 0.9883 & 0.9884 & 0.9876 & 0.9883 & 0.9885 & 0.9883 & 0.9822 \\
\hline 8.7 & 114.198 & 0925 & & 0.9929 & 0.9932 & 0.9933 & 0.9940 & 0.9943 & 0.9944 & 0.9944 & 0.9945 & 0.9945 & 0.9945 & 0.9942 & 0.9935 & 0.9928 & 0.9918 & 0.9893 \\
\hline 10.8 & 137.722 & & & 0.9870 & 0.9875 & & 0.9887 & 0.9892 & & 0.9898 & 0.9 & & & 0.9901 & 0.9894 & 0.9877 & 0.9859 & 0.9836 \\
\hline 12.8 & 150.365 & & & 0.9856 & 0.9862 & 0.9867 & 0.9887 & 0.9891 & 0.9899 & 0.9898 & 0.9901 & 0.9900 & & 0.9902 & & 0.9885 & 0.9868 & 0.9833 \\
\hline 15.3 & 150.236 & 60 & & 0.9792 & 0.9804 & 0.9811 & 0.9834 & 0.9841 & 0.9852 & 0.9855 & 0.9861 & 0.9865 & 0.9870 & 0.9872 & 0.9868 & 0.9853 & 0.9831 & 0.9771 \\
\hline 17.5 & 24 & & & 0.9755 & 0.9770 & & 0.9803 & & 0.9823 & 0.9830 & 0.9838 & & 0.9852 & 0.9854 & 0.9853 & 0.9832 & 0.9802 & 0.9755 \\
\hline 20.1 & 150.096 & & & 0.9691 & 0.9700 & 0.9715 & 0.9733 & 0.9751 & 0.9766 & 0.9775 & 0.9787 & 0.9795 & 0.9811 & 0.9823 & 0.9819 & 0.9795 & 0.9764 & 0.9707 \\
\hline 22.4 & 150.153 & 10 & & 0.9639 & 0.9653 & 0.9663 & 0.9672 & 0.9689 & 0.9708 & 0.9723 & 0.9736 & 0.9748 & 0.9763 & 0.9778 & 0.9787 & 0.9760 & 0.9721 & 0.9656 \\
\hline 25.1 & 179 & & & 0.9563 & 0.9 & & 0.9623 & & & 0.9669 & 0.9 & & & 0.9746 & & 0.9740 & 0.9691 & 0.9613 \\
\hline 27.5 & 150.376 & & & 0.9484 & 0.9541 & 0.9579 & 0.9606 & 0.9615 & 0.9628 & 0.9639 & 0.9659 & 0.9681 & 0.9705 & 0.9725 & 0.9740 & 0.9720 & 0.9667 & 0.9593 \\
\hline 29.8 & 150.233 & 0465 & & 0.9351 & 0.9448 & 0.9506 & 0.9553 & 0.9579 & 0.9593 & 0.9597 & 0.9607 & 0.9630 & 0.9656 & 0.9682 & 0.9706 & 0.9684 & 0.9624 & 0.9541 \\
\hline 32.6 & 15 & & & 0.9079 & & & & & 0.9568 & 0.9568 & & & 0.9607 & 0.9633 & & 0.9679 & 0.9611 & 0.9487 \\
\hline 35.8 & \begin{tabular}{|l|l|l|l|l|}
150.156 \\
\end{tabular} & & & 0.8492 & 0.8956 & 0.9180 & 0.9309 & 0.9390 & 0.9457 & 0.9500 & 0.9516 & 0.9528 & 0.9535 & 0.9554 & 0.9600 & 0.9616 & 0.9552 & 0.9433 \\
\hline 38.8 & 150.37 & 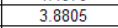 & & 0.6466 & 0.8324 & 0.8839 & 0.9094 & 0.9241 & 0.9344 & 0.9401 & 0.9447 & 0.9486 & 0.9504 & 0.9517 & 0.9558 & 0.9586 & 0.9522 & 0.9354 \\
\hline 41.3 & 150 & & & 0.2 & & & & & & 0.9 & & & & 0.9504 & & 0.9548 & 0.9482 & 0.9287 \\
\hline 44.8 & 150.065 & 3 & & 0.2892 & 0.2683 & 0.5811 & 0.8010 & 0.8617 & 0.8939 & 0.9110 & 0.9235 & 0.9328 & 0.9402 & 0.9453 & 0.9498 & 0.9525 & 0.9435 & 0.9238 \\
\hline 47.5 & 149.255 & & & 0.3061 & 0.2813 & 0.25 & 0.5905 & 0.80 & 0.86 & 0.89 & 0.90 & & & 0.9377 & . & 0.9530 & 0.9460 & 0.9272 \\
\hline 50.4 & & & & & 0.2 & & 0.2 & & 0.7 & 0.8 & & 0.9 & & 0.9262 & 0.9 & 0.9472 & 0.9424 & 0.9198 \\
\hline 54.3 & 150.247 & & & 0.3493 & 0.3208 & 0.2955 & 0.2710 & 0.2529 & 0.5116 & 0.7608 & 0.8306 & 0.8707 & 0.8916 & 0.9075 & 0.9230 & 0.9371 & 0.9397 & 0.9144 \\
\hline 57.6 & 150.136 & 2.6080 & & 0.3708 & 0.3405 & 0.31 & 0.2872 & 0.26 & 0.24 & 0.4732 & 0.7 & 0.8 & 0.8 & 0.8877 & 0.90 & 0.9268 & 0.9352 & 0.9133 \\
\hline 60.1 & & & & & 0.3 & & 0.3006 & & & 0.2423 & & & 0.8 & 0.8595 & 0.8 & 0.9143 & 0.9270 & 0.9091 \\
\hline 63.9 & 150.212 & 2.3515 & & 0.4117 & \begin{tabular}{|l|l|}
0.3776 \\
\end{tabular} & 0.3479 & 0.3194 & 0.2968 & 0.2743 & 0.2539 & 0.2407 & 0.5035 & 0.7408 & 0.8080 & 0.8578 & 0.8943 & 0.9130 & 0.9054 \\
\hline 67.5 & 150.286 & 2.2260 & & 0.4353 & 0.3994 & 0.3675 & 0.3374 & 0.3140 & 0.28 & 0.2686 & 0.2520 & 0.2403 & 0.4820 & 0.7354 & 0.8176 & 0.8711 & 0.8958 & 0.9066 \\
\hline 71.4 & & & & & 0.4 & 0.3 & 0.3572 & 0.3 & 0.3 & 0.2837 & 0.2661 & 0.2500 & 0.2 & 0.5375 & 0.7638 & 0.8454 & 0.8776 & 0.9080 \\
\hline 77.9 & 150.425 & 1.9310 & & 0.5018 & 0.4609 & 0.4241 & 0.3900 & 0.3620 & 0.3351 & 0.3097 & 0.2905 & 0.2729 & 0.2563 & 0.2444 & 0.5023 & 0.7918 & 0.8452 & 0.9140 \\
\hline 84.0 & 150.396 & 1.7905 & & 0.5412 & 0.4971 & 0.4569 & 0.4206 & 0.3904 & 0.3614 & 0.3340 & 0.3139 & 0.2943 & 0.2770 & 0.2614 & 0.2497 & 0.6657 & 0.8054 & 0.9104 \\
\hline 97.2 & 150.242 & & & 0.6270 & 0.5746 & 0.5 & 0.4859 & 0.4 & 0.4 & 0.3863 & 0.3 & 0.3 & 0.3 & 0.3028 & 0.2866 & 0.2750 & 0.5467 & 0.8994 \\
\hline 111.1 & 150.39 & 1.3535 & & 0.7159 & 0.6576 & 0.6051 & 0.5556 & 0.5157 & 0.4780 & 0.4418 & 0.4145 & 0.3894 & 0.3665 & 0.3458 & 0.3273 & 0.3066 & 0.3022 & 0.8349 \\
\hline 380.8 & 150.223 & 0.3945 & & 2.4537 & 2.2510 & 2.0735 & 1.9037 & 1.7693 & 1.6350 & 1.5133 & 1.4221 & 1.3359 & 1.2548 & 1.1838 & 1.1229 & 1.0469 & 1.0063 & 0.9632 \\
\hline
\end{tabular}


Table A2a. TIC $180^{\circ}$ Azimuth normalized (by $P_{c}$ ) wall pressures as presented in figure 15a. Diffuser inlet 76 mm downstream.

\begin{tabular}{|c|c|c|c|c|c|c|c|c|c|c|c|c|c|c|c|c|c|c|}
\hline \multirow[b]{2}{*}{ NPR } & \multirow[b]{2}{*}{$\begin{array}{c}\text { Nozzle } \\
P_{\text {totos }}(p s i a)\end{array}$} & \multirow[b]{2}{*}{\begin{tabular}{|c|} 
Pamb, Vacuum \\
Chamber \\
Pressure, psia \\
\end{tabular}} & \multicolumn{16}{|c|}{$\mathrm{x} / \mathrm{r}^{\star}, 180^{\circ}$ Azimuth } \\
\hline & & & 0.3600 & 8133 & 1.2667 & 1.7200 & 2.1733 & 2.6267 & 3.0800 & 3.5333 & 3.9867 & 4.4400 & 4.8933 & 5.3467 & 5.8000 & 6.2533 & 6.7067 & 7.1600 \\
\hline 7.7 & \begin{tabular}{|l|}
101.81 \\
\end{tabular} & .2675 & & & & & & & & & & & & & & & & \\
\hline 9.8 & 66.511 & & & & & & & & \begin{tabular}{|l|l|}
9.98 \\
\end{tabular} & & & & BE-01 & 9E-01 & 1. & $1 \mathrm{E}-01$ & EE-01 & $2 E-01$ \\
\hline 11.8 & \begin{tabular}{|l|l|}
149.531 \\
\end{tabular} & 12.6375 & 9.42 & & $5.444 \mathrm{E}-02$ & 4.14 & & \begin{tabular}{|c|c|}
$7.919 E-02$ \\
\end{tabular} & \begin{tabular}{|l|l|}
8.119 \\
\end{tabular} & $E-02$ & 8 & 8.2 & 8. & \begin{tabular}{|l|l}
$8.283 \mathrm{E}-02$ \\
\end{tabular} & \begin{tabular}{|l|l|}
$8.292 \mathrm{E}$ \\
\end{tabular} & \begin{tabular}{|l|l}
$8.304 E-02$ \\
\end{tabular} & $15-0$ & \\
\hline 14.1 & 150.289 & 10.6950 & & 7.310 & $5.446 \mathrm{E}-02$ & & & & $6.557 \mathrm{E}-0$ & \begin{tabular}{|l|l|}
$6.779 \mathrm{E}-02$ \\
\end{tabular} & & & & & 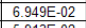 & & & \\
\hline 16.4 & \begin{tabular}{|l|}
150.216 \\
\end{tabular} & 9.1570 & & & & & & & & 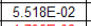 & & & & \begin{tabular}{|l}
$5.896 \mathrm{E}-02$ \\
\end{tabular} & & & & \\
\hline 18.8 & \begin{tabular}{|l|}
150.267 \\
\end{tabular} & 7.9800 & & 7.31 & $5.446 \mathrm{E}-02$ & & & & 2.13 & & \begin{tabular}{|l|l|}
$4.691 \mathrm{E}-02$ \\
\end{tabular} & 4.9 & 5.05 & & & & & \\
\hline 21.4 & \begin{tabular}{|l|}
150.191 \\
\end{tabular} & 7.0 & 9.42 & & 5.44 & & & & & & & & & & & & & 4. \\
\hline 24.0 & 150.157 & 6.2 & 9.41 & & & & & & 2.134 & & 1.51 & & 3.39 & & & & & \\
\hline 26.6 & 150.384 & 5.6 & 9.45 & & 5.45 & & & & 2.13 & & & & & & & & & \\
\hline 28.9 & 150.365 & 5.1970 & 9.45 & & 5.45 & & & & 2.13 & & $1.514 \mathrm{E}-02$ & & & & & & & \\
\hline 31.6 & 150.394 & & 9.45 & & 5.44 & 4.14 & & & 2.13 & & & & \begin{tabular}{|l|l|}
$1.128 \mathrm{E}-02$ \\
\end{tabular} & & & & & \\
\hline 34.9 & 150.362 & & 9.45 & & & & & & 2.13 & & & & & & & & & \\
\hline 37.2 & 150.43 & & 9.44 & & & & & & 2.13 & & & & & & & & & \\
\hline 40.4 & \begin{tabular}{|l|l}
150.187 \\
\end{tabular} & 3.7210 & 9.43 & & & 4.14 & & & 2.13 & & & & & & & & & \\
\hline 43.7 & 150.265 & 3.4 & 9.44 & & & & & & 2.13 & & & & & & & & & \\
\hline 46.9 & 149.316 & & 9.45 & & & & & & 2.13 & & & & & & & & & \\
\hline 49.6 & 149.404 & & 9.43 & & & & & & 2.13 & & & & & & & & & \\
\hline 53.0 & 149.973 & 2.8 & 9.42 & & & & & & 2.1 & & & & & & & & & \\
\hline 56.5 & \begin{tabular}{|l|}
150.101 \\
\end{tabular} & 2.6 & & & & & & & 2.1 & & & & & & & & & \\
\hline 59.6 & 150.317 & 2.5 & & & & & & & & & & & & & & & & \\
\hline 64.2 & 150.268 & 2.3 & & & & 4.14 & & & & & & & & & & & & \\
\hline 67.8 & 150.278 & 2.2 & & & 5.44 & & & & 2.13 & & & & \begin{tabular}{|l|l}
1.1 \\
\end{tabular} & & & & & \\
\hline 71.7 & 150.249 & 2.0960 & 9.41 & & & & & & & & & & \begin{tabular}{|l|l}
1.1 \\
\end{tabular} & & & & & \\
\hline 76.8 & \begin{tabular}{|r|}
150.37 \\
150.397
\end{tabular} & 1.9590 & 9.46 & & 5.45 & 4.14 & & & & & & & & & & & & \\
\hline 83.5 & \begin{tabular}{|l|l|}
50.397 \\
153230
\end{tabular} & 1.8005 & 9.45 & & 5.44 & 4.13 & & & 2.13 & & & & \begin{tabular}{|l|l}
1.1 \\
\end{tabular} & & & & & \\
\hline 91.9 & \begin{tabular}{|l|l|}
50.339 \\
15303
\end{tabular} & 1.6355 & \begin{tabular}{|c|}
$9.429 \mathrm{E}-02$ \\
\end{tabular} & 7.31 & 5.443 & 4.14 & & & 2.13 & & & & $\begin{array}{l}1.12 \\
\end{array}$ & & & & & \\
\hline 105.8 & 150.303 & 1.4205 & $9.449 \mathrm{E}-02$ & $7.312 \mathrm{E}-02$ & $5.445 \mathrm{E}-02$ & $4.141 \mathrm{E}-02$ & \begin{tabular}{|l|l}
$3.245 \mathrm{E}-02$ \\
\end{tabular} & $2.676 \mathrm{E}-02$ & $2.132 \mathrm{E}-02$ & $1.775 \mathrm{E}-02$ & $1.516 \mathrm{E}-02$ & \begin{tabular}{|l}
$1.317 \mathrm{E}-02$ \\
\end{tabular} & 1.129E-02 & \begin{tabular}{|l|l}
$1.030 \mathrm{E}-02$ \\
\end{tabular} & $9.195 \mathrm{E}-03$ & $8.283 \mathrm{E}-03$ & & $6.773 \mathrm{E}-03$ \\
\hline 164.5 & 150.297 & 0.9135 & $9.451 \mathrm{E}-02$ & $7.313 \mathrm{E}-02$ & $5.447 \mathrm{E}-02$ & $4.140 \mathrm{E}-02$ & $3.244 \mathrm{E}-02$ & $2.674 \mathrm{E}-02$ & $2.131 \mathrm{E}-02$ & $1.774 \mathrm{E}-02$ & $1.514 \mathrm{E}-02$ & \begin{tabular}{|l}
$1.317 \mathrm{E}-02$ \\
\end{tabular} & $1.128 \mathrm{E}-02$ & $1.029 \mathrm{E}-02$ & $9.182 \mathrm{E}-03$ & $8.284 \mathrm{E}-03$ & $7.425 \mathrm{E}-03$ & \begin{tabular}{|l|l|}
6.7677 \\
\end{tabular} \\
\hline
\end{tabular}

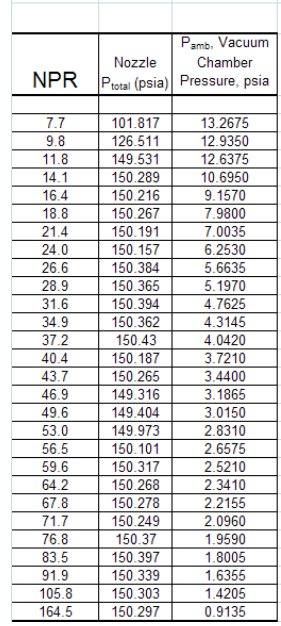

\begin{tabular}{|c|c|c|c|c|c|c|c|c|c|c|c|c|c|}
\hline \multicolumn{14}{|c|}{$\mathrm{x} / \mathrm{r}^{*}, 180^{\circ}$ Azimuth } \\
\hline 7.6133 & 8.0667 & 8.5200 & 8.9733 & 9.4267 & 9.8800 & \begin{tabular}{|l|}
10.3333 \\
\end{tabular} & 10.7867 & \begin{tabular}{|l|l} 
& 11.2400
\end{tabular} & \begin{tabular}{|l|}
11.6933 \\
\end{tabular} & \begin{tabular}{|l|l} 
& 12.1467
\end{tabular} & \begin{tabular}{|l|l|} 
& 12.6000 \\
\end{tabular} & 13.0533 & 13.5067 \\
\hline & & & & & & & & & & & & & \\
\hline & & & & & & & & 4776- & $\frac{0.344 c}{7}$ & & & trete & \begin{tabular}{|l|}
$1.003 \mathrm{E}-01$ \\
$8.250 \mathrm{E}-02$ \\
\end{tabular} \\
\hline & $946 \mathrm{E}-\mathrm{T}$ & & $\begin{array}{l}8955-0 \\
855 E-0\end{array}$ & $5.961 \mathrm{E}-1$ & $997 \mathrm{~g}-\mathrm{9}-\mathrm{9} 5 \mathrm{E}-$ & $5.971 E-C$ & 3E & :001E- & 5.979E & $977 \mathrm{9}$ & 5.964E & 9976 & \begin{tabular}{|l|}
$6.919 E-02$ \\
$5.893 E-02$
\end{tabular} \\
\hline & & & 五 & 510E. & $516 \mathrm{E}$ & & & .198E & & & 536E & & $\begin{array}{l}62 E-02 \\
\end{array}$ \\
\hline & & 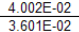 & $\frac{0.02 E-0.0}{302-2}$ & $\frac{603 E-0.2}{603}$ & $\begin{array}{l}\frac{4.016 E-02}{3.607 E-02} \\
3\end{array}$ & $\begin{array}{l}24 E-0-0 \\
115 E-0\end{array}$ & $\frac{8 E-0}{11-0-0}$ & 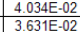 & 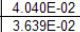 & 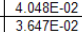 & 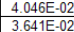 & $\begin{array}{l}4.019 \mathrm{E}-0 . \\
3.6177-0.0\end{array}$ & $3576-02$ \\
\hline & & & 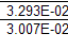 & $\begin{array}{l}3.296 \mathrm{E}-\mathrm{C} \\
3.071 \mathrm{E}-0\end{array}$ & $\begin{array}{l}3.294 \mathrm{E}-\mathrm{C} \\
3.017 \mathrm{E}-\mathrm{C}\end{array}$ & 3.298E-0.0 & $\begin{array}{l}\frac{3.303 \mathrm{E}-0}{3016 \mathrm{E}-0} \\
30\end{array}$ & $\frac{31}{312}$ & 0.024 & 344E & $052 \mathrm{E}$ & 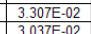 & $\begin{array}{l}3.2645-02 \\
2995 E-02\end{array}$ \\
\hline & & & BEE & $\begin{array}{l}2.7049 \\
250959\end{array}$ & $\begin{array}{l}2.713 \mathrm{E}-\mathrm{C} \\
2525 \mathrm{E}-\mathrm{e}\end{array}$ & $\frac{2.7186}{25356}$ & $2.719 \mathrm{E}-\mathrm{-}$ & $\frac{2.718 E}{2541 E}$ & $2.723 \mathrm{E}-\mathrm{t}$ & $2.733 \mathrm{E}-\mathrm{E}$ & $2.745 \mathrm{E}$ & 35E- & $\begin{array}{l}2.690 E^{2}-02 \\
2557-52\end{array}$ \\
\hline & & 525 & $\begin{array}{l}1,1 E-0 \\
11-0\end{array}$ & $\frac{2.278 E-0.2}{20525-20}$ & $\begin{array}{l}\frac{2.30119-}{2.089 E-} \\
\end{array}$ & . & $26-1$ & 9E- & , $342 E-0.0$ & \begin{tabular}{|l|}
$2.346 \mathrm{E}-0$ \\
$2.170 \mathrm{E}-0$
\end{tabular} & 52E- & \begin{tabular}{|l|}
$2.342 \mathrm{E}-\mathrm{I}$ \\
$2.161 \mathrm{E}-\mathrm{e}$
\end{tabular} & \begin{tabular}{|l|}
$2.2886-02$ \\
$2.14 E$
\end{tabular} \\
\hline & & & 78E-0:2 & 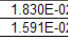 & $\begin{array}{ll}93 \mathrm{E}-\mathrm{C} \\
1 \mathrm{~F}-\mathrm{s}\end{array}$ & $\frac{1.935 E-02}{1.780 E-02}$ & 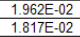 & $1.982 E-1.846-$. & $\frac{1.989 \mathrm{E}-0.25}{1.665-02}$ & & $\begin{array}{l}2.023 \mathrm{E} \\
1.902 \mathrm{E}\end{array}$ & $\frac{2.29010-6}{1904}$ & 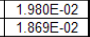 \\
\hline & & $\begin{array}{ll}4 E-03 \\
30-03\end{array}$ & $\frac{E-03}{E-03}$ & 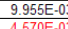 & $\begin{array}{l}1.455 E-02 \\
9.960-03\end{array}$ & \begin{tabular}{|l|}
$1.579 E-0$ \\
$1348-0$
\end{tabular} & $\begin{array}{l}1.646-0.0 \\
11765 \Omega\end{array}$ & 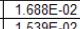 & \begin{tabular}{|l|l|}
$1.718 E-0$ \\
$150=0$
\end{tabular} & $\begin{array}{l}741 E-0.0 \\
667 F-0\end{array}$ & 1E- & 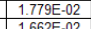 & 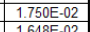 \\
\hline $200-03$ & & $\begin{array}{l}5.056-50.03 \\
5.196-03\end{array}$ & 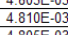 & 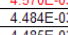 & 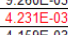 & $\begin{array}{l}.3 .456-02 \\
8.655-0.03 \\
\end{array}$ & 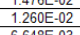 & \begin{tabular}{|l}
$1.3552-02$ \\
$1.382-026.02$ \\
\end{tabular} & $\begin{array}{l}1.5050-02 \\
1.450-02 \\
\end{array}$ & $\begin{array}{l}1.495 E-02 \\
1.43-02\end{array}$ & 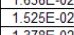 & 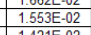 & $\begin{array}{l}.0606-02 \\
1.561 E-02 \\
\end{array}$ \\
\hline$\frac{122 \mathrm{E}}{122 \mathrm{E}}$ & 整E & $\begin{array}{l}5.917-0.3 \\
5.1972-03\end{array}$ & 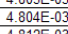 & 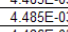 & 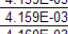 & 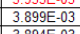 & 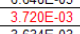 & 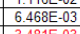 & \begin{tabular}{|l|l|}
$1.0795 E-0$ \\
\end{tabular} & $1.204 E-02$ & $\begin{array}{l}1.1756-02 \\
1.274-02 \\
\end{array}$ & 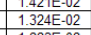 & \begin{tabular}{|l|}
$\begin{array}{l}1.4546-02 \\
1.371 E-02\end{array}$ \\
\end{tabular} \\
\hline & & & $.8125-03$ & $\begin{array}{l}4.466-0.0 \\
4.482 E-0.0 \\
\end{array}$ & $\begin{array}{l}\frac{4.160 E-03}{4.156-03} \\
4.03\end{array}$ & $\begin{array}{l}3.8 .9496-0 \\
.904 E-0\end{array}$ & $\begin{array}{l}\frac{3.634 E-0}{3.631 E-0} \\
3\end{array}$ & 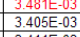 & & $\frac{1.466-0.2}{6.025-0.0}$ & $\begin{array}{l}1.1566-02 \\
9 . .842-03 \\
\end{array}$ & $\begin{array}{l}\frac{1.223 E-0}{1.096 E-0} \\
1\end{array}$ & $\begin{array}{l}\frac{1.266 E-02}{1.1806-02} \\
\end{array}$ \\
\hline & $\begin{array}{l}1.12 E-03 \\
0.07 E-03 \\
\end{array}$ & & $4.807 E-03$ & $\begin{array}{l}4.4886-0.0 \\
4.483 E-0 .\end{array}$ & $\begin{array}{l}\frac{4.462 E-03}{4.157 E-03} \\
\end{array}$ & $\begin{array}{l}3.9 .930 \mathrm{E}-0 \\
.898 \mathrm{E}-0 \\
\end{array}$ & $\begin{array}{l}\frac{3.637 E-0}{3.632 E-0} \\
3\end{array}$ & $\begin{array}{l}\text { 3.44111-- } \\
\text { 3.412E- }\end{array}$ & & & & \begin{tabular}{|l|l|}
$5.298 E E-0$ \\
$5.641 E-0$
\end{tabular} & 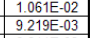 \\
\hline & & & & $\begin{array}{l}4.491-\mathrm{E}^{-} \\
4.77 \mathrm{E}-\end{array}$ & & & & \begin{tabular}{|l}
$3.43130 E-$ \\
$3.400-$
\end{tabular} & $=03$ & \begin{tabular}{|l}
$3.047 E-03$ \\
$3.034 E-03$ \\
\end{tabular} & $\begin{array}{l}\frac{6 E E-03}{61 E-03} \\
1 E\end{array}$ & \begin{tabular}{|l}
$2.744-E-53$ \\
$2.715 E-03$ \\
\end{tabular} & \begin{tabular}{|l}
$\begin{array}{c}6.244 E-0.0 \\
2.602 E-0\end{array}$ \\
\end{tabular} \\
\hline
\end{tabular}


Table A2b. TIC $180^{\circ}$ Azimuth normalized (by $P_{a m b}$ ) wall pressures as presented in figure 15b. Diffuser inlet $76 \mathrm{~mm}$ downstream.

\begin{tabular}{|c|c|c|c|c|c|c|c|c|c|c|c|c|c|c|c|c|c|c|}
\hline \multirow[b]{2}{*}{ NPR } & \multirow[b]{2}{*}{$\begin{array}{c}\text { Nozzle } \\
P_{\text {total }}(\text { psia) }\end{array}$} & \multirow[b]{2}{*}{$\begin{array}{c}P_{\text {amb, Vacuum }} \\
\text { Chamber } \\
\text { Pressure, psia }\end{array}$} & \multicolumn{16}{|c|}{$\mathrm{x} / \mathrm{r}^{*}, 180^{\circ}$ Azimuth } \\
\hline & & & 0.3600 & 0.8133 & 1.2667 & 1.7200 & 2.1733 & 2.6267 & 3.0800 & 3.5333 & 3.9867 & 4.4400 & 4.8933 & 5.3467 & 5.8000 & 6.2533 & 6.7067 & 7.1600 \\
\hline 7.7 & 101.817 & 2675 & 0.7016 & 0.5623 & 0.4219 & 0.9611 & 0.9743 & 0.9799 & 0.9838 & 0.9865 & 0.9883 & 0.9893 & 9905 & 9911 & 0.9918 & 0.9925 & 0.9927 & 0.9930 \\
\hline 9.8 & 126.511 & 12.9350 & 0.9042 & 0.7158 & 0.5320 & 0.4090 & 0.9541 & 0.9698 & 0.9765 & 0.9804 & 0.9830 & 0.9847 & 0.9861 & 0.9869 & 0.9878 & 0.9886 & 0.9890 & 0.9895 \\
\hline 11.8 & 149.531 & 12.6375 & 1.1153 & 0.8658 & 0.6442 & 0.4900 & 0.3888 & 0.9371 & 0.9606 & 0.9690 & 0.9736 & 0.9769 & 0.9792 & 0.9801 & 0.9811 & 0.9826 & 0.9833 & 0.9842 \\
\hline 14.1 & 150.289 & 10.6950 & 1.3269 & 1.0272 & 0.7652 & 0.5820 & 0.4561 & 0.3807 & 0.9214 & 0.9526 & 0.9630 & 0.9688 & 0.9732 & 0.9748 & 0.9764 & 0.9777 & 0.9787 & 0.9799 \\
\hline 16.4 & 150.216 & 9.1570 & 1.5453 & 1.2003 & 0.8928 & 0.6797 & 0.5323 & 0.4380 & 0.3545 & 0.9052 & 0.9444 & 0.9571 & 0.9637 & 0.9672 & 0.9700 & 0.9714 & 0.9719 & 0.9730 \\
\hline 18.8 & 150.267 & 7.9800 & 1.7759 & 1.3774 & 1.0256 & 0.7799 & 0.6110 & 0.5033 & 0.4016 & 0.3381 & 0.8833 & 0.9348 & 0.9510 & 0.9589 & 0.9644 & 0.9678 & 0.9689 & 0.9695 \\
\hline 21.4 & 150.191 & 7.0035 & 2.0210 & 1.5699 & 1.1684 & 0.8883 & 0.6962 & 0.5729 & 0.4573 & 0.3807 & 0.3260 & 0.8464 & 0.9191 & 0.9394 & 0.9498 & 0.9561 & 0.9598 & 0.9618 \\
\hline 24.0 & 150.157 & 6.2530 & 2.2600 & 1.7566 & 1.3069 & 0.9949 & 0.7795 & 0.6419 & 0.5124 & 0.4264 & 0.3637 & 0.3181 & 0.8154 & 0.9077 & 0.9332 & 0.9456 & 0.9523 & 0.9567 \\
\hline 26.6 & 150.384 & 5.6635 & 2.5096 & 1.9437 & 1.4473 & 1.0990 & 0.8613 & 0.7100 & 0.5661 & 0.4713 & 0.4020 & 0.3496 & 0.3009 & 0.7801 & 0.8913 & 0.9229 & 0.9376 & 0.9455 \\
\hline 28.9 & 150.365 & 5.1970 & 2.7368 & 2.1176 & 1.5774 & 1.1976 & 0.9386 & 0.7739 & 0.6169 & 0.5136 & 0.4381 & 0.3808 & 0.3265 & 0.3004 & 0.7735 & 0.8830 & 0.9163 & 0.9315 \\
\hline 31.6 & 150.394 & 4.7625 & 2.9841 & 2.3093 & 1.7191 & 1.3073 & 1.0245 & 0.8451 & 0.6732 & 0.5604 & 0.4783 & 0.4157 & 0.3563 & 0.3250 & 0.2929 & 0.7574 & 0.8764 & 0.9119 \\
\hline 34.9 & 150.362 & 4.3145 & 3.2938 & 2.5484 & 1.8983 & 1.4433 & 1.1297 & 0.9317 & 0.7428 & 0.6181 & 0.5275 & 0.4589 & 0.3933 & 0.3586 & 0.3203 & 0.2893 & 0.6640 & 0.8455 \\
\hline 37.2 & 150.43 & 4.0420 & 3.5153 & 2.7192 & 2.0270 & 1.5418 & 1.2073 & 0.9951 & 0.7934 & 0.6603 & 0.5636 & 0.4901 & 0.4198 & 0.3830 & 0.3422 & 0.3083 & 0.2806 & 0.7098 \\
\hline 40.4 & 150.187 & & 3.8092 & 2.9530 & 2.1967 & 1.6708 & 1.3101 & 1.0785 & 0.8608 & 0.7165 & 0.6114 & 0.5316 & 0.4553 & 0.4155 & 0.3717 & 0.3343 & 0.2997 & 0.2749 \\
\hline 43.7 & 150.265 & & 4.1270 & 3.1951 & 2.3765 & 1.8087 & 1.4166 & 1.1674 & 0.9308 & 0.7750 & 0.6613 & 0.5753 & 0.4930 & 0.4494 & 0.4015 & 0.3619 & 0.3244 & 0.2959 \\
\hline$\frac{73.1}{46.9}$ & 149.316 & 3.1865 & 4.4312 & $\begin{array}{l}3.4282 \\
\end{array}$ & 2.5536 & 1.9397 & 1.5198 & 1.2528 & 0.9989 & 0.8316 & 0.7096 & 0.6173 & 0.5291 & $\begin{array}{l}0.44823 \\
\end{array}$ & $\begin{array}{l}0.4312 \\
0.4312\end{array}$ & 0.3882 & 0.3477 & 0.3173 \\
\hline 49.6 & 149.404 & & 4.6760 & 3.6279 & 2.6992 & 2.0524 & 1.6086 & 1.3244 & 1.0567 & 0.8796 & 0.7506 & 0.6527 & 0.5592 & & 0.4564 & 0.4106 & 0.3682 & 0.3360 \\
\hline 53.0 & 149.973 & 2.8310 & 4.9912 & 3.8781 & 2.8827 & 2.1943 & 1.7199 & 1.4158 & 1.1303 & 0.9407 & 0.8025 & 0.6980 & 0.5977 & 0.5454 & 0.4882 & 0.4391 & 0.3931 & 0.3589 \\
\hline 56.5 & 150.101 & 2.6575 & 5.3302 & 4.1313 & 3.0751 & 2.3394 & 1.8333 & 1.5104 & 1.2045 & 1.0024 & 0.8553 & 0.7439 & 0.6378 & 0.5814 & 0.5193 & 0.4681 & 0.4196 & 0.3827 \\
\hline 59.6 & 150.317 & 2.52 & 5.6196 & 4.3633 & 3.2447 & 2.4701 & 1.9361 & 1.5938 & 1.2721 & 1.0587 & 0.9032 & 0.7858 & 0.6727 & 0.6140 & 0.5498 & 0.4939 & 0.4427 & 0.4042 \\
\hline 64.2 & 150.268 & 2.3410 & 6.0487 & 4.6916 & 3.4930 & 2.6587 & 2.0833 & 1.7155 & 1.3695 & 1.1397 & 0.9722 & 0.8458 & 0.7245 & 0.6608 & 0.5916 & 0.5318 & 0.4767 & 0.4353 \\
\hline 67.8 & 150.278 & 2.2155 & 6.3949 & 4.9592 & 3.6899 & 2.8088 & 2.2009 & 1.8127 & 1.4471 & 1.2042 & 1.0273 & 0.8937 & 0.7655 & 0.6983 & 0.6251 & 0.5619 & 0.5037 & 0.4599 \\
\hline 71.7 & 150.249 & 2.0960 & 6.7500 & 5.2443 & 3.9003 & 2.9699 & 2.3259 & 1.9156 & 1.5291 & 1.2729 & 1.0859 & 0.9447 & 0.8087 & 0.7381 & 0.6603 & 0.5940 & 0.5324 & 0.4857 \\
\hline 76.8 & 150.37 & 1.9590 & 7.2644 & 5.6177 & 4.1863 & 3.1776 & 2.4911 & 2.0536 & 1.6360 & 1.3624 & 1.1628 & 1.0107 & 0.8668 & 0.7907 & 0.7055 & 0.6360 & 0.5702 & 0.5202 \\
\hline 83.5 & 150.397 & 1.8005 & 7.8961 & 6.1122 & 4.5510 & 3.4552 & 2.7092 & 2.2338 & 1.7806 & 1.4824 & 1.2652 & 1.0997 & 0.9431 & 0.8598 & 0.7676 & 0.6920 & 0.6204 & 0.5660 \\
\hline 91.9 & \begin{tabular}{|l|}
150.339 \\
\end{tabular} & 1.6355 & 8.6677 & 6.7270 & 5.0034 & 3.8062 & 2.9832 & 2.4561 & 1.9609 & 1.6325 & 1.3928 & 1.2113 & 1.0376 & 0.9465 & 0.8468 & 0.7618 & 0.6824 & 0.6231 \\
\hline 105.8 & 150.303 & 1.4205 & 9.9979 & 7.7367 & 5.7614 & 4.3816 & 3.4333 & 2.8314 & 2.2562 & 1.8782 & 1.6037 & 1.3932 & 1.1946 & 1.0898 & 0.9729 & 0.8765 & 0.7856 & 0.7166 \\
\hline 164.5 & 150.297 & 0.9135 & 15.5501 & 12.0317 & 8.9622 & 6.8112 & 5.3377 & 4.3996 & 3.5063 & 2.9195 & 2.4915 & 2.1664 & 1.8566 & 1.6935 & 1.5107 & 1.3629 & 1.2217 & 1.1133 \\
\hline
\end{tabular}

\begin{tabular}{c|c|c|}
\hline NPR & $\begin{array}{c}\text { Nozzle } \\
\text { Ptotal }_{\text {(psia) }}\end{array}$ & $\begin{array}{c}P_{\text {amb, Vacuum }} \\
\text { Chamber } \\
\text { Pressure, psia }\end{array}$ \\
\hline & & \\
\hline 7.7 & 101.817 & 13.2675 \\
\hline 9.8 & 126.511 & 12.9350 \\
\hline 11.8 & 149.531 & 12.6375 \\
\hline 14.1 & 150.289 & 10.6950 \\
\hline 16.4 & 150.216 & 9.1570 \\
\hline 18.8 & 150.267 & 7.9800 \\
\hline 21.4 & 150.191 & 7.0035 \\
\hline 24.0 & 150.157 & 6.2530 \\
\hline 26.6 & 150.384 & 5.6635 \\
\hline 28.9 & 150.365 & 5.1970 \\
\hline 31.6 & 150.394 & 4.7625 \\
\hline 34.9 & 150.362 & 4.3145 \\
\hline 37.2 & 150.43 & 4.0420 \\
\hline 40.4 & 150.187 & 3.7210 \\
\hline 43.7 & 150.265 & 3.4400 \\
\hline 46.9 & 149.316 & 3.1865 \\
\hline 49.6 & 149.404 & 3.0150 \\
\hline 53.0 & 149.973 & 2.8310 \\
\hline 56.5 & 150.101 & 2.6575 \\
\hline 59.6 & 150.317 & 2.5210 \\
\hline 64.2 & 150.268 & 2.3410 \\
\hline 67.8 & 150.278 & 2.2155 \\
\hline 71.7 & 150.249 & 2.0960 \\
\hline 76.8 & 150.37 & 1.9590 \\
\hline 83.5 & 150.397 & 1.8005 \\
\hline 91.9 & 150.339 & 1.6355 \\
\hline 105.8 & 150.303 & 1.4205 \\
\hline 164.5 & 150.297 & 0.9135 \\
\hline & & \\
\hline
\end{tabular}

\begin{tabular}{|c|c|c|c|c|c|c|c|c|c|c|c|c|c|}
\hline \multicolumn{14}{|c|}{$\mathrm{x} / \mathrm{r}^{\star}, 180^{\circ}$ Azimuth } \\
\hline 7.6133 & 8.0667 & 8.5200 & 8.9733 & 9.4267 & 9.8800 & 10.3333 & 10.7867 & 11.2400 & 11.6933 & 12.1467 & 12.6000 & 13.0533 & 13.5067 \\
\hline 0.9933 & 0.9933 & 0.9933 & 0.9933 & 0.9936 & 0.9936 & 0.9936 & 09935 & 09932 & 09927 & 0.9923 & 0.9908 & 09886 & 09854 \\
\hline 0.9899 & 0.9903 & 0.9905 & 0.9907 & 0.9912 & 0.9914 & 0.9916 & 0.9915 & 0.9914 & 0.9913 & 0.9909 & 0.9893 & 0.9865 & 0.9814 \\
\hline 0.9847 & 0.9852 & 0.9857 & 0.9861 & 0.9867 & 0.9871 & 0.9874 & 0.9874 & 0.9877 & 0.9873 & 0.9869 & 0.9852 & 0.9818 & 0.9762 \\
\hline 0.9810 & 0.9817 & 0.9820 & 0.9816 & 0.9828 & 0.9832 & 0.9837 & 0.9836 & 0.9838 & 0.9839 & 0.9836 & 0.9813 & 0.9777 & 0.9713 \\
\hline 0.9743 & 0.9754 & 0.9763 & 0.9768 & 0.9779 & 0.9786 & 0.9795 & 0.9798 & 0.9806 & 0.9809 & 0.9806 & 0.9784 & 0.9738 & 0.9667 \\
\hline 0.9707 & 0.9716 & 0.9732 & 0.9742 & 0.9754 & 0.9763 & 0.9772 & 0.9778 & 0.9788 & 0.9792 & 0.9796 & 0.9776 & 0.9731 & 0.9650 \\
\hline 0.9625 & 0.9628 & 0.9639 & 0.9655 & 0.9672 & 0.9685 & 0.9695 & 0.9705 & 0.9715 & 0.9728 & 0.9741 & 0.9727 & 0.9671 & 0.9568 \\
\hline 0.9599 & 0.9608 & 0.9611 & 0.9611 & 0.9624 & 0.9645 & 0.9663 & 0.9674 & 0.9688 & 0.9703 & 0.9720 & 0.9717 & 0.9651 & 0.9527 \\
\hline 0.9515 & 0.9549 & 0.9563 & 0.9559 & 0.9567 & 0.9579 & 0.9598 & 0.9614 & 0.9642 & 0.9662 & 0.9683 & 0.9667 & 0.9604 & 0.9496 \\
\hline 0.9419 & 0.9479 & 0.9511 & 0.9527 & 0.9536 & 0.9530 & 0.9542 & 0.9556 & 0.9582 & 0.9611 & 0.9646 & 0.9640 & 0.9567 & 0.9444 \\
\hline 0.9302 & 0.9403 & 0.9466 & 0.9497 & 0.9527 & 0.9529 & 0.9527 & 0.9524 & 0.9545 & 0.9579 & 0.9627 & 0.9636 & 0.9590 & 0.9459 \\
\hline 0.8923 & 0.9151 & 0.9287 & 0.9368 & 0.9424 & 0.9456 & 0.9473 & 0.9475 & 0.9473 & 0.9491 & 0.9542 & 0.9568 & 0.9531 & 0.9373 \\
\hline 0.8461 & 0.8906 & 0.9119 & 0.9248 & 0.9339 & 0.9394 & 0.9433 & 0.9453 & 0.9456 & 0.9458 & 0.9493 & 0.9525 & 0.9503 & 0.9332 \\
\hline 0.6697 & 0.8320 & 0.8791 & 0.9043 & 0.9196 & 0.9288 & 0.9360 & 0.9411 & 0.9441 & 0.9454 & 0.9471 & 0.9492 & 0.9452 & 0.9237 \\
\hline 0.2727 & 0.6084 & 0.8090 & 0.8651 & 0.8962 & 0.9125 & 0.9235 & 0.9331 & 0.9387 & 0.9436 & 0.9477 & 0.9485 & 0.9439 & 0.9233 \\
\hline 0.2868 & 0.2646 & 0.5602 & 0.7952 & 0.8577 & 0.8872 & 0.9070 & 0.9195 & 0.9289 & 0.9365 & 0.9440 & 0.9481 & 0.9449 & 0.9277 \\
\hline 0.3032 & 0.2776 & 0.2610 & 0.5655 & 0.7884 & 0.8478 & 0.8823 & 0.9002 & 0.9148 & 0.9244 & 0.9333 & 0.9423 & 0.9436 & 0.9260 \\
\hline 0.3239 & 0.2967 & 0.2752 & & 0.5274 & 0.7708 & 0.8365 & 0.8718 & 0.8940 & 0.9103 & 0.9223 & 0.9329 & 0.9424 & 0.9272 \\
\hline 0.3458 & 0.3168 & 0.2939 & 0.2713 & 0.2581 & 0.5230 & 0.7612 & 0.8335 & 0.8692 & 0.8926 & 0.9133 & 0.9249 & 0.9385 & 0.9310 \\
\hline 0.3649 & 0.3340 & 0.3098 & 0.2868 & 0.2674 & 0.2523 & 0.5161 & 0.7513 & 0.8243 & 0.8643 & 0.8901 & 0.9092 & 0.9262 & 0.9306 \\
\hline 0.3930 & 0.3597 & 0.3336 & 0.3084 & 0.2879 & 0.2670 & 0.2525 & 0.4267 & 0.7164 & 0.8052 & 0.8552 & 0.8847 & 0.9120 & 0.9334 \\
\hline 0.4153 & 0.3800 & 0.3525 & 0.3259 & 0.3042 & 0.2821 & 0.2645 & 0.2523 & 0.4387 & 0.7317 & 0.8165 & 0.8644 & 0.8982 & 0.9303 \\
\hline 0.4389 & 0.4017 & 0.3726 & 0.3449 & 0.3216 & 0.2982 & 0.2791 & 0.2605 & 0.2495 & 0.4833 & 0.7500 & 0.8287 & 0.8764 & 0.9218 \\
\hline 0.4696 & 0.4308 & 0.3992 & 0.3686 & 0.3441 & 0.3190 & 0.2996 & 0.2787 & 0.2614 & 0.2522 & 0.4625 & 0.7555 & 0.8412 & 0.9056 \\
\hline 0.5115 & 0.4688 & 0.4349 & 0.4016 & 0.3749 & 0.3477 & 0.3260 & 0.3038 & 0.2849 & 0.2677 & 0.2588 & 0.4738 & 0.7759 & 0.8864 \\
\hline 0.5631 & 0.5154 & 0.4781 & 0.4421 & 0.4121 & 0.3821 & 0.3583 & 0.3338 & 0.3137 & 0.2941 & 0.2788 & 0.2672 & 0.5185 & 0.8474 \\
\hline 0.6477 & 0.5935 & 0.5505 & 0.5083 & 0.4752 & 0.4400 & 0.4132 & 0.3851 & 0.3611 & 0.3386 & 0.3224 & 0.3034 & 0.2936 & 0.6603 \\
\hline 1.0060 & 0.9217 & 0.8550 & 0.7893 & 0.7367 & 0.6831 & 0.6404 & 0.5977 & 0.5594 & 0.5255 & 0.4992 & 0.4707 & 0.4466 & 0.4280 \\
\hline
\end{tabular}


Table A3a. PAR $0^{\circ}$ Azimuth normalized (by $P_{c}$ ) wall pressures as presented in figure 20a. Diffuser inlet 127 mm downstream.

\begin{tabular}{|c|c|c|c|c|c|c|c|c|c|c|c|c|c|c|c|c|c|c|}
\hline \multirow[b]{2}{*}{ NPR } & \multirow[b]{2}{*}{$\begin{array}{c}\text { Nozzle } \\
\text { Prtota (psia) }_{1}\end{array}$} & \multirow[b]{2}{*}{ 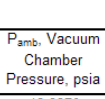 } & \multicolumn{16}{|c|}{$\mathrm{x} / \mathrm{r}^{\star}, 0^{\circ}$ Azimuth } \\
\hline & & & 0.1333 & 0.5867 & 1.0400 & 1.4933 & 1.9467 & 2.4000 & 2.8533 & 3.3067 & 3.7600 & 4.2133 & 4.6667 & 5.1200 & 5.5733 & 6.0267 & 6.4800 & 6.9333 \\
\hline $\begin{array}{l}11: \\
13\end{array}$ & $\frac{142.926}{150.081}$ & $\frac{12.8370}{11.4430}$ & $4.378 E-0$ & & & & & & & & & & & & & & & $\begin{array}{l}355--02 \\
55 F-02\end{array}$ \\
\hline$\frac{13}{15}$ & $\begin{array}{l}150.08078 \\
150.078\end{array}$ & $\begin{array}{l}17.4430 \\
9.9045 \\
\end{array}$ & 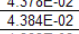 & & & & & & & $\frac{7.37}{6.34}$ & & & & & & & & $\frac{1.495-02}{6.449 E-02}$ \\
\hline & $\begin{array}{l}150.124 \\
150.184\end{array}$ & 8.7265 & $4,378 E-0$ & & & 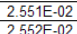 & $163 E-07$ & $178:$ & $62950-0$ & 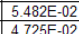 & $17 E_{0}$ & & Q94E- & & & & 6 6E-02 & 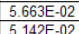 \\
\hline$\frac{10}{2}$ & $\begin{array}{l}150.164 \\
150.166\end{array}$ & $\begin{array}{l}8.000 \\
7.2935 \\
\end{array}$ & $4.5100-$ & 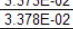 & & & $105 E=0.0$ & & $6395=0$ & $\begin{array}{l}1.467 \mathrm{E} \\
\end{array}$ & - & & & & & & & \\
\hline & 150.158 & 6.6945 & 4.366E--0 & & & & & & $E-02$ & 1460 & & & & & & & & \\
\hline$\frac{23.6}{27.3}$ & $\begin{array}{l}155.24 \\
150.289\end{array}$ & $\begin{array}{l}6.3730 \\
5.5140\end{array}$ & 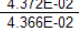 & & & & & & 64 & $\frac{1.406 \mathrm{E}-\mathrm{E}-\mathrm{C}}{1.0}$ & & 119 & 110 & & & & & E- \\
\hline 30.2 & 150.343 & 4.9820 & $4.363 E-02$ & $3.366 \mathrm{E}-02$ & $2.941 \mathrm{E}-02$ & $560 \mathrm{E}-0$ & $2.164 E-02$ & $1.766 E-02$ & $1.650 E-02$ & $1.462 \mathrm{E}-\mathrm{c}$ & $1.324 \mathrm{E}-0$. & $1.200 \mathrm{E}-0$ & $1.106 \mathrm{E}-0$ & $1.028 \mathrm{E}-$ & $611 \mathrm{E}-$ & $\frac{99 \mathrm{E}-0}{2}$ & $9.073 \mathrm{E}-03$ & $1.905 E-02$ \\
\hline $\begin{array}{l}35.8 \\
33.3\end{array}$ & $\begin{array}{l}150.299 \\
1502.217\end{array}$ & 4.2005 & $\begin{array}{l}4.368 E-02 \\
4.363 E-02\end{array}$ & $\begin{array}{l}3.387 E-0-0 \\
3.325 E-0\end{array}$ & 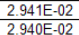 & . & $\frac{2.164 E-02}{2166 E E}$ & $\frac{1.788 E-02}{1.78 E-02}$ & $\begin{array}{ll}1.648 E-02 \\
1.649 E-0.0\end{array}$ & $\frac{1}{1462-02}$ & $13426-0$ & 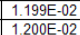 & $\frac{10}{1060-0}$ & $\mid$ & $\frac{50.000-0}{969-0}$ & D7E-0. & $\frac{6.005}{8661-}$ & $301 E-0$ \\
\hline & 150.362 & 3.4975 & $4.373 \mathrm{E}-02$ & & & ne & & 1788 & & 1462 & 102 & 1409 & $1.106 \mathrm{E}-\mathrm{C}$ & 1.02 & $9.617 E--0$ & & & 0250 \\
\hline $\begin{array}{l}46.7 \\
507\end{array}$ & & $\begin{array}{r}3.2205 \\
2.0650\end{array}$ & $\begin{array}{l}4.366-02 \\
4345 E-02\end{array}$ & $\begin{array}{l}3.387 E-02 \\
3.325 E-0\end{array}$ & $\begin{array}{l}9.940 E-02 \\
0.040 E=02\end{array}$ & 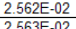 & $\begin{array}{l}2.167 \bar{E}-02 \\
210.5=0\end{array}$ & $\begin{array}{c}1.788 E-02 \\
1770\end{array}$ & \begin{tabular}{|l|l|}
$1.648 E-02$ \\
$1646 E$
\end{tabular} & 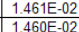 & $\frac{1.325 \mathrm{E}-02}{1325-02}$ & $\begin{array}{l}1.2000-02 \\
1200 E-0.0\end{array}$ & $\begin{array}{l}\frac{1.107 E-02}{11006 E} \\
1\end{array}$ & \begin{tabular}{|l|}
$1.027 \mathrm{E}$ \\
10282
\end{tabular} & $\frac{9.622 \mathrm{E}-0}{9625-0}$ & 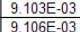 & $8660 \mathrm{E}-$ & $\begin{array}{l}8.298 \mathrm{E}-0 \\
300\end{array}$ \\
\hline 0.1 & $\begin{array}{l}150.250 \\
50.18\end{array}$ & $\begin{array}{l}2.20000 \\
2.7845\end{array}$ & $\begin{array}{l}4.352 \\
4.384 E-02\end{array}$ & $3.376 \mathrm{E}-02$ & 932E-02 & $5554-6$ & $2.163 E-02$ & $1.783 \mathrm{E}-02$ & $1.641 \mathrm{E}-02$ & $1.462 E-02$ & 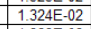 & 100 & $1.114 \mathrm{E}-0$ & & $9.588 \mathrm{E}-0$ & ono & S & 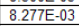 \\
\hline 57.1 & $\frac{150.195}{1150.323}$ & $\frac{2.6315}{2.4757}$ & $\begin{array}{l}4.385 E-02 \\
4\end{array}$ & $\begin{array}{l}3.384 E-0-0 \\
3388 E-0\end{array}$ & $.929 \mathrm{E}-02$ & $\begin{array}{l}551 E-0 \\
561 E-0\end{array}$ & $\begin{array}{l}2.165 E-02 \\
2\end{array}$ & $\frac{1.781 E-02}{1.7875}$ & $\begin{array}{ll}1.6411--02 \\
1.6025\end{array}$ & 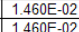 & $\frac{1.323 E=-0}{1325 E-0}$ & $\frac{1.207 \mathrm{E}-0}{1200 \mathrm{E}-0}$ & $\begin{array}{c}1.113 \mathrm{E}-0 \\
1106-2\end{array}$ & \begin{tabular}{|l|l|}
$1.026 \mathrm{E}$ \\
1
\end{tabular} & $\frac{588 \mathrm{E}-0}{618 \mathrm{E}-0}$ & $9.102 \mathrm{E}-0$ & $\begin{array}{c}E-03 \\
E=03\end{array}$ & \begin{tabular}{|l|l|}
$8.276 E-0$ \\
3.30115
\end{tabular} \\
\hline 1 & 150.217 & 2.3990 & oucto & & & & & & & & & & & & & & & \\
\hline & & & & & & & & & & & & & & & & & & \\
\hline
\end{tabular}
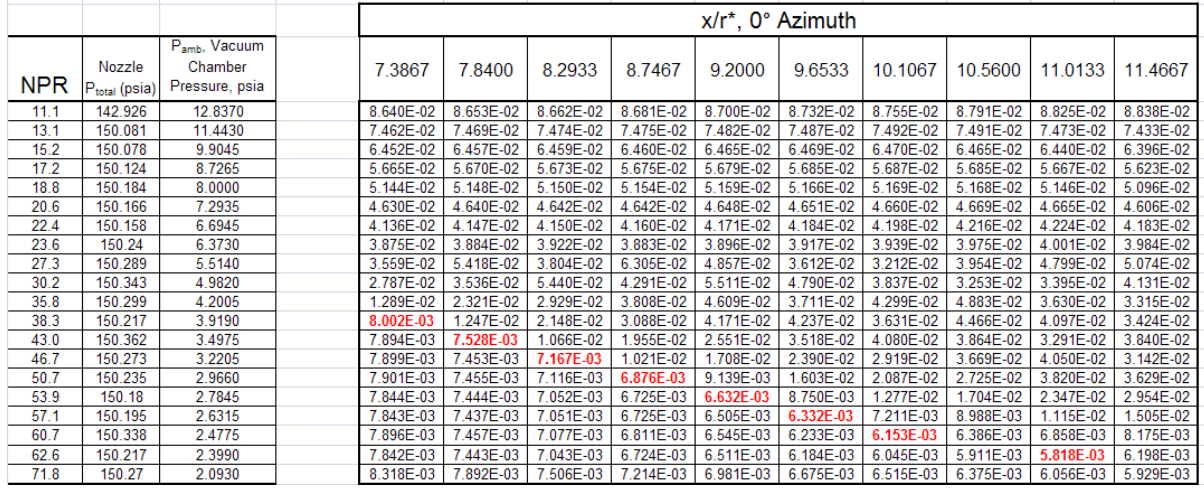

Table A3b. PAR 0 $0^{\circ}$ Azimuth normalized (by $\mathbf{P}_{\mathrm{amb}}$ ) wall pressures as presented in figure $20 \mathrm{~b}$. Diffuser inlet 127 mm downstream.

\begin{tabular}{|c|c|c|c|c|c|c|c|c|c|c|c|c|c|c|c|c|c|c|}
\hline \multirow[b]{2}{*}{ NPR } & \multirow[b]{2}{*}{$\begin{array}{c}\text { Nozzle } \\
P_{\text {total }}(p s i a)\end{array}$} & \multirow[b]{2}{*}{$\begin{array}{c}P_{\text {amb }}, \text { Vacuum } \\
\text { Chamber } \\
\text { Pressure, psia }\end{array}$} & \multicolumn{16}{|c|}{$x / r^{*}, 0^{\circ}$ Azimuth } \\
\hline & & & 0.1333 & 0.5867 & 1.0400 & 1.4933 & 1.9467 & 2.4000 & 2.8533 & 3.3067 & 3.7600 & 4.2133 & 4.6667 & 5.1200 & 5.5733 & 6.0267 & 6.4800 & 6.9333 \\
\hline 111.13 & 142.926 & 12.8370 & 0.4881 & 0.3762 & 0.3278 & 0.8736 & 0.9065 & 2 & 0.9481 & 0.9535 & 0.9554 & 0.9597 & 0 & 0.9598 & 0.9605 & 14 & 18 & 14 \\
\hline 13.12 & 15 & & \begin{tabular}{|l}
0.57 \\
\end{tabular} & & 0.38 & 0.33 & 0.9 & & & & & & 0.9743 & 0. & & & & 83 \\
\hline 15.15 & 1 & 9. & 0.6642 & 0.5118 & 0.4444 & 0.3866 & 0.33 & 0 & 0.9 & 16 & 0.9672 & 0.9716 & 0.9738 & 0.9 & 49 & 0.9757 & 0.9767 & 71 \\
\hline 17.20 & 150.124 & & 0.7540 & \multirow{5}{*}{\multicolumn{3}{|c|}{$\begin{array}{l}1 / 20 / 10 \\
5 / 17,22 \text { and } 4 / 3 \text { data } \\
\text { THis is the } 0 \text { deg azimuth data }\end{array}$}} & $\begin{array}{l}0.3722 \\
\end{array}$ & 0.3085 & 0.8967 & 0.9431 & 0.9561 & 0.9642 & 0.9684 & 0.9698 & 0.9712 & 0.9722 & 0.9732 & 0.9742 \\
\hline 18.77 & 150.184 & & 0.8219 & & & & 0.4060 & 0.3348 & & 0.8870 & 0.9333 & & 0.9563 & 0.9593 & & 0.9635 & & 0.9653 \\
\hline 20.59 & 150.1 & & \begin{tabular}{|l}
0.0219 \\
\end{tabular} & & & & 0.40055 & 0.3 & & 0.3 & 0.8439 & 0.5 & 0.9 & & & & & 0.9528 \\
\hline 22.43 & 150.158 & 6.65 & & & & & 0.4853 & $0.3 \mathrm{~g}$ & 0.3 & 0.3274 & 0.2971 & & 0.8465 & 0.8946 & & & & $\frac{520}{258}$ \\
\hline 23.57 & 150.240 & 6.3730 & 1.0306 & & & & 0.5101 & 0.4212 & 0.3884 & 0.3443 & 0.3119 & 0.3066 & 0.6435 & 0.8323 & 0.8861 & 0.8996 & 0.9070 & 0.9124 \\
\hline 27.26 & 150.289 & 5.5 & 1.1899 & \multirow{2}{*}{\multicolumn{10}{|c|}{ THis sheet was used to move rows around to get into correct order for cp/paste into sheed to the left $\frac{014}{338}$}} & 0.2800 & 0.2621 & 0.2483 & 0.5531 & 0.7697 \\
\hline 30.18 & 150.343 & & 1.3165 & & & & & & & & & & & 0.3101 & 0.2 & 0.2746 & 0.2738 & 0.5749 \\
\hline 35.78 & 150.299 & 4. & 1.5629 & 1.2120 & 1.0525 & 0.9156 & 0.7742 & 0.6397 & 0.5897 & 0.5226 & 0.4738 & \begin{tabular}{|l|l}
0.4290 \\
\end{tabular} & \begin{tabular}{|l}
0.3954 \\
\end{tabular} & 0.3676 & 0.3438 & 0.3254 & 0.3102 & 0.2973 \\
\hline 38.33 & 150.217 & & & 1.2 & 1.1271 & 0.9819 & 0.8301 & 0.6854 & & & & 0.4598 & 0.4241 & 0.3940 & & & \begin{tabular}{|l}
0.3320 \\
\end{tabular} & 0.3182 \\
\hline 42.99 & 150.362 & & 1.8802 & 1.4 & 1.2640 & 1.10 & 0.93 & 0.7 & 0.7 & 0.6 & 0.5 & 0.5 & 0.4 & 0.4 & 0.4 & 0.3 & $\begin{array}{l}0.3731 \\
\end{array}$ & 0.3565 \\
\hline 46.66 & 150.273 & 3.2205 & 2.0373 & 1.5805 & 1.3718 & 1.1955 & 1.0110 & 0.83 & 0.7 & 0.6816 & 0.6182 & 0.5599 & 0.51 & & & 0.4248 & 0.4037 & 0.3872 \\
\hline 50.65 & 150.235 & & 2.2107 & 1.7138 & 1.4892 & 1.2980 & 1.0968 & 0.90 & 0.8 & 0.7397 & & & 0.56 & 0.5 & 0.4 & 0.4612 & 0.4386 & 0.4204 \\
\hline 53.93 & 150.180 & & 2.36 & & 1.5 & 1.3 & 1.16 & 0.96 & & 0.7883 & & & 0.60 & 0.5538 & 0.5171 & 0.4 & 0.4741 & 0.4464 \\
\hline 57.08 & 150.195 & 2.6315 & \begin{tabular}{|l}
2.5028 \\
\end{tabular} & 1.9 & 1.6717 & 1.4 & 1.2358 & 1.0 & 0.9 & 0.8334 & 0.7 & 0.6890 & 0.6354 & 0.5856 & 0.5472 & 0.5195 & 0.5012 & 0.4724 \\
\hline m & 15 & & \begin{tabular}{|l|}
2.65 \\
\end{tabular} & 2.0 & 1.7 & 1.5 & & & & 0.8 & 0 & & & & & 0. & 0.5247 & 0.5037 \\
\hline 62.62 & & & 2.7 & & & 1.5 & & & & 0.9150 & 0.8291 & & 0.6974 & 0.6432 & 0.6003 & 0.5702 & 0.5498 & 0.5181 \\
\hline 71.80 & 150.270 & 2.0930 & $\begin{array}{l}3.1667 \\
\end{array}$ & 2.4611 & 2.1414 & 1.8686 & 1.5848 & 1.3125 & 1.2136 & 1.0784 & 0.9809 & 0.8906 & 0.8237 & 0.7688 & 0.7210 & 0.6842 & 0.6522 & 0.6264 \\
\hline
\end{tabular}
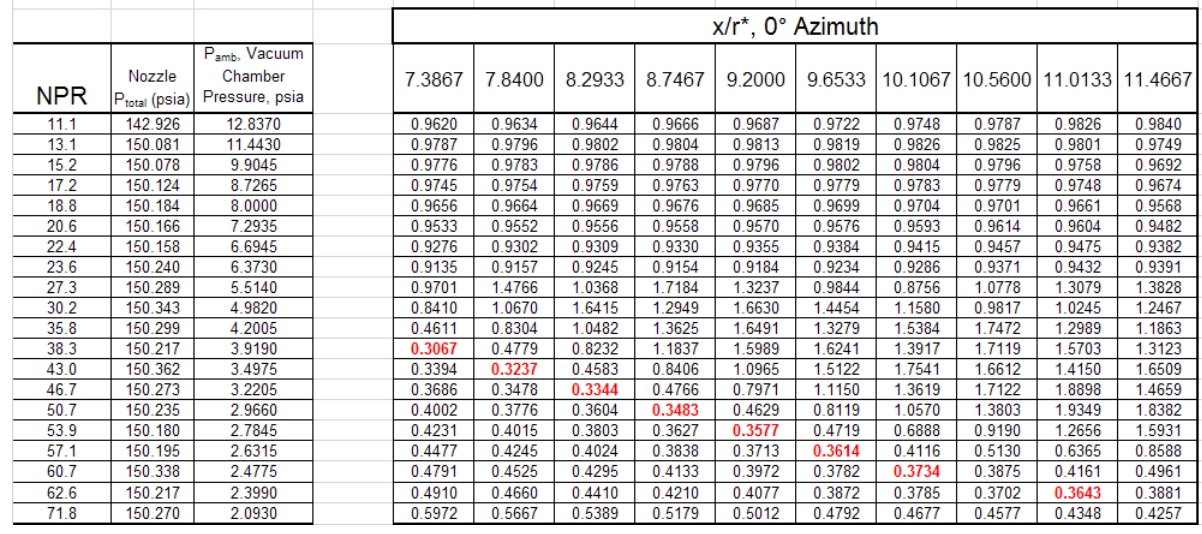

46

American Institute of Aeronautics and Astronautics 
Table A4a. PAR 180 ${ }^{\circ}$ Azimuth normalized (by $P_{c}$ ) wall pressures as presented in figure 21a. Diffuser inlet 127 mm downstream.

\begin{tabular}{|c|c|c|c|c|c|c|c|c|c|c|c|c|c|c|c|c|c|c|}
\hline \multirow[b]{2}{*}{ NPR } & \multirow[b]{2}{*}{$\begin{array}{c}\text { Nozzle } \\
P_{\text {total }}(\mathrm{psia})\end{array}$} & \multirow[b]{2}{*}{$\begin{array}{c}\text { Pamb, Vacuum } \\
\text { Chamber } \\
\text { Pressure, psia }\end{array}$} & \multicolumn{16}{|c|}{$\mathrm{x} / \mathrm{r}^{*}, 180^{\circ}$ Azimuth } \\
\hline & & & 0.3600 & 0.8133 & 1.2667 & 1.7200 & 2.1733 & 2.6267 & 3.0800 & 3.5333 & 3.9867 & 4.4400 & 4.8933 & 5.3467 & 5.8000 & 6.2533 & 6.7067 & 7.1600 \\
\hline 11.0 & 141.393 & 12.8490 & 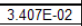 & & $2.682 \mathrm{E}-\mathrm{C}$ & 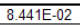 & $700-$ & 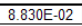 & 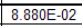 & 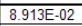 & 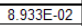 & 0 & $8.948 \mathrm{E}-02$ & $8.946 \mathrm{E}-02$ & $8.951 \mathrm{E}-02$ & 2 & 02 & $8.952 \mathrm{E}-02$ \\
\hline 13.7 & & & & & & & & & & & & & & & & & & \\
\hline 16.0 & 150.25 & 9 & & & 2.747 & & & 5. & & & & & & & & & & $\mathrm{E}-\mathrm{O}$ \\
\hline 18.5 & 150.188 & & 3.403 & & & 2.36 & & 02 & & & & \begin{tabular}{|l}
$5.146 \mathrm{E}-02$ \\
\end{tabular} & 5.1 & & \begin{tabular}{|l}
$5.187 \mathrm{E}-02$ \\
\end{tabular} & $191 \mathrm{E}-02$ & $93 \mathrm{E}-02$ & Fo \\
\hline 19.8 & 150.285 & & $3.420 \mathrm{E}$ & $3.113 \mathrm{E}-02$ & 2.747 & $2.374 \mathrm{E}-02$ & $2.032 \mathrm{E}-02$ & $1.771 \mathrm{E}-02$ & \begin{tabular}{|c|}
$1.570 \mathrm{E}-02$ \\
\end{tabular} & \begin{tabular}{|l|l|}
4.329 \\
\end{tabular} & $4.662 \mathrm{E}-02$ & $4.749 \mathrm{E}-02$ & $4.792 \mathrm{E}-02$ & 4.81 & $4.829 \mathrm{E}-02$ & $4.831 \mathrm{E}-02$ & $4.831 \mathrm{E}-02$ & $4.835 \mathrm{E}-02$ \\
\hline 21.4 & 150.315 & & $3.408 \mathrm{E}$ & $3.105 \mathrm{E}-02$ & 2.704 & $2.365 \mathrm{E}-02$ & $2.034 \mathrm{E}-02$ & $1.770 \mathrm{E}-02$ & \begin{tabular}{|l|l}
$1.570 \mathrm{E}-02$ \\
\end{tabular} & $1.40 \mathrm{~s}$ & $3.559 \mathrm{E}-02$ & $4.139 \mathrm{E}-02$ & 4.26 & 4.31 & $4.351 \mathrm{E}-02$ & $4.361 \mathrm{E}-02$ & $4.363 \mathrm{E}-02$ & $4.370 \mathrm{E}-02$ \\
\hline 22.7 & 46 & & 3.40 & 3.10 & & 2.36 & & 1.76 & & & 1.28 & $3.043 \mathrm{E}-02$ & & & & & 4.024E-02 & $4.040 \mathrm{E}-02$ \\
\hline 24.7 & 15 & & & & & 2.36 & & & & & & & & & & & & $4.270 \mathrm{E}-02$ \\
\hline 27.6 & 150.2 & & 3.414 & & & & & 1.77 & & & $1.271 \mathrm{E}-02$ & $1.159 \mathrm{E}-02$ & & & & & $2.214 \mathrm{E}-02$ & \begin{tabular}{|l|l}
$2.879 \mathrm{E}-02$ \\
\end{tabular} \\
\hline 31.9 & 150.3 & & 3.41 & 3.11 & 2.75 & 2.373 & & 1.77 & \begin{tabular}{|l|}
$1.566 E-0 L$ \\
$1.566 \mathrm{E}-02$
\end{tabular} & \begin{tabular}{|l}
1.40 \\
1.40
\end{tabular} & $\begin{array}{l}1.2717 \mathrm{E}-02 \\
1.276\end{array}$ & \begin{tabular}{|l|l|}
$1.15 E-0 L$ \\
$1.163 E-02$
\end{tabular} & 1.07 & & \begin{tabular}{|l|l|}
9.412 \\
\end{tabular} & \begin{tabular}{|l}
0.93 \\
8.91
\end{tabular} & $\begin{array}{l}8.214 \mathrm{E}-02.03 \\
8.807 \mathrm{E}\end{array}$ & \begin{tabular}{|l|}
$2.019 L-02$ \\
$1.822 E-02$ \\
\end{tabular} \\
\hline 37.9 & $\frac{150.356}{150.321}$ & & $\begin{array}{l}3.416 \\
3.407\end{array}$ & 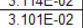 & $\begin{array}{l}2.152 \mathrm{E}-02 \\
2.710 \mathrm{E}-02\end{array}$ & $\begin{array}{l}2.373 \mathrm{E}-02 \\
2.365 \mathrm{E}-02\end{array}$ & $\frac{2.03}{2.02}$ & 1.77 & \begin{tabular}{|l|}
1.56 \\
1.57
\end{tabular} & & $\frac{1.27}{1.273}$ & \begin{tabular}{|l|l|}
1.165 \\
\end{tabular} & $\frac{1.07}{1.07}$ & & \begin{tabular}{|l|}
9.45 \\
9.41
\end{tabular} & \begin{tabular}{|l}
8.91 \\
8.89 \\
\end{tabular} & $8.870 \mathrm{EE}-03$ & \begin{tabular}{|l|}
$1.622 \mathrm{E}-\mathrm{V}-2$ \\
\end{tabular} \\
\hline 40.0 & 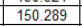 & & 3.41 & & & & & & & & & & & & & & & \begin{tabular}{|l|}
$0.010 E-03$ \\
$8.058 E-03$
\end{tabular} \\
\hline & & & & & & & & & & & & & & & & & & \\
\hline & & & & & & & & & & & & & & & & & & \\
\hline 52.2 & & & & & & & & & & & & & & & & & & \\
\hline 56.9 & 150.2220 & 2.6405 & 3.41 & 3.10 & & 2.36 & & & \begin{tabular}{|l}
1.57 \\
\end{tabular} & & & \begin{tabular}{|l|l|l|}
1.15 \\
\end{tabular} & & & \begin{tabular}{|l|l|}
9.41 \\
\end{tabular} & & 8.45 & 8.008 \\
\hline 63.5 & 150.282 & 2.3675 & $3.412 \mathrm{E}-02$ & $3.105 \mathrm{E}-02$ & $2.708 \mathrm{E}-02$ & $2.366 \mathrm{E}-02$ & $2.036 \mathrm{E}-02$ & $1.772 \mathrm{E}-02$ & \begin{tabular}{|l}
$1.572 \mathrm{E}-02$ \\
\end{tabular} & 1.403E-02 & $1.273 \mathrm{E}-02$ & 1.160E-02 & 1.074 & $1.003 \mathrm{E}-02$ & \begin{tabular}{|l}
$9.416 \mathrm{E}-03$ \\
\end{tabular} & $8.890 \mathrm{E}-03$ & $8.451 \mathrm{E}-03$ & \begin{tabular}{|l|l|}
$8.012 \mathrm{E}-03$ \\
\end{tabular} \\
\hline 67.4 & 150.295 & 2.2300 & $3.420 \mathrm{E}-02$ & $3.113 \mathrm{E}-02$ & $2.752 \mathrm{E}-02$ & $2.377 \mathrm{E}-02$ & $2.035 \mathrm{E}-02$ & $1.773 \mathrm{E}-02$ & \begin{tabular}{|l}
$1.568 \mathrm{E}-02$ \\
\end{tabular} & \begin{tabular}{|l|l}
$1.402 \mathrm{E}-02$ \\
\end{tabular} & $1.278 \mathrm{E}-02$ & \begin{tabular}{|l}
$1.164 \mathrm{E}-02$ \\
\end{tabular} & \begin{tabular}{|l|l}
$1.081 \mathrm{E}-02$ \\
\end{tabular} & $1.006 \mathrm{E}-02$ & \begin{tabular}{|l|}
$9.461 \mathrm{E}-03$ \\
\end{tabular} & $8.922 \mathrm{E}-03$ & $8.490 \mathrm{E}-03$ & \begin{tabular}{|l|l|}
$8.064 \mathrm{E}-03$ \\
\end{tabular} \\
\hline
\end{tabular}
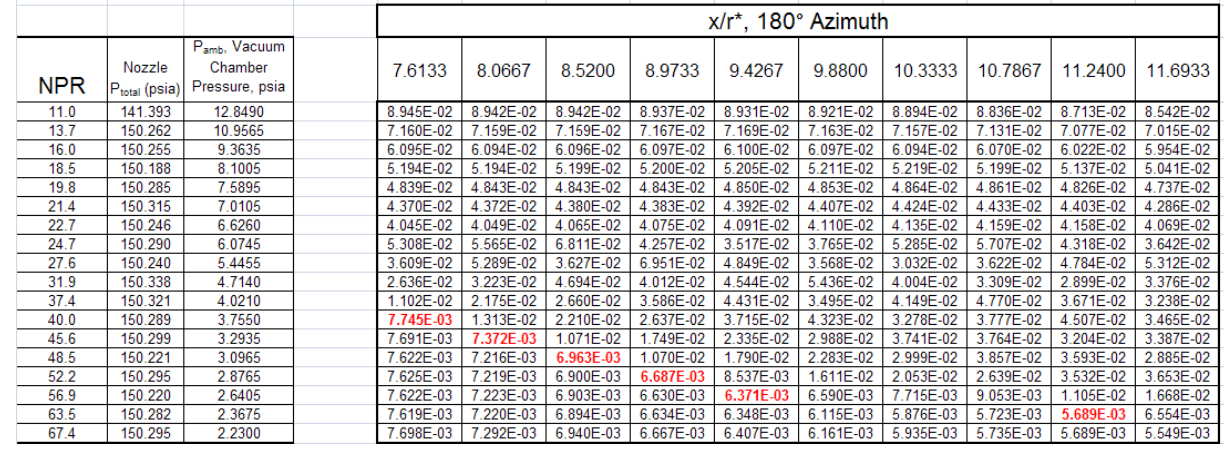

Table A4b. PAR $180^{\circ}$ Azimuth normalized (by $P_{\mathrm{amb}}$ ) wall pressures as presented in figure $21 \mathrm{~b}$. Diffuser inlet $127 \mathrm{~mm}$ downstream.

\begin{tabular}{|c|c|c|c|c|c|c|c|c|c|c|c|c|c|c|c|c|c|c|}
\hline \multirow[b]{2}{*}{ NPR } & \multirow[b]{2}{*}{$\mid \begin{array}{c}\text { Nozzlele } \\
P_{\text {rotal }}\end{array}$} & \multirow[b]{2}{*}{\begin{tabular}{|l} 
Pambo, Vacuum \\
Chamber \\
Pressure, psia
\end{tabular}} & \\
\hline & & & 0.3600 & 8133 & 1.2667 & 1.7200 & 2.1733 & 2.6267 & 3.0800 & 3.5333 & 9867 & 4.4400 & 8933 & |5.3467 & 8000 & 2533 & 6.7067 & 1600 \\
\hline $\begin{array}{l}11.00 \\
13.71\end{array}$ & 141.393 & 12.8490 & \begin{tabular}{|l|l|}
0.3749 \\
\end{tabular} & \begin{tabular}{|l|l|l|l} 
\\
\end{tabular} & \begin{tabular}{|l|l|}
0.2951 \\
\end{tabular} & \begin{tabular}{|l}
0.9289 \\
\end{tabular} & \begin{tabular}{|l|}
0.9581 \\
\end{tabular} & 0.9717 & 0.9772 & 0.9808 & 0.9830 & 0.9842 & 0.9847 & 0.9844 & 0.9850 & 0.9850 & 0.9846 & 0.9851 \\
\hline 16.05 & \begin{tabular}{|l|l|l|c|}
150.255 \\
\end{tabular} & $\begin{array}{r}10.9565 \\
9.3635 \\
\end{array}$ & $\begin{array}{l}0.4690 \\
0.5479 \\
\end{array}$ & \begin{tabular}{|l|}
0.4276 \\
0.5000 \\
\end{tabular} & \begin{tabular}{|l|l|}
0.3773 \\
0.4408 \\
\end{tabular} & \begin{tabular}{|l|} 
\\
0.3298 \\
\end{tabular} & \begin{tabular}{|l|}
0.9422 \\
0.3284 \\
\end{tabular} & \begin{tabular}{|l}
0.9280 \\
\end{tabular} & $\begin{array}{l}0.9683 \\
0.9550 \\
\end{array}$ & 0.9637 & 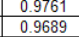 & $\begin{array}{l}0.9979 \\
0.9720\end{array}$ & \begin{tabular}{|l}
0.9744 \\
\end{tabular} & $\begin{array}{l}0.902 \\
0.9755\end{array}$ & 0.9762 & \begin{tabular}{|l|}
0.9811 \\
0.9766 \\
\end{tabular} & $\frac{0.9815}{0.9771}$ & \begin{tabular}{|l|l|}
0.9776 \\
\end{tabular} \\
\hline 18.54 & 150.188 & 8.1005 & 0.6309 & \begin{tabular}{|l}
0.5749 \\
\end{tabular} & \begin{tabular}{|l|l|}
0.50006 \\
\end{tabular} & \begin{tabular}{|l}
0.4382 \\
\end{tabular} & 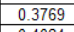 & \begin{tabular}{|l|l|}
0.3281 \\
\end{tabular} & 0.8375 & 0.9292 & \begin{tabular}{|l}
0.9466 \\
\end{tabular} & 0.9541 & \begin{tabular}{|l|l|}
0.9583 \\
\end{tabular} & \begin{tabular}{|l|l}
0.9608 \\
\end{tabular} & 0.9618 & \begin{tabular}{|l|}
0.9625 \\
\end{tabular} & 0.9628 & \\
\hline 19.80 & & & 0.6771 & 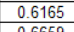 & \begin{tabular}{|l|l|}
0.5440 \\
\end{tabular} & \begin{tabular}{|l|l|}
0.4701 \\
0.600 \\
\end{tabular} & 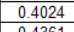 & & 0.3108 & & & 0.9404 & & & & & & \\
\hline $\begin{array}{l}21.44 \\
2268\end{array}$ & 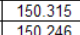 & $\begin{array}{l}7.0105 \\
66260\end{array}$ & $\begin{array}{l}0.7306 \\
0.772\end{array}$ & \begin{tabular}{|l|}
0.6659 \\
0
\end{tabular} & \begin{tabular}{|l|l|}
0.5798 \\
\end{tabular} & \begin{tabular}{|l|}
0.5071 \\
\end{tabular} & \begin{tabular}{|l|}
0.4361 \\
\end{tabular} & \begin{tabular}{|l|l|}
0.3794 \\
\end{tabular} & 0.3366 & \begin{tabular}{|l|l|}
0.3021 \\
03717
\end{tabular} & \begin{tabular}{|l|l|}
0.7631 \\
\end{tabular} & 0.8874 & 0.9135 & \begin{tabular}{|l|l|} 
& .9255 \\
\end{tabular} & 0.9329 & \begin{tabular}{|l|}
0.9350 \\
\end{tabular} & 0.9355 & 0.9370 \\
\hline 2474 & $\frac{150.246}{15020}$ & 6.6260 & 0.7724 & \begin{tabular}{|l|}
0.7042 \\
\end{tabular} & \begin{tabular}{|l|}
0.6141 \\
\end{tabular} & \begin{tabular}{|l|}
0.5364 \\
\end{tabular} & \begin{tabular}{|l|l|}
0.4615 \\
\end{tabular} & \begin{tabular}{|l|}
0.4011 \\
\end{tabular} & 0.3562 & 0.3178 & \begin{tabular}{|l|}
0.2916 \\
\end{tabular} & 0.6900 & \begin{tabular}{|l|}
0.8515 \\
\end{tabular} & 0.8877 & \begin{tabular}{|l|}
0.9037 \\
\end{tabular} & \begin{tabular}{|l|}
0.9110 \\
61157
\end{tabular} & 0.9125 & 0.9161 \\
\hline $\begin{array}{l}24.74 \\
27.59\end{array}$ & $\begin{array}{l}150.290 \\
1150220\end{array}$ & $\begin{array}{r}6.0745 \\
5.4455\end{array}$ & $\begin{array}{l}0.8416 \\
0.9419\end{array}$ & \begin{tabular}{|l}
0.7673 \\
0.8569 \\
\end{tabular} & \begin{tabular}{|l|}
0.6684 \\
0.7778
\end{tabular} & \begin{tabular}{|l|}
0.5857 \\
0.6552 \\
\end{tabular} & \begin{tabular}{|l|}
0.5023 \\
0.563 \\
\end{tabular} & \begin{tabular}{|l|}
0.4377 \\
0.4883 \\
\end{tabular} & $\begin{array}{l}0.3890 \\
0.4330\end{array}$ & $\begin{array}{l}0.3469 \\
0.3687\end{array}$ & \begin{tabular}{|l|l|}
0.3144 \\
0.3506
\end{tabular} & $\begin{array}{l}0.2871 \\
0.3197\end{array}$ & \begin{tabular}{|l|l|}
0.2655 \\
\end{tabular} & \begin{tabular}{|l|l|}
0.2479 \\
0.2796
\end{tabular} & 0.2382 & \begin{tabular}{|l|}
0.6157 \\
02717
\end{tabular} & 0.7584 & 1.0564 \\
\hline$\frac{2.59}{31.89}$ & \begin{tabular}{|l|}
150.240 \\
150.338 \\
\end{tabular} & $\begin{array}{r}\quad .4453 \\
4.7140\end{array}$ & $\begin{array}{l}0.9419 \\
1.0895 \\
\end{array}$ & \begin{tabular}{|l}
0.05932 \\
0.9932 \\
\end{tabular} & \begin{tabular}{|l|l|l|l|}
0.8778 \\
\end{tabular} & \begin{tabular}{|l|}
0.05667 \\
0.7567 \\
\end{tabular} & 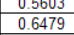 & \begin{tabular}{|l|}
0.48633 \\
0.5649 \\
\end{tabular} & $\begin{array}{l}0.4330 \\
0.4996 \\
\end{array}$ & \begin{tabular}{|l}
0.3677 \\
0.4470
\end{tabular} & 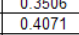 & \begin{tabular}{|l}
0.39197 \\
0.3708 \\
\end{tabular} & \begin{tabular}{|l|}
0.2692 \\
0.3441 \\
\end{tabular} & \begin{tabular}{|l|}
0.2766 \\
0.3205 \\
\end{tabular} & $\frac{0.2597}{0.3017}$ & \begin{tabular}{|l|}
0.242 .2 \\
0.284
\end{tabular} & $\begin{array}{l}0.6110 \\
0.2809 \\
\end{array}$ & \begin{tabular}{|l|}
0.1984 \\
0.5810 \\
\end{tabular} \\
\hline 37. & 150.321 & 4.0210 & 1.2738 & & \begin{tabular}{|l|l|} 
\\
\end{tabular} & 0.8841 & \begin{tabular}{|l|l|}
0.75 \\
\end{tabular} & 0.6623 & 0.5877 & 0.5245 & 0.4760 & 0.4337 & \begin{tabular}{|l|l|}
0.4014 \\
\end{tabular} & 0.3748 & 0.3519 & \begin{tabular}{|l|l|}
0.3325 \\
\end{tabular} & 0.3161 & \begin{tabular}{|l|l|}
0.2994 \\
\end{tabular} \\
\hline 40.02 & 150.289 & 3.7550 & 1.3664 & \begin{tabular}{|l|l}
1.2 \\
1.1
\end{tabular} & \begin{tabular}{|l|l|l|}
1.1004 \\
\end{tabular} & \begin{tabular}{|l|l|}
1.95 \\
\end{tabular} & 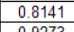 & \begin{tabular}{|l|l}
0.7 \\
\end{tabular} & 0.6277 & 0.5609 & & 0.4658 & 0.4320 & 0.4024 & 0.3787 & & 0.3393 & 0.322 \\
\hline 45.64 & 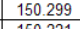 & 3.2935 & 1.5594 & \begin{tabular}{|l|l}
1.4201 \\
\end{tabular} & \begin{tabular}{|l|l|}
1.2558 \\
\end{tabular} & 1.0840 & \begin{tabular}{|l|}
0.9273 \\
\end{tabular} & 0.8083 & 0.7144 & 0.6394 & \begin{tabular}{|l|l|}
0.5827 \\
\end{tabular} & 0.5310 & \begin{tabular}{|l|l|}
0925 \\
\end{tabular} & 0.4588 & 0.4318 & \begin{tabular}{|l|l|}
0.4069 \\
\end{tabular} & 0.3868 & 3677 \\
\hline$\frac{48.51}{52.25}$ & $\frac{150.221}{11502925}$ & $\begin{array}{r}3.0965 \\
2.8765\end{array}$ & $\begin{array}{l}1.6515 \\
17779\end{array}$ & \begin{tabular}{|l|}
1.5062 \\
16232
\end{tabular} & \begin{tabular}{|l|}
1.3163 \\
14146
\end{tabular} & \begin{tabular}{|l|}
1.1481 \\
12376 \\
\end{tabular} & \begin{tabular}{|l|}
0.9869 \\
1069
\end{tabular} & \begin{tabular}{|l|}
0.8597 \\
\end{tabular} & 0.7628 & $\begin{array}{l}0.6801 \\
07321\end{array}$ & \begin{tabular}{|l|}
0.6175 \\
0.6653
\end{tabular} & $\begin{array}{l}0.5626 \\
0.65059\end{array}$ & \begin{tabular}{|l|}
0.5209 \\
0.5611
\end{tabular} & \begin{tabular}{|l|}
0.4867 \\
$5^{52237}$
\end{tabular} & $\begin{array}{l}0.4570 \\
0.4919\end{array}$ & & 0.4101 & $\begin{array}{l}0.3885 \\
01196\end{array}$ \\
\hline$\frac{52.25}{56.89}$ & \begin{tabular}{|l}
150.295 \\
150.220
\end{tabular} & $\begin{array}{l}2.8655 \\
2.6405\end{array}$ & $\begin{array}{l}1 . / 7 / 9 \\
1.9413\end{array}$ & \begin{tabular}{|l|}
1.6232 \\
1.7686 \\
\end{tabular} & \begin{tabular}{|l|}
1.44146 \\
1.5448 \\
\end{tabular} & 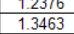 & \begin{tabular}{|l|l|l|l|l|}
1.1577 \\
\end{tabular} & \begin{tabular}{|l|}
0.9244 \\
1.0066 \\
\end{tabular} & $\begin{array}{l}0.829110 \\
0.8930\end{array}$ & \begin{tabular}{|l}
0.721 \\
0.7972 \\
\end{tabular} & \begin{tabular}{|l|}
0.6643 \\
0.7237 \\
\end{tabular} & \begin{tabular}{|l}
0.6559 \\
0.6593
\end{tabular} & \begin{tabular}{|l|}
0.5611 \\
0.6109 \\
\end{tabular} & \begin{tabular}{|l|}
0.5263 \\
0.5703 \\
\end{tabular} & \begin{tabular}{|l|}
0.49919 \\
0.5355 \\
\end{tabular} & \begin{tabular}{|l|}
0.4645 \\
0.5060 \\
\end{tabular} & $\begin{array}{l}0.44815 \\
0.4810\end{array}$ & \begin{tabular}{|l|}
0.4186 \\
0.4556 \\
\end{tabular} \\
\hline $\begin{array}{l}63.48 \\
67.40\end{array}$ & $\frac{150.282}{150202}$ & 2.3675 & 2.1656 & \begin{tabular}{|l|}
1.9709 \\
2090
\end{tabular} & $\begin{array}{l}1.7187 \\
18547\end{array}$ & 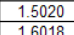 & \begin{tabular}{|l|l}
1.2925 \\
1.3717
\end{tabular} & \begin{tabular}{|l|l|}
1.1248 \\
11994
\end{tabular} & $\begin{array}{l}0.9977 \\
10570\end{array}$ & $\begin{array}{l}0.8904 \\
0948\end{array}$ & 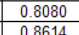 & 0.7362 & \begin{tabular}{|l|l|}
0.6817 \\
072833
\end{tabular} & \begin{tabular}{|l|l|}
0365 \\
0678
\end{tabular} & \begin{tabular}{|l|l|}
0.5977 \\
\end{tabular} & \begin{tabular}{|l|}
0.5643 \\
\end{tabular} & 0.5364 & \begin{tabular}{|l|l|}
0.5086 \\
05436
\end{tabular} \\
\hline & & & & & & & & & & & & & & & & & & \\
\hline
\end{tabular}

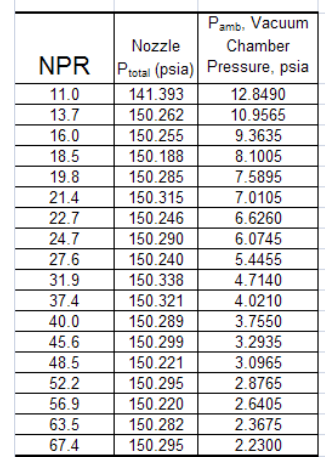

\begin{tabular}{|c|c|c|c|c|c|c|c|c|c|}
\hline \multicolumn{10}{|c|}{$\mathrm{x} / \mathrm{r}^{\star}, 180^{\circ}$ Azimuth } \\
\hline 7.6133 & 8.0667 & 8.5200 & 8.9733 & 9.4267 & 9.8800 & 10.3333 & 10.7867 & 11.2400 & 11.6933 \\
\hline 0.9844 & 0.9840 & 0.9840 & 9834 & 0.9828 & 9816 & 0.9787 & 0.9724 & 0.9588 & $\overline{0.94}$ \\
\hline 0.9820 & 0.9819 & 0.9818 & 0.9830 & 0.9833 & 0.9824 & 0.9816 & 0.9780 & 0.9706 & 007 \\
\hline \begin{tabular}{|l|}
0.9781 \\
0.9630 \\
\end{tabular} & 0.9779 & 0.9782 & \begin{tabular}{|l|l|}
0.9784 \\
0.941
\end{tabular} & 0.9788 & 0.9784 & \begin{tabular}{|l|l|}
0.9779 \\
0.0676
\end{tabular} & 0.9741 & 0.9664 & 0.9554 \\
\hline \begin{tabular}{|l|l|}
0.95603 \\
0.9583
\end{tabular} & $\begin{array}{l}0.9630 \\
0.9500 \\
\end{array}$ & 0.96590 & \begin{tabular}{|l|}
0.9641 \\
0.9591 \\
\end{tabular} & $\begin{array}{l}0.9650 \\
0.9604 \\
\end{array}$ & 0.96611 & \begin{tabular}{|l}
$0.96 / 6$ \\
0.9632 \\
\end{tabular} & \begin{tabular}{|l}
0.9640 \\
0.9626 \\
\end{tabular} & $\begin{array}{l}0.9924 \\
0.9557 \\
\end{array}$ & \begin{tabular}{|l|l|}
0.93460 \\
\end{tabular} \\
\hline & 0.9375 & & 0.9 & 0.9417 & 0.9 & 0.9 & 0.9506 & 0.9440 & \\
\hline & & & & 0.9276 & & & 0.9431 & 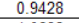 & \\
\hline$\frac{1.3132}{0.095}$ & 1.3769 & 1.6851 & 1.0533 & 0.8702 & 0.9316 & 1.3 & 1.4120 & 1.0682 & $0.9 c$ \\
\hline$\frac{0.9951}{0.8407}$ & $\frac{1.45}{1.20}$ & 1.0006 & $\frac{1.99717}{1.720}$ & 1.3536 & 0.96 & $\frac{0.8360}{1076}$ & \begin{tabular}{|l|l|}
1.99 \\
\end{tabular} & 1.39196 & 1.4 \\
\hline 0.4121 & 0.8132 & 0.9945 & 13405 & 1.6563 & 13066 & 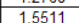 & 1.7834 & 0.9445 & \begin{tabular}{|l|l|}
1.2106 \\
106
\end{tabular} \\
\hline & 0.5257 & 0.8844 & & 1.4868 & 1.7302 & 1.3119 & & 1.8040 & 1.3870 \\
\hline & 0.3364 & 0.4888 & 0.7982 & & & 1.7 & 1.7176 & 1.4623 & 1.5455 \\
\hline 0.3698 & 0.3501 & 0.3378 & 0.5190 & 0.8684 & 1.1077 & 1.4549 & \begin{tabular}{|l}
1.8711 \\
\end{tabular} & 1.7429 & 1.3996 \\
\hline 0.398 & 0.3772 & & 0.3494 & 0.4460 & 0.8420 & 1.0728 & \begin{tabular}{|l}
1.3788 \\
0.51
\end{tabular} & 1.8456 & 9086 \\
\hline \begin{tabular}{|l}
0.4336 \\
0.4836 \\
\end{tabular} & 0.4099 & 0.09376 & 0.4211 & $\begin{array}{l}0.3624 \\
0.4030 \\
\end{array}$ & 0.3748 & \begin{tabular}{|l|l|}
0.43739 \\
03730
\end{tabular} & \begin{tabular}{|l|}
0.5151 \\
0.3633 \\
\end{tabular} & 0.0 .3611 & \begin{tabular}{|l|l|}
0.946 \\
0.416 \\
\end{tabular} \\
\hline & 0.4915 & 0.4677 & 0.4493 & 0.4318 & 0.4152 & 0.4000 & 0.3865 & 0.3834 & 0.374 \\
\hline
\end{tabular}

47

American Institute of Aeronautics and Astronautics 
Table A5a. PAR $0^{\circ}$ Azimuth normalized (by $P_{c}$ ) wall pressures as presented in figure 22a. Diffuser inlet 127 mm downstream.

\begin{tabular}{|c|c|c|c|c|c|c|c|c|c|c|c|c|c|c|c|c|c|c|}
\hline \multirow[b]{2}{*}{ NPR } & \multirow[b]{2}{*}{$\begin{array}{c}\text { Nozzle } \\
P_{\text {totat }} \text { (psia) }\end{array}$} & \multirow[b]{2}{*}{$\begin{array}{l}\text { Pamb, Vacuum } \\
\text { Chamber } \\
\text { Pressure, psia }\end{array}$} & \multicolumn{16}{|c|}{$\mathrm{x} / \mathrm{r}^{\star}, 0^{\circ}$ Azimuth } \\
\hline & & & 0.1333 & 0.5867 & 1.0400 & 1.4933 & 1.9467 & 2.4000 & 2.8533 & 3.3067 & 3.7600 & 4.2133 & 4.6667 & 5.1200 & 5.5733 & 6.0267 & 6.4800 & 6.9333 \\
\hline 12.9 & 150.207 & 11.6750 & $4.382 \mathrm{E}-02$ & \begin{tabular}{|l|}
$3.379 \mathrm{E}-02$ \\
\end{tabular} & $2.929 \mathrm{E}-02$ & $2.553 \mathrm{E}-02$ & $2.167 \mathrm{E}-02$ & \begin{tabular}{|l|}
$1.783 \mathrm{E}-02$ \\
\end{tabular} & 1 1.697E-02 & $2.313 \mathrm{E}-02$ & $3.244 \mathrm{E}-02$ & 4.134E-02 & \begin{tabular}{|l|}
$5.047 \mathrm{E}-02$ \\
\end{tabular} & $8.024 \mathrm{E}-02$ & $7.966 \mathrm{E}-02$ & $6.657 \mathrm{E}-02$ & $7.462 \mathrm{E}-02$ & $7.423 \mathrm{E}-02$ \\
\hline 13.3 & 150.200 & 11.3110 & $4.382 \mathrm{E}-02$ & $3.379 \mathrm{E}-02$ & $2.930 \mathrm{E}-02$ & $2.552 \mathrm{E}-02$ & 2.164E-02 & $1.781 \mathrm{E}-02$ & $1.640 \mathrm{E}-02$ & 1.460E-02 & \begin{tabular}{|l|l|}
$1.326 \mathrm{E}-02$ \\
\end{tabular} & $3.467 \mathrm{E}-02$ & \begin{tabular}{|l|}
$4.130 \mathrm{E}-02$ \\
\end{tabular} & $7.358 \mathrm{E}-02$ & $9.885 \mathrm{E}-02$ & $7.397 \mathrm{E}-02$ & $6.452 \mathrm{E}-02$ & $7.896 \mathrm{E}-02$ \\
\hline 14.4 & 150.173 & 10.4535 & $4.386 \mathrm{E}-02$ & \begin{tabular}{|c|}
$3.377 \mathrm{E}-02$ \\
\end{tabular} & $2.932 \mathrm{E}-02$ & $2.552 \mathrm{E}-02$ & $2.166 \mathrm{E}-02$ & \begin{tabular}{|c|}
$1.784 \mathrm{E}-02$ \\
\end{tabular} & $1.641 \mathrm{E}-02$ & 1.462E-02 & $1.325 \mathrm{E}-02$ & $1.218 \mathrm{E}-02$ & \begin{tabular}{|c|}
$3.604 \mathrm{E}-02$ \\
\end{tabular} & $4.824 \mathrm{E}-02$ & \begin{tabular}{|l|l|}
$9.887 \mathrm{E}-02$ \\
\end{tabular} & $7.920 \mathrm{E}-02$ & $5.263 \mathrm{E}-02$ & \begin{tabular}{|l|l|}
$6.716 \mathrm{E}-02$ \\
\end{tabular} \\
\hline 17.6 & 150.111 & 8.5365 & 4.390E-02 & \begin{tabular}{|l|}
$3.385 \mathrm{E}-02$ \\
\end{tabular} & $2.934 \mathrm{E}-02$ & $2.552 \mathrm{E}-02$ & $2.163 \mathrm{E}-02$ & $1.781 \mathrm{E}-02$ & $1.640 \mathrm{E}-02$ & 1.460E-02 & $1.323 \mathrm{E}-02$ & $1.206 \mathrm{E}-02$ & $1.148 \mathrm{E}-02$ & $3.240 \mathrm{E}-02$ & \begin{tabular}{|l|l|}
$4.265 \mathrm{E}-02$ \\
\end{tabular} & $6.647 \mathrm{E}-02$ & $1.017 \mathrm{E}-01$ & $5.335 \mathrm{E}-02$ \\
\hline 21.3 & 150.078 & 7.0395 & 4.383E-02 & \begin{tabular}{|l|}
$3.381 \mathrm{E}-02$ \\
\end{tabular} & $2.930 \mathrm{E}-02$ & $2.552 \mathrm{E}-02$ & $2.165 \mathrm{E}-02$ & \begin{tabular}{|l|l|}
$1.781 \mathrm{E}-02$ \\
\end{tabular} & $1.640 \mathrm{E}-02$ & $1.461 \mathrm{E}-02$ & \begin{tabular}{|l|l|}
$1.324 \mathrm{E}-02$ \\
\end{tabular} & $1.207 \mathrm{E}-02$ & \begin{tabular}{|l|l|}
$1.114 \mathrm{E}-02$ \\
\end{tabular} & \begin{tabular}{|l|}
$1.031 \mathrm{E}-02$ \\
\end{tabular} & $2.302 \mathrm{E}-02$ & $3.216 \mathrm{E}-02$ & \begin{tabular}{|l|}
$4.807 \mathrm{E}-02$ \\
\end{tabular} & \begin{tabular}{|l|l|}
$6.261 \mathrm{E}-02$ \\
\end{tabular} \\
\hline \multirow[t]{2}{*}{23.3} & 150.312 & 6.4470 & $4.360 \mathrm{E}-02$ & \begin{tabular}{|l|l|}
$3.385 \mathrm{E}-02$ \\
\end{tabular} & $2.943 \mathrm{E}-02$ & $2.562 \mathrm{E}-02$ & $2.165 \mathrm{E}-02$ & 1.788E-02 & $1.648 \mathrm{E}-02$ & $1.461 \mathrm{E}-02$ & $1.323 \mathrm{E}-02$ & $1.200 \mathrm{E}-02$ & \begin{tabular}{|l|}
$1.106 \mathrm{E}-02$ \\
\end{tabular} & $1.027 \mathrm{E}-02$ & \begin{tabular}{|c|}
$9.793 \mathrm{E}-03$ \\
\end{tabular} & $2.701 \mathrm{E}-02$ & $3.216 \mathrm{E}-02$ & $5.428 \mathrm{E}-02$ \\
\hline & & & & \multicolumn{10}{|c|}{$\mathrm{x} / \mathrm{r}^{\star}, 0^{\circ}$ Azimuth } & & & & & \\
\hline NPR & $\begin{array}{c}\text { Nozzle } \\
P_{\text {total }}(\mathrm{psia})\end{array}$ & $\begin{array}{c}P_{\text {amb. }} \text { Vacuum } \\
\text { Chamber } \\
\text { Pressure, psia }\end{array}$ & & 7.3867 & 7.8400 & 8.2933 & 8.7467 & 9.2000 & 9.6533 & 10.1067 & 10.5600 & 11.0133 & |11.4667 & & & & & \\
\hline 12.9 & \begin{tabular}{|l|l|}
150.207 \\
\end{tabular} & 11.6750 & & \begin{tabular}{|l|}
$7.349 \mathrm{E}-02$ \\
\end{tabular} & & $7.372 \mathrm{E}-02$ & $7.316 \mathrm{E}-02$ & $7.390 \mathrm{E}-02$ & 7.394E-02 & $7.463 \mathrm{E}-02$ & $7.516 \mathrm{E}-02$ & $7.518 \mathrm{E}-02$ & \begin{tabular}{|l|}
$7.581 \mathrm{E}-02$ \\
\end{tabular} & & & & & \\
\hline 13.3 & 150.200 & 11.3110 & & $6.740 \mathrm{E}-02$ & $6.965 \mathrm{E}-02$ & $7.313 \mathrm{E}-02$ & $6.803 \mathrm{E}-02$ & $7.390 \mathrm{E}-02$ & $7.106 \mathrm{E}-02$ & 7.295E-02 & $7.286 \mathrm{E}-02$ & $7.254 \mathrm{E}-02$ & $7.320 \mathrm{E}-02$ & & & & & \\
\hline 14.4 & 150.173 & 10.4535 & & \begin{tabular}{|l|}
$7.894 \mathrm{E}-02$ \\
\end{tabular} & $5.593 \mathrm{E}-02$ & $6.684 \mathrm{E}-02$ & $7.198 \mathrm{E}-02$ & \begin{tabular}{|l|l|}
$5.976 \mathrm{E}-02$ \\
\end{tabular} & $7.216 \mathrm{E}-02$ & $6.452 \mathrm{E}-02$ & $6.893 \mathrm{E}-02$ & $6.658 \mathrm{E}-02$ & \begin{tabular}{|l|l|}
$6.821 \mathrm{E}-02$ \\
\end{tabular} & & & & & \\
\hline 17.6 & 150.111 & 8.5365 & & \begin{tabular}{|l|}
$4.268 \mathrm{E}-02$ \\
\end{tabular} & $6.304 \mathrm{E}-02$ & $7.111 \mathrm{E}-02$ & $4.856 \mathrm{E}-02$ & & & $5.721 \mathrm{E}-02$ & $5.554 \mathrm{E}-02$ & $6.379 \mathrm{E}-02$ & & & & & & \\
\hline 21.3 & 150.078 & 7.0395 & & $7.678 \mathrm{E}-02$ & $\begin{array}{l}.0 .994 \mathrm{~L}-02 \\
.02\end{array}$ & $3.909 \mathrm{E}-02$ & 4.127E-02 & \begin{tabular}{|l|}
$5.952 \mathrm{E}-02$ \\
\end{tabular} & $5.808 \mathrm{E}-02$ & $4.516 \mathrm{E}-02$ & \begin{tabular}{|l|}
$4.452 \mathrm{E}-02$ \\
\end{tabular} & $5.405 \mathrm{E}-02$ & \begin{tabular}{|l|}
$5.686 \mathrm{E}-02$ \\
\end{tabular} & & & & & \\
\hline 23.3 & 150.312 & 6.4470 & & \begin{tabular}{|l|}
$5.051 \mathrm{E}-02$ \\
\end{tabular} & 7.641E-02 & $5.658 \mathrm{E}-02$ & $3.738 \mathrm{E}-02$ & \begin{tabular}{|c|}
$3.774 \mathrm{E}-02$ \\
\end{tabular} & $5.320 \mathrm{E}-02$ & $5.982 \mathrm{E}-02$ & 4.837E-02 & $3.942 \mathrm{E}-02$ & \begin{tabular}{|c|}
$4.569 \mathrm{E}-02$ \\
\end{tabular} & & & & & \\
\hline
\end{tabular}

Table A5b. PAR $0^{\circ}$ Azimuth normalized (by $P_{a m b}$ ) wall pressures as presented in figure 22b. Diffuser inlet 127 mm downstream.

\begin{tabular}{|c|c|c|c|c|c|c|c|c|c|c|c|c|c|c|c|c|c|c|}
\hline \\
\hline & & & \multicolumn{16}{|c|}{$\mathrm{x} / \mathrm{r}^{\star}, 0^{\circ}$ Azimuth } \\
\hline NPR & $\mid \begin{array}{c}\text { Nozzle } \\
P_{\text {total }}(\text { psia) }\end{array}$ & $\begin{array}{c}P_{\text {amb }} \text { Vacuum } \\
\text { Chamber } \\
\text { Pressure, psia }\end{array}$ & 0.1333 & 0.5867 & 1.0400 & 1.4933 & 1.9467 & 2.4000 & 2.8533 & 3.3067 & 3.7600 & 4.2133 & 4.6667 & 5.1200 & 5.5733 & 6.0267 & 6.4800 & 6.9333 \\
\hline 12.9 & 150.207 & 11.6750 & 0.5638 & 0.4348 & 0.3768 & 0.3285 & 0.2788 & 0.2294 & 0.2183 & 0.2976 & 0.4173 & 0.5319 & 0.6493 & 1.0323 & 1.0249 & 0.8565 & 0.9600 & 0.9550 \\
\hline 13.3 & 150.200 & 11.3110 & 0.5819 & 0.4488 & 0.3891 & 0.3389 & 0.2874 & 0.2365 & 0.2178 & 0.1939 & 0.1761 & 0.4604 & 0.5484 & 0.9771 & 1.3127 & 0.9823 & 0.8568 & 1.0485 \\
\hline 14.4 & 150.173 & 10.4535 & 0.6301 & 0.4851 & 0.4212 & 0.3667 & 0.3112 & 0.2563 & 0.2358 & 0.2101 & 0.1904 & 0.1750 & 0.5177 & 0.6931 & 1.4203 & 1.1377 & 0.7560 & 0.9647 \\
\hline 17.6 & 150.111 & $\frac{10.4365}{8.535}$ & 0.7720 & 0.5953 & 0.5160 & 0.4488 & 0.3804 & 0.3131 & 0.2884 & 0.2567 & 0.2326 & 0.2121 & 0.2020 & 0.5698 & 0.7500 & 1.1689 & 1.7888 & 0.9382 \\
\hline 21.3 & 150.078 & 7.0395 & 0.9344 & 0.7208 & 0.6248 & 0.5441 & 0.4615 & 0.3797 & 0.3497 & 0.3115 & 0.2823 & 0.2573 & 0.2375 & 0.2199 & 0.4908 & 0.6857 & 1.0248 & 1.3348 \\
\hline \multirow[t]{2}{*}{23.3} & 150.312 & 6.4470 & 1.0164 & 0.7892 & 0.6861 & 0.5973 & 0.5049 & 0.4168 & 0.3842 & 0.3406 & 0.3085 & 0.2797 & 0.2579 & 0.2395 & 0.2283 & 0.6298 & 0.7498 & 1.2655 \\
\hline & & & & \multicolumn{10}{|c|}{$\mathrm{x} / \mathrm{r}^{\star}, 0^{\circ}$ Azimuth } & & & & & \\
\hline NPR & $\left|\begin{array}{c}\text { Nozzle } \\
P_{\text {total }}(\text { psia) }\end{array}\right|$ & $\begin{array}{l}\text { Pamb, Vacuum } \\
\text { Chamber } \\
\text { Pressure, psia }\end{array}$ & & 7.3867 & 7.8400 & 8.2933 & 8.7467 & 9.2000 & 9.6533 & 10.1067 & 10.5600 & 11.0133 & 11.4667 & & & & & \\
\hline 12.9 & 150.207 & 11.6750 & & 0.9454 & 0.9598 & 0.9484 & 0.9412 & 0.9508 & 0.9513 & 0.9602 & 0.9670 & 0.9673 & 0.9753 & & & & & \\
\hline 13.3 & 150.200 & 11.3110 & & 0.8951 & 0.9249 & 0.9711 & 0.9034 & 0.9813 & 0.9436 & 0.9687 & 0.9676 & 0.9633 & 0.9721 & & & & & \\
\hline 14.4 & 150.173 & 10.4535 & & 1.1340 & 0.8035 & 0.9602 & 1.0341 & 0.8586 & 1.0367 & 0.9269 & 0.9903 & 0.9565 & 0.9800 & & & & & \\
\hline 17.6 & 150.111 & 8.5365 & & 0.7504 & 1.1085 & 1.2504 & 0.8539 & 0.9533 & 1.1989 & 1.0060 & 0.9766 & 1.1218 & 1.0334 & & & & & \\
\hline 21.3 & 150.078 & 7.0395 & & 1.6369 & 1.2778 & 0.8334 & 0.8799 & 1.2690 & 1.2382 & 0.9629 & 0.9491 & 1.1522 & 1.2122 & & & & & \\
\hline 23.3 & 150.312 & 6.4470 & & 1.1776 & 1.7816 & 1.3191 & 0.8714 & 0.8799 & 1.2404 & 1.3948 & 1.1278 & 0.9190 & 1.0653 & & & & & \\
\hline
\end{tabular}


Table A6a. PAR 180 ${ }^{\circ}$ Azimuth normalized (by $P_{c}$ ) wall pressures as presented in figure 23a. Diffuser inlet 127 mm downstream.

\begin{tabular}{|c|c|c|c|c|c|c|c|c|c|c|c|c|c|c|c|c|c|c|}
\hline \multirow{2}{*}{\multicolumn{19}{|c|}{$\mathrm{x} / \mathrm{r}^{*}, 180^{\circ}$ Azimuth }} \\
\hline & & & & & & & & & & & & & & & & & & \\
\hline NPR & $\left|\begin{array}{c}\text { Nozzle } \\
P_{\text {total }} \text { (psia) }\end{array}\right|$ & $\begin{array}{l}P_{\text {amb }} \text { Vacuum } \\
\text { Chamber } \\
\text { Pressure, psia }\end{array}$ & 0.3600 & 0.8133 & 1.2667 & 1.7200 & 2.1733 & 2.6267 & 3.0800 & 3.5333 & 3.9867 & 4.4400 & 4.8933 & 5.3467 & 5.8000 & 6.2533 & 6.7067 & 7.1600 \\
\hline 13.03 & 150.199 & 11.5275 & $3.411 \mathrm{E}-02$ & $3.110 \mathrm{E}-02$ & $2.712 \mathrm{E}-02$ & $2.368 \mathrm{E}-02$ & $2.044 \mathrm{E}-02$ & $1.770 \mathrm{E}-02$ & $1.571 \mathrm{E}-02$ & \begin{tabular}{|l|}
$1.401 \mathrm{E}-02$ \\
\end{tabular} & $3.154 \mathrm{E}-02$ & $4.045 \mathrm{E}-02$ & 6.427E-02 & $1.023 \mathrm{E}-01$ & $8.133 \mathrm{E}-02$ & $6.489 \mathrm{E}-02$ & $7.808 \mathrm{E}-02$ & $7.133 \mathrm{E}-02$ \\
\hline 13.74 & 150.178 & 10.9320 & $3.414 \mathrm{E}-02$ & $3.103 \mathrm{E}-02$ & $2.709 \mathrm{E}-02$ & $2.365 \mathrm{E}-02$ & $2.041 \mathrm{E}-02$ & $1.771 \mathrm{E}-02$ & \begin{tabular}{|c|}
$1.571 \mathrm{E}-02$ \\
\end{tabular} & $1.403 \mathrm{E}-02$ & 1.281E-02 & $3.715 \mathrm{E}-02$ & $4.977 \mathrm{E}-02$ & $1.010 \mathrm{E}-01$ & $7.833 \mathrm{E}-02$ & $5.613 \mathrm{E}-02$ & $7.540 \mathrm{E}-02$ & $7.245 \mathrm{E}-02$ \\
\hline 16.28 & 150.217 & 9.2260 & $3.412 \mathrm{E}-02$ & \begin{tabular}{|c|}
$3.108 \mathrm{E}-02$ \\
\end{tabular} & $2.716 \mathrm{E}-02$ & $2.367 \mathrm{E}-02$ & $2.042 \mathrm{E}-02$ & $1.771 \mathrm{E}-02$ & \begin{tabular}{|l|}
$1.571 \mathrm{E}-02$ \\
\end{tabular} & $1.403 \mathrm{E}-02$ & $1.273 \mathrm{E}-02$ & $1.168 \mathrm{E}-02$ & $3.341 \mathrm{E}-02$ & $4.049 \mathrm{E}-02$ & $6.882 \mathrm{E}-02$ & $1.040 \mathrm{E}-01$ & $5.310 \mathrm{E}-02$ & $4.580 \mathrm{E}-02$ \\
\hline $\begin{array}{l}18.20 \\
18.94 \\
\end{array}$ & $\begin{array}{l}150.124 \\
150.124\end{array}$ & 7.9270 & $\begin{array}{l}3.492 \mathrm{E}-02 \\
3.3992 \\
\end{array}$ & \begin{tabular}{|l|}
$3.1002-02$ \\
$.103 E-02$ \\
\end{tabular} & \begin{tabular}{|l|}
$2.706 \mathrm{~L}-02$ \\
2.02 \\
\end{tabular} & $2.368 \mathrm{E}-02$ & $2.042 E-02$ & $1.770 \mathrm{E}-02$ & \begin{tabular}{|l|}
$1.573 \mathrm{E}-02$ \\
1.02 \\
\end{tabular} & \begin{tabular}{|l|l|l}
$.40303 \mathrm{E}-02$ \\
\end{tabular} & $1.274 \mathrm{E}-02$ & $\begin{array}{l}1.1006-02 \\
1.161 E-02 \\
\end{array}$ & $\begin{array}{l}\mid .034 \mathrm{EL}-02 \\
1.084 \mathrm{E}\end{array}$ & $\begin{array}{l}3.4045 \mathrm{~L}-02 \\
3.085 \mathrm{E}-02 \\
\end{array}$ & $\frac{0.002 \mathrm{~L}-02}{3.590 \mathrm{E}-02}$ & \begin{tabular}{|l|}
$6.0278 \mathrm{~L}-01$ \\
\end{tabular} & $\begin{array}{l}8.306 \mathrm{E}-02 \\
8.866 \mathrm{E}\end{array}$ & \begin{tabular}{|l|}
$4.5060 \mathrm{~L}-2 \mathrm{~L}$ \\
$6.60 \mathrm{E}-02$
\end{tabular} \\
\hline \multirow[t]{3}{*}{22.13} & 150.133 & 6.7850 & $3.409 \mathrm{E}-02$ & \begin{tabular}{|l|l|}
$3.106 \mathrm{E}-02$ \\
\end{tabular} & \begin{tabular}{|l|}
$2.708 \mathrm{E}-02$ \\
\end{tabular} & $2.366 \mathrm{E}-02$ & $2.044 \mathrm{E}-02$ & \begin{tabular}{|l|l|}
$1.771 \mathrm{E}-02$ \\
\end{tabular} & \begin{tabular}{|l|l|}
$1.572 \mathrm{E}-02$ \\
\end{tabular} & $1.401 \mathrm{E}-02$ & $1.274 \mathrm{E}-02$ & $1.160 \mathrm{E}-02$ & $1.074 \mathrm{E}-02$ & $1.010 \mathrm{E}-02$ & \begin{tabular}{|l|l|}
$2.688 \mathrm{E}-02$ \\
\end{tabular} & $3.235 \mathrm{E}-02$ & $4.986 \mathrm{E}-02$ & \begin{tabular}{|l|l|l|l|l|l|} 
\\
\end{tabular} \\
\hline & & & & & & & & & & & & & & & & & & \\
\hline & & & & \multicolumn{10}{|c|}{$\mathrm{x} / \mathrm{r}^{*}, 180^{\circ}$ Azimuth } & & & & & \\
\hline NPR & $\begin{array}{c}\text { Nozzle } \\
\text { Ptozal (psia) }\end{array}$ & \begin{tabular}{|l|}
$\begin{array}{c}\text { Pamb, Vacuum } \\
\text { Chamber } \\
\text { Pressure, psia }\end{array}$ \\
\end{tabular} & & 7.6133 & 8.0667 & 8.5200 & 8.9733 & 9.4267 & 9.8800 & 10.3333 & 10.7867 & 11.2400 & 11.6933 & & & & & \\
\hline 13.03 & \begin{tabular}{|l|l|}
150.199 \\
\end{tabular} & 11.5275 & & 6.852E-02 & $7.596 \mathrm{E}-02$ & $6.893 \mathrm{E}-02$ & $7.480 \mathrm{E}-02$ & $7.166 \mathrm{E}-02$ & $7.358 \mathrm{E}-02$ & 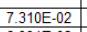 & $7.389 \mathrm{E}-02$ & $7.439 \mathrm{E}-02$ & 7.511E-02 & & & & & \\
\hline 13.74 & 150.178 & 10.9320 & & \begin{tabular}{|l|l|}
$6.131 \mathrm{E}-02$ \\
\end{tabular} & $7.399 \mathrm{E}-02$ & $6.673 \mathrm{E}-02$ & $6.923 \mathrm{E}-02$ & $7.030 \mathrm{E}-02$ & \begin{tabular}{|c|}
$6.866 \mathrm{E}-02$ \\
\end{tabular} & $6.991 \mathrm{E}-02$ & $6.972 \mathrm{E}-02$ & $7.031 \mathrm{E}-02$ & 7.078E-02 & & & & & \\
\hline 16.28 & 150.217 & 9.2260 & & \begin{tabular}{|l|l|}
$7.341 \mathrm{E}-02$ \\
\end{tabular} & \begin{tabular}{|l|l|}
$6.722 \mathrm{E}-02$ \\
\end{tabular} & $4.868 \mathrm{E}-02$ & \begin{tabular}{|c|}
$6.566 \mathrm{E}-02$ \\
\end{tabular} & \begin{tabular}{|l|l|}
$6.881 \mathrm{E}-02$ \\
\end{tabular} & \begin{tabular}{|l|}
$5.418 \mathrm{E}-02$ \\
\end{tabular} & $6.591 \mathrm{E}-02$ & $6.317 \mathrm{E}-02$ & $5.922 \mathrm{E}-02$ & $6.541 \mathrm{E}-02$ & & & & & \\
\hline 18.94 & $\begin{array}{l}50.124 \\
\end{array}$ & 7.9270 & & \begin{tabular}{|l|l|}
$4.351 \mathrm{E}-02$ \\
\end{tabular} & 4.417E-02 & 7.103E-02 & $6.145 \mathrm{E}-02$ & \begin{tabular}{|l|l|}
$4.287 \mathrm{E}-02$ \\
\end{tabular} & \begin{tabular}{|l|}
$5.267 \mathrm{E}-02$ \\
\end{tabular} & $6.896 \mathrm{E}-02$ & $5.128 \mathrm{E}-02$ & $4.913 \mathrm{E}-02$ & $6.393 \mathrm{E}-02$ & & & & & \\
\hline 22.13 & 150.133 & 6.7850 & & $\begin{array}{l}7.984 \mathrm{E}-02 \\
\end{array}$ & $5.722 \mathrm{E}-02$ & $3.917 \mathrm{E}-02$ & $3.721 \mathrm{E}-02$ & \begin{tabular}{|l|l|}
$5.527 \mathrm{E}-02$ \\
\end{tabular} & \begin{tabular}{|l|l|}
$6.302 \mathrm{E}-02$ \\
\end{tabular} & $4.591 \mathrm{E}-02$ & $3.976 \mathrm{E}-02$ & $4.773 \mathrm{E}-02$ & $5.905 \mathrm{E}-02$ & & & & & \\
\hline
\end{tabular}

Table A6b. PAR $180^{\circ}$ Azimuth normalized (by $P_{\mathrm{amb}}$ ) wall pressures as presented in figure $23 \mathrm{~b}$. Diffuser inlet $127 \mathrm{~mm}$ downstream.

\begin{tabular}{|c|c|c|c|c|c|c|c|c|c|c|c|c|c|c|c|c|c|c|}
\hline \multirow[b]{2}{*}{ NPR } & \multirow[b]{2}{*}{$\left|\begin{array}{c}\text { Nozzle } \\
P_{\text {total }}(\mathrm{psia})\end{array}\right|$} & \multirow[b]{2}{*}{$\begin{array}{l}P_{\text {ambo, Vacuum }} \\
\text { Chamber } \\
\text { Pressure, psia }\end{array}$} & \multicolumn{16}{|c|}{$\mathrm{x} / \mathrm{r}^{*}, 180^{\circ}$ Azimuth } \\
\hline & & & 0.3600 & 0.8133 & 1.2667 & 1.7200 & 2.1733 & 2.6267 & 3.0800 & 3.5333 & 3.9867 & 4.4400 & 4.8933 & 5.3467 & 5.8000 & 6.2533 & 6.7067 & 7.1600 \\
\hline 13.0 & 150.199 & 11.5275 & 0.4444 & 0.4052 & 0.3534 & 0.3085 & 0.2663 & 0.2307 & 0.2047 & 0.1826 & 0.4110 & 0.5270 & 0.8375 & 1.3328 & 1.0596 & 0.8455 & 1.0174 & 0.9294 \\
\hline 13.7 & 150.178 & 10.9320 & 0.4690 & 0.4263 & 0.3721 & 0.3249 & 0.2804 & 0.2433 & 0.2159 & 0.1927 & 0.1760 & 0.5103 & 0.6838 & 1.3876 & 1.0761 & 0.7710 & 1.0358 & 0.9953 \\
\hline 16.3 & 150.217 & 9.2260 & 0.5556 & 0.5060 & 0.4422 & 0.3854 & 0.3325 & 0.2884 & 0.2558 & 0.2285 & 0.2072 & 0.1901 & 0.5439 & 0.6592 & 1.1205 & 1.6927 & 0.8645 & 0.7457 \\
\hline 18.9 & 150.124 & 7.9270 & 0.6437 & 0.5876 & 0.5124 & 0.4485 & 0.3867 & 0.3352 & 0.2978 & 0.2657 & 0.2413 & 0.2199 & 0.2052 & 0.5843 & 0.6798 & 1.1890 & 1.6791 & 1.2614 \\
\hline \multirow{3}{*}{$\begin{array}{l}10.9 \\
22.1 \\
\end{array}$} & 150.133 & 6.7850 & 0.7543 & 0.6873 & 0.5993 & 0.5235 & 0.4522 & 0.3919 & 0.3478 & 0.3101 & 0.2819 & 0.2566 & 0.2377 & 0.2234 & 0.5947 & 0.7158 & 1.1033 & 1.1531 \\
\hline & & & & & & & & & & & & & & & & & & \\
\hline & & & & \multicolumn{10}{|c|}{$\mathrm{x} / \mathrm{r}^{*}, 180^{\circ}$ Azimuth } & & & & & \\
\hline NPR & $\left|\begin{array}{c}\text { Nozzle } \\
P_{\text {total }}(\mathrm{psia})\end{array}\right|$ & $\begin{array}{l}\text { Pamb, Vacuum } \\
\text { Chamber } \\
\text { Pressure, psia }\end{array}$ & & 7.6133 & 8.0667 & 8.5200 & 8.9733 & 9.4267 & 9.8800 & 10.3333 & 10.7867 & 11.2400 & 11.6933 & & & & & \\
\hline 13.0 & \begin{tabular}{|l|l|} 
\\
150.199
\end{tabular} & 11.5275 & & 0.8928 & 0.9897 & 0.8981 & 0.9746 & 0.9337 & 0.9588 & 0.9525 & 0.9627 & 0.9692 & 0.9786 & & & & & \\
\hline 13.7 & 150.178 & 10.9320 & & 0.8423 & 1.0164 & 0.9167 & 0.9511 & 0.9657 & 0.9432 & 0.9604 & 0.9578 & 0.9659 & 0.9724 & & & & & \\
\hline 16.3 & 150.217 & 9.2260 & & 1.1952 & 1.0944 & 0.7925 & 1.0690 & 1.1203 & 0.8822 & 1.0732 & 1.0285 & 0.9642 & 1.0650 & & & & & \\
\hline$\frac{10.3}{18.9}$ & 150.124 & 7.9270 & & 0.8240 & 0.8365 & 1.3451 & 1.0037 & 0.8119 & $\begin{array}{l}0.0022 \\
0.9975\end{array}$ & 1.3059 & 0.020312 & 0.9305 & $\begin{array}{l}1.050 \\
1.2107\end{array}$ & & & & & \\
\hline 22.1 & 150.133 & 6.7850 & & 1.7665 & 1.2660 & 0.8666 & 0.8233 & 1.2230 & 1.3945 & 1.0158 & 0.8799 & 1.0562 & 1.3066 & & & & & \\
\hline
\end{tabular}


Table A7a. PAR 0 ${ }^{\circ}$ Azimuth normalized (by $P_{c}$ ) wall pressures as presented in figure 28a. Diffuser inlet 51 mm downstream.

\begin{tabular}{|c|c|c|c|c|c|c|c|c|c|c|c|c|c|c|c|c|c|c|}
\hline \multirow[b]{2}{*}{ NPR } & \multirow[b]{2}{*}{$\begin{array}{c}\text { Nozzle } \\
P_{\text {total }} \text { (psia) }\end{array}$} & \multirow[b]{2}{*}{$\begin{array}{l}P_{\text {ambo, Vacuum }} \text { Chamber } \\
\text { Pressure, psia }\end{array}$} & \multicolumn{16}{|c|}{$\mathrm{x} / \mathrm{r}^{\star}, 0^{\circ}$ Azimuth } \\
\hline & & & 0.1333 & 0.5867 & 1.0400 & 1.4933 & 1.9467 & 2.4000 & 2.8533 & 3.3067 & .760 & 4.2133 & 4.6667 & 5.1200 & 5.5733 & .0267 & 6.4800 & 6.9333 \\
\hline 11.3 & 143.859 & 12.7550 & 4 & $3.376 \mathrm{E}-02$ & $2.934 \mathrm{E}-02$ & 7. & $8.087 \mathrm{E}-02$ & $8.294 \mathrm{E}-02$ & $8.445 \mathrm{E}-02$ & $8.488 \mathrm{E}-02$ & $8.503 \mathrm{E}-02$ & $8.544 \mathrm{E}-02$ & $8540=0$ & $8.542 \mathrm{E}-02$ & $8.553 \mathrm{E}-02$ & 2 & $8.555 \mathrm{E}-02$ & $8.559 \mathrm{E}-02$ \\
\hline 13 & & & & & & & & & & & & & & & & & & \\
\hline 18.3 & 150.603 & 8 & $4.355 \mathrm{E}-02$ & \begin{tabular}{|l|l|}
3.373 \\
\end{tabular} & & 2.56 & $2.163 \mathrm{E}-02$ & 02 & $=02$ & $829 \mathrm{E}-02$ & -02 & & & & & & & \\
\hline 19.8 & 15 & & & $3.374 \mathrm{E}-02$ & & & \begin{tabular}{|l}
$2.163 \mathrm{E}-02$ \\
\end{tabular} & 1.78 & $1.650 \mathrm{E}-02$ & \begin{tabular}{|l}
$3.472 \mathrm{E}-02$ \\
\end{tabular} & 4.41 & & & & & & & E-02 \\
\hline 21.2 & 15 & & $257 \mathrm{E}-02$ & $3.379 \mathrm{E}-02$ & 2.93 & 2.56 & 2.16 & \begin{tabular}{|l|l|}
1.78 \\
\end{tabular} & 1.64 & \begin{tabular}{|l|l}
$1.473 \mathrm{E}-02$ \\
\end{tabular} & $3.106 \mathrm{E}-02$ & & 4.27 & 4.33 & 4.40 & 4.4 & 4.42 & $4.440 \mathrm{E}-02$ \\
\hline 22.6 & & & -02 & \begin{tabular}{|l|l|}
3.381 \\
\end{tabular} & & & 2.161 & \begin{tabular}{|l|l}
1.780 \\
\end{tabular} & 1.64 & $1.461 \mathrm{E}-02$ & 1.352 & & 3.64 & 3.91 & 4.02 & & 4.07 & $4.088 \mathrm{E}-02$ \\
\hline 25.8 & 15 & & & 3.37. & & 2.56 & 2.162 & \begin{tabular}{|l|l|}
1.779 \\
\end{tabular} & & & 1.32 & & & & & & & $2.892 \mathrm{E}-02$ \\
\hline 29.0 & 150.6 & & 02 & \begin{tabular}{|l|}
3.37 \\
\end{tabular} & & & 2.16 & 1.78 & & & 1.32 & & & & & & \begin{tabular}{|l|l}
$8.662 \mathrm{E}-03$ \\
\end{tabular} & \begin{tabular}{|l|l|}
$1.343 \mathrm{E}-02$ \\
\end{tabular} \\
\hline 33.3 & 15 & & & \begin{tabular}{|l|l|}
3.379 \\
\end{tabular} & 2.93 & 2.56 & \begin{tabular}{|l}
$2.161 \mathrm{E}-02$ \\
\end{tabular} & 1.77 & & 1.46 & 1.32 & $1.205 \mathrm{E}-02$ & 1.11 & $1.025 \mathrm{E}-02$ & 958 & 9.07 & $8.634 \mathrm{E}-03$ & $8.315 \mathrm{E}-03$ \\
\hline 37.2 & 15 & & & & & & & & & & & & & & & & & \begin{tabular}{|l|l}
$8.283 \mathrm{E}-03$ \\
\end{tabular} \\
\hline 41.5 & & & & & & & & & & & & & & & & & & $8.281 \mathrm{E}-03$ \\
\hline & & & & & & & & & & & & & & & & & & $0.20 \mathrm{TL}-0 \mathrm{~J}$ \\
\hline 44.0 & & & & & & & & \begin{tabular}{|l|l}
1.7 \\
\end{tabular} & & \begin{tabular}{|l|l|}
1.46 \\
\end{tabular} & & & & & & & \begin{tabular}{|l|}
0.05 \\
8.64
\end{tabular} & \begin{tabular}{|l|l|l|}
$8.279 E-03$ \\
\end{tabular} \\
\hline 48.9 & 15 & & $E-02$ & $3.387 \mathrm{E}-02$ & & & $2.162 \mathrm{E}-02$ & $1.779 \mathrm{E}-02$ & 1.64 & \begin{tabular}{|l|l}
$1.461 \mathrm{E}-02$ \\
\end{tabular} & 1.31 & & & & & 9.07 & \begin{tabular}{|l|l}
$8.631 \mathrm{E}-03$ \\
\end{tabular} & \begin{tabular}{|l|l}
$8.278 \mathrm{E}-03$ \\
\end{tabular} \\
\hline 50.4 & 150.496 & 2.9855 & 4.369E-02 & $3.385 \mathrm{E}-02$ & $2.938 \mathrm{E}-02$ & $2.560 \mathrm{E}-02$ & $2.160 \mathrm{E}-02$ & $1.778 \mathrm{E}-02$ & $1.646 \mathrm{E}-02$ & \begin{tabular}{|l|l}
$1.461 E-02$ \\
\end{tabular} & $1.320 \mathrm{E}-02$ & 1.204E-02 & \begin{tabular}{|l|l}
$1.111 \mathrm{E}-02$ \\
\end{tabular} & $1.025 \mathrm{E}-02$ & \begin{tabular}{|l|l}
$982 E-03$ \\
\end{tabular} & $9.077 \mathrm{E}-03$ & \begin{tabular}{|l}
$8.638 \mathrm{E}-03$ \\
\end{tabular} & $8.273 \mathrm{E}-03$ \\
\hline 51.9 & 150.402 & 2.9000 & 4.366E-02 & \begin{tabular}{|l|l}
$3.382 \mathrm{E}-02$ \\
\end{tabular} & $2.939 \mathrm{E}-02$ & $2.560 \mathrm{E}-02$ & \begin{tabular}{|l|l|}
$2.161 \mathrm{E}-02$ \\
\end{tabular} & \begin{tabular}{|l|l}
$1.778 \mathrm{E}-02$ \\
\end{tabular} & $1.645 \mathrm{E}-02$ & \begin{tabular}{|l|l}
$1.462 E-02$ \\
\end{tabular} & $1.320 \mathrm{E}-02$ & 1.203E-02 & $1.112 \mathrm{E}-02$ & $1.026 \mathrm{E}-02$ & \begin{tabular}{|l|l}
$9.581 \mathrm{E}-03$ \\
\end{tabular} & $9.082 \mathrm{E}-03$ & \begin{tabular}{|l|l|}
$8.644 \mathrm{E}-03$ \\
\end{tabular} & \begin{tabular}{|l|l|}
$8.278 E-03$ \\
\end{tabular} \\
\hline
\end{tabular}
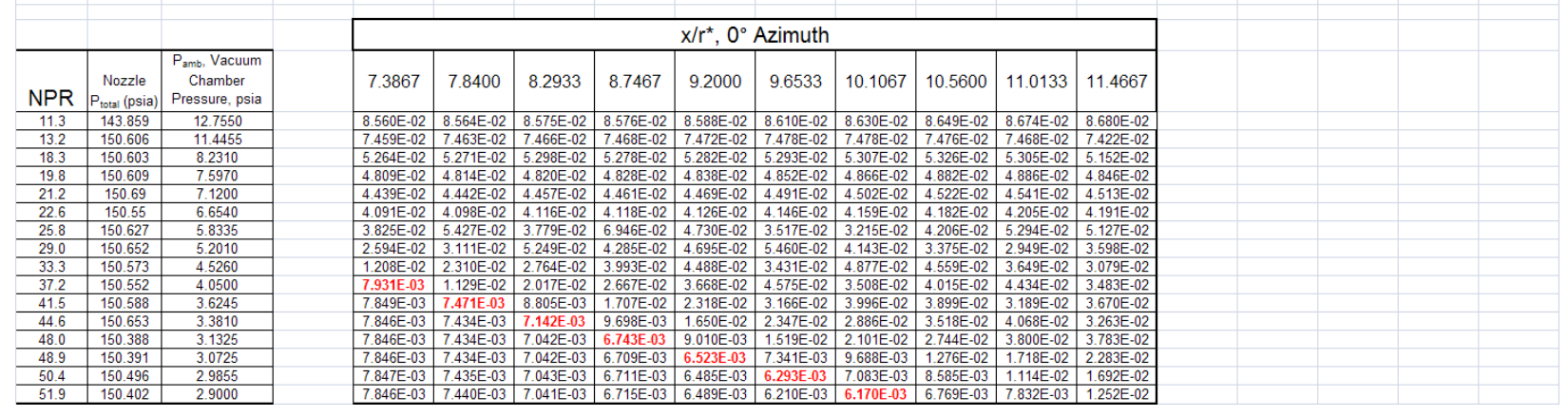

Table A7b. PAR 0 ${ }^{\circ}$ Azimuth normalized (by $P_{a m b}$ ) wall pressures as presented in figure $28 b$. Diffuser inlet 51 mm downstream.

\begin{tabular}{|c|c|c|c|c|c|c|c|c|c|c|c|c|c|c|c|c|c|c|}
\hline \\
\hline & & & \multicolumn{16}{|c|}{$\mathrm{x} / \mathrm{r}^{\star}, 0^{\circ}$ Azimuth } \\
\hline NPR & \begin{tabular}{|c} 
Nozzle \\
$P_{\text {Potas }}$ (psia
\end{tabular} & \begin{tabular}{|l|} 
Pamb, Vacuum \\
Chamber \\
Pressure, psia
\end{tabular} & 1333 & 0.5867 & 1.0400 & 1.4933 & 1.9467 & 2.4000 & 2.8533 & 3.3067 & 3.7600 & 4.2133 & 4.6667 & 5.1200 & 5.5733 & 6.0267 & 6.4800 & 9333 \\
\hline 11.3 & 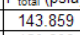 & 12.7550 & 0.4909 & 0.3808 & 0.3309 & 0.8800 & 0.91 & 0.935 & 0.9525 & 0.95 & 0.9590 & 0.9637 & 0.9 & 0.96 & .9646 & 0.9649 & 0.9649 & 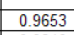 \\
\hline$\frac{13}{18}$ & 150.606 & & & & & & & & & & & & & & & & & \\
\hline$\frac{18}{10}$ & 1 & & 0.7 & 0. & 0.537 & 0.46 & 0.3958 & 0. & 6878 & 0.88 & 0.9333 & 0.9 & 0.9 & 0.95 & & 0.9592 & 0.9610 & 0.9620 \\
\hline & & & 0.8 & 0. & 0.5819 & 0.5085 & 0.4 & & 0. & & 46 & 0.9 & & 0.9 & 0.9484 & & 0.9517 & 0.9534 \\
\hline & & & & & & 0.5427 & 0.45 & & & & & & 0.9 & & & & & 0.9396 \\
\hline & & & 0.5 & & 0.6641 & 0.5803 & 0.48 & 04594 & nat & & 0.3058 & 0.5 & & 0.8 & & & & 0.9249 \\
\hline & \begin{tabular}{|l|}
150.627 \\
15.652 \\
\end{tabular} & & \begin{tabular}{|l|l} 
& 12240 \\
\end{tabular} & & 0.7572 & 0.6617 & & 0.4594 & 0.42 & & 0.3408 & 0.3 & 0.2873 & 0.26 & 0.2 & & & 0.7467 \\
\hline$\frac{29.0}{333}$ & \begin{tabular}{|l|}
150.65 \\
150.57 \\
\end{tabular} & & \begin{tabular}{|l|l|}
.2615 \\
1.4505
\end{tabular} & \begin{tabular}{|l|l|}
11 \\
11
\end{tabular} & 0.8506 & 0.7424 & \begin{tabular}{|c|c|}
0.62 \\
.71
\end{tabular} & 0.5157 & 0.47 & 0.4 & 0.3826 & 0.34 & 0.3 & 0.29 & 0.2 & & & 0.3890 \\
\hline 37.2 & $\begin{array}{l}150.50 \\
155\end{array}$ & & 1.45032 & & 0.9091 & & \begin{tabular}{|l|l|}
0.803 \\
\end{tabular} & $\begin{array}{l}0.5919 \\
0.6612\end{array}$ & & & $\mid 0.4500$ & $\begin{array}{l}0.4 \\
0.4\end{array}$ & & 0.5471 & \begin{tabular}{|l|l} 
\\
\end{tabular} & \begin{tabular}{|l|l} 
\\
\end{tabular} & $0.28 / 2$ & 0.2766 \\
\hline & \begin{tabular}{|l|l|}
150.538 \\
150.58
\end{tabular} & & \begin{tabular}{|l|l|}
1.02127 \\
1.817
\end{tabular} & \begin{tabular}{|l|l|}
1.4 \\
\end{tabular} & 1.2200 & & \begin{tabular}{|l|}
0.0032 \\
0.8978 \\
\end{tabular} & 0.0012 & $\frac{0.0}{0.6}$ & & $\begin{array}{ll}0.4034 \\
05485 \\
\end{array}$ & \begin{tabular}{|l|l|l|l|}
0.5005 \\
\end{tabular} & \begin{tabular}{|l|l|}
0.4153 \\
0.419 \\
\end{tabular} & 0.0263 & \begin{tabular}{|l|l|}
0.03981 \\
0391
\end{tabular} & \begin{tabular}{|l|l|}
0.37772 \\
\end{tabular} & $\begin{array}{l}0.2512 \\
0.3589 \\
\end{array}$ & \begin{tabular}{|l|}
0.3019 \\
0.3440 \\
\end{tabular} \\
\hline 44.6 & & & 1.9 & & & & & & & & 0.5 & & & & & & & 0.3688 \\
\hline 48.0 & 15 & & & & 1.40. & 1.2 & 1.0 & 0.8540 & 0.7 & 0.7 & 0.6337 & & 0.5338 & 0.4926 & & \begin{tabular}{|l|}
0.4358 \\
\end{tabular} & 0.4150 & 0.3974 \\
\hline 48.9 & \begin{tabular}{|l|l|} 
\\
\end{tabular} & 3.0725 & 2.1357 & \begin{tabular}{|l|l|} 
\\
\end{tabular} & 1.4382 & 1.2 & 1.0581 & 0.8710 & 0.8065 & 0.7151 & 0.6457 & 0.5894 & \begin{tabular}{|l}
0.5439 \\
\end{tabular} & 0.5019 & 0.4690 & 0.4443 & 0.4225 & 0.4052 \\
\hline 50.4 & \begin{tabular}{|l|l|}
150.496 \\
150.402 \\
\end{tabular} & 2.9855 & $\frac{2.2023}{2.2641}$ & 17541 & $\begin{array}{l}1.4808 \\
1.521 \\
\end{array}$ & $\begin{array}{l}1.2906 \\
1.3276\end{array}$ & $\frac{1.0889}{1.207}$ & 0.8963 & \begin{tabular}{|l|l|}
0.8297 \\
0.8531 \\
\end{tabular} & \begin{tabular}{|l|l|}
0.7362 \\
0.7583
\end{tabular} & \begin{tabular}{|l|l|}
0.6652 \\
0.6855 \\
\end{tabular} & \begin{tabular}{|l|l|}
0.6069 \\
0.6241
\end{tabular} & \begin{tabular}{|l|l|}
0.5600 \\
0.576
\end{tabular} & 0.5168 & \begin{tabular}{|l|l|}
0.4830 \\
0.999
\end{tabular} & \begin{tabular}{|l|}
0.4575 \\
0.471 \\
\end{tabular} & 0.4354 & 0.4170 \\
\hline & & & & & & & & & & & & & & & & & & 0.4293 \\
\hline
\end{tabular}

\begin{tabular}{|c|c|c|}
\hline NPR & \begin{tabular}{|l} 
Nozzla \\
P
\end{tabular} & $\begin{array}{l}\text { Pamb, Vacuum } \\
\text { Chamber } \\
\text { Pressure, psia }\end{array}$ \\
\hline & & \\
\hline & $\mid 150.606$ & 11.4455 \\
\hline$\frac{18.3}{198}$ & \begin{tabular}{|l|l|}
150.603 \\
150.6
\end{tabular} & $\begin{array}{l}8.2310 \\
75907\end{array}$ \\
\hline$\frac{19.8}{21.2}$ & $\begin{array}{l}150.609 \\
150.69\end{array}$ & $\begin{array}{l}7.5970 \\
7.1200\end{array}$ \\
\hline 22.6 & 150.55 & 6.6540 \\
\hline 25.8 & 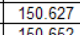 & 5.8335 \\
\hline 29.0 & \begin{tabular}{|l|l|l|}
50.652 \\
150.573
\end{tabular} & $\begin{array}{r}5.2010 \\
45260\end{array}$ \\
\hline 37.2 & \begin{tabular}{|l|}
$150.5 / 3$ \\
150.552 \\
\end{tabular} & $\frac{4.5200}{4.0500}$ \\
\hline 41.5 & 150.588 & 3.6245 \\
\hline 44.6 & & 3.3810 \\
\hline 48.0 & 150.388 & 3.1325 \\
\hline 48.9 & 150.391 & 3.0725 \\
\hline 519 & 150.496 & \\
\hline 51.9 & 150.402 & 2.9000 \\
\hline
\end{tabular}

\begin{tabular}{|c|c|c|c|c|c|c|c|c|c|}
\hline \multicolumn{10}{|c|}{$\mathrm{x} / \mathrm{r}^{\star}, 0^{\circ}$ Azimuth } \\
\hline 7.3867 & 7.8400 & 8.2933 & 8.7467 & 9.2000 & 9.6533 & 10.1067 & 10.5600 & 11.0133 & 11.4667 \\
\hline 0.9655 & 0.9659 & 0 & 9673 & 0.9686 & 0.9711 & 0.97 & 0.97 & 0.9784 & \\
\hline 0.9814 & 0.9020 & 0.9824 & 0.9827 & 0.9832 & 0.9841 & 0.9840 & & & \\
\hline 0.9631 & 0.9644 & 0.9694 & 0.9657 & 0.9665 & 0.9684 & 0.9710 & 0.9745 & \begin{tabular}{|l|l|}
0.9706 \\
0.077
\end{tabular} & 19427 \\
\hline 5534 & 0.95433 & \begin{tabular}{|l|l|}
0.9555 \\
0.934
\end{tabular} & 0.9572 & 0.9591 & \begin{tabular}{|l|}
0.9620 \\
0.9504 \\
\end{tabular} & 0.9646 & 0.9678 & \begin{tabular}{|l|l|}
0.9687 \\
0.9611
\end{tabular} & 0 \\
\hline 0.9256 & 0.9271 & \begin{tabular}{|l|l|}
0.9313 \\
\end{tabular} & 0.94316 & $\begin{array}{l}0.9435 \\
0.9334 \\
\end{array}$ & \begin{tabular}{|l|}
0.9384 \\
0.931 \\
\end{tabular} & 0.94411 & $\begin{array}{l}0.9956 \\
0.9462\end{array}$ & \begin{tabular}{|l}
0.9611 \\
0.9513 \\
\end{tabular} & 0.955 \\
\hline 0.987 & 1.4014 & 0.9757 & 1.7934 & 1.2212 & & 0.8302 & 1.0860 & 1.3669 & \\
\hline 0.7514 & 0.90 & & 1.2411 & 1.3599 & 1.5 & & 0.9777 & 0.8543 & \\
\hline 0.401 & 0.7684 & 0.9196 & 1.3285 & 1.4929 & 1.1 & & & & 1.0243 \\
\hline 0.2948 & 0.4198 & \begin{tabular}{|l|l|}
0.7496 \\
069
\end{tabular} & 0.9914 & 1.3637 & & 1.3040 & & & 1.2946 \\
\hline & 0.3104 & & $\begin{array}{l}0.7093 \\
0.4321 \\
\end{array}$ & 0.9629 & \begin{tabular}{|l|l|}
1.3155 \\
1.0458
\end{tabular} & 1.6601 & & \begin{tabular}{|l|l|}
1.3249 \\
1.125
\end{tabular} & $\frac{1.5249}{14540}$ \\
\hline $\begin{array}{l}0.3466 \\
0.3767\end{array}$ & 0.3313 & $\frac{0.3182}{0.3381}$ & 0.4321 & 0.7353 & & $\frac{1.2860}{10088}$ & & & $\frac{1.4540}{1.8161}$ \\
\hline $\begin{array}{l}0.367 \\
0.3841 \\
\end{array}$ & 0.03659 & 0.33817 & $\begin{array}{l}0.3231 \\
0.3284 \\
\end{array}$ & 0.431963 & \begin{tabular}{|l}
0.1254 \\
0.3593 \\
\end{tabular} & 0.07742 & $\begin{array}{l}1.3515 \\
0.6246 \\
\end{array}$ & \begin{tabular}{|l|l|}
1.8241 \\
0.8407 \\
\end{tabular} & $\frac{1.861}{1.1177}$ \\
\hline $\begin{array}{l}0.3956 \\
0.409 \\
\end{array}$ & 0.3748 & $\begin{array}{l}0.3550 \\
0.352 \\
\end{array}$ & 0.3383 & $\begin{array}{l}0.3269 \\
0.3365\end{array}$ & \begin{tabular}{|l|l|}
0.3172 \\
0.3221 \\
\end{tabular} & $\begin{array}{l}0.3571 \\
0.3200\end{array}$ & $\begin{array}{l}0.4328 \\
0.3510\end{array}$ & \begin{tabular}{|l|}
0.5617 \\
0.4062 \\
\end{tabular} & $\begin{array}{l}0.853 \\
0.6493\end{array}$ \\
\hline
\end{tabular}


Table A8a. PAR $180^{\circ}$ Azimuth normalized (by $P_{c}$ ) wall pressures as presented in figure 29a. Diffuser inlet 51 mm downstream.

\begin{tabular}{|c|c|c|c|c|c|c|c|c|c|c|c|c|c|c|c|c|c|c|}
\hline \multirow[b]{2}{*}{ NPR } & \multirow[b]{2}{*}{$\begin{array}{c}\text { Nozzle } \\
P_{\text {total }} \text { (psia) }\end{array}$} & \multirow[b]{2}{*}{$\begin{array}{l}P_{\text {ambb }} \text { Vacuum } \\
\text { Chamber } \\
\text { Pressure, psia }\end{array}$} & \multicolumn{16}{|c|}{$\mathrm{x} / \mathrm{r}^{*}, 180^{\circ}$ Azimuth } \\
\hline & & & 3600 & 0.8133 & 1.2667 & 1.7200 & 2.1733 & 2.6267 & 3.0800 & 3.533 & 3.9867 & 4.4400 & 4.893 & 5.3467 & 5.8000 & 6.253 & 6.7067 & 7.16 \\
\hline 14.6 & 150.663 & 10.3400 & $3.408 \mathrm{E}-02$ & 3.1 & $2.693 \mathrm{E}-02$ & 2.3 & 6.3 & $6594 E_{-S}$ & $6.664 \mathrm{E}$ & 2 & $6716 \mathrm{~F}$ & $6799 E-02$ & $6.736 \mathrm{E}-02$ & $67385-0$ & $6.742 \mathrm{E}-02$ & $6.745 \mathrm{E}-02$ & 02 & $46 \mathrm{E}-02$ \\
\hline 19.0 & & & & & & & & & & & & & & & & & & \\
\hline 20.6 & 640 & & & & & & & & 1.56 & & & & 4.4 & & & & & $\mathrm{E}-02$ \\
\hline 22.0 & 150.553 & & & & & & & & & \begin{tabular}{|l|l|}
$1.404 \mathrm{E}-02$ \\
\end{tabular} & & & & & & & & 4.234E-02 \\
\hline 23.7 & 150.641 & & & & & & & $1.768 \mathrm{E}-02$ & & \begin{tabular}{|l|l|}
$1.397 E-02$ \\
\end{tabular} & $1.285 \mathrm{E}-02$ & & & & & & & $3779 E_{0}$ \\
\hline 24.4 & 150.400 & 6.1610 & $3.423 \mathrm{E}-02$ & 3.11 & $2.712 \mathrm{E}-02$ & 2.36 & $2.033 \mathrm{E}-02$ & $1.772 \mathrm{E}-02$ & $1.559 \mathrm{E}-02$ & \begin{tabular}{|l|l|}
$1.398 E-02$ \\
\end{tabular} & $1.275 \mathrm{E}-02$ & 1.160E-02 & 1.07 & 1.00 & E-03 & $2.274 \mathrm{E}-02$ & & $3.946 \mathrm{E}-02$ \\
\hline 26. & 150 & & & & 2.698 & & $2.034 \mathrm{E}-02$ & & & \begin{tabular}{|l|l|}
$1.399 E-02$ \\
\end{tabular} & 1.27 & & 1.07 & & & E-03 & $=-02$ & $2.901 \mathrm{E}-02$ \\
\hline 29.4 & 150 & & & & 2.69 & & & & & & & & & & & & & $2.008 \mathrm{E}-02$ \\
\hline 34.2 & 15 & & & & & & & & & & & & & & & 8.8 & & $8.140 \mathrm{E}-03$ \\
\hline 37.2 & 150.617 & & 3.412 & & 2.702 & & $2.034 \mathrm{E}-02$ & 1.773 & & \begin{tabular}{|l|l|}
$1.400 E-02$ \\
\end{tabular} & $1.277 \mathrm{E}-02$ & & & & 9.401 & & & $8.000 \mathrm{E}-03$ \\
\hline 42.5 & 150.623 & & 3.411 & & 2.700 & & $2.036 \mathrm{E}-02$ & 1.773 & \begin{tabular}{|l}
1.56 \\
1.56 \\
\end{tabular} & $\begin{array}{ll}.4400 \mathrm{E}-02 \\
1.402\end{array}$ & $1.275 \mathrm{E}-02$ & & & & 9.40 & $8.883 \mathrm{E}-03$ & 8.47 & $8.007 \mathrm{E}-03$ \\
\hline 46.2 & 150.359 & & 3.422 & 3.11 & $2.712 \mathrm{E}-02$ & $2.362 \mathrm{E}-02$ & $2.034 \mathrm{E}-02$ & 1.773 & $1.560 \mathrm{E}-02$ & 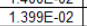 & $1.275 \mathrm{E}-02$ & 1.159 & & & $9.404 \mathrm{E}-03$ & 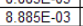 & $\frac{8.47}{8.46}$ & $3.001 E-03$ \\
\hline 48.7 & 150.56 & & & & & & & & & $1.399 \mathrm{E}-02$ & & & & & & & & \\
\hline & & & & & & & & & & & & & & & & & & \\
\hline & & & & & & & & & & & & & & & & & & \\
\hline 52 & & & & & & & & & & & & & & & & & & 03 \\
\hline 55.8 & 150.62 & & 3.40 & & \begin{tabular}{|l|}
$2.697 \mathrm{E}-02$ \\
\end{tabular} & 2.36 & $2.033 \mathrm{E}-02$ & 1.77 & \begin{tabular}{|l|l|}
$1.561 \mathrm{E}-02$ \\
\end{tabular} & $1.400 \mathrm{E}-02$ & $1.276 \mathrm{E}-02$ & 1.16 & & 1.00 & \begin{tabular}{|c|}
$9.401 E-03$ \\
\end{tabular} & $8.883 \mathrm{E}-03$ & $8.471 \mathrm{E}-03$ & $8.007 \mathrm{E}-03$ \\
\hline 65.4 & 150.515 & 2.3025 & $3.415 E-02$ & $3.106 \mathrm{E}-02$ & $2.701 \mathrm{E}-02$ & $2.364 \mathrm{E}-02$ & $2.032 E-02$ & $1.771 \mathrm{E}-02$ & $1.559 \mathrm{E}-02$ & \begin{tabular}{|l|l|}
$1.399 E-02$ \\
\end{tabular} & $1.275 \mathrm{E}-02$ & 1.161E-02 & $1.073 \mathrm{E}-02$ & $1.001 \mathrm{E}-02$ & $9.408 \mathrm{E}-03$ & $8.883 E-03$ & $8.471 \mathrm{E}-03$ & $8.006 E-03$ \\
\hline
\end{tabular}
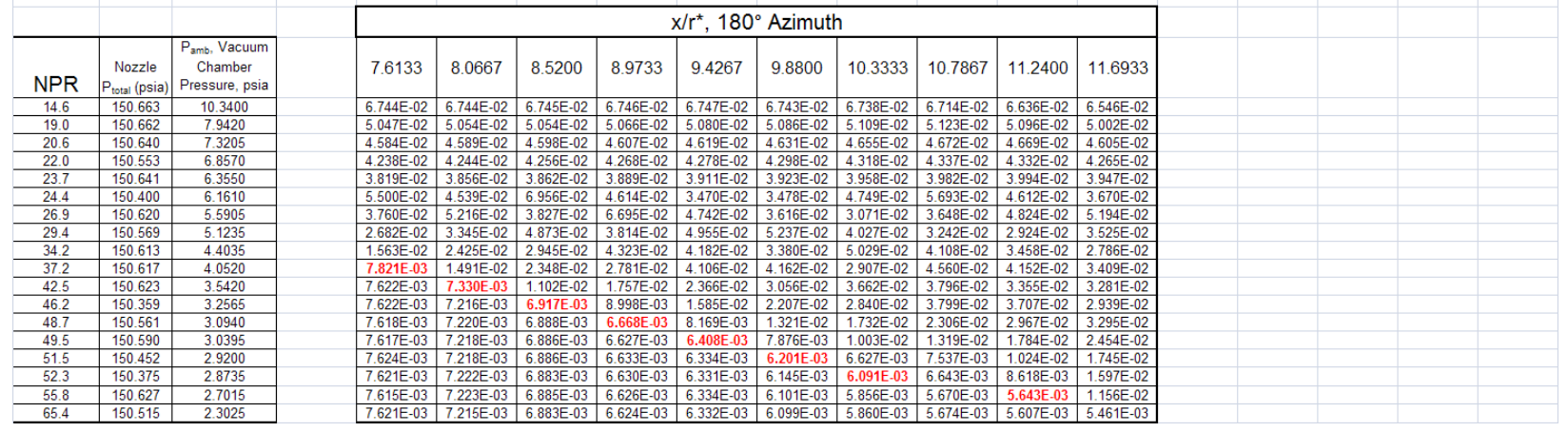

Table A8b. PAR $180^{\circ}$ Azimuth normalized (by $P_{a m b}$ ) wall pressures as presented in figure 29b. Diffuser inlet $51 \mathrm{~mm}$ downstream.

\begin{tabular}{|c|c|c|c|c|c|c|c|c|c|c|c|c|c|c|c|c|c|c|}
\hline \multirow[b]{2}{*}{ NPR } & \multirow[b]{2}{*}{\begin{tabular}{|c|} 
Nozzle \\
$\mathrm{P}_{\text {total }}(\mathrm{psia})$
\end{tabular}} & \multirow[b]{2}{*}{$\begin{array}{l}\text { Pamb, Vacuum } \\
\text { Chamber } \\
\text { Pressure, psia }\end{array}$} & \multicolumn{16}{|c|}{$\mathrm{x} / \mathrm{r}^{\star}, 180^{\circ}$ Azimuth } \\
\hline & & & 0.3600 & 0.8133 & 1.2667 & 1.7200 & 2.1733 & 2.6267 & 3.0800 & 3.5333 & 3.9867 & 4.4400 & 4.8933 & 5.3467 & 5.8000 & 6.2533 & 6.7067 & 7.1600 \\
\hline 14.6 & \begin{tabular}{|l|}
150.663 \\
\end{tabular} & 10.3400 & 0.4965 & 0.4519 & 0.3925 & 0.3456 & 0.9258 & 0.9608 & 0.9710 & 0.9756 & 0.9786 & 0.9805 & 0.9815 & 0.9817 & 0.9824 & 0.9828 & 0.9830 & 0.9829 \\
\hline 19.0 & \begin{tabular}{|l|}
150.662 \\
\end{tabular} & 7.9420 & 0.6443 & 0.5890 & 0.5115 & 0.4486 & 0.3860 & 0.3388 & 0.7375 & 0.8916 & 0.9324 & 0.9406 & 0.9484 & 0.9533 & 0.9529 & 0.9548 & 0.9567 & 0.9564 \\
\hline 20.6 & 150.640 & 7.3205 & 0.7015 & 0.6390 & 0.5556 & 0.4870 & 0.4181 & 0.3638 & 0.3222 & 0.6605 & 0.8570 & 0.9077 & 0.9237 & 0.9335 & 0.9381 & 0.9398 & 0.9415 & 0.9435 \\
\hline 22.0 & 150.553 & 6.8570 & 0.7483 & 0.6818 & 0.5922 & 0.5195 & 0.4460 & 0.3884 & 0.3423 & 0.3083 & 0.5938 & 0.8413 & 0.8918 & 0.9097 & 0.9224 & 0.9250 & 0.9265 & 0.9296 \\
\hline 23.7 & 150.641 & 6.3550 & 0.8082 & 0.7364 & 0.6389 & 0.5610 & 0.4818 & 0.4190 & 0.3693 & 0.3312 & 0.3046 & 0.4412 & 0.7204 & 0.8466 & 0.8757 & 0.8881 & 0.9043 & 0.8957 \\
\hline 24.4 & 150.400 & 6.1610 & 0.8356 & 0.7599 & 0.6621 & 0.5770 & 0.4963 & 0.4326 & 0.3806 & 0.3412 & 0.3112 & 0.2832 & 0.2620 & 0.2444 & 0.2336 & 0.5551 & 0.7328 & 0.9633 \\
\hline 26.9 & 150.620 & 5.5905 & 0.9158 & 0.8371 & 0.7269 & 0.6370 & 0.5479 & 0.4772 & 0.4211 & 0.3769 & 0.3434 & 0.3129 & 0.2889 & 0.2697 & 0.2533 & 0.2442 & 0.6057 & 0.7815 \\
\hline 29.4 & 150.569 & 5.1235 & 1.0015 & 0.9121 & 0.7932 & 0.6943 & 0.5980 & 0.5211 & 0.4591 & 0.4114 & 0.3747 & 0.3412 & 0.3152 & 0.2941 & 0.2764 & 0.2610 & 0.2541 & 0.5902 \\
\hline 34.2 & 150.613 & 4.4035 & 1.1654 & 1.0626 & 0.9240 & 0.8087 & 0.6965 & 0.6066 & 0.5341 & 0.4787 & 0.4362 & 0.3972 & 0.3670 & 0.3425 & 0.3216 & 0.3038 & 0.2898 & 0.2784 \\
\hline 37.2 & 150.617 & 4.0520 & 1.2683 & 1.1530 & 1.0044 & 0.8791 & 0.7562 & 0.6589 & 0.5800 & 0.5202 & 0.4746 & 0.4314 & 0.3988 & 0.3722 & 0.3495 & 0.3302 & 0.3147 & 0.2974 \\
\hline 42.5 & 150.623 & 3.5420 & 1.4503 & 1.3216 & 1.1482 & 1.0056 & 0.8656 & 0.7538 & 0.6637 & 0.5951 & 0.5423 & 0.4935 & 0.4562 & 0.4257 & 0.3998 & 0.3778 & 0.3602 & 0.3405 \\
\hline 46.2 & 150.359 & 3.2565 & 1.5802 & 1.4371 & 1.2520 & 1.0907 & 0.9394 & 0.8187 & 0.7201 & 0.6458 & 0.5887 & 0.5352 & 0.4956 & 0.4622 & 0.4342 & 0.4103 & 0.3909 & 0.3694 \\
\hline 48.7 & 150.561 & 3.0940 & 1.6590 & 1.5120 & 1.3142 & 1.1506 & 0.9903 & 0.8630 & 0.7595 & 0.6807 & 0.6206 & 0.5650 & 0.5223 & 0.4871 & 0.4577 & 0.4324 & 0.4121 & 0.3895 \\
\hline 49.5 & 150.590 & 3.0395 & 1.6914 & 1.5381 & 1.3377 & 1.1709 & 1.0074 & 0.8781 & 0.7732 & 0.6932 & 0.6317 & 0.5748 & 0.5317 & 0.4961 & 0.4655 & 0.4402 & 0.4195 & 0.3964 \\
\hline 51.5 & 150.452 & 2.9200 & 1.7616 & 1.6045 & 1.3949 & 1.2188 & 1.0483 & 0.9130 & 0.8038 & 0.7205 & 0.6572 & 0.5976 & 0.5531 & 0.5158 & 0.4842 & 0.4579 & 0.4363 & 0.4123 \\
\hline 52.3 & 150.375 & 2.8735 & 1.7881 & 1.6276 & 1.4185 & 1.2372 & 1.0642 & 0.9278 & 0.8161 & 0.7319 & 0.6675 & 0.6069 & 0.5617 & 0.5241 & 0.4921 & 0.4649 & 0.4434 & 0.4190 \\
\hline 55.8 & 150.627 & 2.7015 & 1.8997 & 1.7313 & 1.5040 & 1.3170 & 1.1334 & 0.9880 & 0.8703 & 0.7807 & 0.7115 & 0.6470 & 0.5982 & 0.5582 & 0.5242 & 0.4953 & 0.4723 & 0.4464 \\
\hline \multirow[t]{2}{*}{65.4} & 150.515 & 2.3025 & 2.2324 & 2.0304 & 1.7659 & 1.5453 & 1.3286 & 1.1579 & 1.0193 & 0.9142 & 0.8334 & 0.7587 & 0.7014 & 0.6545 & 0.6150 & 0.5807 & 0.5537 & 0.5233 \\
\hline & & & & \multicolumn{10}{|c|}{$\mathrm{x} / \mathrm{r}^{\star}, 180^{\circ}$ Azimuth } & & & & & \\
\hline NPR & $\left|\begin{array}{c}\text { Nozzle } \\
P_{\text {total }}(p s i a)\end{array}\right|$ & $\begin{array}{l}P_{\text {ambb }} \text { Vacuum } \\
\text { Chamber } \\
\text { Pressure, psia }\end{array}$ & & 7.6133 & 8.0667 & 8.5200 & 8.9733 & 9.4267 & 9.8800 & 10.3333 & 10.7867 & 11.2400 & 11.6933 & & & & & \\
\hline 14.6 & \begin{tabular}{l|l|}
150.663 \\
\end{tabular} & 10.3400 & & 0.9827 & 0.9827 & 0.9828 & 0.9830 & 0.9831 & 0.9825 & 0.9817 & 0.9782 & 0.9669 & 0.9539 & & & & & \\
\hline 19.0 & 150.662 & 7.9420 & & 0.9574 & 0.9587 & 0.9587 & 0.9610 & 0.9636 & 0.9649 & 0.9693 & 0.9718 & 0.9668 & 0.9489 & & & & & \\
\hline 20.6 & 150.640 & 7.3205 & & 0.9434 & 0.9443 & 0.9462 & 0.9480 & 0.9505 & 0.9529 & 0.9579 & 0.9614 & 0.9607 & 0.9476 & & & & & \\
\hline 22.0 & 150.553 & 6.8570 & & 0.9306 & 0.9319 & 0.9344 & 0.9371 & 0.9393 & 0.9437 & 0.9481 & 0.9523 & 0.9511 & 0.9364 & & & & & \\
\hline 23.7 & 150.641 & 6.3550 & & 0.9053 & 0.9141 & 0.9155 & 0.9218 & 0.9270 & 0.9300 & 0.9383 & 0.9438 & 0.9468 & 0.9356 & & & & & \\
\hline 24.4 & 150.400 & 6.1610 & & 1.3426 & 1.1079 & 1.6981 & 1.1264 & 0.8471 & 0.8491 & 1.1592 & 1.3897 & 1.1258 & 0.8958 & & & & & \\
\hline 26.9 & 150.620 & 5.5905 & & 1.0130 & 1.4052 & 1.0310 & 1.8038 & 1.2777 & 0.9743 & 0.8273 & 0.9827 & 1.2997 & 1.3993 & & & & & \\
\hline 29.4 & 150.569 & 5.1235 & & 0.7883 & 0.9831 & 1.4320 & 1.1207 & 1.4560 & 1.5390 & 1.1836 & 0.9527 & 0.8592 & 1.0358 & & & & & \\
\hline 34.2 & 150.613 & 4.4035 & & 0.5346 & 0.8293 & 1.0072 & 1.4786 & 1.4302 & 1.1559 & 1.7202 & 1.4050 & 1.1827 & 0.9529 & & & & & \\
\hline 37.2 & 150.617 & 4.0520 & & 0.2907 & 0.5540 & 0.8727 & 1.0338 & 1.5262 & 1.5471 & 1.0805 & 1.6950 & 1.5432 & 1.2673 & & & & & \\
\hline 42.5 & 150.623 & 3.5420 & & 0.3241 & 0.3117 & 0.4687 & 0.7473 & 1.0059 & 1.2995 & 1.5573 & 1.6141 & 1.4266 & 1.3953 & & & & & \\
\hline 46.2 & 150.359 & 3.2565 & & 0.3519 & 0.3332 & 0.3194 & 0.4155 & 0.7318 & 1.0192 & 1.3112 & 1.7540 & 1.7117 & 1.3570 & & & & & \\
\hline 48.7 & 150.561 & 3.0940 & & 0.3707 & 0.3513 & 0.3352 & 0.3245 & 0.3975 & 0.6429 & 0.8429 & 1.1222 & 1.4438 & 1.6034 & & & & & \\
\hline 49.5 & 150.590 & 3.0395 & & 0.3774 & 0.3576 & 0.3412 & 0.3283 & 0.3175 & 0.3902 & 0.4971 & 0.6534 & 0.8840 & 1.2157 & & & & & \\
\hline 51.5 & 150.452 & 2.9200 & & 0.3928 & 0.3719 & 0.3548 & 0.3418 & 0.3264 & 0.3195 & 0.3414 & 0.3884 & 0.5277 & 0.8990 & & & & & \\
\hline 52.3 & 150.375 & 2.8735 & & 0.3988 & 0.3779 & 0.3602 & 0.3470 & 0.3313 & 0.3216 & 0.3188 & 0.3477 & 0.4510 & 0.8356 & & & & & \\
\hline 55.8 & 150.627 & 2.7015 & & 0.4246 & 0.4027 & 0.3839 & 0.3694 & 0.3531 & 0.3402 & 0.3265 & 0.3161 & 0.3146 & 0.6448 & & & & & \\
\hline 65.4 & 150.515 & 2.3025 & & 0.4982 & 0.4717 & 0.4499 & 0.4330 & 0.4139 & 0.3987 & 0.3831 & 0.3709 & 0.3666 & 0.3570 & & & & & \\
\hline
\end{tabular}


Table A9a. PAR $0^{\circ}$ Azimuth normalized (by $P_{c}$ ) wall pressures as presented in figure 30a. Diffuser inlet 51 mm downstream.

\begin{tabular}{|c|c|c|c|c|c|c|c|c|c|c|c|c|c|c|c|c|c|c|}
\hline \multirow[b]{2}{*}{ NPR } & \multirow[b]{2}{*}{$\begin{array}{c}\text { Nozzle } \\
P_{\text {total }}(p s i a)\end{array}$} & \multirow[b]{2}{*}{$\begin{array}{l}\text { Pamb. Vacuum } \\
\text { Chamber } \\
\text { Pressure, psia }\end{array}$} & \multicolumn{16}{|c|}{$\mathrm{x} / \mathrm{r}^{\star}, 0^{\circ}$ Azimuth } \\
\hline & & & 0.1333 & 0.5867 & 1.0400 & 1.4933 & 1.9467 & 2.4000 & 2.8533 & 3.3067 & 3.7600 & 4.2133 & 4.6667 & 5.1200 & 5.5733 & 6.0267 & 6.4800 & 6.9333 \\
\hline 12.7 & 150.582 & 11.8370 & & & & & & & & & & & & & & & & \\
\hline 13.0 & & & & & & & & & & & 3.60 & & & & & & & \\
\hline 13.3 & 150.6 & & $4.356 \mathrm{E}-02$ & 3.37 & $2.934 \mathrm{E}-02$ & 2.56 & $2.161 \mathrm{E}-02$ & $1.778 \mathrm{E}-\mathrm{C}$ & $1.647 \mathrm{E}-02$ & 1.461E-02 & $1.321 \mathrm{E}-02$ & $3.450 \mathrm{E}-02$ & $4.096 \mathrm{E}-02$ & $7.275 \mathrm{E}-02$ & $9.923 \mathrm{E}-02$ & 7.43 & & \\
\hline 14.3 & 150.614 & & $4.357 \mathrm{E}-02$ & $3.378 \mathrm{E}-02$ & $2.935 \mathrm{E}-02$ & $2.562 \mathrm{E}-02$ & $2.160 \mathrm{E}-02$ & $1.777 \mathrm{E}-02$ & $1.647 \mathrm{E}-02$ & \begin{tabular}{|l|l|}
$1.461 \mathrm{E}-02$ \\
\end{tabular} & $1.319 \mathrm{E}-02$ & $1.218 \mathrm{E}-02$ & $3.624 \mathrm{E}-02$ & $4.816 \mathrm{E}-02$ & $1.019 \mathrm{E}-01$ & $7.815 \mathrm{E}-02$ & \begin{tabular}{|l|l}
$5.320 \mathrm{E}-02$ \\
\end{tabular} & $6.831 \mathrm{E}-02$ \\
\hline 17.4 & 150.609 & 8.6775 & $4.360 \mathrm{E}-02$ & $3.376 \mathrm{E}-02$ & $2.934 \mathrm{E}-02$ & $2.558 \mathrm{E}-02$ & \begin{tabular}{|l}
$2.161 \mathrm{E}-02$ \\
\end{tabular} & & & & & & & & & & & \\
\hline 20.0 & & & & & & 2.56 & 2.16 & 1.7 & & & & & & \begin{tabular}{|l|l|}
1.04 \\
\end{tabular} & 2.8 & & 5.9 & 5.96 \\
\hline 22.4 & 150.539 & 6.7225 & 4.360 & & 2.9366 & & $2.162 \mathrm{E}$ & $1.780 \mathrm{E}$ & $1.647 \mathrm{E}-$ & 1.461 & $1.319 \mathrm{E}$ & & $1.111 \mathrm{E}-0$ & & & $2.575 \mathrm{E}$ & $3.165 \mathrm{E}$ & $4.930 \mathrm{E}-02$ \\
\hline
\end{tabular}
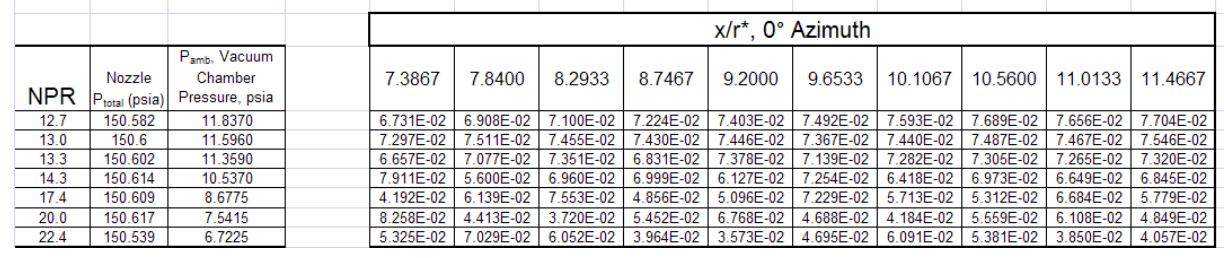

Table A9b. PAR 0 $0^{\circ}$ Azimuth normalized (by $P_{a m b}$ ) wall pressures as presented in figure 30b. Diffuser inlet 51 mm downstream.

\begin{tabular}{|c|c|c|c|c|c|c|c|c|c|c|c|c|c|c|c|c|c|c|}
\hline \multirow[b]{2}{*}{ NPR } & \multirow[b]{2}{*}{$\begin{array}{c}\text { Nozzle } \\
\mathrm{P}_{\text {total }} \text { (psia) }\end{array}$} & \multirow[b]{2}{*}{$\begin{array}{l}\text { Pamb, Vacuum }_{\text {ande, }} \\
\text { Chamber } \\
\text { Pressure, psia }\end{array}$} & \multicolumn{16}{|c|}{$\mathrm{x} / \mathrm{r}^{*}, 0^{\circ}$ Azimuth } \\
\hline & & & 0.1333 & 0.5867 & 1.0400 & 1.4933 & 1.9467 & 2.4000 & 2.8533 & 3.3067 & 3.7600 & 4.2133 & 4.6667 & 5.1200 & 5.5733 & 6.0267 & 6.4800 & 6.9333 \\
\hline 12.7 & \begin{tabular}{|l|l}
150.582 \\
\end{tabular} & 11.8370 & 0.5550 & 0.4302 & 0.3735 & 0.3257 & 0.2747 & 0.2262 & 0.3489 & 0.4355 & 5243 & 0.5679 & 0.6267 & 0.8098 & 0.9339 & 0.8653 & 0.8706 & 0.8647 \\
\hline 13.0 & 150.6 & 11.5960 & 0.5674 & 0.4390 & 0.3815 & 0.3324 & 0.2804 & 0.2309 & 0.2184 & 0.3641 & 0.4675 & 0.5465 & 0.6068 & 0.8405 & 0.9157 & 0.8625 & 0.8957 & 0.9301 \\
\hline 13.3 & 150.602 & 11.3590 & 0.5775 & 0.4477 & 0.3889 & 0.3399 & 0.2865 & 0.2358 & 0.2183 & 0.1937 & 0.1752 & 0.4574 & 0.5431 & 0.9646 & 1.3156 & 0.9860 & 0.8430 & 1.0553 \\
\hline 14.3 & 150.614 & 10.5370 & 0.6228 & 0.4828 & 0.4196 & 0.3662 & 0.3088 & 0.2541 & 0.2354 & 0.2089 & 0.1886 & 0.1741 & 0.5181 & 0.6883 & 1.4570 & 1.1171 & 0.7604 & 0.9764 \\
\hline 17.4 & 150.609 & 8.6775 & 0.7567 & 0.5859 & 0.5092 & 0.4440 & 0.3751 & 0.3088 & 0.2857 & 0.2538 & 0.2293 & 0.2089 & 0.1943 & 0.5591 & 0.6836 & 1.1473 & 1.8223 & 0.9351 \\
\hline 20.0 & 150.617 & 7.5415 & 0.8710 & 0.6751 & 0.5862 & 0.5114 & 0.4315 & 0.3552 & 0.3287 & 0.2917 & 0.2635 & 0.2405 & 0.2220 & 0.2090 & 0.5728 & 0.6871 & 1.1811 & 1.1917 \\
\hline 22.4 & 150.539 & 6.7225 & 0.9764 & 0.7572 & 0.6575 & 0.5739 & 0.4840 & 0.3985 & 0.3689 & 0.3271 & 0.2953 & 0.2695 & 0.2489 & 0.2294 & 0.2154 & 0.5767 & 0.7088 & 1.1041 \\
\hline
\end{tabular}

\begin{tabular}{c|c|c|}
\hline NPR & $\begin{array}{c}\text { Nozzle } \\
P_{\text {total }} \text { (psia) }\end{array}$ & $\begin{array}{c}P_{\text {amb, }} \text { Vacuum } \\
\text { Chamber } \\
\text { Pressure, psia }\end{array}$ \\
\hline 12.7 & 150.582 & 11.8370 \\
\hline 13.0 & 150.6 & 11.5960 \\
\hline 13.3 & 150.602 & 11.3590 \\
\hline 14.3 & 150.614 & 10.5370 \\
\hline 17.4 & 150.609 & 8.6775 \\
\hline 20.0 & 150.617 & 7.5415 \\
\hline 22.4 & 150.539 & 6.7225 \\
\hline
\end{tabular}

\begin{tabular}{|c|c|c|c|c|c|c|c|c|c|}
\hline \multicolumn{9}{|c|}{$\mathrm{x} / \mathrm{r}^{\star}, 0^{\circ}$ Azimuth } \\
\hline 7.3867 & 7.8400 & 8.2933 & 8.7467 & 9.2000 & 9.6533 & 10.1067 & 10.5600 & 11.0133 & 11.4667 \\
& & & & & & & & & \\
\hline 0.8563 & 0.8788 & 0.9033 & 0.9190 & 0.9418 & 0.9530 & 0.9660 & 0.9781 & 0.9739 & 0.9801 \\
\hline 0.9477 & 0.9755 & 0.9682 & 0.9649 & 0.9671 & 0.9568 & 0.9663 & 0.9723 & 0.9697 & 0.9801 \\
\hline 0.8826 & 0.9383 & 0.9746 & 0.9056 & 0.9782 & 0.9465 & 0.9655 & 0.9686 & 0.9632 & 0.9705 \\
\hline 1.1308 & 0.8005 & 0.9948 & 1.0005 & 0.8758 & 1.0368 & 0.9173 & 0.9968 & 0.9504 & 0.9785 \\
\hline 0.7275 & 1.0655 & 1.3110 & 0.8428 & 0.8845 & 1.2546 & 0.9916 & 0.9220 & 1.1601 & 1.0029 \\
\hline 1.6493 & 0.8813 & 0.7430 & 1.0888 & 1.3517 & 0.9363 & 0.8366 & 1.1103 & 1.2199 & 0.9665 \\
\hline 1.1924 & 1.5740 & 1.3553 & 0.8878 & 0.8001 & 1.0514 & 1.3641 & 1.2051 & 0.8622 & 0.9086 \\
\hline
\end{tabular}


Table A10a. PAR $180^{\circ}$ Azimuth normalized (by $P_{c}$ ) wall pressures as presented in figure 31a. Diffuser inlet 51 mm downstream.

\begin{tabular}{|c|c|c|c|c|c|c|c|c|c|c|c|c|c|c|c|c|c|c|}
\hline & & & \multicolumn{16}{|c|}{$\mathrm{x} / \mathrm{r}^{*}, 180^{\circ}$ Azimuth } \\
\hline NPR & $\begin{array}{c}\text { Nozzle } \\
\text { Ptozal (psia) }_{1}\end{array}$ & 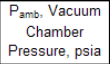 & 0.3600 & 0.8133 & 1.2667 & 1.7200 & 2.1733 & 2.6267 & 3.0800 & 3.5333 & 3.9867 & 4.4400 & 4.8933 & 5.3467 & 5.8000 & 6.2533 & 6.7067 & 7.1600 \\
\hline $\begin{array}{l}13.19 \\
1370\end{array}$ & \begin{tabular}{|l|}
150.594 \\
150.594
\end{tabular} & $\begin{array}{l}11.4130 \\
10.9920\end{array}$ & $\begin{array}{l}3.409 E-02 \\
3410 E-02\end{array}$ & \begin{tabular}{|l|}
$3.104 E-02$ \\
$3.14 E-02$
\end{tabular} & \begin{tabular}{|l|}
$2.699 \mathrm{E}-02$ \\
$2.699 \mathrm{E}-02$
\end{tabular} & \begin{tabular}{|l|}
$2.365 \mathrm{E}-02$ \\
$2.355 \mathrm{E}-02$
\end{tabular} & \begin{tabular}{|l|}
$2.033 \mathrm{E}-02$ \\
$2.034 \mathrm{E}-02$
\end{tabular} & $1.772 \mathrm{E}-02$ & \begin{tabular}{|l|}
$1.561 \mathrm{E}-02$ \\
$1560 \mathrm{E}-02$
\end{tabular} & $1.398 \mathrm{E}-02$ & $2.462 \mathrm{E}-02$ & $3.971 \mathrm{E}-02$ & $6.506 \mathrm{E}-02$ & \begin{tabular}{|l|l|}
$1.063 \mathrm{E}-01$ \\
\end{tabular} & $7.475 \mathrm{E}-02$ & \begin{tabular}{|l|l|}
$6.427 \mathrm{E}-02$ \\
$5.717-0 ?$
\end{tabular} & \begin{tabular}{|l|l|}
$7.965 \mathrm{E}-02$ \\
\end{tabular} & $6.705 \mathrm{E}-02$ \\
\hline $\begin{array}{l}13.70 \\
15.55\end{array}$ & $\begin{array}{l}150.594 \\
150.560\end{array}$ & $\begin{array}{r}10.9920 \\
9.6835\end{array}$ & $\begin{array}{l}3.410 \mathrm{E}-02 \\
3.419 \mathrm{E}-02\end{array}$ & \begin{tabular}{|l|}
$3.104 E-02$ \\
$3.107 E-02$
\end{tabular} & \begin{tabular}{|l|}
$2.699 \mathrm{E}-02$ \\
$2701 \mathrm{E}-02$
\end{tabular} & \begin{tabular}{|l|}
$2.365 \mathrm{E}-02$ \\
$2.363 \mathrm{E}-02$
\end{tabular} & \begin{tabular}{|l|}
$2.034 \mathrm{E}-02$ \\
$2.032 \mathrm{E}-02$
\end{tabular} & \begin{tabular}{|l|}
$1.772 E-02$ \\
$1.772 E-02$ \\
\end{tabular} & \begin{tabular}{|l|}
$1.560 \mathrm{E}-02$ \\
$1.560 \mathrm{E}-02$ \\
\end{tabular} & \begin{tabular}{|l|}
$1.399 \mathrm{E}-02$ \\
$1398 \mathrm{E}-02$ \\
\end{tabular} & \begin{tabular}{|l|}
$1.280 \mathrm{E}-02$ \\
$1.275 \mathrm{E}-02$ \\
\end{tabular} & \begin{tabular}{|l|}
$3.754 \mathrm{E}-02$ \\
$1.165 \mathrm{E}-02$
\end{tabular} & $\begin{array}{l}5.173 \mathrm{E}-02 \\
3418 \mathrm{E}-02\end{array}$ & \begin{tabular}{|l|}
$1.030 \mathrm{E}-01$ \\
$4.284 \mathrm{E}-02$ \\
\end{tabular} & \begin{tabular}{|l|}
$7.702 E-02$ \\
$6.985 E-02$
\end{tabular} & \begin{tabular}{|l|}
$5.547 E-02$ \\
$1006 E-01$
\end{tabular} & \begin{tabular}{|l|l|}
$7.502 \mathrm{E}-02$ \\
$5120 \mathrm{E}-02$
\end{tabular} & \begin{tabular}{|l|}
$7.302 \mathrm{E}-02$ \\
$4588 \mathrm{E}-02$
\end{tabular} \\
\hline 18.40 & 150.620 & 8.1845 & \begin{tabular}{|l|l|}
$3.413 \mathrm{E}-02$ \\
\end{tabular} & \begin{tabular}{|l|l|}
$3.105 \mathrm{E}-02$ \\
\end{tabular} & $2.700 \mathrm{E}-02$ & \begin{tabular}{|l|l|}
$2.364 \mathrm{E}-02$ \\
\end{tabular} & $2.035 \mathrm{E}-02$ & $1.773 \mathrm{E}-02$ & \begin{tabular}{|l|}
$.560 \mathrm{E}-02$ \\
\end{tabular} & $1.399 \mathrm{E}-02$ & $1.275 \mathrm{E}-02$ & $1.161 \mathrm{E}-02$ & $\begin{array}{l}.409 \mathrm{E}-02 \\
1.099 \mathrm{E}-02 \\
\end{array}$ & \begin{tabular}{|l|}
$4.204 L-02$ \\
$3.163 \mathrm{E}-02$ \\
\end{tabular} & $3.733 \mathrm{E}-02$ & \begin{tabular}{|l|l|}
$6.380 \mathrm{E}-02$ \\
\end{tabular} & $\begin{array}{l}0.120 \mathrm{~L}-02 \\
9.724 \mathrm{E}-02 \\
\end{array}$ & \begin{tabular}{|l|}
$6.0300-02$ \\
$6.032-02$ \\
\end{tabular} \\
\hline \multirow[t]{4}{*}{21.25} & $\begin{array}{l}150.609 \\
\end{array}$ & 7.0885 & $\begin{array}{l}3.407 \mathrm{E}-02 \\
\end{array}$ & \begin{tabular}{|l|l|}
$3.104 \mathrm{E}-02$ \\
\end{tabular} & \begin{tabular}{|l|l|}
$2.702 E-02$ \\
\end{tabular} & \begin{tabular}{|l|l|}
$2.367 \mathrm{E}-02$ \\
\end{tabular} & $2.034 \mathrm{E}-02$ & \begin{tabular}{|l|l|}
$1.773 \mathrm{E}-02$ \\
\end{tabular} & \begin{tabular}{|c|}
$1.560 \mathrm{E}-02$ \\
\end{tabular} & $\begin{array}{l}1.399 \mathrm{E}-02 \\
\end{array}$ & $1.275 \mathrm{E}-02$ & $1.161 \mathrm{E}-02$ & $1.074 \mathrm{E}-02$ & \begin{tabular}{|l|l|}
$1.016 \mathrm{E}-02$ \\
\end{tabular} & $2.866 \mathrm{E}-02$ & $3.295 \mathrm{E}-02$ & \begin{tabular}{|l|l|}
$5.612 \mathrm{E}-02$ \\
\end{tabular} & \begin{tabular}{|l|l|}
$4.827 \mathrm{E}-02$ \\
\end{tabular} \\
\hline & & & & & & & & & & & & & & & & & & \\
\hline & & & & & & & & & & & & & & & & & & \\
\hline & & & & \multicolumn{10}{|c|}{$\mathrm{x} / \mathrm{r}^{\star}, 180^{\circ}$ Azimuth } & & & & & \\
\hline NPR & $\left|\begin{array}{c}\text { Nozzle } \\
P_{\text {total }} \text { (psia) }\end{array}\right|$ & $\begin{array}{c}P_{\text {amb }} \text { Vacuum } \\
\text { Chamber } \\
\text { Pressure, psia }\end{array}$ & & 7.6133 & 8.0667 & 8.5200 & 8.9733 & 9.4267 & 9.8800 & 10.3333 & 10.7867 & 11.2400 & 11.6933 & & & & & \\
\hline 13.19 & \begin{tabular}{|l|}
150.594 \\
\end{tabular} & 11.4130 & & \begin{tabular}{|l|}
$7.071 \mathrm{E}-02$ \\
\end{tabular} & $7.318 \mathrm{E}-02$ & $7.006 \mathrm{E}-02$ & $7.259 \mathrm{E}-02$ & $7.103 \mathrm{E}-02$ & \begin{tabular}{|l|}
$7.241 \mathrm{E}-02$ \\
\end{tabular} & 7.197E-02 & $7.280 \mathrm{E}-02$ & $7.322 \mathrm{E}-02$ & 7.377E-02 & & & & & \\
\hline 13.70 & 150.594 & 10.9920 & & \begin{tabular}{|l|l|}
$6.036 \mathrm{E}-02$ \\
$736-$
\end{tabular} & \begin{tabular}{|l}
$7.618 \mathrm{E}-02$ \\
\end{tabular} & $6.680 \mathrm{E}-02$ & $6.948 \mathrm{E}-02$ & $7.020 \mathrm{E}-02$ & $6.900 \mathrm{E}-02$ & $7.026 \mathrm{E}-02$ & $7.028 \mathrm{E}-02$ & $7.065 \mathrm{E}-02$ & $7.120 \mathrm{E}-02$ & & & & & \\
\hline 15.55 & 150.560 & 9.6835 & & \begin{tabular}{|l|l|}
$7.788 \mathrm{E}-02$ \\
\end{tabular} & $6.101 \mathrm{E}-02$ & $4.758 \mathrm{E}-02$ & $7.144 \mathrm{E}-02$ & $6.318 \mathrm{E}-02$ & $5.335 E-02$ & $7.023 \mathrm{E}-02$ & $5.931 \mathrm{E}-02$ & $6.200 \mathrm{E}-02$ & $6.469 \mathrm{E}-02$ & & & & & \\
\hline 18.40 & 150.620 & 8.1845 & & \begin{tabular}{|l|l|}
$4.264 \mathrm{E}-02$ \\
\end{tabular} & $4.697 \mathrm{E}-02$ & 7.263E-02 & \begin{tabular}{|l|l|}
$5.747 E-02$ \\
\end{tabular} & $4.226 \mathrm{E}-02$ & $5.655 \mathrm{E}-02$ & $6.858 \mathrm{E}-02$ & $4.891 E-02$ & $5.175 \mathrm{E}-02$ & $6.518 \mathrm{E}-02$ & & & & & \\
\hline 21.25 & 150.609 & 7.0885 & & \begin{tabular}{|l|l|}
$8.596 \mathrm{E}-02$ \\
\end{tabular} & $5.028 \mathrm{E}-02$ & $3.908 \mathrm{E}-02$ & $3.998 \mathrm{E}-02$ & $6.067 E-02$ & \begin{tabular}{|l|}
$6.072 \mathrm{E}-02$ \\
\end{tabular} & $4.216 \mathrm{E}-02$ & $4.085 \mathrm{E}-02$ & $5.415 \mathrm{E}-02$ & $5.851 \mathrm{E}-02$ & & & & & \\
\hline
\end{tabular}

Table A10b. PAR $180^{\circ}$ Azimuth normalized (by $P_{a m b}$ ) wall pressures as presented in figure 31b. Diffuser inlet $51 \mathrm{~mm}$ downstream.

\begin{tabular}{|c|c|c|c|c|c|c|c|c|c|c|c|c|c|c|c|c|c|c|}
\hline \multirow[b]{2}{*}{ NPR } & \multirow[b]{2}{*}{$\mid \begin{array}{c}\text { Nozzle } \\
\mathrm{P}_{\text {total }}(\mathrm{psia})\end{array}$} & \multirow[b]{2}{*}{$\begin{array}{c}P_{\text {amb, }} \text { Vacuum } \\
\text { Chamber } \\
\text { Pressure, psia }\end{array}$} & \multicolumn{16}{|c|}{ nuth } \\
\hline & & & 0.3600 & 0.8133 & 1.2667 & 1.7200 & 2.1733 & 2.6267 & 3.0800 & 3.5333 & 3.9867 & 4.4400 & 4.8933 & 5.3467 & 5.8000 & 6.2533 & 6.7067 & 7.1600 \\
\hline 13.19 & 150.594 & 11.4130 & 0.4498 & 0.4096 & 0.3561 & 0.3120 & 0.2682 & 0.2338 & 0.2060 & 0.1845 & 0.3249 & 0.5240 & 0.8585 & 1.4023 & 0.9863 & 0.8481 & 1.0510 & 0.8848 \\
\hline 13.70 & 150.594 & 10.9920 & 0.4672 & 0.4253 & 0.3698 & 0.3240 & 0.2787 & 0.2428 & 0.2138 & 0.1917 & 0.1754 & 0.5143 & 0.7087 & 1.4109 & 1.0551 & 0.7599 & 1.0277 & 1.0004 \\
\hline 15.55 & 150.560 & 9.6835 & 0.5315 & 0.4831 & 0.4200 & 0.3674 & 0.3160 & 0.2755 & 0.2425 & 0.2174 & 0.1982 & 0.1811 & 0.5314 & 0.6661 & 1.0860 & 1.5647 & 0.7960 & 0.7133 \\
\hline 18.40 & 150.620 & 8.1845 & 0.6280 & 0.5713 & 0.4968 & 0.4350 & 0.3745 & 0.3262 & 0.2871 & 0.2574 & 0.2346 & 0.2136 & 0.2023 & 0.5821 & 0.6870 & 1.1740 & 1.7896 & 1.1100 \\
\hline \multirow[t]{4}{*}{21.25} & 150.609 & 7.0885 & 0.7238 & 0.6595 & 0.5740 & 0.5029 & 0.4322 & 0.3767 & 0.3315 & 0.2972 & 0.2710 & 0.2467 & 0.2281 & 0.2158 & 0.6089 & 0.7000 & 1.1924 & 1.0256 \\
\hline & & & & & & & & & & & & & & & & & & \\
\hline & & & & & & & & & & & & & & & & & & \\
\hline & & & & \multicolumn{10}{|c|}{$\mathrm{x} / \mathrm{r}^{\star}, 180^{\circ}$ Azimuth } & & & & & \\
\hline NPR & $\mid \begin{array}{c}\text { Nozzle } \\
P_{\text {total }} \text { (psia) }\end{array}$ & $\begin{array}{l}P_{\text {amb }} \text { Vacuum } \\
\text { Chamber } \\
\text { Pressure, psia }\end{array}$ & & 7.6133 & 8.0667 & 8.5200 & 8.9733 & 9.4267 & 9.8800 & 10.3333 & 10.7867 & 11.2400 & 11.6933 & & & & & \\
\hline 13.19 & 150.594 & 11.4130 & & 0.9330 & 0.9656 & 0.9244 & 0.9579 & 0.9372 & 0.9554 & 0.9496 & 0.9606 & 0.9661 & 0.9734 & & & & & \\
\hline 13.70 & 150.594 & 10.9920 & & 0.8270 & 1.0438 & 0.9151 & 0.9520 & 0.9617 & 0.9453 & 0.9626 & 0.9628 & 0.9680 & 0.9754 & & & & & \\
\hline 15.55 & 150.560 & 9.6835 & & 1.2109 & 0.9485 & 0.7397 & 1.1108 & 0.9823 & 0.8296 & 1.0920 & 0.9221 & 0.9640 & 1.0057 & & & & & \\
\hline 18.40 & 150.620 & 8.1845 & & 0.7848 & 0.8644 & 1.3367 & 1.0576 & 0.7777 & 1.0407 & 1.2620 & 0.9001 & 0.9524 & 1.1995 & & & & & \\
\hline 21.25 & 150.609 & 7.0885 & & 1.8263 & 1.0682 & 0.8304 & 0.8495 & 1.2890 & 1.2901 & 0.8958 & 0.8680 & 1.1505 & 1.2431 & & & & & \\
\hline
\end{tabular}

